\title{
EFFECTIVENESS OF THE EXTRACTIVE INDUSTRIES TRANSPARENCY INITIATIVE
}

By

\section{Olayinka Moses}

\author{
A thesis submitted to \\ Victoria University of Wellington \\ in fulfilment of the requirements for the degree of \\ Doctor of Philosophy in Accounting.
}

Victoria University of Wellington 


\section{RESEARCH SUPERVISORS}

\section{Professor Tony van Zijl}

Professor of Accounting and Financial Management

Director, Centre for Accounting, Governance and Taxation Research

Victoria Business School,

Victoria University of Wellington,

New Zealand

\section{Associate Professor Noor Houqe \\ School of Accountancy, \\ Massey Business School, \\ Massey University, Auckland, \\ New Zealand}




\section{ACKNOWLEDGEMENT}

I am thankful to my supervisors, Professor Tony van Zijl and Associate Professor Noor Houqe for their support and guidance which is far and beyond this project. Visits by Professors Tony van Zijl and Keitha Dunstan to the Department of Accounting, University of Jos-Nigeria in April 2008 and again later in August 2009 had a major impact on the academic advancement of Dr Dimu Ehalaiye and myself. Although the purpose of the visits was to facilitate a World Bank sponsored programme for Capacity Building for Sustainable Management of Mineral Resources in Nigeria, the contact provided an opportunity for Dr Ehalaiye and myself to gain admission to Victoria University of Wellington, for the doctoral programme in Accounting. I am indeed deeply grateful to Professor Tony van Zijl. I will like to also thank Dr Dimu Ehalaiye for his support from the start of this project.

I am grateful to several persons and organisations for their support in making this project a reality. In particular, I am indebted to the late Craig Buck Andrews of the World Bank, for the Craig Buck Andrews Scholarship (CBAS) in Financial Reporting and Financial Management I received. This research was also made possible by the support and financial assistance of the under listed:

i. The University of Jos-Nigeria and the Nigerian Tertiary Education Trust Fund for the Needs Assessment Funding I received. Specifically, I am thankful to the Vice-Chancellor, Professor Sebastian Seddi 
Maimako for his huge support and the former Vice-Chancellor, Professor Hayward Babale Mafuyai for approving this study. I like to also acknowledge the kind support of the current and past Heads of Department of Accounting- Professor Ekoja Benjamin Ekoja and Dr Saratu Lassa Jim-Suleiman. I thank Mrs Ulan Victoria Jatau and Mr Patrick Opara, and other members of staff of the Department of Accounting, University of Jos-Nigeria for their support as well.

ii. R W Steele Scholarship in Accounting (2015), from the Victoria University Foundation through the School of Accounting and Commercial Law (SACL), Victoria University of Wellington.

iii. Philip Brown Travel Scholarship (2016), from the Accounting \& Finance Association of Australia and New Zealand Doctoral Education Network (AFDEN).

iv. The Institute of Finance Professionals New Zealand (INFINZ), for the 2016 INFINZ Conference Scholarship.

v. Wellington Regional Council, for the Wellington International Students Award (2016). 
vi. The School of Accounting and Commercial (SACL), Victoria University of Wellington, for the many conferences and academic training funding I received during my candidature. I am very appreciative of Professor Ian Eggleton's generous support in this regard.

I am particularly, grateful to all those with whom I have had the pleasure to work with in the SACL both as a PhD candidate and as an Assistant Lecturer. I will like to also extend my gratitude to everyone I worked with on my many University-wide assignments here at Victoria University of Wellington. Special thanks to all the team members I worked with as President of the Postgraduate Students Association from 2015-2016.

Nobody has been more important to me in the pursuit of this degree than the members of my family. I am obliged to my mother Eunice Oguntade and my late father Moses Oguntade. To my father- although you did not live to see me achieve this height, I am comforted by your guidance and the investment you made in me early in life. Special acknowledgement to my siblings- Bose and her husband Bob-Manuel, Tunde and his wife Ruth, Duro, Lola and Toyin. I also want to thank my parents-in-law, Israel and Rhoda Dabel for their love and support. 
Most importantly, I wish to thank my loving and supportive wife Joy for her sacrifice and understanding throughout my study period. To my three wonderful children, Ifeoluwapo, Olanike and Morolaoluwa, you are the reason I wake up every day working hard to reciprocate the love and inspiration you provide me. 


\section{DECLARATION}

I hereby confirm that the work presented in this thesis is my own and original work that has been carried out through the School of Accounting and Commercial Law, Victoria University of Wellington, during my candidature as a PhD student. I declare that the material of this thesis has not been submitted either in whole or in part for the award of any other degree or diploma at this or any other university. To the best of my knowledge and belief, it contains no material previously published or written by other persons or institutions except where due reference has been made.

\section{Olayinka Moses}

20 August 2018 


\begin{abstract}
I investigate two aspects of the Extractive Industries Transparency Initiative (EITI). The first issue is the effectiveness of the EITI in mitigating corruption in EITI implementing countries. The second issue is the economic value of extractive companies' information disclosed under the EITI implementation regime.
\end{abstract}

I address the first issue by examining the influence of EITI implementation experience on the perceived control of corruption in EITI implementing countries. Specifically, I address two questions (i) whether EITI implementation experience is associated with improved control of corruption for all implementing countries taken together, and (ii) whether the effect of EITI implementation experience on the perceived level of corruption varies across implementing countries. Based on the sampled 51 implementing countries over the period 2003-2015, I find that across-the-board, EITI implementation experience is not associated with improved control of corruption. The findings show that the interaction term for EITI implementation experience with SubSaharan African countries is positively associated with improved control of corruption. Thus, the negative effect associated with EITI implementation experience is less for Sub-Saharan African countries.

I address the second issue by investigating the economic value of extractive companies' exploration payments information disclosed under the EITI implementation process. Using the United States Extractive Industries Transparency Initiative (USEITI), I examine the impact of disclosure of non-tax payments by extractive companies to the US government, as an illustration of the economic value of information disclosed as a result of the EITI. I address two research questions (i) whether investors react to the initial disclosure of the 
USEITI information and hence whether the information is of value to investors, and (ii) the value relevance of this information over the whole period for which this information has been available. The issue employs two separate but related methods to examine these questions. First, it employs a standard event study methodology, to test for trading volume and price reaction, around the event date of the first-time release of this information. Second, it employs the Collins, Pincus, and Xie, (1999) adaptation of the Ohlson (1995) model to examine the value relevance of USEITI information disclosure over the period 2013-2016. The results show that the USEITI disclosure evoked both trading volume and price reactions, thus suggesting that the disclosure of extractive payments had information content relevant to price setting. The price reaction, as evidenced in the cross-sectional regression, is associated with oil and gas firms, and the working capital and asset turnover of the sample extractive companies. The results also indicate that the continuing disclosure of the USEITI information was value relevant.

Taken together, the findings from the thesis suggest that the EITI has been relatively effective in lessening the level of perceived corruption in the countries in dire need of reform and more importantly, the information released under the EITI implementation regime has economic value both at initial release and subsequent continued release. Thus, policymakers and managers of companies operating in countries rich in natural resources need to take note of the impact of EITI implementation. 
TABLE OF CONTENTS

RESEARCH SUPERVISORS ......................................................................................................ii

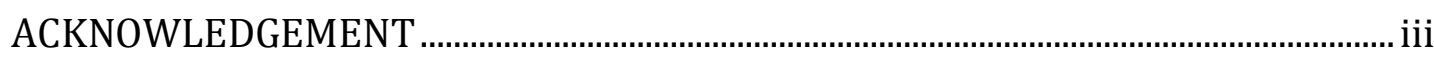

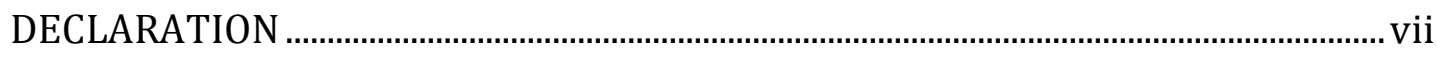

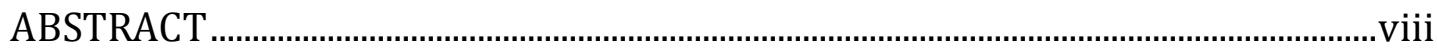

TABLE OF CONTENTS........................................................................................................

LIST OF ABBREVIATIONS..............................................................................................

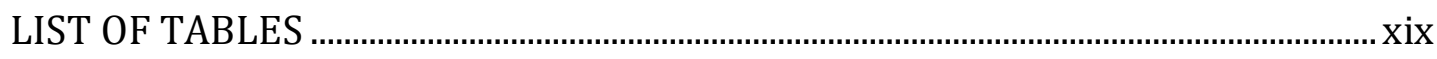

LIST OF FIGURES.......................................................................................................

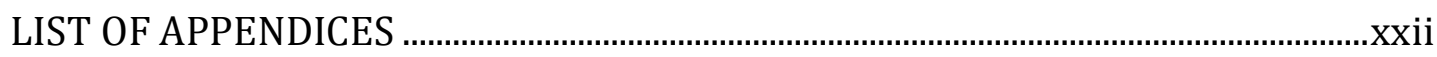

CHAPTER ONE.......................................................................................................................

INTRODUCTION

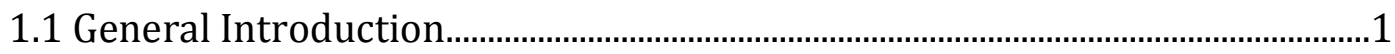

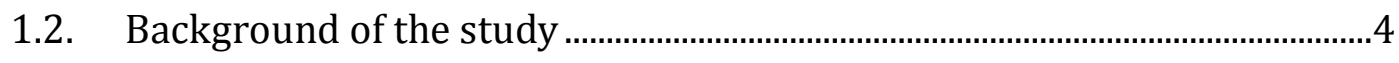

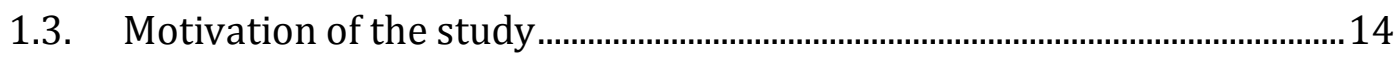

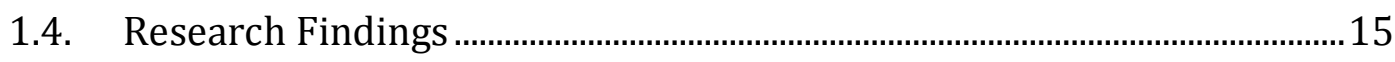

1.4.1. EITI implementation and the perception of corruption ......................15

1.4.2. Economic value of EITI information disclosure ……………………....16

1.5. Overview of the remaining chapters of the thesis ........................................16

1.5.1. Chapter two: Literature review.............................................................16 
1.5.2. Chapter three: EITI implementation and the perception of corruption

1.5.3. Chapter four: Economic value of EITI Information

1.5.4. Chapter five: Conclusions and implications for future research .....18 CHAPTER TWO 19

LITERATURE REVIEW 19

2.1. Introduction 19

2.2. Conceptualisation of corruption 19

2.3. EITI effectiveness and the reduction of corruption. 23

2.4. Extractive companies' information disclosure and market reaction 31

2.5. Extractive firms information disclosure and value relevance. 34

2.6. Jurisdictional implementation of EITI firm-level disclosures .37

2.6.1 Juxtaposition of US, UK and Canada firm-level reporting requirements 42

2.7. Theoretical Framework 43

2.7.1. Agency dilemma in citizen-government relationship 43

2.8. Chapter summary. 47

CHAPTER THREE 49

EITI IMPLEMENTATION AND THE PERCEPTION OF CORRUPTION. 49

3.0. Synopsis 49 


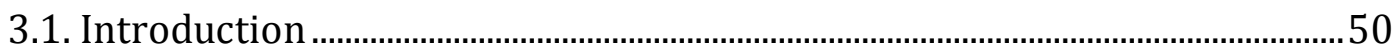

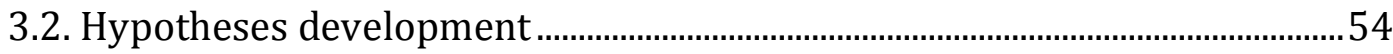

3.2.1. Argument and hypotheses .......................................................................... 54

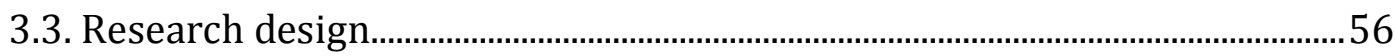

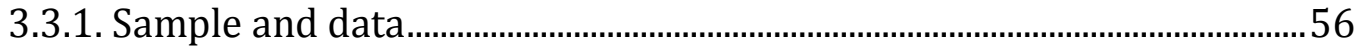

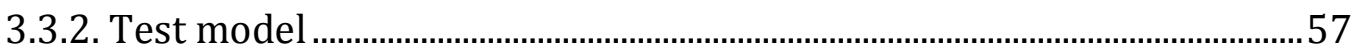

3.3.3. Dependent variable ...................................................................................... 58

3.3.4. Independent variable ........................................................................................59

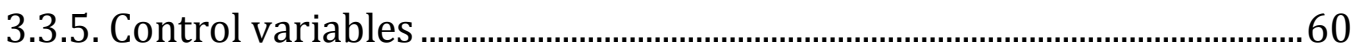

3.3.6. Robustness tests variables ……………………………………………………...62

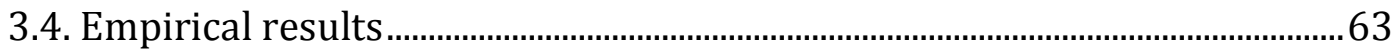

3.4.1. Descriptive statistics .............................................................................................63

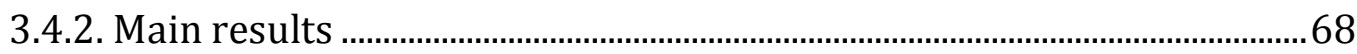

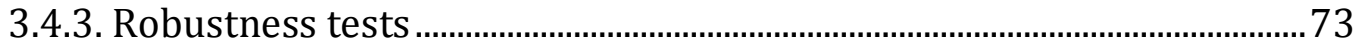

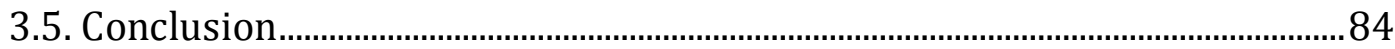

CHAPTER FOUR ..................................................................................................................

ECONOMIC VALUE OF EITI INFORMATION...................................................................8

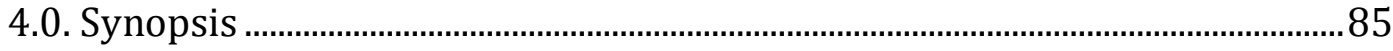

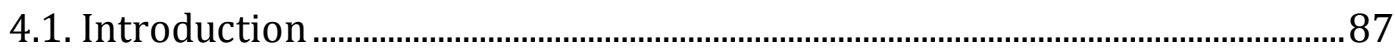

4.2. Background and hypotheses .............................................................................91 


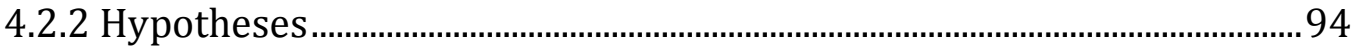

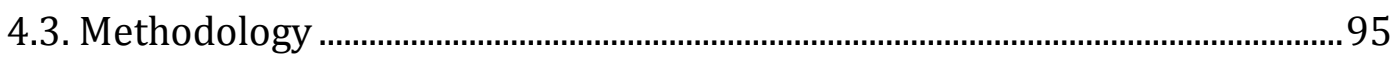

4.3.1. Market reaction .....................................................................................................97

4.3.1.1. Market reaction: Trading volume..............................................................97

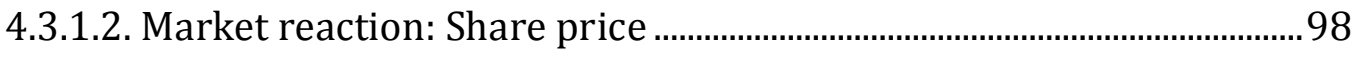

4.3.2. Examination of cross-sectional variation in abnormal return ............105

4.3.3. Value relevance analysis................................................................................108

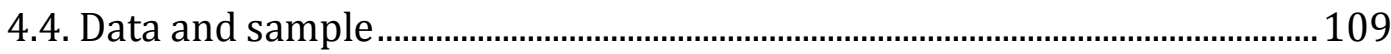

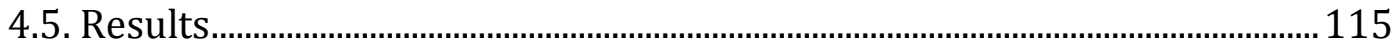

4.5.1. Reaction tests.....................................................................................................115

4.5.1.1. Market reaction: Trading volume............................................................115

4.5.1.2. Market reaction: Share price ....................................................................116

4.5.1.2.1 Non-parametric test: Share price …………………………………….118

4.5.2. Cross-sectional variation in abnormal return ............................................120

4.5.3 Value relevance analysis ..................................................................................132

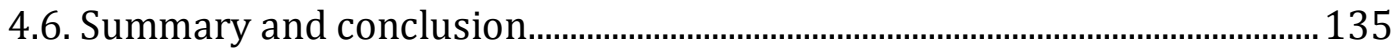

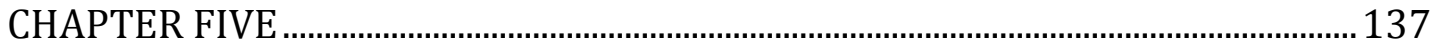

CONCLUSIONS AND IMPLICATIONS FOR FUTURE RESEARCH ...............................137

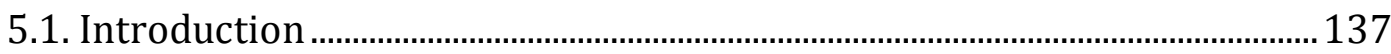


5.2. Summary of findings

5.2.1 Summary of findings: The first two research questions

5.2.2. Summary of findings: The second two research questions

5.3 Contributions of the study

5.4 Limitations of the study 142

5.5 Future research

References. 144

APPENDICES 168

Appendix A. Low Human Development Index Countries 2014 169

Appendix B. Countries Resource Governance Index Ranking (RGI) for 2013

Appendix C. Sub-Saharan African Countries Resource Governance Index

Ranking for 2013. 173

Appendix D. Sub-Saharan African Countries Corruption Perception Index for 2015 174

Appendix E: Extractive Industries Transparency Initiative Principles............176 Appendix F: Extractive Industries Transparency Initiative countries and their status 177

Appendix G. 2016 State of Peace and Ethnic Fractionalisation of EITI

Countries. 178 
Appendix H. EITI countries CPI Ranking overtime

Appendix I: Variable description and data sources 183

Appendix J: EITI countries geographical and economic categorization 185

Appendix K: USEITI Initial listed sample companies for 2013 186

Appendix L. Companies with confounding news excluded from the final sample 188

Appendix M. Comparison of legislative requirement for extractive reporting at

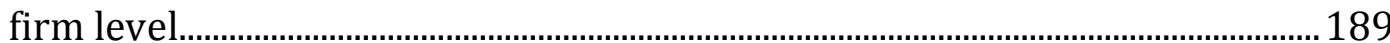

Appendix N. Summary of key empirical studies reviewed. 199 


\section{LIST OF ABBREVIATIONS}

\begin{tabular}{|c|c|c|}
\hline $\mathbf{S} / \mathbf{N}$ & ACRONYM & MEANING \\
\hline 1 & ADRs & American Depository Receipts \\
\hline 2 & API & American Petroleum Institute \\
\hline 3 & AR & Abnormal Return \\
\hline 4 & ASX & Australian Stock Exchange \\
\hline 5 & AVOL & Average Abnormal Trading Volume \\
\hline 6 & BP & British Petroleum \\
\hline 7 & CAR & Cumulative Abnormal Return \\
\hline 8 & CATVOL & Cumulative Average Abnormal Trading Volume \\
\hline 9 & $\mathrm{CCI}$ & Control of Corruption Index \\
\hline 10 & CPI & Corruption Perception Index \\
\hline 11 & CSOs & Civil Society Organisations \\
\hline 12 & CSR & Corporate Social Responsibility \\
\hline 13 & DFID & United Kingdom Department for International Development \\
\hline \multirow[t]{2}{*}{14} & Dodd-Frank & Dodd-Frank Wall Street Reform and Consumer Protection Act \\
\hline & & 2010 \\
\hline 15 & DOI & Department of the Interior \\
\hline 16 & EDGAR & Electronic Data Gathering, Analysis, and Retrieval System \\
\hline 17 & EITI & Extractive Industries Transparency Initiative \\
\hline 18 & ESTMA & Extractive Sector Transparency Measures Act \\
\hline 19 & EU & European Union \\
\hline 20 & EXP & EITI Implementation Experience \\
\hline
\end{tabular}




\begin{tabular}{|c|c|c|}
\hline $\mathbf{S} / \mathbf{N}$ & ACRONYM & MEANING \\
\hline 21 & FDI & Foreign Direct Investment \\
\hline 22 & FOI & Freedom of Information \\
\hline 23 & GDP & Gross Domestic Product \\
\hline 24 & GPI & Global Peace Index \\
\hline 25 & HDI & Human Development Index \\
\hline 26 & HIPC & Heavily Indebted Poor Countries \\
\hline 27 & IA & Independent Administrator \\
\hline 28 & IEP & Institute for Economics and Peace \\
\hline 29 & IFRS & International Financial Reporting Standards \\
\hline 30 & HIS & Inverse Hyperbolic Sine \\
\hline 31 & IPAA & Independent Petroleum Association of America \\
\hline 32 & JORC & Joint Ore Reserves Committee Code \\
\hline 33 & MIN & Mineral rents as a percentage of GDP \\
\hline 34 & MMBOE & Million Barrels of Oil Equivalent \\
\hline 35 & MSG & Multi-Stakeholder Group \\
\hline 36 & NFTC & National Foreign Trade Council \\
\hline 37 & NGOs & Non-governmental organizations \\
\hline 38 & OIL & Oil rents as a percentage of GDP \\
\hline 39 & ONRR & Office of the National Resources Revenue \\
\hline 40 & OPEC & Organization of the Petroleum Exporting Countries \\
\hline 41 & OTC & Over-The-Counter Market \\
\hline 42 & PERMNO & Permanent Security Identification Numbers \\
\hline
\end{tabular}




\begin{tabular}{lll} 
S/N & ACRONYM & MEANING \\
\hline 43 & PI & Performance Indicators \\
44 & Pol_Inst & Political Institution and Stability \\
45 & RGI & Resource Governance Index \\
46 & RRD & Resource Revenue Dependency \\
47 & RWI & Revenue Watch Institute's \\
48 & S \& P & Standard \& Poor's Composite Index \\
49 & SEC & Securities and Exchange Commission \\
50 & SFAS & Statement of Financial Accounting Standards \\
51 & SOE & State Owned Enterprise \\
52 & SSA & Sub-Saharan African \\
53 & TAIs & Transparency and Accountability Initiatives \\
54 & UK & United Kingdom \\
55 & US & United States of America \\
56 & UNDP & United Nations Development Programme \\
57 & USEITI & United States Extractive Industries Transparency Initiative \\
58 & VIF & Variable Inflation Factor \\
59 & VOL & Trading Volume \\
60 & WGI & World Governance Indicator \\
\hline
\end{tabular}




\begin{tabular}{llc}
\hline TABLE & TITLE & PAGE \\
\hline Table 3.1 & Descriptive statistics & 65 \\
Table 3.2 & Pairwise correlation matrix & 67 \\
Table 3.3 & Control of corruption and EITI implementation & 71 \\
& experience &
\end{tabular}

Table 3.4 Control of corruption, EITI implementation experience and Sub-Saharan African countries

Table $3.5 \quad$ Control of corruption, EITI implementation experience and Sub-Saharan African (Alternate resource predictorMineral Rent)

Table 3.6 and Sub-Saharan African (Alternate resource predictorOil Rent)

Table $3.7 \quad$ Control of corruption and EITI implementation experience (alternate SSA measure [HIPC])

Table 3.8 Control of corruption and EITI implementation experience [SSA reduced sample]

Table 3.9 Control of corruption and EITI implementation experience- [HIPC measure reduced sample]

Table $4.1 \quad$ Sample selection

Table 4.2. US Extractive companies' payments for 2013 (\$US) 
TABLE

TITLE

PAGE

Table 4.3A

Median Adjusted Abnormal Trading Volume $(N=80)$

116

Table 4.3B

Median Adjusted Cumulative Abnormal Trading Volume

116

$(N=80)$

Table 4.4A Daily abnormal returns $(N=80)$

Table 4.4B Cumulative abnormal returns by event period $(N=80)$

Tables 4.4C Non-Parametric Rank and Sign significance test statistics

$(N=80)$

Tables 4.4D Non-Parametric Rank significance test statistic across

partitioned intervals $(N=80)$

Table 4.5A Descriptive statistics for cross-sectional analysis

Table 4.5B

Pairwise correlation matrix for cross-sectional analysis

Table 4.5C

The US sampled extractive companies' cross-sectional

128

results for main and partitioned event intervals

Table 4.5D

US sampled extractive companies' cross-sectional results

for main and partitioned event interval with payment

categories

Table 4.6A Descriptive statistics for value relevance analysis

Table 4.6B Correlation matrix for the value relevance analysis

Table 4.6C

Value relevance regression results 


\section{LIST OF FIGURES}

\begin{tabular}{llc} 
FIGURE & TITLE & PAGE \\
\hline Figure 4.1 & Timeline for event & 96 \\
Figure 4.2 & Plot of CAR for the event period $(-4,4)$ & 118 \\
\hline
\end{tabular}


LIST OF APPENDICES

\begin{tabular}{|c|c|c|}
\hline APPENDIX & TITLE & PAGE \\
\hline Appendix A & Low Human Development Index Countries 2014 & 169 \\
\hline Appendix B & $\begin{array}{l}\text { Countries Resource Governance Index Ranking (RGI) for } \\
2013\end{array}$ & 171 \\
\hline Appendix C & $\begin{array}{l}\text { Sub-Saharan Africa Countries Resource Governance } \\
\text { Index Ranking for } 2013\end{array}$ & 173 \\
\hline Appendix D & $\begin{array}{l}\text { Sub-Saharan African Countries Corruption Perception } \\
\text { Index (CPI) for } 2015\end{array}$ & 174 \\
\hline Appendix E & Extractive Industries Transparency Initiative Principles & 176 \\
\hline Appendix F & $\begin{array}{l}\text { Extractive Industries Transparency Initiative Countries } \\
\text { and their status }\end{array}$ & 177 \\
\hline Appendix G & $\begin{array}{l}2016 \text { State of Peace and Ethnic Fractionalisation of EITI } \\
\text { Countries }\end{array}$ & 178 \\
\hline Appendix $\mathrm{H}$ & EITI countries CPI Ranking overtime & 181 \\
\hline Appendix I & Variable description and data sources & 183 \\
\hline Appendix J & $\begin{array}{l}\text { EITI countries geographical and economic } \\
\text { categorization }\end{array}$ & 185 \\
\hline Appendix K & USEITI Initial listed sample companies for 2013 & 186 \\
\hline Appendix L & $\begin{array}{l}\text { Companies with confounding news and excluded from } \\
\text { the final sample }\end{array}$ & 188 \\
\hline Appendix M & $\begin{array}{l}\text { Comparison of legislative requirement for extractive } \\
\text { reporting at firm level }\end{array}$ & 189 \\
\hline
\end{tabular}


Appendix N

Summary of key empirical studies reviewed 


\section{CHAPTER ONE}

\section{INTRODUCTION}

\subsection{General Introduction}

This study investigates whether the Extractive Industries Transparency Initiative (EITI) contributes to reducing the perceived level of corruption in resource-rich countries, and the economic value of information disclosed under the EITI implementation regime. The first issue is addressed as follows:

1. Is EITI implementation experience associated with improved control of corruption in all implementing countries taken together?

2. Does the effect of EITI implementation experience on the perceived control of corruption vary across implementing countries?

The second issue, the economic value of EITI information is addressed by using, as an illustration, the United States Extractive Industries Transparency Initiative (USEITI) information disclosure on non-tax payments by US extractive companies to the US government. The following research questions are addressed:

1. Did the initial release of non-tax payments made by extractive companies to the United States government evoke market reactions?

2. Is the USEITI information released over time value relevant? 
The above four research questions addressed in this study are pertinent to understanding the influence of the EITI, both at a macro (country-level) and micro (company-level). I answer these questions using different empirical methods. For the first two questions, I employ panel data comprising 648 country-year observations for 51 implementing countries from 2003 to 2015 to examine how the experience of implementing the EITI has impacted on the perceived level corruption in implementation countries.

To address the second two questions, I use two separate but related methods. First, I test for trading volume reaction and employ a standard event study methodology, with a two-factor price model incorporating an oil and gas index, to measure cumulative abnormal returns around the event date of the initial release of the USEITI information. Second, I use the Collins, Pincus, and Xie (1999) adaptation of the Ohlson (1995) model to test for value relevance of the continuing disclosure of the USEITI information.

The literature on country-level corruption indicates that many poor but resource-rich countries' governments have failed to exploit their natural resources wealth for meaningful growth (Kolstad \& Søreide, 2009; Svsensson, 2005). While this situation is likely true for most developing countries, the case of Sub-Saharan African (SSA) countries is extreme. Poor resource revenue management, facilitated by opacity and lack of accountability to citizens makes it 
likely that people living in countries richly endowed with subsoil resources will gain only minimal benefit from the proceeds of these resources (Auty, 1997; Kolstad \& Wiig, 2009; Venables, 2016). Pitlik, Frank, and Firchow (2010) observe that by facilitating socially unproductive rent-seeking and wasteful corruption, natural resource abundance becomes a country's curse rather than a blessing, reinforcing rather than relieving the extreme poverty of the inhabitants of these countries. For example, Nigeria and Angola are the top oil producers in Africa (U.S. Energy Information Administration, 2013) but financial mismanagement of their extractive revenues over many years, has resulted in these countries being a shadow of their potential, based on their extractive resources endowment.

The United Nation's Human Development Report for 2015 shows that Angola, Nigeria, Cameroon, and other Sub-Saharan African countries, rich in natural resources, rank extremely low on Human Development Index (HDI) (UNDP, 2015). ${ }^{1} \mathrm{~A}$ similar situation holds for natural resources revenue governance which is critically the crux of many years of near economic stagnation. The Revenue Watch Institute's Resource Governance Index (RGI)² for 2013, ranked Nigeria $40^{\text {th }}$ and Angola $41^{\text {st }}$ in a 58-country assessment (Revenue Watch Institute, 2013). These rankings categorised them as failing states in respect of resource

\footnotetext{
${ }^{1}$ See Appendix A for countries ranking and scores on HDI.

${ }^{2}$ Resource Governance Index a global measure of governance in the oil, gas and mining sector.
} 
governance. ${ }^{3}$ Nigeria, Angola and other Sub-Saharan African countries also rank poorly on the 2015 Corruption Perception Index (CPI) released by (Transparency International, 2015) ${ }^{4}$. These indicators and others provide a vivid portrayal of the troubling economic and financial situation facing poor but resource-rich countries in Africa.

The rest of this chapter is organized as follows: Section 1.2 outlines the background of the study and explanation of the EITI. In section 1.3 the research motivation is presented. In Section 1.4 the research findings are outlined. Finally, Section 1.5 sets out the structure of the thesis.

\subsection{Background of the study}

The EITI is the leading international Transparency and Accountability Initiative (TAI) ${ }^{5}$ focused on transparency around the governance of oil, gas and mineral

\footnotetext{
${ }^{3}$ Appendices B and C contain information on the Resource Governance Index (RGI) of natural resources countries and a subset for Sub-Saharan African countries respectively.

${ }^{4}$ Appendix D shows the 2015 Corruption Perception Index (CPI) for Sub-Saharan African countries, most of whom are also classified as resource-rich countries.

5 Transparency and Accountability Initiatives (TAIs) are citizen-led demand-side accountability mechanism that demand information, which is adapted to combat governance and developmental failures. It is used to improve the traditional ways (i.e. the state-led supply-side) of delivering accountability (Gaventa \& McGee, 2013). Thus, it empowers the weak and poor people in a country who desire accountability the most from their government but are unable to obtain that due to obstacles surrounding state-centred political and bureaucratic accountability mechanisms (Joshi \& Houtzager, 2012; World Bank, 2004).
} 
resources. It achieves this objective at the national level of each implementing country via a tripartite Multi-Stakeholder Group (MSG)6 validation process using standards that require participating extractive companies to disclose their payments made to national governments for the exploration of natural resources, with the governments likewise required to publish revenue they have received from these extractive companies. The two sets of information are then reconciled by an Independent Administrator (IA) ${ }^{7}$ who provides third-party assurance on the information reported. The reconciliation involves the IA comparing the payments from an extractive company for the year under review with the government's reported revenue receipts from the same company. The EITI

${ }^{6}$ The Multi-Stakeholder Group (MSG) at the country level is also known as the national EITI Council (Aaronson, 2011). Composition of the MSG draws from three constituencies- government (country), industry (extractive companies) and Civil Society Organisations (CSOs) working at a horizontal level, which allows for constructive engagement and exchange of information. It develops a country's work plan to oversee implementation and management of the EITI programme. Its core functions include (i) overall strategic decision-making, (ii) defining the scope of EITI process, (iii) identifying, assessing and removing barriers to implementation, (iv) preparing the work plan and monitoring implementation, (v) selecting and overseeing the work of the Independent Administrator, (vi) contributing to approval of reporting templates, (vii) communicating about the EITI and engaging stakeholders, (viii) ensuring that EITI reports are comprehensible and publicly accessible so as to contribute to open, public debate, (ix) appoint the Validator and approve validation reports, and ( $\mathrm{x}$ ) take steps to act on lessons learnt, address discrepancies, and ensure the sustainability of the EITI process.

7 The IA also referred to as the Reconciler, is an independent entity (usually an audit firm) that is appointed by the MSG to reconcile the revenue received by the government and payments made by the extractive companies. Although, required to apply international auditing standards in the reconciliation process, the Reconciler's task is not to carry out an audit in the traditional accounting manner, but rather (i) to compile and analyse the information received from government and companies, and (ii) to investigate and explain any discrepancies as set out in the terms of reference agreed upon with the MSG. 
report, which is publicly distributed, confirms the payments made or reports unresolved discrepancies ${ }^{8}$ (if any).

Establishment of the EITI in September 2002, is traceable to the call by Civil Society Organisations (CSOs) such as Publish What You Pay, Global Witness, Oxfam America and Transparency International (Short, 2014; Williams, 2011) for stronger efforts to stem growing poverty and corruption in poor resource-rich countries. This pressure was reinforced by research indicating the presence of low or negative growth in most countries with an abundance of natural resources (Auty, 2001; Ross, 1999; Sachs \& Warner, 1997, 2001).

The announcement by the former British Prime Minister, Tony Blair, at the World Summit on Sustainable Development in Johannesburg, of the establishment of the EITI as a policy intervention mechanism was praised by developed countries, donors, and international organizations as a key to resurrecting the stagnating economies of poor resource-rich countries (Hilson \& Maconachie, 2008). Consequently, the United Kingdom Department for International Development

\footnotetext{
${ }^{8}$ Discrepancies are amounts the IA is unable to resolve from the summary of payments made to the government by extractive companies and the disclosures made by the government. Discrepancies, if any, may arise from (i) companies' incorrect inclusion of certain payments in a wrong category (e.g. classifying royalties under surface lease payments or reporting payments for production fees as royalties); (ii) government agencies' mix-up, (e.g. classifying amount received from companies under a category other than payment made); and (iii) embezzlement and/or corruption- where public officials (government) under-report payments received from extractive companies.
} 
(DFID) convened the Lancaster House Conference in London on 17 June 20039, where the first set of EITI Principles ${ }^{10}$ were adopted by a group of countries, companies and CSOs signifying consensus and commitment to reducing financial opacity overpayments and revenues in the extractive sector.

A fundamental agreement in literature is that transparent disclosure reduces information asymmetry (Bertomeu \& Magee, 2015; Healy \& Palepu, 2001) and improves natural resources revenue management and governance (Short, 2014; Williams, 2011). As such the EITI seeks to provide an international platform for openness in management and reduction of information asymmetry regarding revenues from extractive resources. It strengthens accountability and transparency and aids public trust in the governance of extractive resources through disclosure and reconciliation of payments by extractive companies to governments. ${ }^{11}$ Countries that follow the EITI standards must publish reports in which companies and government publicly disclose detailed disaggregated payments (i.e. expenditure for natural resources exploration paid to sovereign states) and revenue respectively.

\footnotetext{
${ }^{9}$ Some studies refer to 2003 as the establishment date of EITI, however the Lancaster House Conference was only a furtherance of the decision announced in the previous year.

10 The EITI's 12 Principles (see Appendix E) are the cornerstone on which it operates and consenting to them signifies a country's desire to become an implementing member.

11 This is executed at the national EITI level by the MSG through a well-developed work plan, to oversee implementation of and management of the EITI programme.
} 
Country membership of the EITI is voluntary and primarily involves the government of the country undertaking to disclose revenue received from extractive companies operating in the country. It is important to note that, once a country signs up to implement the EITI Standards, it becomes mandatory for extractive companies operating in such a country to report payments made to the host government for extraction of minerals, hydrocarbon or other commodities covered by the EITI process (EITI, 2015). Membership of the EITI reached 51 implementing countries by June 2016, of whom 31 were fully compliant ${ }^{12}$.

The decision to join the EITI rests on the government's willingness to sign-up and enact enabling laws that drive the process according to the EITI Standards. The government is responsible for (i) ensuring financial support and management of the process, including staffing a national EITI secretariat, (ii) committing to work with CSOs and companies on the implementation of EITI, including establishing a MSG to oversee implementation, (iii) ensuring that the EITI Work Plan objectives are linked to national priorities and reforms in the extractive sector, (iv) creating an enabling framework for EITI implementation, including removing any legal, administrative or other obstacles to implementation, especially concerning the release of EITI-related data and effective participation of civil society, ( $\mathrm{v}$ ) ensuring timely and comprehensive reporting by extractive companies and full government disclosure of extractive industry revenues, (vi)

\footnotetext{
${ }^{12}$ Appendix F contains list of EITI implementing countries and their status as at 30 June 2016.
} 
ensuring that there is a credible reporting process with adequate assurance of company and government data, (vii) generating a comprehensible, publicly accessible, widely disseminated EITI Report that contributes to public debate, and (viii) taking remedial actions to address discrepancies, shortcomings, inefficiencies and ensure that EITI implementation is sustainable (EITI, 2015).

Extractive companies are co-partners with the government, as annual payments to the government in implementing countries must be reported promptly and accurately to the IA on request. Basically, extractive companies support the EITI process by (i) helping initiate and guide the EITI process, (ii) shaping the EITI scope, (iii) reporting and helping the IA with additional evidence (when needed) to reconcile EITI data, and (iv) communicating EITI results to communities and the general public at large (EITI, 2015).

Civil Society Organisations (CSOs) are the real influential actors in holding government accountable for EITI processes and publicising (the cause of) discrepancies. Firstly, they pressure the government to join the EITI, to enable them to have the power to scrutinise accountability information, as published in EITI reports (Ölcer, 2009), and persuade government and companies to continue reporting the relevant information over time. The EITI affirms that,

...active participation by CSOs is central to EITI implementation, both in establishing and shaping the process and in facilitating and monitoring EITI implementation. During implementation, international and national 
CSOs provide essential support through training, advocacy, communication and citizen engagement, helping to ensure that the EITI Reports are widely understood and the data used (EITI, 2015).

Thus, the engagement of CSOs in the EITI process free of obstruction is fundamental to success.

Each country's MSG is required to agree on the extent of information to be disclosed but the EITI expects each country to fulfil its minimum disclosure requirements. The requirements on disclosure include both quantitative (financial) and qualitative (non-financial) information relating to the extractive activities in a country. The requirements on disclosure by extractive companies are detailed in Requirement 4- Revenue collection ${ }^{13}$. This Requirement specifies the revenue streams that must be disclosed by extractive companies operating in EITI implementing countries, to include but not limited to (i) host government's production entitlement, (ii) state-owned company production entitlement, (iii) profit taxes, (iv) royalties, (v) dividends, (vi) bonuses, such as signature, discovery and production bonuses, (vii) license fees, rental fees, entry fees and other considerations for licences and/or concessions, and (viii) any other

13 The EITI requires a comprehensive reconciliation of company payments and government revenues from the extractive industries. The EITI Requirements related to revenue collection include: (4.1) comprehensive disclosure of taxes and revenues, (4.2) sale of the state's share of production or other revenues collected in kind, (4.3) infrastructure provisions and barter arrangements, (4.4) transportation revenues, (4.5) State Owned Enterprises (SOE) transactions, (4.6) subnational payments, (4.7) level of disaggregation, (4.8) data timeliness, and (4.9) data quality (EITI, 2016). 
significant payments and material benefits provided to the government. At implementing country level, the EITI expects the MSG to agree on the materiality threshold for minimum payments to be reported, as well as ensuring that the information disclosure is in a disaggregated manner at the project level.

Membership of the EITI in the early years was targeted at poor resource-rich countries with weak natural resource governance. As time progressed, however, it became important for transparent resource-rich countries to join the campaign, in order to offer opaque countries the opportunity to learn from the best practices of transparent resource-rich countries in regard to natural resources revenue management. EITI former Chair, Clare Short, puts it in perspective in her foreword to the 2015 EITI Standards when she affirmed that, ... one of the key challenges ahead is to recognise and learn from countries that exceed the minimum requirements and create incentives for more innovative use of EITI to the benefit of the countries that implement the EITI (EITI, 2015).

Consequently, a handful of developed countries have signed up to the EITI, such as Germany, Norway, UK, and the US ${ }^{14}$. The US sign up to the EITI signaled the growing impact of EITI in influencing global reporting practices and governance of the extractive sector, particularly, as the US is one of the top producers of oil and natural gas and has the largest capital market in the world. The US became

${ }^{14}$ However, in November 2017 the US withdrew from membership. Details are available here 
the first G8 country to be admitted as an EITI candidate country on 19 March 2014. This move was followed by the UK on 15 October 2014 and on 22 December 2015, Germany lodged its application to become an EITI implementing country. Although Canada is yet to officially sign up to implement the EITI Standards, however, as an EITI supporting country, it has made significant advancement with respect to legislating EITI regulations. ${ }^{15}$

Australia tops the list of other developed natural resource-rich countries making advancement to implementation of the EITI Standards. Australia officially announced on 6 May 2016 its intention to implement the EITI standards. ${ }^{16}$ This is consistent with its robust code for reporting mineral resources and ore reserves (The Joint Ore Reserves Committee (JORC) Code). Notably, the JORC code shares commonality with EITI in terms of improving transparency in reporting of extractive information by exploration firms. However, the JORC code differs from the EITI in its overall purpose. In brief, the intent of the JORC code is to provide a minimum standard that must be adhered to by listed resource firms

\footnotetext{
${ }^{15}$ Canada enacted its mandatory extractive industries transparency disclosure law following the EITI requirements on 16 December 2014, known as the Extractive Sector Transparency Measures Act (ESTMA) (Department of Justice, 2014). The Act is effective from June 1, 2015. ESTMA is part of Canada's commitments to support global efforts to increase transparency in the extractive industry. Like similar Acts in US and UK, ESTMA, in line with the provisions of EITI, requires extractive companies in Canada to publicly disclose, on an annual basis, specific payments made to all governments in Canada and overseas for the exploration of natural resources.

${ }^{16}$ Details of this announcement by the Minister for Foreign Affairs, the Hon Julie Bishop MP, and the Minister for Resources, Energy and Northern Australia, the Hon Josh Frydenberg MP are available here.
} 
in reporting exploration results (mainly in Australia and New Zealand). This is to provide more accurate and authoritative financial information consistent with requirements of the Australian Stock Exchange (ASX) filing requirements. The JORC code primarily seeks to provide a uniform information environment for capital market users focusing on its three underlying principles of Transparency, Materiality and Competence (Bird, Grosse, \& Yeung, 2013; Ferguson \& Pündrich, 2015; Joint Ore Reserve Committee, 2012).

In comparison to JORC, the EITI provides broader guidance on governance of extractive resources in implementing countries. EITI overarching principles integrate the entire extractive industry value chain. By focusing on national transparency EITI seeks to improve the governance of natural resources via its tripartite procedure that requires extractive firms to make a detailed disclosure of their dealings with national governments. More specifically, EITI reflects the expectation that transparent disclosure of natural resources revenue by resource-rich countries mitigates opacity, corruption and kleptocracy at the national level. Thus, the EITI focuses on national governments financial management process and targets a much wider spectrum of stakeholders beyond capital providers in addressing extractive industries financial transparency. Succinctly, the EITI is not only about companies being required to make certain disclosures or report their payments to government, but governments also having to report on revenues received. 


\subsection{Motivation of the study}

The overarching inspiration for this study stems from the growing level of perceived and actual corruption, and financial opacity prevalent in resource-rich countries, especially those with poor governance and weak capability to efficiently utilise extractive revenue to improve the well-being of their citizens. Additionally, the relative absence of research on the economic value of EITI generated information reinforces the need for the study. Specifically, the lack of empirical evidence on the economic impact EITI information disclosure can have at the government and company levels in EITI implementing countries.

Studies addressing the effectiveness of EITI with respect to the reduction of country-level perceived corruption are limited, and in some respects still emerging. In particular, prior studies, with the exception of the recent work by Papyrakis, Rieger, \& Gilberthorpe (2017) have focused on factors that determine countries' membership of the EITI (Kasekende, Abuka, \& Sarr, 2016; Pitlik et al., 2010) and effectiveness of EITI in reducing the resource curse (Corrigan, 2014; Williams, 2011). Investigating the influence of EITI by linking EITI implementation experience with countries perceived level of corruption provides an assessment of the effects of the EITI in mitigating corruption, taking into account cross-country variation in the timing of countries joining the EITI. 


\subsection{Research Findings}

The findings of the research are outlined below in the order of the research questions addressed in the thesis.

\subsubsection{EITI implementation and the perception of corruption}

The findings indicate that EITI implementation experience is not associated with improved control of corruption for all EITI implementing countries taken together, as the coefficient on EITI experience is negative and significant at $1 \%$ level.

However, I also find that the impact of EITI implementation experience on the perception of corruption varies across the implementing countries. In particular, I find that for Sub-Saharan African countries [and Heavily Indebted Poor Countries], the interaction term for Sub-Saharan African countries with EITI implementation experience is positive and significant at the $1 \%$ level. Thus, the negative effect associated with EITI implementation is less for these countries. This finding aligns with the intent of establishing the EITI, as a policy mechanism for resuscitating failing and poor but resource-rich countries, and indeed congruent with the expectations of the effect of establishing the EITI. 


\subsubsection{Economic value of EITI information disclosure}

The results indicate that investors consider the USEITI information to have economic value. Specifically, the results demonstrate that for firms whose information was released in the initial 2013 implementation process, there was a significant trading volume reaction and significantly positive cumulative abnormal returns in the period surrounding the announcement (release) date of the information. Further, regression analyses employed to explain the crosssectional variation in abnormal returns during the main event period shows that the price reaction is associated with oil and gas firms and firms that had high working capital but low asset turnover.

Furthermore, the value relevance tests results are consistent with the market reaction tests on the initial release of this information and, provide support for this EITI information having economic value.

\subsection{Overview of the remaining chapters of the thesis}

\subsubsection{Chapter two: Literature review}

Chapter two presents a survey of the empirical literature on the EITI with a focus on assessing the success of EITI in achieving its objectives and the intents for which it was established. Since 2009 the EITI has been the subject of a number of studies following on the work of Ölcer (2009). The studies have utilised the 
increasing availability of data across time and countries to assess the impact of the EITI.

\subsubsection{Chapter three: EITI implementation and the perception of corruption}

Chapter three reports the results and analyses from the tests of the first two research questions. Using a sample of 648 country-year observations on all EITI implementing countries, I find that (i) taken together, EITI implementation experience does not lower the level of perceived corruption in the EITI implementing countries, but (ii) the length of EITI implementation experience does lower the perception of corruption in Sub-Saharan African countries [and Heavily Indebted Poor Countries]. A key finding from the analyses reported in this chapter is that there exists considerable variation across countries in the benefits from the implementation of EITI.

\subsubsection{Chapter four: Economic value of EITI Information}

Chapter four, reports the results from the tests of the second two research questions. Data from the United States Extractive Industries Transparency Initiative (USEITI) unilateral release of information on non-tax payments by extractive companies to the US government, is used to illustrate the economic value of EITI information. The findings indicate that investors in extractive companies reacted to the USEITI information on release and, furthermore, the 
continuing disclosure of the USEITI information over the period to 2016 was found to be value relevant.

\subsubsection{Chapter five: Conclusions and implications for future research}

Finally, based on the findings of the study, Chapter Five provides the concluding summary, considers the contributions of the study, and suggests directions for future research. The chapter also outlines the limitations of the study. 


\section{CHAPTER TWO}

\section{LITERATURE REVIEW}

\subsection{Introduction}

This chapter reviews in chronological order the key contributions to the emerging empirical literature on the Extractive Industries Transparency Initiative. The chapter also presents the theoretical underpinning for the empirical tests conducted in the study. As stated earlier, this study is concerned with the assessment of the effectiveness of EITI in mitigating natural resources revenue mismanagement in poor but resource-rich countries. The review is organised into four streams. First, is an overview of corruption and how it is conceptualised in the study. Second, the review addresses the limited but growing number of studies that have investigated the country-level impact of EITI membership on governance and corruption. Thirdly, it explores relevant research that examines market reaction to extractive companies' information disclosure and the value relevance of extractive disclosure practices. Finally, the chapter describes the theoretical framework applied in this study. Specifically, it discusses agency theory in the context of citizen-government relationships.

\subsection{Conceptualisation of corruption}

Most financial and economic players hold the view that corruption obstructs development and growth for all countries. Healy \& Serafeim (2016) assert that corruption is a leading impediment to countries' economic development. Yet, news of corruption tops media headlines on daily basis, despite the apparent 
agreement that corruption is harmful to any country. One explanation for this may perhaps be that the benefits from being involved in corruption outweigh the expectation of incurring penalties, especially in countries where governance and the rule of law are weak. The common behaviour of politicians and government officials explains this prevalence of corruption in business and country level governance globally (Healy \& Serafeim, 2016; Melgar, Rossi, \& Smith, 2010; RoseAckerman, 2002; Shleifer \& Vishny, 1993; Svensson, 2005; Tanzi, 1998).

There is an expanding literature on the key types of corruptions (i.e. private and public sector corruption), but the focus of this study is on public sector corruption. I conceptualise the phenomenon of corruption in line with the definition of Tanzi (1998) which emanates from the World Bank describing "corruption as the abuse of public power for private benefit" ${ }^{17}$ Though simple, this definition emphasises aspects of public sector corruption such as monetary payments to agents (government officials) to induce them to ignore the interest of their principal (citizens) and favour the private interests of a bribe payer (Pillay \& Kluvers, 2014; Rose-Ackerman, 2002) or disposal by government officials of public assets for personal gain (Cuervo-Cazurra, 2016; Shleifer \& Vishny, 1993; Svensson, 2005). Cuervo-Cazurra (2016) argue that corruption has

\footnotetext{
17 While consensus is lacking on a universal definition that best explains corrupt practices or corruption in the literature; this conceptualisation of public sector corruption is shared by several researchers and international organisations as indeed reflective of what public-sector corruption entails across jurisdictions (e.g. Blackburn, Bose, \& Haque, 2010; Elbahnasawy \& Revier, 2012; Neu et al., 2013; Shleifer \& Vishny, 1993; Svensson, 2005).
} 
three key dimensions viz (i) that a person is abusing power entrusted by another person(s) [i.e. citizens], (ii) the power abuser [government official] is engaging in actions that are beyond his or her prescribed position or mandate, and (iii) the person is obtaining a benefit that only accrues to him/her rather than the people. Simply put, corruption entails the betrayal of trust and misuse of privilege or authority bestowed on an individual or government [public official] for selfbenefit of the abuser ${ }^{18}$. However, a fourth dimension that can be added is that the benefit obtained by the recipient of the bribe is typically much less than the benefit obtained by the payer of the bribe. Daily news across the world is jampacked with instances of business and government abuse of authority- and it seems increasingly unabated.

Measurement of corruption presents a severe challenge. Obviously, the person paying a bribe does not publicly admit that, and similarly for the recipient of a bribe. There are therefore no public records of actual corruption other than the relatively few instances of prosecutions taking in respect of detected corrupt action. Furthermore, the notion of what constitutes corruption varies across jurisdictions and cultures, making it difficult to find a one-size-fits-all measure of corruption. Thus, corruption tends to be measured by the perception of

\footnotetext{
18 The reference here is that person or group [i.e. the agent] that is actively involved in unethical behaviour that advances his/her (group) interest rather than the interest of the principal.
} 
corruption ${ }^{19}$ but this is often defined in vague terms. Again, there is an unresolved debate on the relationship between actual and perceived corruption (Heywood, 2015; Houqe \& Monem, 2016; Melgar et al., 2010).

Houqe and Monem (2016) suggest that the relationship between the level of actual corruption and the perception of corruption can be complex, with actual corruption affecting the perception in a country. On the other hand, perception can also influence the actual level of corruption as some people may act corruptly, based on the belief that others are engaging in similar behaviour (Heywood, 2015). Specifically, Melgar et al., (2010) note that high levels of corruption perception could have more devastating effects than actual corruption. This is because the perception of corruption in a country generates distrust of the institutions that are perceived as being corrupt and creates a cultural tradition of gift giving and hence, raising actual corruption levels in that society. Notwithstanding the metric used in estimating corruption, higher levels of perceived corruption portend serious damage for institutions and the overall development and economic growth prospects of a country.

${ }^{19}$ Which is the subjectivity of what constitutes a corrupt phenomenon; or what is understood and interpreted as corruption in each society. 


\subsection{EITI effectiveness and the reduction of corruption}

Few studies have linked the effectiveness of the EITI to the reduction of corruption. One explanation for this is that the EITI has been in existence for a relatively short time. Ölcer (2009) was an early study investigating the effectiveness of EITI on control of corruption. Ölcer (2009) examined the effectiveness of EITI, scrutinising deficiencies in the way the EITI operated and found that although the EITI had drawn the attention of the international development community to extractive sector issues, it was very much an initiative still in progress. She confirmed the teething problems that faced the EITI just six years after its establishment and with then only 26 members.

Focussing on the change in corruption ranking Ölcer (2009) found that EITI countries were worse than non-EITI resource-rich countries on the World Governance Indicator (WGI) for Control of Corruption Index (CCI). A major limitation, at the time of her study, contributing to the apparent lack of success of the EITI in respect of corruption was that the minimum standards were not sufficient to provide quality information on revenue streams. In particular, the high threshold set for payments to be regarded as material. Ölcer recommended that for EITI to achieve maximum impact the developed countries should practice what they preached by not only funding but also joining the EITI. This call has been answered in recent years with Norway, US, UK, Germany and Australia officially committing to implement the EITI Standards. 
Kolstad and Wiig (2009) argue that transparency alone is not sufficient to reduce corruption, especially with the EITI's emphasis on revenue rather than expenditure disclosure. They contend that the correlation between lack of transparency and high levels of corruption, cannot be taken to imply causality. Kolstad and Wiig (2009) found, as in Sachs and Warner (1997), that resource abundance had a negative impact on economic growth. However, as in Mehlum, Moene, and Torvik (2006), they found a significant positive relationship between economic growth, and the interaction term for the rule of law and resource abundance. That is the rule of law mitigates the negative impact of resource abundance. Kolstad and Wiig (2009), conclude that transparency or access to information can have an impact on corruption only under certain conditions. They hypothesise that the impact of transparency or access to information will depend on the level of literacy, and the extent to which stakeholders have the power to hold government accountable. With respect to the effectiveness of the EITI, Kolstad and Wiig (2009) believe that the emphasis on revenue transparency is misplaced.

Pitlik et al., (2010) examined the political and socio-economic factors which determine a country's participation in EITI. Thus, the study focused on the indicative features that determine a country's revealed willingness to reform. Based on a sample of 143 countries $^{20}$ recognized as resource-rich EITI countries

\footnotetext{
20 Due to limitation of available data only 19 of the 23 EITI implementing countries was included in Pitlik et al., (2010) sample.
} 
at the time of the study, Pitlik et al. (2010) identify several characteristics that lead countries to join the EITI. First, is that countries with a higher share of natural resources in their exports are more likely to join the EITI. Thus, contrasting the Ölcer (2009) view that EITI was not attractive to the most resource-abundant and resource-dependent countries. The insight from the Pitlik et al. (2010) results is that public benefits of joining are probably higher the more a country's export income depends on fuels, ores and metals (i.e. resource export).

Secondly, they find that countries with more (Ethnic) fractionalization are more favourable to join the EITI. One explanation for this, suggested by Pitlik et al. (2010), is that joining EITI could serve as a panacea to reduce conflict between rival ethnic groups, who may be at war over accruing resource rents, and in a sense, reduce the portion of natural resources that can be distributed among rivalling interest groups. The intuition here is that political conflict over resource rents is often exacerbated by the presence of more heterogeneous groups in countries rich in natural resources. ${ }^{21}$ Hence making the need for transparency a crucial remediating factor.

${ }^{21}$ Countries endowed with natural resources and having a heterogeneous ethnicity, tend to fit this description. For example, Appendix G show the ranking for 2016 State of Peace and the Ethnic Fractionalisation of EITI countries, which suggests the existence of this phenomenon in some EITI countries. 
Thirdly, Pitlik et al., (2010) found corrupt countries to also be more likely to join the EITI. This perhaps builds on the fact that EITI as a mechanism for transparency and accountability aims at this cohort of countries. A counterargument to this view is that the EITI is not exclusively for the most corrupt countries in terms of its objective, rather its focus is on resource-rich countrieswhich includes corrupt and non-corrupt countries. As argued by Pitlik et al., (2010) it is unlikely that corrupt countries will be more willing to join the EITI simply because they are the targeted countries. This would apply in particular where government actors are indeed the main beneficiaries of corrupt acts.

Finally, the study documents that democratic freedom, political liberties and higher presence of Non-Governmental Organizations (NGOs) increase the likelihood of joining EITI. However, in contrast, the Pitlik et al., (2010) results show that countries with OPEC membership have a lower probability of joining the EITI.

Although the Pitlik et al.'s (2010) findings provide indications for the characteristics of countries that are likely to join the EITI, they equally admit that the motivation of joining the Initiative by some countries could as well be a mere façade for good governance window dressing. In response to this concern Pitlik 
et al., (2010) called for further research on the real effect of implementing the EITI and if the EITI is achieving its intended objective in the long-term. ${ }^{22}$

Based on a 2008 survey of 23 EITI members, 38 supporting firms, and interviews with EITI staff, Aaronson (2011) showed that EITI effectiveness was limited by the different interests of the three stakeholders (governments, companies and CSOs). Furthermore, EITI's effectiveness was also constrained by implementing governments' restriction on full participation by CSOs (viz, that little or no access to information was being provided to CSOs to enable them to hold governments accountable) and the low public and legislators' awareness of EITI. Aaronson found that $71 \%$ of respondents believed that the EITI signals government's credibility in addressing corruption and attracting investment, 64\% thought it had increased transparency, but only $43 \%$ perceived EITI to have increased citizens' monitoring capability of government activities. Thus, the study suggested a general acceptance of the EITI as an effective signal for reform, but weak in enforcing accountability due to limited access to information by CSOs.

Aaronson (2011) argued that despite the number of implementing countries having grown to 32 , at the time of the study, EITI still struggled with a clear

${ }^{22}$ Key limitations of the study by Pitlik et al., (2010) were the recency of the EITI and the relatively small number of countries implementing the EITI Standards at the time of the study. In particular, the EITI was less than a decade old with 23 implementing countries - of which only 19 had a complete dataset available for analysis. 
roadmap for success, slow progression from candidate to compliant status by countries, stakeholders' power imbalance, and repression of CSOs by some implementing countries. Aaronson (2011) concluded that although the EITI MSG partnership is not optimal, nevertheless, experience suggested that it presents important learning opportunities for governments and CSOs.

Corrigan (2014) examined the impact of EITI from its establishment to 2009 and found that EITI membership appeared to have helped countries achieve greater transparency and improve in terms of natural resources benefiting all. She argued that if joining the EITI is a sign of countries' willingness to reform and increase transparency and accountability, then membership should lead to improvements as measured by both economic and governance indicators. With economic growth measured as Gross Domestic Product (GDP) per capita and governance by the World Bank Governance Indicator, Corrigan (2014) found that EITI membership had lessened the negative effects of resource abundance on economic growth and some aspects of governance. However, the effect of membership of EITI remained unclear in terms of Political Stability, Control of Corruption, and Voice and Accountability. Overall, the Corrigan (2014) findings suggest that EITI membership had helped countries improve in terms of natural resources benefiting all, but had not achieved a reduction in the perceived level of corruption. 
Furstenberg (2015) examined the impact of EITI in nondemocratic settings using Kyrgyzstan as a case study. The study used interviews conducted with EITI state officials, CSO members, academics, donors and representatives of the business community to address questions concerning the roles of stakeholders and their political incentives for joining the EITI. Furstenberg (2015) concluded that the functioning of the EITI as a multi-stakeholder initiative reveals certain challenges in its 'one-size-fits-all' approach, for all countries. This was exacerbated by communication deficiencies and limited cooperation (in some jurisdictions) among the members of the MSG ${ }^{23}$. A major point from Furstenberg (2015) is that EITI effectiveness, based on the Kyrgyzstan setting, is conditional on significant domestic factors (such as the form of governance and level of citizens' participation awareness in the national decision-making process.

The recent study by Kasekende et al., (2016) addresses the effectiveness of EITI in two dimensions: (i) the factors that lead a country to voluntarily join the EITI and (ii) whether EITI membership leads to greater control of corruption. The study found that corrupt countries and countries attracting greater shares of Foreign Direct Investment (FDI) and countries with lower per capita GDP are more likely to join the EITI. This was consistent with Pitlik et al., (2010) who found that countries with lower GDP per capita and those with higher levels of

\footnotetext{
${ }^{23}$ Furstenberg (2015) confirms that CSOs representation on the EITI MSG in Kyrgyzstan is fragmented and lacks a strong consolidated approach, suggesting a disconnect between the different groups comprising the CSOs -whose attitude she describes as authoritarian.
} 
corruption are more likely to join the EITI. This, in part, explains why corrupt poor resource-rich countries join the EITI, perhaps as window dressing for better access to foreign donors' support. Overall, Kasekende et al., (2016) found that countries with more press freedom have more incentive to join the EITI. One explanation for this is that governments of countries with press freedom tend to operate in a relatively open manner since it is easier for citizens in those countries to hold them (government) to account through unrestricted access to information. Regarding EITI's effectiveness in reducing corruption, they found no evidence that EITI has been able to reduce corruption.

Papyrakis et al., (2017) explore how EITI membership affects variation in changes in the level of corruption. Using panel data covering the period 20012011, the authors test for change in corruption levels over time as measured by the Corruption Perception Index (CPI). They found that resource-rich countries that joined EITI experienced an increase in corruption but no more than other non-EITI countries. This is not surprising, as national reforms do not necessarily yield immediate results. Pitlik et al., (2010) confirm that the decision to join the EITI, which can signal government's intention to reform, translates to measurable results only in the long-term. The Papyrakis et al., (2017) finding suggests that natural resource-rich countries could remedy corruption and introduce sound reforms by joining the EITI Standards. 
In summary, the above studies provide mixed evidence with respect to the impact of the EITI on corruption. This may be due to the limited period for which the EITI has been in existence, and partly because EITI national reform impact may not be easily observed in the short-term as anticipated in studies that assessed the effect of EITI.

\subsection{Extractive companies' information disclosure and market reaction}

In this subsection, I review studies focussing on extractive companies' information disclosure, and studies on market reaction information disclosure. Generally, the literature on information disclosure considers several measures for improving transparency in financial reporting. Mandated disclosure is arguably one effective mechanism for reducing conflict concerning information asymmetry between firms and external parties. ${ }^{24}$ One explanation given in the literature for mandatory disclosure of certain financial information is that it results in improved information disclosure for unsophisticated financial information users (Healy \& Palepu, 2001; Watts \& Zimmerman, 1986). Leuz and Wysocki (2016) argue that mandated disclosure incentivises acceptable corporate behaviour. They suggest that mandated disclosure encourages (discourages) desirable (undesirable) corporate behaviour in the best interest of financial information users.

\footnotetext{
${ }^{24}$ Firms information can become available to third parties by a variety of mechanisms including regulated reporting, voluntary disclosures and information intermediaries (Healy \& Palepu, 2001; Leuz \& Wysocki, 2016; Verrecchia, 2001).
} 
In general, the literature confirms that there is an increasing demand for more disclosure by firms, especially for extractive companies whose exploration and production activities are perceived to have a significant effect on society. Griffin, Lont, and Sun, (2014) state that "advocates of sustainability accounting seek to encourage or require companies to disclose information on a wide range of issues beyond those within the traditional confines of financial reporting, particularly issues as they relate to companies' involvement in social justice". These additional disclosures are assumed to have several benefits for diverse stakeholders (Grewal, Riedl, \& Serafeim, 2015), although chiefly investors, in making financial decisions about firms, but also as a way of providing information to other financial information users regarding activities of extractive firms that are linked to government revenues.

Event studies are established means of providing evidence on the impact of an event or announcement on the wealth of firms' shareholders (Kothari \& Warner, 2007). Studies on events and announcements from firms' and/or regulatory institutions provide empirical evidence on the reaction of market participants and can assist in identifying the impact of new regulatory initiatives (Wells, 2004). Of importance is how an entire industry adopting a new regulation is perceived by players in the market. The seminal paper by Fama, Fisher, Jensen, and Roll, (1969) established a link between new information and resulting behaviour in rates of return on securities in the period surrounding the release 
of the new information to the market. The market reaction to events or information is often largely anticipatory with the ex-post reaction being a correction of errors made in forming the anticipations. A common thread running through all market reaction research is the fact that market participants are interested and responsive to new information affecting stocks traded in the market. Ball and Brown (1968), one of the pioneer studies on information relevance to investors, contend that given the efficient and unbiased nature of markets in using information, usefulness can be assessed by the impact on securities prices.

Investor reaction to new voluntary disclosures of information or changes in regulatory requirements on disclosure is typically measured by the change in trading volume and the cumulative abnormal returns around the date of such events. The impact of particular information over an extended period of time is assessed by a value relevance study.

Prather-Kinsey and Tanyi (2015) is an example of a study on the impact of regulatory announcements. The study investigates the market reaction to the SEC's press releases between 2007 and 2011 regarding the adoption of IFRS in the US. Prather-Kinsey and Tanyi (2015) use data on American Depository Receipts (ADRs) and find a significant positive reaction to the SEC's announcements relative to the possible application of IFRS. 
Grewal et al., (2015) examine the market reaction to the passage of European Union (EU) mandated disclosures on environmental, social, and governance performance on EU listed firms. Using a sample of 1,249 unique firms affected by the regulation from $28 \mathrm{EU}$ member countries Grewal et al., (2015) document that on average investors anticipate a net cost from the directive; but firms exhibiting strong nonfinancial performance and disclosure before the regulation overall benefited from the passage of the directive. The Grewal et al., (2015) results signify that the market response to this information is not homogeneous across firms and investors. Their results show that overall the market reacted negatively, especially for firms with weak nonfinancial disclosure performance prior to the regulation. However, investors in firms with strong nonfinancial performance benefited as shown by the positive abnormal returns for such firms around the event period.

\subsection{Extractive firms information disclosure and value relevance}

The key studies on the value relevance of information disclosure in the context of extractive firms are Clinch and Magliolo (1992), Berry and Wright (2001), Ferguson and Scott, (2011), Bird, Grosse, and Yeung (2013), and Ferguson and Pündrich (2015).

Based on a sample of 86 US firms from 1984 to 1987 Clinch and Magliolo (1992), examine whether (i) the mandated Statement of Financial Accounting Standards 
(SFAS) No. 69 disclosures for proved reserves and proved developed reserves are value-relevant, and (ii) whether investors' reliance upon SFAS No. 69 reserve quantity disclosures is related to variation in the reliability of such disclosures across firms. Taken together, the Clinch and Magliolo (1992) findings indicate that overall these disclosures do not provide supplementary value-relevant information to investors when production estimates are known. However, they provide evidence that these disclosures are value-relevant for firms whose reserve quantity estimates appear more reliable. Clinch and Magliolo (1992) interpret their results as suggesting that investors' reliance on disclosures varies as a function of disclosure quality.

Berry and Wright (2001) investigate the extent to which supplemental reserve quantity disclosures of US oil and gas companies convey value-relevant information to investors about their effort and ability to discover proved reserves. They find that the market value of firms is positively related to the efforts expended to discover and extend proved reserves. The Berry and Wright (2001) results demonstrate that full cost firms' information regarding effort and ability to discover new reserves are value relevant. However, for successful efforts firms, proved developed reserves are more value relevant than information on effort and ability. 
Ferguson and Scott (2011) examine market reaction to the presentations by Australian extractive firms to investors at mining clubs and conferences. Based on 817 presentations by 325 boutique resource firms from 2000 to 2009, they document evidence that these presentation events were informative. Specifically, Ferguson and Scott (2011) report a significant positive abnormal return around the presentation date, indicative that the events were important to the market. Although their study focused on firm voluntary disclosure of non-financial information, their findings provide incremental insight to extractive firms' information disclosure with specific reference to the Australian setting.

Bird et al., (2013) investigate the market reaction to the Joint Ore Reserves Committee (JORC) code compliant announcements made by extractive firms in Australia and found significant positive abnormal returns for extractive firms that released their exploration information under this mandatory disclosure. Their event study result demonstrates that investors took note of the release of this information and that the announcements had economic value. One explanation offered for this is the complexity surrounding the operations of extractive companies which makes the release of information pertinent to the estimation of their mineral resources and reserves relevant to investors (Bird et al., 2013). Notably, the findings of Bird et al., (2013) differ from prior exploration literature e.g. Clinch and Magliolo (1992) who found no association between reserve disclosure and share price. 
Ferguson and Pündrich (2015) using a sample of 414 Australian extractive firms from 1996 to 2012 examine the market reaction to the mandatory specialist nonfinancial information assurance of mining development stage entities in Australia. The Ferguson and Pündrich (2015) findings provide weak evidence that specialist assurance is relevant to investors, except for base metal reserve disclosures.

\subsection{Jurisdictional implementation of EITI firm-level disclosures}

As part of its mechanism to improve transparency and accountability of natural resources revenue globally, the EITI has advocated for the legislation of disaggregated revenue reporting by extractive companies in EITI implementing and supporting countries. ${ }^{25}$ This advocacy has gained traction with the adoption of the EITI model for extractive revenue reporting in several jurisdictions. The US has been foremost in legislating reporting requirements for exploration and production companies in the US via an amendment to the Dodd-Frank Act 2010 (U.S. Congress, 2010). However, it was the European Union that first implemented a similar reporting directive across European member countries. The adoption of this disclosure regime has widened the opportunity for research, with the availability of data, predominantly, at firm level which is absent in the EITI literature. Studies with regards to EITI firm-level disclosure regime across

\footnotetext{
25 Following the success of the county-level disclosure of extractive revenue by governments of resource-rich countries, the EITI has in addition pushed for firm-level transparency through the enactment of jurisdictional laws mandating extractive companies to provide separate granular information about their extractive dealings with governments of resource-rich countries.
} 
jurisdictions are few in number but examples are Hombach and Sellhorn (2017); Johannesen and Larsen (2016) and Rauter (2017).

Johannesen and Larsen (2016) investigate the effect of the European Union legislation requiring country-by-country disclosure of tax payments on the market value of extractive firms. Based on a sample of 3,642 extractive firms listed in 13 European countries, the study focused on four European Union legislative events leading to the adoption of these disclosure rules. They employed an event study methodology to estimate the market reaction to the sampled extractive firms' value using daily stock prices for the period 2009-2014.

Johannesen and Larsen (2016) report a significant decrease in the sampled extractive firms' market value around the first two events. Specifically, they find a negative cumulative abnormal return that is strongly significant for event one $(-4.6 \%)$ and event two $(-5.1 \%)$ respectively. These first two events relate to the initial endorsement of country-by-country reporting by the EU Parliament on 8 March 2011 and the announcement of the legislative agreement reached between the Parliament, Council and Commission on 9 April 2013, respectively. However, they found no evidence of market reaction around the third and fourth events. Possibly, because the information may have been anticipated in the EU on the basis of the first two events. The third and fourth events related to the EITI disclosure requirements that were adopted by the European Parliament on 12 
June 2013 and by the European Council on 17 October 2013, respectively. These directives specifically require extractive firms registered in Europe or listed on a European stock exchange to disclose on a country-by-country and by project all payments made to foreign governments in excess of €100,000.

Overall, the Johannesen and Larsen (2016) results suggest a value decrease for the extractive companies ranging between 5 and 10 percent during the adoption of these reporting rules cumulated over the four events in the legislative process. The results suggest that EU country-by-country disclosure rules are important mechanisms for reducing extractive firms rents arising from tax evasion in developing countries (Johannesen \& Larsen, 2016). This is interpreted by Johannesen and Larsen (2016) as suggesting that improved financial transparency is a vital tool in curbing natural resource rents.

Based on hand-collected data available from the EITI website for 13 EITI countries' reports across Africa, Asia and Europe, Rauter (2017) examines the effect of EU mandatory extraction payment disclosures requiring extractive companies in the EU to publish in a granular report on their website, payments made to foreign host governments for the exploration of natural resources. The study employed a Difference-in-Difference regression model to assess the real effect of this disclosure by EU extractive companies to foreign host countries from 2010 to 2017. 
The main finding documented by Rauter (2017) is that adoption of the granular disclosure regulation in Europe is associated with higher reported payments to host countries. The results show that extractive companies increased their payments to foreign host governments by £83.86 million following implementation of this disclosure requirement. This suggests that extractive firms engaged in less tax avoidance and corrupt practices following the implementation of this rule.

The results also show that the disclosing EU extractive companies reduced their investment relative to tightly-matched non-EU competitors across the globe as a result of this disclosure regime. Rauter (2017) explains this result as implying that regulated EU firms in the EU reallocated their investment following this regulation compared with unregulated firms. In particular, the results hold stronger for firms that had direct consumer dealings, in line with Corporate Social Responsibility (CSR) best practices. These firms are aware of the penalties (such as public shaming) they risk if found to be engaged in unethical business dealings. Although the study focused on companies' disclosures, the other supplementary tests conducted indicate that extraction payment disclosure is not linked to a reduced perception of corruption at the country level. This is not uncommon in the literature on EITI effectiveness, especially as companies' EITI disclosure do not (in themselves) determine implementing countries' perceived level of corruption. In any case, the findings of Rauter (2017) further reinforce the need 
for additional empirical examination of EITI effectiveness over time in respect of control of corruption, in line with the call by Pitlik et al., (2010).

Hombach and Sellhorn (2017) examine the market reaction to the SEC final rule for the implementation of Section 1504 of the Dodd-Frank Act requiring projectlevel disclosures of payments made by extractive issuers to governments of resource-rich countries for the exploration of natural resources. Specifically, Hombach and Sellhorn (2017) investigate (i) the perception of investors with regards to a likely strict implementation of this regulation by the SEC, and (ii) the cross-sectional variation in the intended use of the proposed disclosures by nontraditional monitors.

Hombach and Sellhorn (2017) employed a sample of 95 US extractive firms to test the market reaction to the first proposal of the SEC final rule in December 2010 to a re-proposal of the rule in December 2015. Hombach and Sellhorn (2017) used event study methodology and found that the market reaction to the rule was negative abnormal returns, signifying on average, that investors believe extractive firms affected by this regulation will incur a net cost from the implementation of the rule by the SEC. In respect of the second question addressed in the study, the Hombach and Sellhorn (2017) evidence suggests that extractive firms subject to strong public scrutiny suffer greater negative cumulative abnormal returns compared to firms not subject to intense public 
scrutiny. A possible explanation for this is that non-traditional monitors (e.g. media and NGOs) are able to use the extraction payment disclosures to compel extractive firms to act responsibly or face a public backlash, particularly with respect to their relationship with local communities or other environmental issues.

While the Hombach and Sellhorn (2017) study reports the effects the proposed rule had on the behaviour of investors, it is an open question as to whether the results are an indication of the impact that might result from actual implementation of the Final Rule ${ }^{26}$. Hombach and Sellhorn (2017) caution that their results should be interpreted with this caveat in mind.

\subsubsection{Juxtaposition of US, UK and Canada firm-level reporting requirements}

The intent of the EITI is to improve extractive revenue transparency at the country-level of implementing countries through disaggregated disclosure of payments by government and extractive firms. The US, UK and Canada independent legislative requirements on extractive payment disclosures

\footnotetext{
${ }^{26}$ A further concern regarding this study is the fact that confounding events around the rule making process can make it difficult to observe the actual impact of the legislation on investors' behaviour as the Dodd Frank Act contains other provisions besides section 1504 disclosure of payments by resource extraction issuers. Again, the rule making process may have little or no effect on the impact of the actual disclosure from companies once implemented, thus further calling for additional testing.
} 
strongly compliment the EITI efforts. Appendix M provides a comparative summary of the EITI legislative requirements across jurisdictions.

\subsection{Theoretical Framework}

As defined by Jensen and Meckling (1976), an agency relationship refers to a situation under which one or more persons (the principal(s)) engage another person (the agent) to perform some service on their behalf which involves delegating decision making authority to the agent. At the heart of the agency theory is the concern that delegation results in information asymmetry between the parties that facilitates agents engaging in actions that promote their own interests at the expense of the interests of the principal. This necessitates the need for monitoring of the agent to control and curtail opportunism in promoting the agent's self-interest. However, monitoring is costly and therefore likely to be undertaken only to the point where the benefit is not less than cost. Thus, there will remain a residual amount of cost arising from the delegation.

\subsubsection{Agency dilemma in citizen-government relationship}

Emanuel and van Zijl (2005) explain that agency explanations have been offered for a wide range of phenomena that are of interest to economists and accountants. Indeed, the citizen-government relationship can be conceptualised as a principal-agent relationship in which asymmetry regarding natural resources revenue information is of concern to citizens (principals). Lack of 
transparency gives rise to conflict between principal and agent, particularly, where it is difficult for citizens to effectively monitor their government's activities (Bale \& Dale, 1998; Kolstad \& Wiig, 2009). This creates ample opportunity for corruption to thrive, as the agents would pursue their personal interests above those of the principal.

One of the ways citizens living in countries with high level of extractive revenue information asymmetry can improve the control of corruption in their country is to demand increased information disclosure on the activities of the government. Vadlamannati and Cooray (2017) advocate that the demands of citizens to be informed of their government's actions with respect to public and natural resources reflects the anti-corruption concerns of the citizens. In practice, this may be difficult, and that is where a country's EITI experience becomes important in offering an alternative approach that overcomes the inadequacies of traditional bureaucratic accountability (Gaventa \& McGee, 2013).

Existing literature suggests that optimal contracting can mitigate the principalagent conflict. An exception, however, is the citizen-government relationship, where it may be difficult for incentive-based covenants to attain optimality between citizens and government. For instance, suppose the citizen-government covenant offers the agent higher incentives either by way of improved pay or reelection based on agreed Performance Indicators (PI), conflict would still arise if 
decision-useful information is not accessible to the principal for stewardship assessment. Besides, citizens are unlikely to be able to write and enforce an optimal contract with their government, given the power imbalance (Aaronson, 2011) between the two parties. However, there may be areas in which governments can reduce agency problems by bonding, that is, constraining their choices, by means such as enacting constraints or constructing mechanisms to perfectly reveal their actions. Nevertheless, information availability is at the heart of the problem and only timely decision-useful information will help resolve the citizen-government information asymmetry problem. This leads to another concern, viz, how do citizens compel their government to disclose required and decision-useful information within an appropriate timeframe?

Monitoring enables the principal to be abreast of the activities of the agent for reward and discipline. This is the mechanism of choice in most developed countries. However, transparency in terms of accountability information is prerequisite to effective monitoring. Lack of transparency in natural resources exacerbates corruption and denies citizens the benefit of these resources (Corrigan, 2014; Kasekende et al., 2016; Williams, 2011). Improved transparency through information disclosure with respect to agent's [government] conduct (Pitlik et al., 2010), increases openness in resource revenue and accountability, which strengthens citizens' capacity to monitor the government. Furthermore, the timely disclosure of financial information by the agent (government) will 
lower information risk (Healy \& Palepu, 2001). Islam (2006) attests that political leaders who know their performance is being monitored are more accountable to voters, because of the effect it may have on their re-election possibilities.

A decrease in natural resources revenue opacity increases the accountability threshold in the citizen-government relationship since citizens would expect elected politicians to make full disclosures of how resources entrusted to them are generated and utilised (International Federation of Accountants, 2015; Robinson, Torvik, \& Verdier, 2006). The major option to accessing this level of information flow in natural resource governance is via a country's commitment to the implementation of the EITI Standards. Joining the EITI by governments of countries who hitherto had minimal or no accountability obligation to their citizens, or were prone to corrupt dealings, lessens the government's opportunity for pervasive corruption. While the EITI's mechanism of "shining the light" as described by Williams (2011), has its constrictions in defeating corruption and improving good governance in poor resource-rich countries, it certainly offers an enhanced alternative for citizens in these countries who previously had no opportunity to demand openness in the activities of their government.

Given that citizens can re-elect politicians (agents), lack of transparency increases citizens' risk of adverse selection, a situation where the principal is unable to discriminate between high and low-performing agents when electing 
leaders (Healy \& Palepu, 2001; Islam, 2006). This leads to lower quality (and in most cases, corrupt) agents (politicians) being elected to positions requiring high-quality performers. The non-disclosure of high-quality information by government creates the 'lemon' factor theorised by Akerlof (1970) and increases citizens' risk of electing the 'wrong' persons (Kolstad \& Wiig, 2009) and, by extension, increasing the opportunity for corruption. Furthermore, lack of control over the agent once elected gives rise to moral hazard.

\subsection{Chapter summary}

This chapter reviewed the literature on the EITI and extractive firms' disclosure practices and described agency theory as the theoretical underpinning employed in the study. It reviewed the literature pertinent to the research questions addressed in the study and thus set the basis for development of the hypotheses tested in the study. Appendix $\mathrm{N}$ contains the tabulated summary of the main empirical literature reviewed in this Chapter, as well as their key findings.

Taken together, the conclusions from this review reveal an absence of existing literature on the specifics of the questions addressed in the thesis. Indeed, when considered from a general view of EITI's impact on corruption, it is clear that the results of previous studies on the role of the EITI in reducing corrupt behaviours in natural resource-rich countries are inconclusive. Particularly, the results from prior studies cannot be affirmed complete in explaining the impact of EITI over 
the years. Further, these results are mixed, especially in recent times on how the EITI has been effective. Added to this, is the absence of data at the firm level, which has made it impracticable for significant work to be considered on the impact of EITI disclosures regime on the share prices of extractive companies operating in resource-rich countries. These gaps are addressed in this study. 


\section{CHAPTER THREE}

\section{EITI IMPLEMENTATION AND THE PERCEPTION OF CORRUPTION27}

\subsection{Synopsis}

Resource-rich countries combating the plague of corruption have adopted various Transparency and Accountability Initiatives. As noted earlier, the EITI is one such Transparency and Accountability Initiative that issues global Standards to guide disclosure of extractive activities to promote efficient management of extraction revenues in resource-rich countries. Using panel data comprising 648 country-year observations covering 51 implementing countries for the period 2003-2015, this chapter investigates for the first time (i) the effect of the length of EITI implementation experience on perceived control of corruption for all implementing countries taken together, and (ii) whether the effect of EITI implementation experience on perceived control of corruption vary across implementing countries. The results show that for the full set of sample countries EITI implementation experience is not associated with lower perceived level of corruption in implementing countries. However, the negative effect associated with implementation experience is less for Sub-Saharan African countries.

\footnotetext{
${ }^{27}$ A paper titled "EITI Implementation Experience and Perceived Control of Corruption" has been developed from this chapter. The paper was presented at the 2017 American Accounting Association annual conference and the 2018 Financial Markets and Corporate Governance Conference. At the later conference it was shortlisted for the best paper in Accounting Information/Disclosure Practices/Earnings Quality. The paper has been accepted for presentation at the 2018 Accounting and Finance Association of Australia and New Zealand Conference and has been submitted to the World Bank, 2018 Annual Bank Conference on Development Economics scheduled for June 2018.
} 


\subsection{Introduction}

Unquestionably, corruption hurts and hurts, even more, the poorest countries that are endowed with an abundance of natural resources but are short of good governance. Increasingly, studies show negative effects of corruption on several countrywide outlooks. The literature has many reports on the negative effects of weak control of corruption on the economic well-being of citizens (Cockx \& Francken, 2016; Kasekende et al., 2016; Venables, 2016). Similarly, many explanations have been offered as plausible reasons for countries' level of corruption. These studies suggest corruption is associated with natural resources abundance (Pitlik et al., 2010; Sachs \& Warner, 1997; Williams, 2011), weak institutional framework (Kolstad \& Wiig, 2009; Pitlik et al., 2010; Vadlamannati \& Cooray, 2017), lack of transparency (Avkiran, Kanol, \& Oliver, 2016), geographical location, and the legal and governance system (La Porta, Lopez-desilanes, Shleifer, \& Vishny, 2000; Svensson, 2005).

In response to these concerns arising from natural resources abundance, the EITI was conceived in 2002 as a mechanism to reduce information asymmetry and corrupt practices in the management of natural resources revenue, particularly in poor but resource-rich countries.

This chapter investigates the impact of the EITI in mitigating the level of perceived corruption in countries implementing its Standards. It examines for 
the first time (i) whether EITI implementation experience is associated with improved control of corruption for all implementing countries, and (ii) whether the effect of EITI implementation experience on perceived control of corruption varies across implementing countries.

The unequal distribution of natural resources across the countries of the world makes the resources hugely sought after and sometimes the cause of conflict and warfare. However, corruption in the management of extractive resources severely limits the benefits to people in countries endowed with these resources (Corrigan, 2014; Pitlik et al., 2010; Shwilima-Ibrahim, 2015). The consensus among international scholars and organisations is that increased transparency and accountability is critical to moving from low to high economic growth in poor resource-rich countries (Hilson, 2014). For example, the International Federation of Accountants, (2015) opines that;

...governments around the world are entrusted by citizens to manage public resources in an effective and efficient way. ...This social contract between governments and citizens requires both parties to be accountable and to hold each other accountable. Timely, high-quality, decision-useful, and publicly available financial information is critical to governments fulfilling this stewardship role, and to citizens holding governments accountable. 
The EITI's Principles ${ }^{28}$ are built upon this belief that increased transparency in extractive revenues facilitates public accountability and consequently reduces opportunities for corruption (EITI, 2015; Kasekende et al., 2016; Pitlik et al., 2010; Sovacool, Walter, Van de Graaf, \& Andrews, 2016). Studies document that many poor resource-rich countries' governments have failed to exploit their natural resources wealth for sustainable economic growth and development (Kolstad \& Søreide, 2009; Svensson, 2005; Venables, 2016). Natural resources revenue mismanagement by poor resource-rich countries has been identified as a major impediment to the advancement of developing resource-rich countries (Kolstad \& Wiig, 2009; Venables, 2016). Relative to other developing resourcerich countries, Sub-Saharan African countries have a deep struggle with widespread public-sector corruption, further compounding the lack of accountability facing this cluster of resource-rich countries.

The contribution of this chapter to the sparse literature on EITI effectiveness in corruption control is twofold. First, it documents the real effect of EITI in reducing the perceived level of corruption in EITI implementing countries in line with countries' disclosure practise. Linking EITI implementation experience with countries level of perceived corruption provides a reliable assessment of the impact EITI Standards can have on perceived corruption. The intuition here is that since the input of EITI adoption is measurable by each country's time of

${ }^{28}$ See Appendix E for full listing of the EITI 12 Principles. 
joining the Initiative, this is able to identify the real effect of EITI implementation process on countries national reform effort. This chapter makes a key contribution to the literature in this respect, as it examines the time, measured to the nearest month, for which a country has committed to the implementation of the EITI Standards. This measure enables the study to ascertain more effectively the influence of the EITI in reducing the perceived level corruption and distinguishes between countries that joined the EITI at different dates within a year.

Secondly, the chapter examines the variation in the benefits of implementing EITI Standards across implementing countries. Specifically, it shows that for SubSaharan African countries, joining the EITI appears to signal a commitment to reduce the perceived level of corruption. Considering implementing countries' unique clustering allows for different expectations of benefits accruing from the EITI implementation. For example, developing countries may join with expectations of drastically reducing corruption, strengthening their natural resources governance framework, and opening their extractive sector (economy) to more foreign investments; developed countries may join the Initiative to support and promote more open government partnership in natural resources revenue management. 
The chapter is structured as follows. The following section describes the hypotheses development based on the literature reviewed in Chapter Two. In Section 3.3 the research design, data and estimation models are explained. The main results, along with results tests of robustness, are presented in Section 3.4. Finally, Section 3.5 presents the concluding remark.

\subsection{Hypotheses development}

\subsubsection{Argument and hypotheses}

Following on from the review of the literature and theoretical underpinning of the study discussed in Chapter Two, this chapter argues that viewing the citizensgovernment relationship as an agent-principal relationship, the absence of accountability and effective monitoring based on transparent information disclosure will increase the level of perceived corruption in a country. Therefore, the degree to which politicians are publicly accountable to citizens, and information on government activities is publicly disclosed or freely accessed in a country, will determine a country's perceived ability to control corruption. In making this argument, it must also be recognised that politicians (government in power) have the ability to use rents from natural resources to coerce citizens or ultimately repress dissent and rig themselves to continue in power, a situation that is common in poor but resource-rich countries. 
Nevertheless, this chapter argues that a public commitment to the EITI exposes politicians (governments) to higher scrutiny and perhaps oversight of not just the EITI, but also other national and international organisations committed to good governance. While some countries may join the EITI to merely give an impression of commitment to national reform, the cost associated with such a strategy of deceit is likely to be counterproductive in the long-term (Dreher, Mikosch, \& Voigt, 2015; EITI, 2016; Pitlik et al., 2010). Pitlik et al., (2010) argue that countries cannot commit to the EITI without serious intention to fight corruption as surmised by Ölcer (2009) because the EITI would not tolerate being used as a window dressing mechanism. The prediction, therefore, is that the length of time that a country has been implementing the EITI Standards (i.e. EITI implementation experience) should be positively associated with improved control of corruption (all things equal) as measured by the perception of corruption. I therefore test the following hypothesis

$\mathrm{H}_{1}$ : Length of EITI implementation experience is associated with lower perceived level of corruption in EITI implementing countries.

Given that the primary objective of establishing the EITI was to help lessen the harmful effects of corruption on natural resources governance of poor but resource-rich countries it should be expected that the incremental benefit of implementing the EITI Standards should be greatest for countries with the most critical need for reform. Thus, the impact of implementation experience should 
be expected to vary across implementing countries with the greatest benefit accruing to the most extreme poor but resource-rich countries- most of whom are Sub-Saharan African countries. I therefore test the following hypothesis:

$\mathrm{H}_{2}$ : The length of EITI implementation experience has greater impact on reduction of the perceived level of corruption of Sub-Saharan African countries.

\subsection{Research design}

\subsubsection{Sample and data}

The study sample comprised of 648 country-year observations for all EITI implementing countries ${ }^{29}$ from 2003 to $2015 .{ }^{30}$ Although the EITI was established in 2002, nevertheless, following the Dyckman and Zeff (2014) recommendation to effectively specify the "[starting] and stopping rule" used for data collection, the sample period for the study is delimited to commence from 2003 (i.e. when the first set of countries officially committed to EITI) and end in 2015 (the year for which complete annual data for the sample countries was available from the different sources used in the analyses).

\footnotetext{
29 The study restricts the sample specifically to only EITI implementing countries because the phenomenon under observation (i.e. EITI implementation experience) is only observable among countries implementing the EITI Standards.

${ }^{30}$ Membership of the EITI as at June 2016 reached 51 implementing countries, of whom 31 are fully compliant (see Appendix F).
} 
The sample period covers more than a decade of EITI Standards implementation, and this period is longer than has been examined in prior studies assessing the effectiveness of EITI with respect to implementing countries. The sample is reduced [filtered] after the main analyses by excluding all developed countries in the sample to appropriately extrapolate the impact of the phenomenon under observation for only developing countries in the further analyses. ${ }^{31}$

\subsubsection{Test model}

The test model for the analyses is specified below:

$$
\begin{aligned}
C C I_{i}=\alpha_{0}+ & \alpha_{1} E X P_{i}+\alpha_{2} \text { FOI }_{i}+\alpha_{3} G D P_{i}+\alpha_{4} P_{\text {Pol_Inst }} \\
& +\alpha_{5} R R D_{i}+\alpha_{6} S S A_{i}+\alpha_{7} E X P * S S A_{i} \\
& +\varepsilon_{i}
\end{aligned}
$$

\begin{tabular}{|c|c|c|}
\hline$C C I_{i t}$ & $=$ & Control of Corruption Index \\
\hline$E X P_{i}$ & $=$ & Length of EITI implementation experience. \\
\hline \multirow[t]{2}{*}{$\mathrm{FOI}_{i}$} & $=$ & Duration for which a country has adopted Freedom of \\
\hline & & Information law. \\
\hline$G D P_{i}$ & $=$ & Gross Domestic Product per capita \\
\hline
\end{tabular}

where:

\footnotetext{
31 The four countries excluded are Germany, Norway, UK and US. These countries are dropped to allow for a tight examination of the effectiveness of EITI in controlling corruption in the countries considered as the primary target for establishing the EITI.
} 


$\begin{array}{ll}\text { Pol_Inst }_{i} & =\text { Political Institution and Stability } \\ R R D_{i} & =\text { The level of Resource Revenue Dependence } \\ S S A_{i} & =\text { Dummy variable equal to } 1 \text { for Sub-Saharan African } \\ & \quad \text { country, else } 0 . \\ E X P * S S A_{i} & =\quad \text { Interaction variable for EXP and SSA. } \\ \varepsilon_{t} & =\text { Error term }\end{array}$

\subsubsection{Dependent variable}

The dependent variable is measured by the Kaufmann Control of Corruption Index (CCI). The index captures perceptions of the extent to which public power is exercised for private gain, including petty and grand forms of corruption, as well as 'capture' of the state by elites and private interests (Kaufmann, Kraay, \& Mastruzzi, 2011). The estimate gives a country's score in units of a standard normal distribution ranging from approximately -2.5 to 2.5 with higher scores denoting better control of corruption (i.e. perceived as a less corrupt country). The choice of this measure of the perception of corruption rather than the Transparency International Corruption Perception Index (CPI) is, firstly, due to its completeness over the sample period ${ }^{32}$. Secondly, 31 unique data sources are used to construct the $C C I$ as against 12 used for the CPI (Heywood, 2015; Houqe \& Monem, 2016; Kaufmann et al., 2011; Shwilima-Ibrahim, 2015). Thirdly and

\footnotetext{
32 Kasekende et al., (2016) explain the limitation with using CPI from 2002 due to its limited data. Likewise, Ibrahim-Shwilima (2015) note similar concern with using the CPI.
} 
most importantly, the CPI for 2012 and earlier years are not comparable for time series estimation. ${ }^{33}$ In general, although all corruption indices come with their inherent limitation, some limitations are more severe than others. In particular, aside measurement challenge which is common to all corruption measures, the number of countries covered by a dataset (Heywood, 2015), and measurement methodology employed in constructing the dataset are the most worrying concerns that determine what dataset is to be utilized for a test model.

\subsubsection{Independent variable}

EITI Implementation Experience (EXP) is the main variable of interest and is the length of time since a country publicly committed to the $\operatorname{EITI}^{34}$ based on published official announcement date available on the EITI website or the implementing country extractive industries transparency initiative website. Where no specific date is available from the EITI and implementing country websites or conflicting dates are reported by the two sources, the date is clarified by an online search on Google for news relating to the announcement date.

\footnotetext{
33 Transparency International emphasise that given the changes to the methodology, country scores for 2012 CPI cannot be compared against those of 2011 or previous editions. However, year to year comparisons will be possible from 2012 onwards. The CPI Technical Methodology Note available here provides full details of this caveat.

${ }^{34}$ It is mandatory for countries wishing to implement the EITI Standards to make a public statement of commitment. Specifically, EITI Requirement 1.1(a), stipulates that "the government is required to issue an unequivocal public statement of its intention to implement the EITI. The statement must be made by the head of state or government, or an appropriately delegated government representative (EITI, 2016).
} 
The EXP variable measured in years, correct to the nearest month of the commitment date. Thus, as an example, a country with a score of 12.58 means that the country has been implementing the EITI Standards for 12 years 7 months while a score of zero means that the country was yet to commit to the EITI as at the time of the country-year observation.

The variable for Sub-Saharan African countries ${ }^{35}$ (SSA), a dummy variable equal to 1 if a country is a Sub-Saharan African country and else 0 .

\subsubsection{Control variables}

The control variables used in the analyses are those that have been found to correlate with the dependent variable in prior studies. Freedom of Information (FOI) measures duration for which a country has adopted FOI law. Such laws empower citizens to question the activities of their governments and can be a mechanism for unearthing corruption (Vadlamannati \& Cooray, 2017). In particular, the accountability process as prescribed by the EITI suggests that information on EITI activities and its published reports must be well disseminated by CSOs to relevant stakeholders if the EITI reports are to achieve the desired impact. Hence, public engagement supported by freedom of information laws is a critical factor that could influence the success of the EITI

\footnotetext{
${ }^{35}$ Appendix J contains details of EITI countries' geographical and economic categorization.
} 
process (Wilson \& Van Alstine, 2014). The FOI variable is measured as the number of years since a country enacted FOI laws.

Gross Domestic Product (GDP) is included following previous findings of its association with countries economic well-being, which impacts on the level of governance (Corrigan, 2014; Papyrakis et al., 2017; Pitlik et al., 2010).

Political Institution and Stability (Pol_Inst) measures the quality of political institutions and their stability in an EITI implementing country. The Pol_Inst variable is the aggregate score for Government Effectiveness and Political Stability and Absence of Violence in a year. It ranges from -4.80 to 3.42 with higher scores indicating a stronger Political Institution and Stability in the country. ${ }^{36}$

The main extractive resources explanatory variable is Resource Revenue Dependence $(R R D)$. It captures the degree to which a country relies on natural resources revenue, relative to its total export earnings and is equal to the country's total primary exports divided by total merchandise exports.

${ }^{36}$ Government Effectiveness captures the perceptions of the quality of public services, the quality of the civil service and the degree of its independence from political pressures, the quality of policy formulation and implementation, and the credibility of the government's commitment to such policies. While Political Stability and Absence of Violence captures perceptions of the likelihood that the government will be destabilised or overthrown by unconstitutional or violent means, including politically-motivated violence and terrorism (Kaufmann et al., 2011). 


\subsubsection{Robustness tests variables}

A number of robustness tests were conducted in part, using alternative measures for SSA and natural resources dependence variables. These were Heavily Indebted Poor Countries (HIPC) for SSA, and Mineral rents (MIN) and Oil rents (OIL) for RRD.

In the robustness tests, an alternative dummy variable Heavily Indebted Poor Countries (HIPC) is constructed and employed for a similar interaction effect. The HIPC explains whether countries with extreme indebtedness to international lending organisations (most of which are Sub-Saharan African countries) benefit from a reduced control of corruption sequel to joining the EITI. The Dummy variable for HIPC indicates a value of 1 if a country is classified as a Heavily Indebted Poor Country by the World Bank and International Monetary Fund and 0 if otherwise.

MIN is a country's mineral rents, measured as the difference between the value of production for a stock of minerals at world prices and their total costs of production expressed as a percentage of GDP. ${ }^{37}$ Similarly, OIL is a country's oil rents, which is the difference between the value of crude oil production at world prices and total costs of production also expressed as a percentage of GDP. These

\footnotetext{
${ }^{37}$ In calculating a country's Mineral rents, the following minerals are included: tin, gold, lead, zinc, iron, copper, nickel, silver, bauxite, and phosphate.
} 
variables have been used in literature to explain that given certain revenue threshold and extractive resources type, natural resources revenue dependence can have a positive (negative) effect on the governance and economic development of people living in resource-rich country akin to corruption and looting (Corrigan, 2014; Kasekende et al., 2016; Papyrakis et al., 2017).

Papyrakis et al., (2017) document that oil rent has received considerable attention in natural resource studies, with evidence in the literature linking oil rent with several extractive resource governance weaknesses including the high levels of perceived corruption. One explanation for this is perhaps the ease with which governments can expropriate oil rent especially in times of boom.

Appendix I provides details on definitions and sources for all the variables both employed in the main and the robustness tests.

\subsection{Empirical results}

\subsubsection{Descriptive statistics}

Table 3.1 reports the descriptive statistics for the variables employed in the tests. Focussing on Control of Corruption Index $C C I$, the mean (median) score of -0.56 $(-0.72)$ suggest on average [most] EITI implementing countries have a problem controlling their perceived level of corruption. The differential between the mean 
and median indicates skewness in the distribution of $C C I$ data and the presence of extremes in the data. For example, the score for Norway in the sample gives the maximum score of 2.30 and in contrast, the score of Myanmar gives the minimum score of -1.70 reported.

The mean (median) score for EXP in the sample is 2.71(1.25) which is approximately 2 years 8 months (1 year 3 months) implementation experience. The most experienced countries in the sample (i.e. 12.58) have been implementing the EITI standards for approximately 12 years 7 months. The mean (median) scores for SSA and HIPC are the same, at 0.49. The mean period for which countries in the sample have adopted FOI law is 3.78 (i.e. 3 years nine months). The maximum (minimum) of 49 (0) score for FOI means that certain countries had adopted freedom of information laws almost half a century, while others were yet to adopt such laws. The mean (median) score of GDP and Pol_Inst were $7.38(7.05)$, and $-1.19(-1.28)$ respectively.

The natural resource dependence level among EITI implementing countries as observed from the mean of $R R D$ suggests that on average $66 \%$ of exports in EITI countries emanate from primary resources which emphasises the importance of having a transparent extractive revenue management process for this cohort of countries. The extreme case of 0.99 is the score for the Republic of the Congo. 
Table 3.1

Descriptive statistics

\begin{tabular}{lcrrrrrrr}
\hline Variable & N & Mean & Median & Std. Dev. & Max & Min & p99 & p1 \\
\hline CCI & 663 & -0.56 & -0.72 & 0.79 & 2.30 & -1.70 & 2.10 & -1.64 \\
EXP & 663 & 2.71 & 1.25 & 3.27 & 12.58 & 0.00 & 11.58 & 0.00 \\
FOI & 663 & 3.78 & 0.00 & 8.99 & 49.00 & 0.00 & 45.00 & 0.00 \\
GDP & 648 & 7.38 & 7.05 & 1.45 & 11.54 & 4.78 & 11.35 & 5.14 \\
Pol_Inst & 663 & -1.19 & -1.28 & 1.54 & 3.28 & -4.80 & 3.14 & -4.20 \\
RRD & 663 & 0.66 & 0.70 & 0.25 & 0.99 & 0.09 & 0.99 & 0.11 \\
MIN & 663 & 3.56 & 0.40 & 7.07 & 44.64 & 0.00 & 33.31 & 0.00 \\
OIL & 663 & 4.91 & 0.18 & 11.00 & 64.31 & 0.00 & 52.58 & 0.00 \\
SSA & 663 & 0.49 & 0.00 & 0.50 & 1.00 & 0.00 & 1.00 & 0.00 \\
HIPC & 663 & 0.49 & 0.00 & 0.50 & 1.00 & 0.00 & 1.00 & 0.00 \\
EXP*SSA & 663 & 1.63 & 0.00 & 2.92 & 12.58 & 0.00 & 10.83 & 0.00 \\
EXP*HIPC & 663 & 1.54 & 0.00 & 2.81 & 12.58 & 0.00 & 10.75 & 0.00 \\
\hline Vaa
\end{tabular}

Variable definition: The $C C I$ is the Control of Corruption Index which measures the perception to which public power is exercised for private gain, including both petty and grand forms of corruption, as well as the capture of the state by elites and private interest. Higher values indicate better control of corruption. EXP is the number of years since a country publicly committed to implementing the EITI Standards, based on the official announcement date provided by each country's national EITI and/or EITI International Secretariat. EXP measures are taken on 31st December each year from 2003 to 2015. FOI is the duration for which a country has adopted FOI laws, measured as the cumulative number of years since the enactment of the law. GDP is the natural logarithm of gross domestic product per capita. GDP per capita (current US\$) is the gross domestic product divided by midyear population. Pol_Inst a country's political institution and stability score. Pol_Inst is the aggregate score of Government Effectiveness and Political Stability and Absence of Violence in a country. $R R D$ is the natural resource revenue dependence level of a country and is measured as total primary export scaled by total merchandise export. MIN is mineral rent which is the difference between the value of production for a stock of minerals at world prices and their total costs of production expressed as a percentage of GDP. OIL rent is the difference between the value of crude oil production at world prices and total costs of production. SSA is a dummy variable that takes the value of 1 if a country is classified as a SubSaharan African country and 0 otherwise. HIPC is a dummy variable that scores a country 1 if categorised as a Heavily Indebted Poor Country and 0 otherwise. EXP*SSA is the interaction term for EITI implementation experience of a country and Sub-Saharan African Countries. EXP*HIPC is the interaction term for EITI implementation experience and Heavily Indebted Poor Countries.

The alternative resource revenue dependence variables employed for the robustness tests, MIN and OIL have a mean (median) of $3.56(0.40)$ and 4.91 (0.18) respectively. 
Table 3.2 presents the Pearson pairwise correlation matrix for variables employed in the analyses. There is a negative linear relationship between $\mathrm{CCI}$ and EXP $(\mathrm{r}=-0.17)$ and also between CCI and SSA. This is contrary to $\mathrm{H}_{1}$ and $\mathrm{H}_{2}$ but the conclusion on association should be based on the regression analysis which tests for the impact of EXP and SSA in a multivariate context. $C C I$ has a negative correlation with the control variables $R R D, M I N$, and $O I L$, a positive correlation with FOI, GDP and Pol_Inst, all significant at 5\%. The correlation coefficient of 0.84 between SSA and HIPC shows that the variables are highly correlated and thus HIPC is only marginally different from SSA as an indicator of poor but resourcerich countries.

Variance inflation factors for the variables in the test model (not tabulated) are all less than 10 and have a mean value of 3 . Consistent with the correlation results, this indicates that multicollinearity is not an issue for the test model. 
Table 3.2

\section{Pairwise correlation matrix}

\begin{tabular}{|c|c|c|c|c|c|c|c|c|c|c|c|c|}
\hline & $C C I$ & $E X P$ & FOI & $G D P$ & Pol_Inst & $R R D$ & $M I N$ & OIL & $S S A$ & HIPC & $E X P^{*} S S A$ & $E X P^{*} H I P C$ \\
\hline$C C I$ & 1.00 & & & & & & & & & & & \\
\hline$E X P$ & $-0.17^{* *}$ & 1.00 & & & & & & & & & & \\
\hline FOI & $0.65^{* *}$ & -0.02 & 1.00 & & & & & & & & & \\
\hline$G D P$ & $0.70^{* *}$ & -0.01 & $0.65^{* *}$ & 1.00 & & & & & & & & \\
\hline Pol_Inst & $0.86^{* *}$ & $-0.18^{* *}$ & $0.51^{* *}$ & $0.69 * *$ & 1.00 & & & & & & & \\
\hline$R R D$ & $-0.37^{* *}$ & $0.24^{* *}$ & $-0.22^{* *}$ & $-0.24^{* *}$ & $-0.31^{* *}$ & 1.00 & & & & & & \\
\hline$M I N$ & $-0.13^{* *}$ & $0.22^{* *}$ & $-0.14^{* *}$ & $-0.14^{* *}$ & -0.06 & $0.11^{* *}$ & 1.00 & & & & & \\
\hline$O I L$ & $-0.23^{* *}$ & $0.11^{* *}$ & -0.06 & $0.14^{* *}$ & $-0.26^{* *}$ & $0.43 * *$ & $-0.11^{* *}$ & 1.00 & & & & \\
\hline$S S A$ & $-0.17^{* *}$ & $0.18^{* *}$ & $-0.37^{* *}$ & $-0.56^{* *}$ & $-0.21^{* *}$ & $0.28^{* *}$ & $0.11^{* *}$ & -0.07 & 1.00 & & & \\
\hline HIPC & $-0.24^{* *}$ & $0.13^{* *}$ & $-0.36^{* *}$ & $-0.65^{* *}$ & $-0.28^{* *}$ & $0.15^{* *}$ & $0.12^{* *}$ & $-0.14^{* *}$ & $0.84^{* *}$ & 1.00 & & \\
\hline$E X P^{*} S S A$ & $-0.16^{* *}$ & $0.71^{* *}$ & $-0.18^{* *}$ & $-0.25^{* *}$ & $-0.23^{* *}$ & $0.20^{* *}$ & $0.26^{* *}$ & 0.02 & $0.57^{* *}$ & $0.48^{* *}$ & 1.00 & \\
\hline$E X P^{*} H I P C$ & $-0.15^{* *}$ & $0.66^{* *}$ & $-0.18^{* *}$ & $-0.28^{* *}$ & $-0.21^{* *}$ & $0.14^{* *}$ & $0.28^{* *}$ & -0.03 & $0.52^{* *}$ & $0.56^{* *}$ & $0.92^{* *}$ & 1.00 \\
\hline
\end{tabular}

Notes: ** denotes statistical significance at $5 \%$ level

Variable definition: The $C C I$ is the Control of Corruption Index which measures the perception to which public power is exercised for private gain, including both petty and grand forms of corruption, as well as the capture of the state by elites and private interest. Higher values indicate better control of corruption. EXP is the number of years since a country publicly committed to implementing the EITI Standards, based on the official announcement date provided by each country's national EITI and/or EITI International Secretariat. EXP measures are taken on 31st December each year from 2003 to 2015. FOI is the duration for which a country has adopted FOI laws, measured as the cumulative number of years since the enactment of the law. GDP is the natural logarithm of gross domestic product per capita. GDP per capita (current US\$) is the gross domestic product divided by midyear population. Pol_Inst a country's political institution and stability score. Pol_Inst is the aggregate score of Government Effectiveness and Political Stability and Absence of Violence in a country. RRD is the natural resource revenue dependence level of a country and is measured as total primary export scaled by total merchandise export. MIN is mineral rent which is the difference between the value of production for a stock of minerals at world prices and their total costs of production expressed as a percentage of GDP. OIL rent is the difference between the value of crude oil production at world prices and total costs of production. SSA is a dummy variable that takes the value of 1 if a country is classified as a Sub-Saharan African country and 0 otherwise. $H I P C$ is a dummy variable that scores a country 1 if categorised as a Heavily Indebted Poor Country and 0 otherwise. EXP*SSA is the interaction term for EITI implementation experience of a country and Sub-Saharan African Countries. EXP*HIPC is the interaction term for EITI implementation experience and Heavily Indebted Poor Countries. 


\subsubsection{Main results}

The main regression results are presented in Tables 3.3 and 3.4. Model [1] of Table 3.3 sets out with the parsimonious estimation and builds to the full test model specification in Model [5] of Table 3.4. Beginning with model [1] the analysis revalidates the explanatory powers of GDP and Pol_Inst of EITI implementing countries in explaining these countries' perceived level of corruption. In line with the literature (e.g. Houqe \& Monem, 2016; Kasekende et al., 2016) the parsimonious test shows better control of corruption is associated with an increase in GDP and strong political institution and stability. As can be observed from the R-squares in Tables 3.3 and 3.4, variables in all the models jointly explain between 76 to 84 percent of the variation in the perceived level of corruption. The average Variance Inflation Factor (VIF) for all the estimated models in the study is below 3, signifying the absence of multicollinearity concerns. ${ }^{38}$

In model [2] the main variable of interest is introduced, viz EITI implementation experience (EXP). The coefficient (p-value) on EXP of -0.013 (0.007) suggests that as a whole, EITI experience is not associated with improved control of corruption for EITI implementing countries and is thus contrary to the first hypothesis $\left(H_{1}\right)$. The results show that a one-year increase in EITI implementation experience is

38 As a general rule of thumb a VIF indicator in excess suggests the presence of serious multicollinearity (O’Brien, 2007). 
associated with -0.013 unit drop in perceived control of corruption. Although contrary to $H_{1}$, this finding is not uncommon in the EITI literature (e.g. Corrigan, 2014; Kasekende et al., 2016; Öge, 2016; Ölcer, 2009). These studies report similar results indicating that EITI may not be as effective as expected in reducing the level of corruption in implementing countries. One plausible explanation for this finding could be linked to the signaling value of joining the EITI (Spence, 1973). As Pitlik et al. (2010) suggest the most corrupt countries that are rich in natural resources, would likely be the first to join the Initiative. This is to signal intent to reduce corruption and thus encourage direct investment and facilitate borrowing from international agencies such as the World Bank. The signal may of course could be false, but this will become evident fairly quickly.

Model [3] incorporates an explanatory variable for the existence of FOI law in EITI implementing countries. As in Model [2], the coefficient (p-value) on EXP $0.013(0.002)$ remain negative and significant at $1 \%$ level. The FOI coefficient (pvalue) of $0.023(0.000)$ indicates that more years of FOI law adoption in EITI implementing countries is associated with better control of corruption. One explanation for this finding in line with prior literature is that countries with more years of freedom of information law tend to have more openness in their economic systems which reduces the effect of corruption (Vadlamannati \& Cooray, 2017). In particular, studies (e.g. Pillay \& Kluvers, 2014; Shleifer \& Vishny, 1993; Svensson, 2005) provide empirical evidence that corruption 
thrives the most in environments that are marred by high levels of secrecy and closed economic systems. Thus, the duration of FOI laws enforcement in a country can have positive impact on the country's efforts to fight corruption. In the case of the result reported in Model (3), the impact of FOI alone did not seem to have changed the effect of corruption for all EITI implementing countries taken together (as the coefficient ( $\mathrm{p}$-value) on EITI is still negative (significant at 1\% level)). A plausible reason for this, as affirmed by Williams (2011), is that openness (i.e. transparency) alone is not sufficient to mitigate the impact of corruption in the presence of the EITI implementation, especially if joining the Initiative could be used as façade rather than genuine intention to mitigate corruption.

Moving to Model [4] in Table 3.4, with the introduction of the RRD variable, the coefficient and p-value of -0.009 and 0.032 respectively on $E X P$, remains negative and statistically significant at the 5\% level. Consistent with the literature and the expected sign, the association between $C C I$ and $R R D$ is negative and significant at $1 \%$ level as observed from the coefficient $(-0.269)$ and p-value $(0.000)$ on $R R D$. 
Table 3.3

Control of corruption and EITI implementation experience

\begin{tabular}{|c|c|c|c|c|c|c|c|c|c|c|}
\hline \multirow{2}{*}{$\begin{array}{l}\text { Dep. Variable: CCI } \\
\text { Variable }\end{array}$} & \multirow[b]{2}{*}{ Sign } & \multicolumn{3}{|c|}{ Model 1} & \multicolumn{3}{|c|}{ Model 2} & \multicolumn{3}{|c|}{ Model 3} \\
\hline & & Coef. & RSE & $\mathrm{P}>/ \mathrm{t} /$ & Coef. & RSE & $\mathrm{P}>/ \mathrm{t} /$ & Coef. & RSE & $\mathrm{P}>/ \mathrm{t} /$ \\
\hline Constant/intercept & $?$ & -0.956 & 0.105 & $0.000^{* * *}$ & -0.980 & 0.103 & $0.000^{* * *}$ & -0.495 & 0.114 & $0.000^{* * *}$ \\
\hline$E X P$ & + & & & & -0.013 & 0.005 & $0.007^{* * *}$ & -0.013 & 0.004 & $0.002^{* * *}$ \\
\hline FOI & + & & & & & & & 0.023 & 0.003 & $0.000^{* * *}$ \\
\hline$G D P$ & + & 0.113 & 0.014 & $0.000^{* * *}$ & 0.119 & 0.014 & $0.000 * * *$ & 0.040 & 0.017 & $0.022 * *$ \\
\hline Pol_Inst & + & 0.366 & 0.012 & $0.000^{* * *}$ & 0.357 & 0.012 & $0.000 * * *$ & 0.341 & 0.011 & $0.000^{* * *}$ \\
\hline R-squared & & 0.76 & & & 0.76 & & & 0.80 & & \\
\hline Mean VIF & & 1.91 & & & 1.69 & & & 1.85 & & \\
\hline Observations & & 648 & & & 648 & & & 648 & & \\
\hline Number of countries & & 51 & & & 51 & & & 51 & & \\
\hline
\end{tabular}

Notes: All models are estimated with robust standard error of coefficients. Superscripts *, **, and ${ }^{* * *}$ represents 10,5 and 1

percent level of significance respectively. The estimated regressions are based on the below specific models:

$C C I_{i}=\alpha_{0}+\alpha_{1} G D P_{i}+\alpha_{2}$ Pol_Inst $_{i} \quad \ldots \ldots \ldots$ (3.1)

$C C I_{i}=\alpha_{0}+\alpha_{1} E X P_{i}+\alpha_{2} G D P_{i}+\alpha_{3}$ Pol_Inst $_{i} \quad \ldots \ldots \ldots(3.2)$

$C C I_{i}=\alpha_{0}+\alpha_{1} E X P_{i}+\alpha_{2} F_{i}+\alpha_{3} G D P_{i}+\alpha_{4} P_{\text {Pol_Inst }} \quad \ldots \ldots \ldots$ (3.3)

Variable definition: The $C C I$ is the Control of Corruption Index which measures the perception to which public power is exercised for private gain, including both petty and grand forms of corruption, as well as the capture of the state by elites and private interest. Higher values indicate better control of corruption. EXP is the number of years since a country publicly committed to implementing the EITI Standards, based on the official announcement date provided by each country's national EITI and/or EITI International Secretariat. EXP measures are taken on 31st December each year from 2003 to 2015. FOI is the duration for which a country has adopted FOI law, measured as the cumulative number of years since the enactment of the law. GDP is the natural logarithm of gross domestic product per capita. GDP per capita (current US\$) is the gross domestic product divided by midyear population. Pol_Inst a country's political institution and stability score. Pol_Inst is the aggregate score of Government Effectiveness and Political Stability and Absence of Violence in a country. 
Table 3.4

Control of corruption, EITI implementation experience and Sub-Saharan African countries

\begin{tabular}{|c|c|c|c|c|c|c|c|}
\hline \multirow{2}{*}{$\begin{array}{l}\text { Dep. Variable: CCI } \\
\text { Variable }\end{array}$} & \multirow[b]{2}{*}{ Sign } & \multicolumn{3}{|c|}{ Model 4} & \multicolumn{3}{|c|}{ Model 5} \\
\hline & & Coef. & RSE & $\mathrm{P}>/ \mathrm{t} /$ & Coef. & RSE & $P>/ t /$ \\
\hline Constant/intercept & $?$ & -0.320 & 0.108 & $0.003^{* * *}$ & -1.027 & 0.115 & $0.000^{* * *}$ \\
\hline EXP & + & -0.009 & 0.004 & $0.032^{* *}$ & -0.038 & 0.006 & $0.000^{* * *}$ \\
\hline FOI & + & 0.022 & 0.002 & $0.000 * * *$ & 0.023 & 0.002 & $0.000 * * *$ \\
\hline GDP & + & 0.037 & 0.016 & $0.022^{* *}$ & 0.120 & 0.017 & $0.000 * * *$ \\
\hline Pol_Inst & + & 0.332 & 0.011 & $0.000^{* * *}$ & 0.294 & 0.011 & $0.000^{* * *}$ \\
\hline$R R D$ & - & -0.269 & 0.066 & $0.000^{* * *}$ & -0.335 & 0.062 & $0.000^{* * *}$ \\
\hline$S S A$ & + & & & & 0.237 & 0.035 & $0.000^{* * *}$ \\
\hline$E X P * S S A$ & + & & & & 0.032 & 0.007 & $0.000^{* * *}$ \\
\hline R-squared & & 0.81 & & & 0.84 & & \\
\hline Mean VIF & & 1.74 & & & 2.59 & & \\
\hline Observations & & 648 & & & 648 & & \\
\hline Number of countries & & 51 & & & 51 & & \\
\hline
\end{tabular}

Notes: All models are estimated on the robust standard error of coefficients. Superscripts ${ }^{*}{ }^{* *}$, and *** represents 10, 5 and 1 percent level of significance respectively. The estimated regressions are based on the below specific models:

$$
\begin{gathered}
C C I_{i}=\alpha_{0}+\alpha_{1} \text { EXP }_{i}+\alpha_{2} \text { FOI }_{i}+\alpha_{3} G D P_{i}+\alpha_{4} \text { Pol_Inst }_{i}+\alpha_{5} R R D_{i} \\
C C I_{i}=\alpha_{0}+\alpha_{1} \text { EXP }_{i}+\alpha_{2} \text { FOI }_{i}+\alpha_{3} G D P_{i}+\alpha_{4} \text { Pol_Inst }_{i}+\alpha_{5} R R D_{i}+\alpha_{6} \text { SSA }_{i} \\
+\alpha_{7} \text { EXPSSA }_{i}
\end{gathered}
$$

Variable definition: The $C C I$ is the Control of Corruption Index which measures the perception to which public power is exercised for private gain, including both petty and grand forms of corruption, as well as the capture of the state by elites and private interest. Higher values indicate better control of corruption. EXP is the number of years since a country publicly committed to implementing the EITI Standards, based on the official announcement date provided by each country's national EITI and/or EITI International Secretariat. EXP measures are taken on 31st December each year from 2003 to 2015. FOI is the duration for which a country has adopted FOI laws, measured as the cumulative number of years since the enactment of the law. GDP is the natural logarithm of gross domestic product per capita. GDP per capita (current US\$) is the gross domestic product divided by midyear population. Pol_Inst a country's political institution and stability score. Pol_Inst is the aggregate score of Government Effectiveness and Political Stability and Absence of Violence in a country. $R R D$ is the natural resource revenue dependence level of a country and is measured as total primary export scaled by total merchandise export. SSA is a dummy variable that takes the value of 1 if a country is classified as a Sub-Saharan African country and 0 otherwise. EXP*SSA is the interaction term for EITI implementation experience of a country and Sub-Saharan African Countries. 
Model [5] in Table 3.5 is the test model. The model is estimated with the interaction term of EITI experience and the SSA countries indicator variable (EXP*SSA). The results show that although the coefficient (p-value) on EXP remained negative and significant at $1 \%$ level, the coefficient on both the SSA and EXP*SSA variables are positive and significant at $1 \%$ level. Thus, SSA countries have a better control of corruption and the negative impact of implementation experience is lower than for other countries. This result supports the second hypothesis $\left(H_{2}\right)$.

\subsubsection{Robustness tests}

This section presents the results of further empirical tests conducted to ascertain whether the main results are robust to different measures of the control variables and to variation in the sample of countries.

\subsubsection{Control of corruption, EITI experience and MIN and OIL}

Tables 3.5 and 3.6 present results of analyses conducted using respectively MIN and $O I L$ as alternative measures of natural resources dependence. The results are in both cases qualitatively similar to the main results. 


\section{Table 3.5}

\section{Control of corruption, EITI implementation experience and Sub-Saharan African (Alternate resource predictor- Mineral Rent)}

\begin{tabular}{|c|c|c|c|c|c|c|c|}
\hline \multirow{2}{*}{$\begin{array}{l}\text { Dep. Variable: CCI } \\
\text { Variable }\end{array}$} & \multirow[b]{2}{*}{ Sign } & \multicolumn{3}{|c|}{ Model 6} & \multicolumn{3}{|c|}{ Model 7} \\
\hline & & Coef. & RSE & $\mathrm{P}>/ \mathrm{t} /$ & Coef. & RSE & $\mathrm{P}>/ \mathrm{t} /$ \\
\hline Constant/intercept & $?$ & -0.449 & 0.114 & $0.000^{* * *}$ & -1.039 & 0.120 & $0.000^{* * *}$ \\
\hline$E X P$ & + & -0.010 & 0.004 & $0.016^{* *}$ & -0.046 & 0.006 & $0.000 * * *$ \\
\hline FOI & + & 0.022 & 0.003 & $0.000^{* * *}$ & 0.023 & 0.002 & $0.000^{* * *}$ \\
\hline GDP & + & 0.035 & 0.017 & $0.039 * *$ & 0.103 & 0.017 & $0.000^{* * *}$ \\
\hline Pol_Inst & + & 0.344 & 0.012 & $0.000^{* * *}$ & 0.316 & 0.012 & $0.000^{* * *}$ \\
\hline$M I N$ & - & -0.005 & 0.002 & $0.015^{* *}$ & -0.006 & 0.002 & $0.001^{* * *}$ \\
\hline$S S A$ & + & & & & 0.154 & 0.032 & $0.000^{* * *}$ \\
\hline$E X P^{*} S S A$ & + & & & & 0.045 & 0.008 & $0.000^{* * *}$ \\
\hline R-squared & & 0.80 & & & 0.83 & & \\
\hline Mean VIF & & 1.73 & & & 2.51 & & \\
\hline Observations & & 648 & & & 648 & & \\
\hline Number of countries & & 51 & & & 51 & & \\
\hline
\end{tabular}

Notes: All models are estimated on the robust standard error of coefficients. Superscripts *, ${ }^{* *}$, and *** represents 10, 5 and 1 percent level of significance respectively. The estimated regressions are based on the below specific models:

$$
\begin{aligned}
& C C I_{i}=\alpha_{0}+\alpha_{1} E X P_{i}+\alpha_{2} \text { FOI }_{i}+\alpha_{3} G D P_{i}+\alpha_{4} \text { Pol_Inst }_{i}+\alpha_{5} M I N_{i} \\
& C C I_{i}=\alpha_{0}+\alpha_{1} E_{X X}+\alpha_{2} F_{i} I_{i}+\alpha_{3} G D P_{i}+\alpha_{4} P_{0} I_{-} I n s t_{i}+\alpha_{5} M I N_{i}+\alpha_{6} S S A_{i} \\
& +\alpha_{7} \operatorname{EXPSSA}_{i}
\end{aligned}
$$

Variable definition: The $C C I$ is the Control of Corruption Index which measures the perception to which public power is exercised for private gain, including both petty and grand forms of corruption, as well as the capture of the state by elites and private interest. Higher values indicate better control of corruption. EXP is the number of years since a country publicly committed to implementing the EITI Standards, based on the official announcement date provided by each country's national EITI and/or EITI International Secretariat. EXP measures are taken on 31st December each year from 2003 to 2015. FOI is the duration for which a country has adopted FOI laws, measured as the cumulative number of years since the enactment of the law. GDP is the natural logarithm of gross domestic product per capita. GDP per capita (current US\$) is the gross domestic product divided by midyear population. Pol_Inst a country's political institution and stability score. Pol_Inst is the aggregate score of Government Effectiveness and Political Stability and Absence of Violence in a country. MIN is mineral rent which is the difference between the value of production for a stock of minerals at world prices and their total costs of production expressed as a percentage of GDP. SSA is a dummy variable that takes the value of 1 if a country is classified as a Sub-Saharan African country and 0 otherwise. EXP*SSA is the interaction term for EITI implementation experience of a country and Sub-Saharan African Countries 
Table 3.6

Control of corruption, EITI implementation experience and Sub-Saharan African (Alternate resource predictor- Oil Rent)

\begin{tabular}{l|c|cccccc}
\hline Dep. Variable: CCI & & \multicolumn{3}{|c}{ Model 8} & \multicolumn{3}{c}{ Model 9 } \\
Variable & Sign & Coef. & RSE & P>/t/ & Coef. & RSE & P $>/ \mathbf{t} /$ \\
\hline Constant/intercept & $?$ & -0.708 & 0.131 & $0.000^{* * *}$ & -1.457 & 0.148 & $0.000^{* * *}$ \\
EXP & + & -0.013 & 0.004 & $0.001^{* * *}$ & -0.046 & 0.006 & $0.000^{* * *}$ \\
FOI & + & 0.021 & 0.003 & $0.000^{* * *}$ & 0.022 & 0.002 & $0.000^{* * *}$ \\
GDP & + & 0.069 & 0.020 & $0.000^{* * *}$ & 0.154 & 0.020 & $0.000^{* * *}$ \\
PoI_Inst & + & 0.315 & 0.013 & $0.000^{* * *}$ & 0.275 & 0.013 & $0.000^{* * *}$ \\
OIL & - & -0.005 & 0.001 & $0.000^{* * *}$ & -0.007 & 0.001 & $0.000^{* * *}$ \\
SSA & + & & & & 0.206 & 0.034 & $0.000^{* * *}$ \\
EXP*SSA & + & & & & 0.038 & 0.007 & $0.000^{* * *}$ \\
R-squared & & 0.80 & & & 0.83 & & \\
Mean VIF & & 2.04 & & & 2.82 & & \\
Observations & & 648 & & & 648 & & \\
Number of countries & & 51 & & & 51 & & \\
\hline
\end{tabular}

Notes: All models are estimated on the robust standard error of coefficients. Superscripts *, ${ }^{* *}$, and $^{* * *}$ represents 10,5 and 1 percent level of significance respectively. The estimated regressions are based on the below specific models:

$$
\begin{aligned}
& C C I_{i}=\alpha_{0}+\alpha_{1} E X P_{i}+\alpha_{2} F O I_{i}+\alpha_{3} G D P_{i}+\alpha_{4} \text { Pol_Inst }_{i}+\alpha_{5} O I L_{i} \\
& C C I_{i}=\alpha_{0}+\alpha_{1} E_{X P P_{i}}+\alpha_{2} \text { FOI }_{i}+\alpha_{3} G D P_{i}+\alpha_{4} \text { Pol_Inst }_{i}+\alpha_{5} \text { OIL }_{i}+\alpha_{6} S S A_{i} \\
& +\alpha_{7} \operatorname{EXPSSA}_{i}
\end{aligned}
$$

Variable definition: The $C C I$ is the Control of Corruption Index which measures the perception to which public power is exercised for private gain, including both petty and grand forms of corruption, as well as the capture of the state by elites and private interest. Higher values indicate better control of corruption. EXP is the number of years since a country publicly committed to implementing the EITI Standards, based on the official announcement date provided by each country's national EITI and/or EITI International Secretariat. EXP measures are taken on 31st December each year from 2003 to 2015. FOI is the duration for which a country has adopted FOI laws, measured as the cumulative number of years since the enactment of the law. GDP is the natural logarithm of gross domestic product per capita. GDP per capita (current US\$) is the gross domestic product divided by midyear population. Pol_Inst a country's political institution and stability score. Pol_Inst is the aggregate score of Government Effectiveness and Political Stability and Absence of Violence in a country. OIL rent is the difference between the value of crude oil production at world prices and total costs of production. SSA is a dummy variable that takes the value of 1 if a country is classified as a Sub-Saharan African country and 0 otherwise. EXP*SSA is the interaction term for EITI implementation experience of a country and Sub-Saharan African Countries. 


\subsubsection{Control of corruption and EITI experience: Alternative proxy for location}

Table 3.7 presents the results of robustness tests using Heavily Indebted Poor Countries (HIPC) ${ }^{39}$ as an alternative to Sub-Saharan African countries. The models include variation in the measure of natural resource dependence. In all cases, the results are qualitatively similar to those obtained in the main tests.

${ }^{39}$ Heavily Indebted Poor Countries are all developing countries with extreme debt burden and poverty, and most of which are Sub-Saharan Africa countries whose perceived level of corruption is high. 
Table 3.7

Control of corruption and EITI implementation experience (alternate SSA measure [HIPC])

\begin{tabular}{|c|c|c|c|c|c|c|c|c|c|c|}
\hline \multirow{2}{*}{$\begin{array}{l}\text { Dep. Variable: CCI } \\
\text { Variable }\end{array}$} & \multirow[b]{2}{*}{ Sign } & \multicolumn{3}{|c|}{ Model 10} & \multicolumn{3}{|c|}{ Model 11} & \multicolumn{3}{|c|}{ Model 12} \\
\hline & & Coef. & RSE & $P>/ t /$ & Coef. & RSE & $\mathrm{P}>/ \mathrm{t} /$ & Coef. & RSE & $P>/ t /$ \\
\hline Constant/intercept & $?$ & -0.963 & 0.142 & $0.000 * * *$ & -1.013 & 0.148 & $0.000 * * *$ & -1.364 & 0.171 & $0.000^{* * *}$ \\
\hline$E X P$ & + & -0.034 & 0.006 & $0.000^{* * *}$ & -0.040 & 0.006 & $0.000^{* * *}$ & -0.040 & 0.006 & $0.000^{* * *}$ \\
\hline FOI & + & 0.022 & 0.002 & $0.000^{* * *}$ & 0.022 & 0.002 & $0.000^{* * *}$ & 0.021 & 0.002 & $0.000^{* * *}$ \\
\hline$G D P$ & + & 0.110 & 0.019 & $0.000^{* * *}$ & 0.103 & 0.020 & $0.000^{* * *}$ & 0.145 & 0.023 & $0.000^{* * *}$ \\
\hline Pol_Inst & + & 0.307 & 0.011 & $0.000^{* * *}$ & 0.320 & 0.011 & $0.000^{* * *}$ & 0.287 & 0.012 & $0.000^{* * *}$ \\
\hline$R R D$ & - & -0.238 & 0.061 & $0.000^{* * *}$ & & & & & & \\
\hline$M I N$ & - & & & & -0.006 & 0.002 & $0.000^{* * *}$ & & & \\
\hline OIL & - & & & & & & & -0.006 & 0.001 & $0.000^{* * *}$ \\
\hline HIPC & + & 0.149 & 0.039 & $0.000^{* * *}$ & 0.112 & 0.036 & $0.002^{* * *}$ & 0.150 & 0.039 & $0.000^{* * *}$ \\
\hline$E X P^{*} H I P C$ & + & 0.035 & 0.007 & $0.000^{* * *}$ & 0.045 & 0.008 & $0.000^{* * *}$ & 0.038 & 0.007 & $0.000 * * *$ \\
\hline R-squared & & 0.82 & & & 0.82 & & & 0.82 & & \\
\hline Mean VIF & & 2.55 & & & 2.53 & & & 2.79 & & \\
\hline Observations & & 648 & & & 648 & & & 648 & & \\
\hline Number of countries & & 51 & & & 51 & & & 51 & & \\
\hline
\end{tabular}

Notes: All models are estimated on the robust standard error of coefficients. Superscripts $*$, **, and ${ }^{* * *}$ represents 10,5 and 1 percent level of significance respectively. The estimated regressions are based on the below specific models:

$$
\begin{aligned}
& C C I_{i}=\alpha_{0}+\alpha_{1} E X P_{i}+\alpha_{2} F_{i}+\alpha_{3} G D P_{i}+\alpha_{4} P_{\text {olnst }}+\alpha_{5} R R D_{i}+\alpha_{6} H I P C_{i}+\alpha_{7} E X P H I P C_{i} \\
& C C I_{i}=\alpha_{0}+\alpha_{1} E_{X P}+\alpha_{2} \text { OOI }_{i}+\alpha_{3} G D P_{i}+\alpha_{4} \text { Pol }_{\text {Inst }_{i}}+\alpha_{5} \text { MIN }_{i}+\alpha_{6} H I P C_{i}+\alpha_{7} \text { EXPHIPC }_{i} \\
& C C I_{i}=\alpha_{0}+\alpha_{1} E X P_{i}+\alpha_{2} \text { OOI }_{i}+\alpha_{3} G D P_{i}+\alpha_{4} \text { Pol }_{\text {Inst }_{i}}+\alpha_{5} \text { OIL }_{i}+\alpha_{6} \text { HIPC }_{i}+\alpha_{7} \text { EXPHIPC }_{i}
\end{aligned}
$$




\section{Table 3.7 continued}

Variable definition: The $C C I$ is the Control of Corruption Index which measures the perception to which public power is exercised for private gain, including both petty and grand forms of corruption, as well as the capture of the state by elites and private interest. Higher values indicate better control of corruption. EXP is the number of years since a country publicly committed to implementing the EITI Standards, based on the official announcement date provided by each country's national EITI and/or EITI International Secretariat. EXP measures are taken on 31st December each year from 2003 to 2015. FOI is the duration for which a country has adopted FOI laws, measured as the cumulative number of years since the enactment of the law. GDP is the natural logarithm of gross domestic product per capita. GDP per capita (current US\$) is the gross domestic product divided by midyear population. Pol_Inst a country's political institution and stability score. Pol_Inst is the aggregate score of Government Effectiveness and Political Stability and Absence of Violence in a country. $R R D$ is the natural resource revenue dependence level of a country and is measured as total primary export scaled by total merchandise export. MIN is mineral rent which is the difference between the value of production for a stock of minerals at world prices and their total costs of production expressed as a percentage of GDP. OIL rent is the difference between the value of crude oil production at world prices and total costs of production. HIPC is a dummy variable that scores a country 1 if categorised as a Heavily Indebted Poor Country and 0 otherwise. EXP*HIPC is the interaction term for EITI implementation experience and Heavily Indebted Poor Countries. 


\subsubsection{Control of corruption, EITI implementation, different set of countries}

Table 3.8 reports results of robustness tests specifically focusing on developing countries (i.e. excluding all developed countries). In conducting this supplementary analysis, developed (OECD) countries implementing the EITI Standards were excluded from the sample, to ensure the tests are conducted on a relatively more homogenous group (i.e. developing countries only). ${ }^{40}$ The results of the tests were again qualitatively similar to the results of the main tests.

${ }^{40} \mathrm{~A}$ further univariate analysis of the difference in raw scores (ranking) of all EITI countries using the Corruption Perception Index (CPI) was conducted to examine yearly changes in perceived level of corruption for EITI implementing countries overtime. First, countries score for the periods 2003-2011 and 2012-2015 were averaged and ranked. The analyses show that all the developed (OECD) countries in the sample remained in the top four positions. Suggesting that EITI membership did not alter their level of perceived corruption. For example, Norway and the US did not change in average ranking for these periods. Germany and UK both had only one average score change for the period which is marginal. In contrast, the magnitude of change for Sub-Saharan African countries was huge. For instance, the highest positive change in position was recorded by Madagascar which had on average 20 points differences between these periods. Thus, affirming the results observed in the multivariate regression analyses. Hence, reiterating the importance of excluding these countries from the sample employed for the subsequent robustness tests. Appendix H reports the results of this analyses. 
Table 3.8

Control of corruption and EITI implementation experience [SSA reduced sample]

\begin{tabular}{|c|c|c|c|c|c|c|c|c|c|c|}
\hline \multirow{2}{*}{$\begin{array}{l}\text { Dep. Variable: CCI } \\
\text { Variable }\end{array}$} & \multirow[b]{2}{*}{ Sign } & \multicolumn{3}{|c|}{ Model 13} & \multicolumn{3}{|c|}{ Model 14} & \multicolumn{3}{|c|}{ Model 15} \\
\hline & & Coef. & RSE & $\mathrm{P}>/ \mathrm{t} /$ & Coef. & RSE & $\mathrm{P}>/ \mathrm{t} /$ & Coef. & RSE & $\mathrm{P}>/ \mathrm{t} /$ \\
\hline Constant/intercept & $?$ & -0.607 & 0.112 & $0.000^{* * *}$ & -0.573 & 0.111 & $0.000^{* * *}$ & -0.958 & 0.128 & $0.000^{* * *}$ \\
\hline$E X P$ & + & -0.021 & 0.005 & $0.000^{* * *}$ & -0.022 & 0.004 & $0.000^{* * *}$ & -0.022 & 0.004 & $0.000^{* * *}$ \\
\hline FOI & + & 0.014 & 0.003 & $0.000^{* * *}$ & 0.014 & 0.003 & $0.000^{* * *}$ & 0.011 & 0.003 & $0.000^{* * *}$ \\
\hline$G D P$ & + & 0.025 & 0.015 & $0.091^{*}$ & 0.016 & 0.014 & 0.260 & 0.065 & 0.016 & $0.000^{* * *}$ \\
\hline Pol_Inst & + & 0.238 & 0.009 & $0.000^{* * *}$ & 0.245 & 0.009 & $0.000^{* * *}$ & 0.207 & 0.011 & $0.000^{* * *}$ \\
\hline$R R D$ & - & -0.087 & 0.047 & $0.067^{*}$ & & & & & & \\
\hline$M I N$ & - & & & & -0.003 & 0.001 & $0.022^{* *}$ & & & \\
\hline OIL & - & & & & & & & -0.006 & 0.001 & $0.000^{* * *}$ \\
\hline$S S A$ & + & 0.178 & 0.034 & $0.000^{* * *}$ & 0.152 & 0.031 & $0.000^{* * *}$ & 0.191 & 0.031 & $0.000^{* * *}$ \\
\hline$E X P^{*} S S A$ & + & 0.016 & 0.006 & $0.009 * * *$ & 0.020 & 0.006 & $0.001^{* * *}$ & 0.014 & 0.006 & $0.015^{* *}$ \\
\hline R-squared & & 0.61 & & & 0.61 & & & 0.63 & & \\
\hline Mean VIF & & 2.15 & & & 2.10 & & & 2.32 & & \\
\hline Observation & & 596 & & & 596 & & & 596 & & \\
\hline Number of countries & & 47 & & & 47 & & & 47 & & \\
\hline
\end{tabular}

Notes: All models are estimated on the robust standard error of coefficients. Superscripts *, $* *$, and ${ }^{* * *}$ represents 10,5 and 1 percent level of significance respectively. The estimated regressions are based on the below specific models:

$$
\begin{aligned}
& C C I_{i}=\alpha_{0}+\alpha_{1} E_{\text {XXP }}+\alpha_{2} \text { FOI }_{i}+\alpha_{3} \text { GDP }_{i}+\alpha_{4} \text { Pol }_{\text {Inst }_{i}}+\alpha_{5} \text { RRD }_{i}+\alpha_{6} \text { SSA }_{i}+\alpha_{7} \text { EXPSSA }_{i} \\
& C C I_{i}=\alpha_{0}+\alpha_{1} \text { EXP }_{i}+\alpha_{2} \text { FOI }_{i}+\alpha_{3} G D P_{i}+\alpha_{4} \text { Pol }_{\text {Inst }_{i}}+\alpha_{5} \text { MIN }_{i}+\alpha_{6} \text { SSA }_{i}+\alpha_{7} \text { EXPSSA }_{i} \\
& C C I_{i}=\alpha_{0}+\alpha_{1} \text { EXP }_{i}+\alpha_{2} \text { FOI I }_{i}+\alpha_{3} G D P_{i}+\alpha_{4} \text { Pol }_{\text {Inst }_{i}}+\alpha_{5} \text { OIL }_{i}+\alpha_{6} \text { SSA }_{i}+\alpha_{7} \text { EXPSSA }_{i}
\end{aligned}
$$




\section{Table 3.8 continued}

Variable definition: The $C C I$ is the Control of Corruption Index which measures the perception to which public power is exercised for private gain, including both petty and grand forms of corruption, as well as the capture of the state by elites and private interest. Higher values indicate better control of corruption. EXP is the number of years since a country publicly committed to implementing the EITI Standards, based on the official announcement date provided by each country's national EITI and/or EITI International Secretariat. EXP measures are taken on 31st December each year from 2003 to 2015. FOI is the duration for which a country has adopted FOI laws, measured as the cumulative number of years since the enactment of the law. GDP is the natural logarithm of gross domestic product per capita. GDP per capita (current US\$) is the gross domestic product divided by midyear population. Pol_Inst a country's political institution and stability score. Pol_Inst is the aggregate score of Government Effectiveness and Political Stability and Absence of Violence in a country. $R R D$ is the natural resource revenue dependence level of a country and is measured as total primary export scaled by total merchandise export. MIN is mineral rent which is the difference between the value of production for a stock of minerals at world prices and their total costs of production expressed as a percentage of GDP. OIL rent is the difference between the value of crude oil production at world prices and total costs of production. SSA is a dummy variable that takes the value of 1 if a country is classified as a Sub-Saharan African country and 0 otherwise. EXP*SSA is the interaction term for EITI implementation experience of a country and Sub-Saharan African Countries. 
Table 3.9

Control of corruption and EITI implementation experience- [HIPC measure reduced sample]

\begin{tabular}{|c|c|c|c|c|c|c|c|c|c|c|}
\hline \multirow{2}{*}{$\begin{array}{l}\text { Dep. Variable: CCI } \\
\text { Variable }\end{array}$} & \multirow[b]{2}{*}{ Sign } & \multicolumn{3}{|c|}{ Model 16} & \multicolumn{3}{|c|}{ Model 17} & \multicolumn{3}{|c|}{ Model 18} \\
\hline & & Coef. & RSE & $\mathrm{P}>/ \mathrm{t} /$ & Coef. & RSE & $\mathrm{P}>/ \mathrm{t} /$ & Coef. & RSE & $\mathrm{P}>/ \mathrm{t} /$ \\
\hline Constant/intercept & $?$ & -0.343 & 0.121 & $0.005^{* * *}$ & -0.291 & 0.118 & $0.014^{* *}$ & -0.614 & 0.135 & $0.000 * * *$ \\
\hline$E X P$ & + & -0.021 & 0.005 & $0.000^{* * *}$ & -0.021 & 0.004 & $0.000^{* * *}$ & -0.021 & 0.004 & $0.000^{* * *}$ \\
\hline FOI & + & 0.011 & 0.003 & $0.000^{* * *}$ & 0.011 & 0.003 & $0.001^{* * *}$ & 0.008 & 0.003 & $0.011^{* *}$ \\
\hline$G D P$ & + & -0.007 & 0.016 & 0.646 & -0.011 & 0.016 & 0.482 & 0.030 & 0.018 & $0.097^{*}$ \\
\hline Pol_Inst & + & 0.254 & 0.009 & $0.000^{* * *}$ & 0.258 & 0.009 & $0.000^{* * *}$ & 0.226 & 0.011 & $0.000^{* * *}$ \\
\hline$R R D$ & - & 0.002 & 0.046 & 0.973 & & & & & & \\
\hline$M I N$ & - & & & & -0.004 & 0.002 & $0.007^{* * *}$ & & & \\
\hline OIL & - & & & & & & & -0.005 & 0.001 & $0.000^{* * *}$ \\
\hline HIPC & + & 0.018 & 0.032 & 0.581 & 0.005 & 0.030 & 0.863 & 0.032 & 0.032 & 0.315 \\
\hline$E X P^{*} H I P C$ & + & 0.026 & 0.006 & $0.000^{* * *}$ & 0.030 & 0.006 & $0.000^{* * *}$ & 0.025 & 0.006 & $0.000^{* * *}$ \\
\hline R-squared & & 0.58 & & & 0.58 & & & 0.59 & & \\
\hline Mean VIF & & 2.08 & & & 2.08 & & & 2.27 & & \\
\hline Observation & & 596 & & & 596 & & & 596 & & \\
\hline Number of countries & & 47 & & & 47 & & & 47 & & \\
\hline \multicolumn{11}{|c|}{$\begin{array}{l}\text { Notes: All models are estimated on the robust standard error of coefficients. Superscripts } *, * * \text {, and }{ }^{* * *} \text { represents } 10,5 \text { and } 1 \\
\text { percent level of significance respectively. }\end{array}$} \\
\hline \multicolumn{11}{|c|}{ The estimated regressions are based on the below specific models: } \\
\hline \multicolumn{8}{|c|}{$C C I_{i}=\alpha_{0}+\alpha_{1} E X P_{i}+\alpha_{2} F_{i}+\alpha_{3} G D P_{i}+\alpha_{4} P_{\text {Inst }_{i}}+\alpha_{5} R R D_{i}+\alpha_{6} H I P C_{i}+\alpha_{7} E X P H I P C_{i}$} & \multicolumn{3}{|c|}{$\ldots(3.16)$} \\
\hline \multicolumn{8}{|c|}{$C C I_{i}=\alpha_{0}+\alpha_{1} E X P_{i}+\alpha_{2} F O I_{i}+\alpha_{3} G D P_{i}+\alpha_{4} P_{\text {Inst }_{i}}+\alpha_{5}$ MIN $_{i}+\alpha_{6} H I P C_{i}+\alpha_{7} E X P H I P C_{i}$} & \multicolumn{3}{|c|}{$\ldots(3.17)$} \\
\hline \multicolumn{8}{|c|}{$C C I_{i}=\alpha_{0}+\alpha_{1} E X P_{i}+\alpha_{2} F_{i}+\alpha_{3} G D P_{i}+\alpha_{4} P_{\text {Pol }}$ Inst $_{i}+\alpha_{5}$ OIL $_{i}+\alpha_{6} H I P C_{i}+\alpha_{7}$ EXPHIPC $_{i}$} & \multicolumn{3}{|c|}{$\ldots(3.18)$} \\
\hline
\end{tabular}




\section{Table 3.9 continued}

Variable definition: The $C C I$ is the Control of Corruption Index which measures the perception to which public power is exercised for private gain, including both petty and grand forms of corruption, as well as the capture of the state by elites and private interest. Higher values indicate better control of corruption. EXP is the number of years since a country publicly committed to implementing the EITI Standards, based on the official announcement date provided by each country's national EITI and/or EITI International Secretariat. EXP measures are taken on 31st December each year from 2003 to 2015 . FOI is the duration for which a country has adopted FOI laws, measured as the cumulative number of years since the enactment of the law. GDP is the natural logarithm of gross domestic product per capita. GDP per capita (current US\$) is the gross domestic product divided by midyear population. Pol_Inst a country's political institution and stability score. Pol_Inst is the aggregate score of Government Effectiveness and Political Stability and Absence of Violence in a country. RRD is the natural resource revenue dependence level of a country and is measured as total primary export scaled by total merchandise export. MIN is mineral rent which is the difference between the value of production for a stock of minerals at world prices and their total costs of production expressed as a percentage of GDP. OIL rent is the difference between the value of crude oil production at world prices and total costs of production. HIPC is a dummy variable that scores a country 1 if categorised as a Heavily Indebted Poor Country and 0 otherwise. EXP*HIPC is the interaction term for EITI implementation experience and Heavily Indebted Poor Countries. 
The interest in Model [13] is the coefficient on EXP*SSA considering only a subsample of developing countries. The finding validates the second hypothesis with the coefficients (p-value) on $\operatorname{EXP}^{*} S S A 0.016$ (0.009), reaffirming the main result in the Model [5] that Sub-Saharan African countries are indeed able to improve on the level of their perceived corruption viz EITI implementation process. This is not unconnected with the fact that Sub-Saharan African countries are considered to have more corruption challenge (Blackburn, Bose, Emranul Haque, \& Haque, 2010; Houqe \& Monem, 2016) compared to other developing countries.

Table 3.9, reports the results of the tests reported in Table 3.8 but with HIPC as an alternative to SSA. Again, the results remained qualitatively similar to the main results.

\subsection{Conclusion}

This chapter has examined the effect of EITI implementation experience on the perceived control of corruption for all EITI implementing countries. The results suggest that for the whole set of countries EITI experience has a negative impact on control of corruption which is contrary to $H_{1}$. However, the negative effect associated with EITI implementation experience is less for Sub-Saharan African countries which is consistent with $\mathrm{H}_{2}$. 


\section{CHAPTER FOUR}

\section{ECONOMIC VALUE OF EITI INFORMATION ${ }^{41}$}

\subsection{Synopsis}

This chapter addresses the second two research questions discussed in Chapter

One. The USEITI unilateral release of information on non-tax payments by extractive companies to the US government is used to illustrate the economic value of EITI information. The study focuses on the information content of the USEITI disclosure, both for the initial release and the entire period for which the data is available. The research tests for market reaction to the initial disclosure of this information in terms of change in trading volume and abnormal returns around the date of the information release. It also employs the Collins et al., (1999) adaptation of the Ohlson (1995) model to examine the value relevance of the continuing disclosure of the information over the period 2013-2016. The results show that the initial release resulted in a significant trading volume reaction and produced positive cumulative abnormal returns in the period immediately surrounding the release date. Regression analyses of the cross-

\footnotetext{
${ }^{41}$ A paper developed from this chapter titled "What is the Economic value of the Extractive Industries Transparency Initiative (EITI) Information Disclosure?" coauthored with my supervisors has been accepted for publication in the Journal of Contemporary Accounting and Economics (JCAE). I am grateful to participants at the following conferences that provided helpful feedback to earlier versions of the paper: 2016 Financial Markets and Corporate Governance Conference in Melbourne, Australia; 2016 Accounting and Finance Association of Australia and New Zealand conference in Gold Coast, Queensland, Australia; 2016 African Accounting and Finance Association conference in Nairobi, Kenya; 2017 School of Accounting and Commercial Law PhD Colloquium, Victoria University of Wellington, New Zealand; 2017 Financial Markets and Corporate Governance Conference at Victoria University of Wellington, New Zealand. I thank the JCAE Editor and the anonymous Reviewer for their comments. I would also like to acknowledge the helpful comments received from Professors Mike Bradbury, Massey University, New Zealand; Stuart McLeay, University of Lancaster, UK; Joy Begley, University of British Columbia, Canada and Holger Daske, University of Mannheim, Germany.
} 
sectional variation in abnormal returns during the event period show that the reaction is associated with oil and gas firms, and firms with high working capital and lower asset turnover. Furthermore, the tests for value relevance show that the USEITI information released over the period to 2016 is value relevant. 


\subsection{Introduction}

This chapter uses the United States Extractive Industries Transparency Initiative (USEITI) unilateral 42 information release on non-tax payments of extractive companies to the US government as an illustration of the economic value of EITI information. As discussed in Chapter Two, EITI as an international accountability and transparency initiative is focused on transparency around the governance of oil, gas and mineral resources. The EITI achieves its objective via disclosure Standards that require extractive companies operating in EITI implementing jurisdiction to publish payments made to national governments for the exploration of natural resources, with the governments likewise required to publish revenue they have received from companies. In line with this aim for information transparency, it is important to gain insight into how the release of USEITI information impacts extractive companies in the US where the extractive industry is among the top global leaders in production reserves. ${ }^{43}$

The US became an EITI candidate country in March 2014 but announced in November 2017 that it was withdrawing from the EITI as an implementing country. Nevertheless, the disaggregated information released on the annual non-tax payments by extractive companies to the US government over the period

\footnotetext{
42 The term unilateral as used in this thesis denotes governmental disclosure of corporate information.

43 The US was ranked as the world's top producer of petroleum and natural gas hydrocarbons in 2016. A position it has maintained for the last five years (U.S. Energy Information Administration, 2017).
} 
2013-2016 has remained available on the USEITI on-line portal and provides the first opportunity to illustrate the economic value of EITI information. The USEITI on-line portal currently provides disaggregated non-tax payment information made by extractive companies to the U.S. government for separate extractive commodities and revenue streams. The annual profit (or loss) reported in the annual reports of extractive companies reflects the non-tax payments made to the US government but the payments are not disclosed as disaggregated detailed line items as stipulated in the EITI requirements. In particular, annual reports do not inform investors on the non-tax payments made to the US government in respect of royalties, rents or other classes of exploration expenditure. Since 2013 this arguable inadequacy in company disclosure has been bridged by the USEITI unilateral disclosure of the information. ${ }^{44}$

This chapter focuses on the information content of disclosure of non-tax payments by extractive companies to the US government, first for the initial release of the 2013 calendar year data and second for the period to 2016. Specifically, the study tests (i) whether the initial release of non-tax payments made by extractive companies to the US government evoked market reactions,

\footnotetext{
${ }^{44}$ Requirements for similar disaggregated disclosures are being introduced in Canada and are already being applied in certain European Union countries. In Canada, with the enactment of Extractive Sector Transparency Measures Act (2014) (Department of Justice, 2014) and in Europe, with the implementation of Chapter 10, of the European Union Accounting Directive (2013/34/EU) and Transparency Directive (2013/50/EU) (European Parliament and the Council, 2013; Rauter, 2017).
} 
and (ii) the value relevance of this information over the period for which data is now available.

The investigation into the impact of the USEITI information is conducted utilising two separate but related methods. First, the study tests for trading volume reaction and employs a standard event study methodology, using a two-factor model incorporating an oil and gas industry index, to measure cumulative abnormal returns around the event date of the first-time release of this information. In this initial test, the aim is to obtain evidence that investors indeed took notice of this information. Second, the study the employs Collins et al., (1999) adaptation of the Ohlson (1995) model to examine the value relevance of USEITI information disclosure over the period to 2016.

There is no empirical evidence on how EITI required information disclosure affects extractive companies in implementing countries. The fundamental reason for this has been the lack of disclosure of the payments made by individual companies to the government of implementing countries. The USEITI data provides the first opportunity to measure market reaction and value relevance of EITI information disclosures. This chapter thus provides the first illustration of the economic value of information disclosed under the requirements of the EITI. 
The results show that firms whose information was released in the initial 2013 implementation process experienced a significant trading volume reaction, and a significantly positive cumulative abnormal return, in the period surrounding the announcement (release) date. Regression analyses employed to explain the cross-sectional variation in abnormal returns during the main event period show that oil and gas firms, and sample firms with high working capital, and lower asset turnover had larger abnormal returns during the event window. The event study results are robust to the Corrado and Zivney (1992) non-parametric test statistics. The study also finds the coefficient on EITI information in the value relevance analysis to be positive and statistically significant.

The study is novel in two ways. It provides an illustration of the impact of the EITI's disclosure requirements and furthermore, it determines the impact of the release of individual company data gathered by an EITI implementing government but not fully disclosed by the extractive companies themselves to the market (that is, a unilateral ${ }^{45}$ disclosure).

45 This unilateral disclosure by the USEITI through the Office of the National Resources Revenue (ONRR) is similar to information released via intermediaries. Information on the financial activities of corporations is provided via disclosure from several channels including regulatory filings (Healy \& Palepu, 2001). Whereas studies have looked at mandatory and voluntary disclosures, there seems to be no evidence in the literature on how unilateral disclosure of information held by regulatory agencies impact firms' valuation when released to third parties or the market. 
The remainder of the chapter is structured as follows. Section 4.2 gives the institutional background of the study and the hypotheses tested in the study. Section 4.3 outlines the methodology employed in the study. Section 4.4 describes the samples selection procedure. Section 4.5 presents the empirical results. Finally, Section 4.6 summarises the findings and presents the conclusions.

\subsection{Background and hypotheses}

\subsubsection{Institutional background}

The US is an important player in global energy production and a leading producer of petroleum and other liquids (U.S. Energy Information Administration, 2016). BP (2017) reports that the US remained the largest producer of oil and natural gas in 2016. In 2016 the US produced 13.4\% of global oil averaging about 12,354 thousand barrels per day, with its natural gas production accounting for $21.1 \%$ of the global production. In terms of energy consumption, the US led the world with $2,272.7$ million tonnes of oil equivalent representing $17.1 \%$ of the global consumption in 2016. The US position in the production and consumption of energy makes it an important setting for understanding the impact of EITI at the specific country level.

The first official statement on the US joining the EITI was made in September 2011. This was the start of multi-year steps towards attaining EITI compliant 
status and committed the US to develop plans and a roadmap necessary to achieve the goals for compliance. In March 2014, the EITI Board approved the US application as an EITI candidate country.

On 11 December 2014, in line with the decision reached in the USEITI MultiStakeholder Group meetings, the US Department of the Interior (DOI) launched an On-line Data Portal which contains Office of Natural Resources Revenue (ONRR) company-level data. Legal authority for disclosing this category of information had been discussed in meetings where it was accepted that for all inscope commodities, the DOI would disclose company-level data to the extent that is permitted by law (approximately $100 \%$ of DOI revenue is in-scope). The ONRR source, for the first time, provided disaggregated information about the extractive industry in the US (United States Extractive Industries Transparency Initiative, 2014).

Extractive companies in the US make several payments (royalties, rents, and other classes of payments) to the US government or the landowners when they explore and/or develop natural resources on federal lands and waters. However, these payments are not separately reported in the financial statements of the extractive companies. The payments are included within operating expenses by extractive firms, with no disaggregated details or line items on these payments, either by way of notes or supplementary explanation in the financial statement 
and/or statutory filings with the SEC (e.g. forms 10-K, 10-Q or 8-K). The USEITI online portal thus contains previously unavailable information relating to the production of natural resources, revenues received from companies, and disbursements made to different agencies, funds, and local governments.

Full implementation of the Final Rule for Section 1504 of the Dodd-Frank Act, was to require companies to mandatorily provide non-tax payment ${ }^{46}$ information in their annual reports and file same with the SEC using Form SD. However, the proposed rule encountered significant industry opposition and was withdrawn by the US government in February 2017. In a similar vein, the US withdrew from its membership of the EITI in November 2017. The American Petroleum Institute (API), the US Chamber of Commerce, the Independent Petroleum Association of America (IPAA), and the National Foreign Trade Council (NFTC) had filed a suit against the SEC in October 2012 regarding the implementation of the Final Rule for Section 1504 of the Dodd-Frank Act, 2010.47 The API and the other industry

\footnotetext{
${ }^{46}$ Section 1504 (1) (C) defines the term 'payment' as "(i) means a payment that is "(I) made to further the commercial development of oil, natural gas, or minerals; and "(II) not de minimis; and (ii) includes taxes, royalties, fees (including license fees), production entitlements, bonuses, and other material benefits, that the SEC, consistent with the guidelines of the Extractive Industries Transparency Initiative (to the extent practicable), determines are part of the commonly recognized revenue stream for the commercial development of oil, natural gas, or minerals."
}

${ }^{47}$ Section 1504 (2) (A) stipulates that "Not later than 270 days after the date of enactment of the Dodd-Frank Wall Street Reform and Consumer Protection Act, the Commission shall issue final rules that require each resource extraction issuer to include in an annual report of the resource extraction issuer information relating to any payment made by the resource extraction issuer, a subsidiary of the resource extraction issuer, or an entity under the control of the resource extraction issuer to a foreign government or the Federal Government for the purpose of the commercial development of oil, natural gas, or minerals, including (i) the type and total amount of such payments made for each project of the resource extraction issuer relating to the 
Plaintiffs' argument is that the SEC acted arbitrarily and capriciously in promulgating the rules without carrying out sufficient cost-benefit analysis. Further, they argued that the rule violated the First Amendment guarantee of freedom of speech since disclosing such information would allow companies' competitors access to sensitive proprietary information. 48

\subsubsection{Hypotheses}

In the light of the empirical literature reviewed in Chapter Two, and the discussion above it is unclear whether the USEITI information disclosure of nontax payment by exploration and production companies in the US would be interpreted by the market as good or bad news for the individual firms or even relevant. Thus, a matter for empirical investigation- which this chapter addresses. I therefore propose the following null hypotheses to test for the market reaction and value relevance of the EITI information:

$H_{1}$ : There is no significant market reaction to the release of information on the non-tax payments made by extractive firms to the United States government.

\footnotetext{
commercial development of oil, natural gas, or minerals; and (ii) the type and total amount of such payments made to each government."

${ }^{48}$ On June 27, 2016, the SEC adopted the re-proposed Rule 13q-1 and an amendment to Form SD to implement Section 1504 of Dodd-Frank Act. The intent of the reissued Final Rule was to require extractive issuers to comply with the reporting requirements for fiscal years ending on or after September 30, 2018. However, this did not happen, as the US Senate passed a resolution under the Congregational Review Act, disapproving the SEC's rule on resource extraction payments on February 3, 2017. The effect is that the SEC's rule no longer applies (Graber \& Flow, 2017).
} 
$H_{2}$ : The United States Extractive Industries Transparency Initiative information is not value relevant for extractive firms.

\subsection{Methodology}

The tests into the impact of the USEITI information disclosure is conducted using two distinct, but related methods. First, the study undertakes a market reaction assessment, in terms of trading volume and price as indicated by the cumulative abnormal returns, around the date of the initial release of this information. The aim here is to obtain empirical evidence on whether the market took notice of, and priced the information. In addition, the study also examines the impact of firm-specific characteristics on the cross-sectional variation in the price reaction. Second, the study conducts a test of the value relevance of the continuing disclosure of this information over the 2013-2016 period. The timeline for the reaction tests is shown as below:

$\tau=0: \quad$ the event day, 12 December $2014 .{ }^{49}$

$T_{0}+1$ to $T_{1}: \quad$ represents the estimation window of 120 days before the event period.

\footnotetext{
${ }^{49}$ Although the on-line portal for USEITI became live on the 11 December 2014, the selected event date is 12 December 2014 as this was the date on which the press release by the EITI on the launch of the portal was made and thus is the date the public and stock market became aware of this information release. Additional details on this is accessible via https://eiti.org/news/us-eitilaunches-natural-resource-revenues-portal
} 

$T_{1}+1$ to $T_{2}: \quad \quad \quad$ represents the event window; that is, the trading days before the event day $(\tau)$ and days after the event date.
$\tau+1$ to $T_{2}: \quad$ represents the post-event window (trading days after event day)

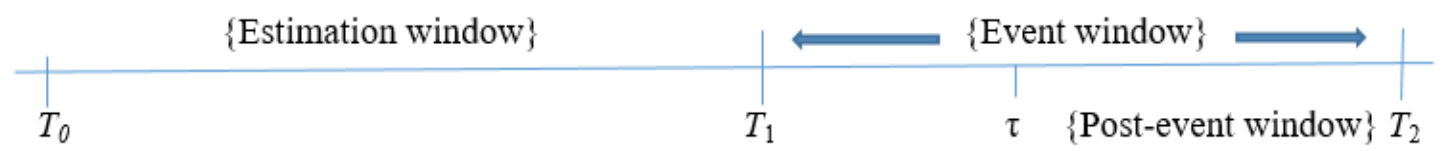

Figure 4.1: Timeline for event

The reaction tests consider the following event periods relative to the event day: $(-4,4),(-3,3),(-2,2)$ and $(-1,1)$.

The assumption underlying market reaction research is that markets are efficient in the sense that market participants are interested in and responsive to new information affecting the value of stocks traded in the market. Thus, the value of the information can be inferred and assessed by, trading volume and price reaction studies. 


\subsubsection{Market reaction}

\subsubsection{Market reaction: Trading volume}

This section assesses the trading volume reaction by abnormal or unexpected trading volume, formed by comparison of actual trading volume around the event date with the normal or expected volume of shares traded and thus follows studies such as Atiase and Bamber (1994), Bamber, Barron and Stevens (2011), Beaver (1968), Chae (2005), and Chen and Sami (2008). This test provides an initial indication of whether the information disclosure evoked a response from the market.

As acknowledged by Bamber et al., (2011) and Chen and Sami (2008) there is no universally accepted approach to measuring unexpected (or abnormal) trading volume. This study applies the approach that appears to be the most common in the trading volume literature, viz, the median-adjusted trading volume measure for the main and partitioned event windows. First, it measures the percentage of firm $i$ shares traded on day $t$ denoted as $V O L_{i t}$ across the estimation and event periods. The trading volume $\left(V O L_{i t}\right)$ per firm is measured as:

$V O L_{i t}=\frac{\text { Shares traded }_{i t}}{\text { outstanding } \text { shares }_{i t}}$

Second, abnormal trading volume per firm $\left(A V O L_{i t}\right)$ is calculated by subtracting from the trading volume, the firm's median trading volume during the estimation period, that is, 


$$
A V O L_{i t}=V O L_{i t}-m d\left(V O L_{i,-124, \ldots .,} V O L_{i,-5}\right)
$$

Thus, the mean abnormal trading volume for each day in the event window denoted as $\overline{A V O L_{t}}$, is the mean of $A V O L_{i t}$ across all $N$ sample firms on day $t$ and operationalised as:

$\overline{A V O L_{t}}=\frac{1}{N} \sum_{i=1}^{N} A V O L_{i t}$

Finally, to obtain the cumulative abnormal trading volume over the event period, the mean daily abnormal trading volume is cumulated across the main and partitioned event periods. The cumulative average abnormal trading volume metric is presented below as equation (4.4)

$\overline{\operatorname{CATVOL}_{t_{1}, t_{n}}}=\sum_{t=t_{1}}^{t_{n}} \overline{\operatorname{AVOL}_{t}}$

where:

$\mathrm{CAVTOL}_{t_{1}, t_{n}}$ is the median-adjusted cumulative mean abnormal trading volume for the main and partitioned event periods.

\subsubsection{Market reaction: Share price}

Price reaction studies trace to the seminal paper by Fama, Fisher, Jensen, and Roll (1969) and form an extensive literature on tests of the price impact of the release 
of new information by companies and the price impact of new regulatory requirements (Wells, 2004). The usual approach to the measurement of the cumulative abnormal return around the event date impact is to use the single factor market model but given that all the companies are in the same industry, I use a two-factor model including the market return and an industry factor. Abnormal return is defined as actual return less expected returns based on the two-factor market model estimated from data on the period preceding the event period - the estimation period. The two-factor market model is specified as follows:

$R_{i t}=\beta_{0 i}+\beta_{1 i} R_{m t}+\beta_{2 i} I_{n d}+\varepsilon_{i t}$

where:

$R_{i t} \quad=$ Period return for security $i$

$\beta_{0 i} \quad=$ Constant (intercept) estimate for security $i$

$\beta_{1 i}=$ Estimated beta for return on Standard \& Poor's Composite Index

$R_{m t}=$ Return on the Standard \& Poor's Composite Index in period $t$

$\beta_{2 i} \quad=$ Estimated beta for return on US Oil and Gas Index

$\operatorname{Ind}_{t}=$ Return on the US Oil and Gas Index in period $t$

$\varepsilon_{i t} \quad=$ Disturbance term (residual). 
The parameters of the model are estimated for each company from data on the estimation period using ordinary least squares regression and are then used to calculate the abnormal return during the main and partitioned event periods.

$\widehat{A R_{l t}}=R_{i t}-\widehat{R_{l t}}$

where

$R_{i t}=$ actual return

$\widehat{R_{l t}}=\widehat{\beta_{0 l}}+\widehat{\beta_{1 l}} R_{m t}+\widehat{\beta_{2 l}} I n d_{t} \quad$ (expected return)

where

$\hat{\beta}=$ estimates of the coefficients of equation (4.5)

$\widehat{A R_{l t}}=$ the component of the actual return which is "abnormal"

Cumulative abnormal return is calculated as the aggregate over the event period of the daily mean abnormal returns across the companies.

$\overline{\operatorname{CAR}_{\left(T_{1}, T_{2}\right)}}=\sum_{t=T 1}^{T 2} \overline{A R_{t}}$

where

$\overline{A R_{t}}=\frac{1}{N} \sum_{i=1}^{N} \widehat{A R_{l t}}$ 
$\overline{C A R_{\left(T_{1}, T_{2}\right)}}=$ mean cumulative abnormal return for sampled companies for the main (or partitioned) event periods.

The parametric test statistic for statistical significance is calculated as follows:

$t_{A R_{t}}=\frac{\overline{A R_{t}}}{S\left(\overline{A R} T_{0}, T_{1}\right)}$

where

$t_{A R_{t}}$ is the t-statistic for abnormal return on day $t$.

$\overline{A R_{t}}$ is the mean abnormal return for sampled companies on day $t$.

$S\left(\overline{A R}_{T_{0}}, T_{1}\right)$ is the standard deviation of mean abnormal returns over the estimation window.

Following the recommendation by Kothari and Warner (2007) and Kryzanowski and Jenkins (1993), with modification, the parametric $t$-statistic for CAR over different intervals is calculated using equation (4.11) below:

$t_{C A R_{\left(T_{1}, T_{2}\right)}}=\frac{\operatorname{CAR}\left(T_{1}, T_{2}\right)}{\left[\sigma^{2}\left(T_{1}, T_{n}\right)\right]^{1 / 2}}$

where

$t_{C A R_{\left(T_{1}, T_{2}\right)}}$ is the t-statistics of CAR for mean cumulative abnormal return for sampled companies for the main and partitioned event periods.

$\sigma^{2}\left(T_{1}, T_{n}\right)=L \sigma^{2}\left(A R_{t}\right)$ 
$L \sigma^{2}\left(A R_{t}\right)$ is the variance of the one-period average abnormal returns.

$\operatorname{CAR}\left(T_{1}, T_{n}\right)$ is the one-event period cumulative abnormal return for the main and partitioned event periods.

Mackinlay (1997) suggest the use of non-parametric tests as a robustness check on conclusions reached using parametric tests in event studies. Non-parametric tests statistics in event studies have been recommended as an appropriate correction for the absence of normality in the abnormal returns distribution (Corrado \& Truong, 2008). Specifically, Corrado and Truong (2008) show that parametric tests can be more prone to misspecification than non-parametric tests in event studies. The assumption of a normal distribution underlining the use of parametric tests in event studies leads [in most cases] to poorly specified and imprecise inferences. In contrast, the use of non-parametric tests is appropriate under varying gradations of skewness (Corrado \& Zivney, 1992; Corrado, 1989).

Corrado (2011) notes that the overall conclusion in the literature is that sign and rank tests are well specified and provide an improvement in test power compared to standard parametric tests. I follow this suggestion in the literature and employ the rank and sign tests introduced by Corrado (1989), subsequently modified with adjustments in Corrado and Zivney (1992) to conduct robustness 
tests. The rank test given an event-induced shift in the cross-sectional variance formula, implemented as below:

$S A R_{j, t}=A R_{j, t} / \sqrt{\operatorname{Var}\left(A R_{j, t}\right)}$

where $S A R_{j, t}$ in equation (4.13) denotes the standardized abnormal returns series for $j$ th security over the estimation period (i.e. control period) and the event date $\{$ i.e. in this case $t=-124, \ldots,-5,0\} . A R_{j, t}$ is the abnormal return for the event date. Thus, each series is then specified as below:

$S A R_{j, t}=\left\{\begin{array}{lr}A R_{j, t} / \sqrt{\operatorname{Var}\left(A R_{j, t}\right)} & t=-124, \ldots-5 \\ \frac{A R_{j, t} / \sqrt{\operatorname{Var}\left(A R_{j, t}\right)}}{\sqrt{\operatorname{Var}\left(A R_{, . t} / \sqrt{\operatorname{Var}\left(A_{, t}\right)}\right)}} t=0\end{array}\right.$

Let $r\left(S A R_{j, 0}\right)$ denote the rank of the event date standardized abnormal return $S A R_{j, 0}$ within the vector of $n+1$ standardized abnormal returns for the $j t h$ security. Ranks are then used to compute the Corrado-Zivney-Rank $\left(T_{C Z k}\right)$ rank test shown in equation (4.15).

$T_{C Z k}=\frac{1}{\sqrt{m}} \sum_{j=1}^{m} \frac{r\left(S A R_{j, 0}\right)-\left(\frac{n+1}{2}\right)}{\sqrt{\frac{n(n+1)}{12}}}$

where $m$ is sample size and $n$ denotes the length of the estimation (pre-event) window 
Corrado and Zivney (1992) provide a test model that corrects for missing observations in the abnormal returns of the sampled firms. This is implemented $\{$ with regards to this chapter as $-124, \ldots+4,0\}$ in equation (4.16) below.

$K_{i t}=\operatorname{rank}\left(A_{i t}\right) \quad t=-124, \ldots .+4$

To allow for missing returns, ranks are standardised by dividing by one plus the number of non-missing returns in each firm's abnormal returns time series, based on equation (4.17) below:

$U_{i t}=\frac{K_{i t}}{\left(1+M_{i}\right)}$

where $M_{i}$ is the number of the non-missing returns for security $i$. The rank test statistics substitutes $\left(U_{i t}-\frac{1}{2}\right)$ for the excess return of $A_{i t}$. This yields the event day 0 test statistic as follows:

$T_{C Z k}^{*}=\frac{1}{\sqrt{N}} \sum_{i=1}^{N}\left(\frac{U_{i t}-\frac{1}{2}}{S(U)}\right)$

where $N$ is the number of firms in the sample portfolio and $S(U)$ is the standard deviation calculated using equation (4.19) below (as applied in this chapter):

$S(U)=\sqrt{\frac{1}{129} \sum_{t=-124}^{+5}\left(\frac{1}{\sqrt{80}} \sum_{i=1}^{80}\left(U_{i t}-\frac{1}{2}\right)\right)^{2}}$ 
The sign test is operationalised as $G_{i t}=\operatorname{sign}\left(A_{i t}-\right.$ median $\left.\left(A_{i}\right)\right)$, where $A_{i t}$ is the excess abnormal return for firm $i$ on day $t . G_{i t}$ is the sign from which day 0 test statistics is constructed.

$T_{G}=\frac{1}{\sqrt{N}} \frac{\sum_{i=1}^{N} G_{i t}}{S(G)}$

$S(G)=\sqrt{\frac{1}{129} \sum_{t=124}^{+4}\left(\frac{1}{\sqrt{N_{t}}} \sum_{i=1}^{N_{t}} G_{i t}\right)}$

$N_{t}$ is the number of non-missing returns in the cross-section of $N$-firms on the day $t$ in event time.

\subsubsection{Examination of cross-sectional variation in abnormal return}

This analysis focuses on the determinants of cross-sectional variation in the share price reaction. Accordingly, it examines the firm-specific characteristics that influenced the price reaction to the release of the USEITI information. In line with prior studies (e.g. Akyol, Lim, \& Verwijmeren, 2012; Bird et al., 2013; Ferguson, Grosse, Kean, \& Scott, 2011; Ferguson \& Scott, 2011; Marsden, 2000; Prather-Kinsey \& Tanyi, 2015), the estimation model includes a number of firmspecific variables that are commonly used in stock price reaction studies. The multivariate regression model employed for the analysis is as follows:

$$
\begin{aligned}
\text { CAR }_{(t 1, t n)} & =\beta_{0}+\beta_{1} \operatorname{StdRET}_{i}+\beta_{2} \text { BTM }_{i}+\beta_{3} \text { LEV }_{i}+\beta_{4} \text { MCAP }_{i} \\
+ & \beta_{5} \text { IND }_{i}+\beta_{6} \text { RESERVE }_{i}+\beta_{7} \text { ANALYST }_{i}+\beta_{8} \text { Dir_SH }_{i} \\
+ & \beta_{9} \text { WCAP }_{i}+\beta_{10} \text { Asset_Turn }_{i}+\varepsilon_{i}
\end{aligned}
$$

where: 
$C A R_{(t 1, t n)}$ is the one-period cumulative abnormal return across firms estimated using the two-factor market model based on equation (4.7)

StdRET Standard deviation of the of firm's daily stock return during the estimation window (120 days before the event period)

BTM Book-to-Market ratio measured as firm's book value per share scaled by market price per share

LEV Leverage is the summation of firm's short and long-term debt scaled by the total asset

MCAP The Market Capitalisation is companies proxy for size measured as the Inverse Hyperbolic Sine of the Market Capitalisation

IND Industry is a dummy variable to check the effect of a firm's industry. The variable allocates 1 if the company is an oil and gas firm and 0 if otherwise

RESERVE Reserve is companies natural reserve expressed in million barrels of oil equivalent (MMBOE) and transformed using the Inverse Hyperbolic Sine. 
ANALYST Number of public equity financial analysts following (covering) each firm. This controls for stock market activity and monitoring mechanism

Dir_SH Directors Shareholding is a measure of firm's ownership structure estimated as the total percentage of shares held by directors of the company

WCAP Working capital balance relative to the total assets. WCAP is measured as current assets minus current liabilities scaled by total assets consistent with Ferguson et al., (2011a)

Asset_Turn This the firm's total sale scaled by total assets

$\varepsilon_{i} \quad$ Error term.

The standard deviation of the of firm's daily stock return (StdRET) is included to check for the impact of volatility of firms' stock returns and leverage (LEV) to control for firms' external level of financing. Leverage is also a good measure of the risk of firms. In line with Ferguson and Scott (2011), the study used market capitalisation (MCAP) to proxy for firms size. The indicator variable IND is used to denote whether a firm is an oil and gas, or mining firm. To control for firms' exploration and production future cash flow expectations firms' proved reserves (RESERVE) are included in the model. 
Other firm-specific variables include analyst coverage (ANALYST) which controls for the stock market information environment. Analysts coverage serve as both information intermediaries and monitoring mechanism channels (Ferguson, et al., 2011b). Directors' shareholding (Dir_SH) is used to control for ownership concentration in terms of board members' shareholding. Following Ferguson, et al., (2011a), working capital (WCAP) and asset turnover are also included to control for firms' financial performance. The last control variable is asset turnover (Asset_Turn) of firms which measures the ability of management to efficiently generate sales (revenue) relative to total assets. Typically a higher ratio of asset turnover is indicative of better performance.

\subsubsection{Value relevance analysis}

This section describes the test analysis based on the Collins et al., (1999) adaptation of the Ohlson (1995) model to examine the value relevance of the USEITI information. The test model used is as follows:

$$
P=\gamma_{0}+\gamma_{1} B V P S_{t-1}+\gamma_{2} E P S_{t}+\gamma_{3} E_{I T I_{-} O S_{t}}+\varepsilon
$$

where:
$P \quad$ Share price of firm as at 30 June each year 50
$B V P S_{t-1} \quad$ Beginning-of-year book value per share of firm

\footnotetext{
${ }^{50}$ Normal practice is to take the share price as at 3 months after balance date. However, given some variation in balance dates (with most common being 31 December) and that the USEITI information is released at 31 March each year, the share price is taken 3 months after that date.
} 
$E P S_{t} \quad$ Current period earnings per share of firm

EITI_OS $\quad$ USEITI information measured as the aggregate annual payments made by an extractive company to the US government for exploration of natural resources, and then scaled by the company's common shares outstanding

$\varepsilon \quad$ Error term.

\subsection{Data and sample}

The data employed in this study was accessed from several sources. The USEITI information was hand-collected from the USEITI website.51 The USEITI online data portal is tracked and managed by the Department of the Interior's Office of Natural Resources Revenue. The online portal contains non-tax payments categorized by company, commodity and revenue type for each calendar year. These open datasets are revenues for US Federal lands and offshore areas. The payment types are royalty, rent, bonus and other payments (for example, civil penalties, inspection fees and other revenue) disaggregated as part of the EITI disclosure process. Specifically, the data relates to companies paying US $\$ 100,000$ and above for various exploration and production activities starting from the 2013 calendar year (i.e. the year for which this dataset was first released).

\footnotetext{
${ }^{51}$ As the primary variable of interest has not been previously populated on a subscriber database, programming commands followed by a manual search on Excel and STATA was used to match USEITI listed companies and/or their subsidiaries making payments during the period of the investigation with companies' ticker symbol identifier provided by COMPUSTAT.
} 
As shown in Table 4.1, the initial sample comprised the 563 companies that made payments for the 2013 calendar year to the US government. All 428 companies that were not publicly listed were deleted. The 19 companies listed outside the US and the 6 that traded on the OTC were also dropped from the sample. To avoid double counting, 5 companies with dual unique permanent security identification numbers (PERMNO) were dropped from the sample (i.e. companies for which the parent and one or more subsidiaries made payments) since only one identifier data is available for such firms. In addition, 4 companies that had filed for bankruptcy, reorganisation or merged, and 6 other companies with missing price data on COMPUSTAT were also deleted. This resulted in a sample of 95 extractive companies that made payments to the US government for the 2013 calendar year (detail in Appendix K).

To ensure that a complete set of clean data is used for all the analyses, that is, that the companies in the sample were not subject to confounding news appearing at the same time as the release of the USEITI information, a search on FACTIVA52 was conducted for price-sensitive news related to the companies in the sample during the period 8 to 16 December 2014. The 15 companies found that had

\footnotetext{
52 Factiva is a business information and research tool owned by Dow Jones and Company. It aggregates content from both licensed and free sources, and provides search, alerting, dissemination, and other information management capabilities.
} 
confounding news during the period were further excluded.53 Thus, the final sample comprised 80 companies.

Table 4.1. Sample selection

\begin{tabular}{|c|c|c|}
\hline & & $N$ \\
\hline & Total number of companies & 563 \\
\hline Less: & Companies not publicly listed & 428 \\
\hline & Base sample & 135 \\
\hline Less: & Companies listed outside the US & 19 \\
\hline & Traded on OTC & 6 \\
\hline & Companies with double PERMNO & 5 \\
\hline & Filed for bankruptcy, reorganization or merged & 4 \\
\hline & Companies with missing price data on COMPUSTAT & 6 \\
\hline & & 95 \\
\hline & Companies with confounding news during the event period & 15 \\
\hline & Final Sample & 80 \\
\hline
\end{tabular}

${ }^{53}$ In addition to the two-factor regression estimation model employed to measure abnormal returns, several sensitivity tests to correct for firm-specific confounding news were conducted. First, a search for extreme (outlier) abnormal returns was done. Followed by a calculation of the mean and standard deviation for CAR during the event window- which is used to estimate the 'one standard deviation' away from the mean as the benchmark for outliers. Using this criterion, the sample was further filtered to separate companies with extreme (outlier) abnormal returns. This process identified 25 companies in the initial process. Second, following the above step, additional search was conducted for confounding news available on FACTIVA. Specifically, information relating to takeover, oil and gas discoveries, and other general price sensitive announcements for the sample of 25 companies was searched for. The exercise resulted in 14 of the 25 companies having confounding news during this period. Thirdly, given the high proportion of the 25 companies with confounding news (i.e. 56\%), additional search for all the other sample companies (i.e. all the 95 companies) for confounding news was also conducted. This comprehensive search revealed one additional company with confounding news, thus, bringing the total of companies with confounding news to 15 . The list of these companies is reported in Appendix L with an appended explanation of the process. Finally, these 15 companies were dropped from final test sample to minimise the possibility the companies unduly influenced the results. 
Table 4.2 gives the breakdown of the sample listed companies by payment category. As observed from the table, total payments by sample companies were approximately $\$$ US7.0 billion, comprising $57.31 \%$ of total payments made for the 2013 calendar year, which shows that a significant proportion of the payments were made by the sampled companies. In terms of the number of companies making payments in the different categories to the US government, the table shows that 75 of the 80 companies made payments for Royalties in the 2013 calendar year (representing 93.75 percent). The next highest payment categories are Rent and Bonus tied at 72 companies (representing 90 percent). Payments for Civil Penalties, Other Revenue and Inspection Fees were made by 35, 17 and 7 companies respectively (representing 43.75, 21.25 and 8.75 percent).

Data on the proved reserves of the companies and ownership structure (proxied as the percentage of directors' shareholding) were hand-collected from companies Form 10-K. The analysts' coverage data was accessed from IBES and daily trading data for individual securities and the indexes from CRSP/Stock/Security Files/Daily Stock Files database in WRDS. Data on other variables were obtained from COMPUSTAT.

The value relevance test was conducted on the 80 sample companies for the financial years 2013-2016. Taking only firm-year observations with complete values on the test variables and correcting for the influence of outliers in the 
sample (that is, excluding observations registering at the top and bottom 1\%), a final sample of 310 firm-year observations was obtained. 
Table 4.2. US Extractive companies' payments for 2013 (\$US)

\begin{tabular}{|c|c|c|c|c|c|}
\hline Revenue Type & $\begin{array}{c}\text { Payments by } \\
\text { Sample- Companies } \\
(N=80)\end{array}$ & $\begin{array}{c}\text { Total Payments } \\
\text { (All Companies) } \\
(N=563)\end{array}$ & $\begin{array}{c}\text { Percentage of } \\
\text { payments by Sample } \\
\text { Companies to total } \\
\text { payments }\end{array}$ & $\begin{array}{r}\text { Number of } \\
\text { companies } \\
\text { making } \\
\text { payments }\end{array}$ & $\begin{array}{r}\text { Percentage of } \\
\text { companies } \\
\text { making payment }\end{array}$ \\
\hline Royalties & 5353688222.39 & $9,846,027,319.72$ & 54.37 & 75 & 93.75 \\
\hline Rent & 159293624.04 & $290,439,898.10$ & 54.85 & 72 & 90.00 \\
\hline Bonus & 1482600574.44 & $2,079,690,467.26$ & 71.29 & 72 & 90.00 \\
\hline Civil Penalties & 1520450.00 & $5,668,138.90$ & 26.82 & 35 & 43.75 \\
\hline Inspection Fees & 17462080.11 & $53,246,992.07$ & 32.79 & 7 & 8.75 \\
\hline \multirow[t]{2}{*}{ Other Revenue } & 65756398.00 & $78,847,316.06$ & 83.40 & 17 & 21.25 \\
\hline & 7080321348.98 & $12,353,920,132.11$ & 57.31 & & \\
\hline
\end{tabular}

Definitions for each payment category:

Royalties are payments made by companies after they start producing extractive resources in paying quantities. The amount is based on a percentage of revenue from the extractive commodity sold. The rate for Royalties is set at $12.5 \%$ for onshore leases. While offshore rates vary between $12.5 \%, 16.67 \%$, and $18.75 \%$. Rent is the periodic payments made by a company for the right to continue exploration and development of the land for future natural resources production. Rent payment is usually for natural resource leases that are yet to produce commodities in paying quantities. Bonus is the amount paid by the highest successful bidder for a natural resource lease. That is, the one-off payment made for winning the bid. Civil penalties are payments made by companies for violation of laws applicable to natural resources extraction and production activities. Inspection fees are payments related to fees for annual inspections performed by the US Bureau of Safety and Environmental Enforcement on each offshore permanent structure and drilling rig that conducts drilling, completion, or workover operations. Other Revenue refer to payments that are not included in the royalty, rent, or bonus categories, such as minimum royalties, estimated royalties, settlement agreements, and interests. 


\subsection{Results}

\subsubsection{Reaction tests}

\subsubsection{Market reaction: Trading volume}

Tables $4.3 \mathrm{~A}$ and $4.3 \mathrm{~B}$ report the daily abnormal trading volume for each day of the period $(-4,4)$ and the cumulative abnormal trading volume for each of the event periods. The tables show that the daily and cumulative abnormal trading volume in all cases are statistically significant at conventional levels. Specifically, in Table 4.3A, the t-test for daily abnormal trading volume for each day during the event period is statistically significant at the $1 \%$ level, except for day $(-1)$ and the event day which is significant at $10 \%$ and $5 \%$ levels respectively. Table $4.3 \mathrm{~B}$ shows that the results for the cumulative abnormal trading volume are significant at the $1 \%$ level $^{54}$ and thus indicate abnormal trading volume around the time of the USEITI information release, in particular in the days following the release of the information.

However, the observed investor reaction does not necessarily indicate that the information provided was good news to investors as bad news could also initiate abnormal levels of trading. Bajo (2010) cautions that stock markets experience changes in trading volume which may not necessarily be driven by the introduction of new information. One possible explanation, especially in this situation, is the unconventional type and source of the information disclosure.

54 Test statistic calculated as described in Campbell and Wasley (1996). 
Thus, change in trading volume alone may be inadequate as a basis for inferences regarding market motivation.

Table 4.3A. Median Adjusted Abnormal Trading Volume ( $N=80$ )

\begin{tabular}{clll}
\hline Event Day & AVOL & t-test & CATVOL $(-4, \mathbf{T})$ \\
\hline-4 & 0.011 & $2.79^{* * *}$ & 0.011 \\
-3 & 0.010 & $2.40^{* * *}$ & 0.021 \\
-2 & 0.010 & $2.40^{* * *}$ & 0.031 \\
-1 & 0.007 & $1.76^{*}$ & 0.038 \\
0 & 0.009 & $2.17^{* *}$ & 0.047 \\
1 & 0.011 & $2.76^{* * *}$ & 0.058 \\
2 & 0.015 & $3.68^{* * *}$ & 0.073 \\
3 & 0.014 & $3.53^{* * *}$ & 0.087 \\
4 & 0.013 & $3.26^{* * *}$ & 0.100 \\
\hline ***,** and *indicating significance at levels of 1\%, 5\% \\
and 10\% respectively \\
\hline
\end{tabular}

Table 4.3B. Median Adjusted Cumulative Abnormal Trading Volume $(N=80)$

\begin{tabular}{ccc}
\hline Event period & CATVOL & t-test \\
\hline$-4,4$ & 0.100 & $5.66^{* * *}$ \\
$-3,3$ & 0.076 & $5.50^{* * *}$ \\
$-2,2$ & 0.052 & $5.26^{* * *}$ \\
$-1,1$ & 0.027 & $4.59^{* * *}$ \\
\hline ***,** and ${ }^{*}$ indicating significance at levels of $1 \%, 5 \%$ \\
and 10\% respectively \\
\hline
\end{tabular}

\subsubsection{Market reaction: Share price}

Table 4.4A shows the daily abnormal returns over the event period $(-4,4)$ and the cumulative abnormal returns over the period $(-4,4)$. The cumulative abnormal returns are plotted in Figure 4.2. Table 4.4B shows that the CAR was not statistically significant for the event period $(-1,1)$ but was statistically significant for each of the wider periods. ${ }^{55}$ As with the trading volume reaction,

55 Mackinlay (1997) suggest the use of non-parametric tests as a check of the robustness of
conclusions reached following parametric tests in market reaction studies. Accordingly, the non- 
the bulk of the price reaction occurred subsequent to the release of the information. One possible explanation for the minimal reaction prior to the release of the information is that this was the first release of the information.

Table 4.4A. Daily abnormal returns $(N=80)$

\begin{tabular}{cclc}
\hline Event Day & AR & t-test & CAR $(-4$, T) \\
\hline-4 & -0.04 & $2.83^{* * *}$ & -0.04 \\
-3 & 0.05 & $3.44^{* * *}$ & 0.01 \\
-2 & -0.01 & 0.63 & 0.00 \\
-1 & 0.00 & 0.13 & 0.00 \\
0 & 0.02 & 1.19 & 0.01 \\
1 & -0.01 & 0.83 & 0.00 \\
2 & 0.06 & $4.17^{* * *}$ & 0.06 \\
3 & 0.06 & $4.57^{* * *}$ & 0.13 \\
4 & -0.01 & 1.04 & 0.11 \\
\hline ***,** and * indicating significance at levels of 1\%, \\
$5 \%$ and 10\% respectively. \\
\hline
\end{tabular}

Table 4.4B. Cumulative abnormal returns by event period $(N=80)$

\begin{tabular}{ccc}
\hline Event Period & CAR & t-test \\
\hline$(-4,4)$ & 0.110 & $3.22^{* * *}$ \\
$(-3,3)$ & 0.160 & $5.44^{* * *}$ \\
$(-2,2)$ & 0.052 & $2.04^{* *}$ \\
$(-1,1)$ & 0.003 & 0.28 \\
\hline ***,** and * indicating significance at levels of $1 \%, 5 \%$ and \\
$10 \%$ respectively.
\end{tabular}

parametric test procedure developed in Corrado (1989) and Corrado and Zivney (1992) was applied but the results were qualitatively similar to those reported in Tables 4.4A and 4.4B. 


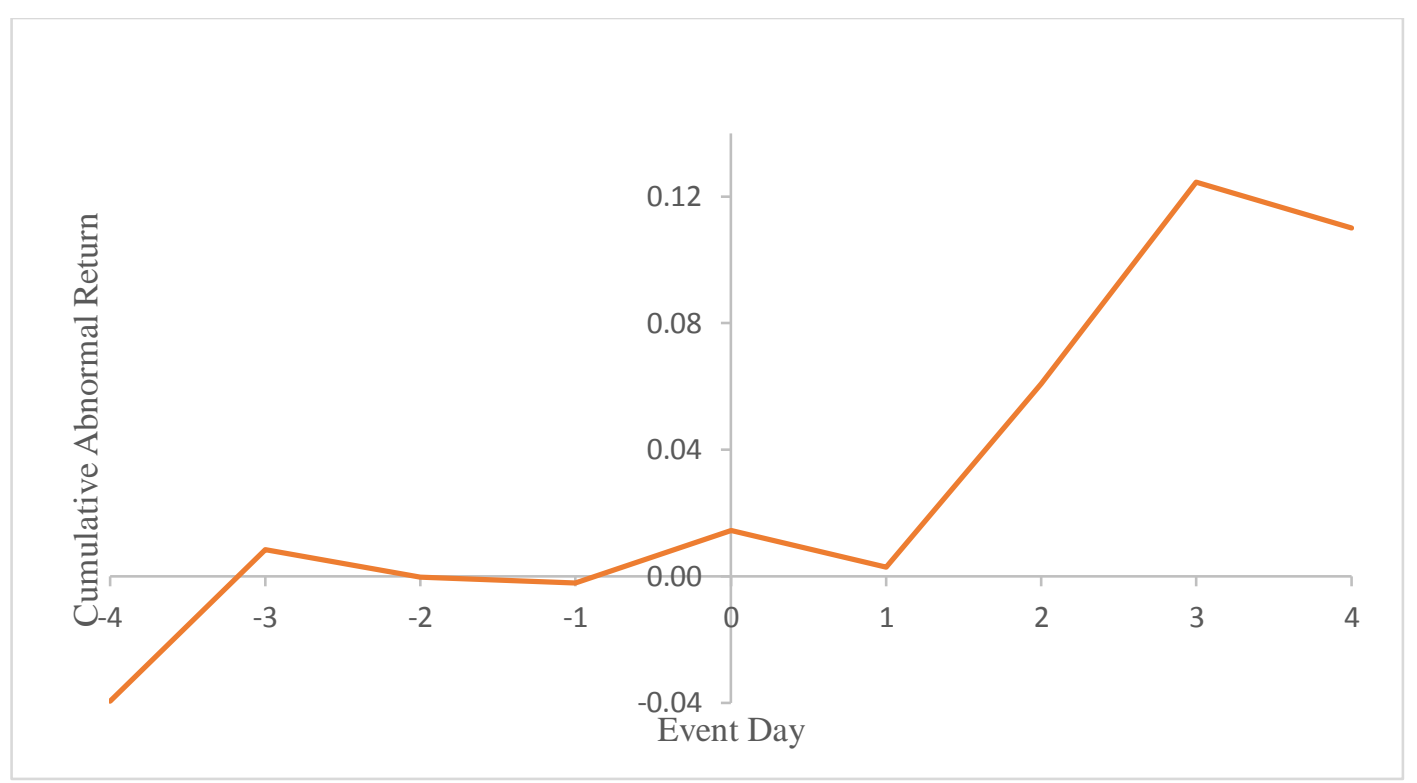

Figure 4.2. Plot of CAR for the event period $(-4,4)$

\subsection{Non-parametric test: Share price}

The results of the supplementary non-parametric tests are presented in Tables 4.4C and 4.4D. The results are qualitatively similar to the parametric tests in most respects. Thus, it validates the initial findings on price reaction conducted using the parametric tests. Specifically, Table $4.4 \mathrm{C}$ reports the t-test for each day abnormal returns using both the Rank and Sign non-parametric tests. As can be observed both tests show similar results for event days $-4,-3,2$, and 3 with statistical significance at conventional levels. Notably, the cumulative abnormal returns during the partitioned event period performed better under the nonparametric test. The rank test statistic performed better than parametric test for event window $(-1,1)$ shown in Table 4.4D when compared with the parametric result reported in Table 4.4B. 
Table 4.4C

Non-Parametric Rank and Sign significance test statistics $(N=80)$

\begin{tabular}{ccll}
\hline Event Day & AR & $\begin{array}{l}\text { Rank } \\
\text { t-test }\end{array}$ & $\begin{array}{l}\text { Sign } \\
\text { Test }\end{array}$ \\
\hline-4 & -0.04 & $2.199^{* *}$ & $2.392^{* *}$ \\
-3 & 0.05 & $2.292^{* *}$ & $2.900^{* * *}$ \\
-2 & -0.01 & 0.814 & 0.537 \\
-1 & 0.00 & 0.050 & 0.108 \\
0 & 0.02 & 0.935 & 0.999 \\
1 & -0.01 & 0.438 & 0.699 \\
2 & 0.06 & $2.483^{* *}$ & $3.514^{* * *}$ \\
3 & 0.06 & $2.518^{* * *}$ & $3.854^{* * *}$ \\
4 & -0.01 & 0.848 & 0.881 \\
\hline$* * *, * *$ and * indicating significance at levels of $1 \%, 5 \%$ and \\
$10 \%$ respectively \\
\hline
\end{tabular}

\section{Table 4.4D \\ Non-Parametric Rank significance test statistic across partitioned intervals $(N=80)$}

\begin{tabular}{lccl}
\hline Event Period & Interval & CAR & Rank t-test $^{56}$ \\
\hline December 8 -December 18, 2014 & $-4,4$ & 0.110 & $2.761^{* * *}$ \\
December 9 -December 17, 2014 & $-3,3$ & 0.160 & $2.203^{* *}$ \\
December 10 - December 16, 2014 & $-2,2$ & 0.052 & $2.769^{* * *}$ \\
December 11 - December 15, 2014 & $-1,1$ & 0.003 & $3.043^{* * *}$ \\
\hline
\end{tabular}

Significance levels are represented by ${ }^{* * *}, * *$ and $*$ at $1 \%, 5 \%$ and $10 \%$ respectively.

56 Extending Corrado and Zivney, (1992) single event day test Campbell and Wasley, (1993) provide a modified t-test for analyzing a multiday event period. This modification offers an implied formulation for defining the Rank-test taking into account the sum of the abnormal rank over the event window as below: $t_{\text {rank }}=\sqrt{L_{2}}\left(\frac{\bar{K}_{T_{1}, T_{2}}-0.5}{S_{\bar{K}}}\right)$,

Where

$\bar{K}_{T_{1}, T_{2}}=\frac{1}{L_{2}} \sum_{t=T_{1}+1}^{T_{2}} \bar{K}_{t}$ which is the mean rank across firms during the event period.

$S_{\bar{K}}=\sqrt{\frac{1}{L_{1}+L_{2}} \sum_{t=T_{0}}^{T_{2}} \frac{N_{t}}{N}\left(\bar{K}_{t}-0.5\right)^{2}}$.

$L_{1}$ and $L_{2}$ are the lengths of the estimation and event windows respectively.

While $N_{t}$ is the non-missing returns across firms and $N$ denotes the sample size (Müller, 2015). 
Overall, the findings suggest rejection of the null hypothesis of no significant market reaction to the release of this information. Thus, the results of the reaction studies, trading volume and price, provide support for the alternative hypothesis to $H 1$. That is, the release of the USEITI information evoked a reaction from the market and was regarded as good news. The reactions, volume and price, to the initial release thus suggests that the information had economic value for investors.

The economic significance of the price reaction can be interpreted as follows. The aggregate market value of the sample companies as at the event date was $\$ 1,267$ million (that is the aggregate of each company's outstanding common shares multiplied by share price on the event date) and thus the aggregate dollar amount of the abnormal return over the event period $(-4,4)$ is approximately $\$ 139$ million and over the event period $(-3,3)$ is $\$ 203$ million. ${ }^{57}$

\subsubsection{Cross-sectional variation in abnormal return}

This section reports on the degree to which cross-sectional variation in the price reaction is explained by (associated with) firm-specific characteristics. Specifically, analyses are conducted for each partition of the event period. Table 4.5A shows the descriptive statistics for the variables used in the cross-sectional variation analysis. In Panel A, the firms' standard deviation for stock returns shows low volatility across the estimation window with a mean (median) of

${ }^{57}$ Estimated as $0.110 \times \$ 1,267$ and $0.1160 \times \$ 1,267$ respectively. 
$0.027(0.024)$. The mean (median) book-to-market ratio of firms in the sample is 0.250 (0.646), indicating that, on average, the companies are valued at significantly more in the market than historical book value. Mean (median) leverage of the companies is $0.365(0.328)$ indicating that, on average, the firms do not have a high proportion of debt to total assets. Approximately 76 percent of the companies in the sample belongs to the oil and gas industry as indicated by the mean of the binary variable IND. This supports the inclusion of the US Oil and Gas industry index in estimating abnormal returns to control for industryspecific effects that could be driven by the oil and gas companies.

In terms of analysts' coverage, the mean (median) number of analysts following a firm is approximately 13 (12), while the most (least) followed firm in the sample has $39(0)$ analysts. It is not uncommon to find low or even no analyst coverage for (some) extractive firms. As acknowledged by Ferguson et al., (2011b) the number of analysts following non-extractive firms is about twice the number following extractive firms. One plausible explanation for this, as suggested by Bird et al., (2013), could be the extra technical skills required by traditional financial analysts to understand extractive firms' complex geological reports and accounting rules. The average percentage of shares held by board members is approximately $9 \%$, with the maximum (minimum) at 68 (near zero) percent. With regards to firms working capital, the mean (median) proportion of firms' working capital balance to total assets is $0.004(0.002)$. The asset turnover 
ratio mean (median) is $0.613(0.325)$ provides an indication of the sample firms management efficiency in generating revenue relative to assets.

In Panel B of Table 4.5A, the market capitalisation and proved exploration reserves of the sampled firms are reported. The mean (median) firm market value is approximately $\$ 20$ (\$3.8) billion. The spread indicates the presence of some very large and very small firms in the sample. The largest (smallest) firm capitalisation is approximately $\$ 388$ (7) billion. Proved reserves of the companies expressed in million barrels of oil equivalent (MMBOE) indicate a mean (median) of 117,354.40 (433.51), again indicating the presence of large and small firms. The capitalisation and reserves variables thus have extreme skewness and are therefore transformed using the inverse hyperbolic sine transformation (IHS) (Ehalaiye, Tippett, \& van Zijl, (2017)58. Panel A reports both variables in the transformed form. Market capitalisation has a mean (median) of 8.810 (8.955). For reserves the mean (median) value is 12.230 (13.673), thus indicating that, on average, the exploration and production companies sampled have positive prospect for future cash flow in line with the resource reserves held.

58 The inverse hyperbolic sine transformation (HIS) mitigates the limitation on the natural logarithm transformation in respect of negative and zero values. The IHS is defined at zero and can be interpreted in the same way as a standard logarithmic transforamtion (Burbidge, Magee, \& Robb, 1988; Laubscher, 1961). 
Table 4.5A. Descriptive statistics for cross-sectional analysis

\begin{tabular}{|c|c|c|c|c|c|c|c|c|}
\hline \multicolumn{9}{|c|}{ Panel A: Firm characteristics for cross-sectional regression } \\
\hline Variable & Obs. & Mean & Median & Std. Dev & Max & Min & p99 & p1 \\
\hline CAR11 & 80 & 0.003 & 0.008 & 0.072 & 0.135 & -0.336 & 0.135 & -0.336 \\
\hline CAR22 & 80 & 0.052 & 0.041 & 0.090 & 0.297 & -0.274 & 0.297 & -0.274 \\
\hline CAR33 & 80 & 0.164 & 0.128 & 0.167 & 0.866 & -0.271 & 0.866 & -0.271 \\
\hline CAR44 & 80 & 0.110 & 0.085 & 0.147 & 0.543 & -0.362 & 0.543 & -0.362 \\
\hline StdRET & 80 & 0.027 & 0.024 & 0.016 & 0.112 & 0.009 & 0.112 & 0.009 \\
\hline BTM & 80 & 0.250 & 0.646 & 4.155 & 4.905 & -31.831 & 4.905 & -31.831 \\
\hline$L E V$ & 80 & 0.365 & 0.328 & 0.266 & 1.747 & 0.000 & 1.747 & 0.000 \\
\hline MCAP & 80 & 8.810 & 8.955 & 2.144 & 13.563 & 2.604 & 13.563 & 2.604 \\
\hline$I N D$ & 80 & 0.763 & 1.000 & 0.428 & 1.000 & 0.000 & 1.000 & 0.000 \\
\hline RESERVE & 80 & 12.230 & 13.673 & 6.497 & 22.165 & 0.000 & 22.165 & 0.000 \\
\hline ANALYST & 80 & 13.400 & 12.000 & 10.132 & 39.000 & 0.000 & 39.000 & 0.000 \\
\hline Dir_SH & 80 & 9.036 & 1.450 & 16.756 & 68.960 & 0.000 & 68.960 & 0.000 \\
\hline$W C A P$ & 80 & 0.004 & 0.002 & 0.185 & 0.382 & -1.415 & 0.382 & -1.415 \\
\hline Asset_Turn & 80 & 0.613 & 0.325 & 1.378 & 12.126 & 0.000 & 12.126 & 0.000 \\
\hline
\end{tabular}

Panel B: Market capitalisation and proved reserves in USD and MMBOE respectively

\begin{tabular}{lcrrrrrrr} 
& Obs. & Mean & Median & Std. Dev & Max & Min & p99 & p1 \\
\hline MCAP (Million USD) & 80 & 20020.49 & 3877.75 & 53656.48 & 388382.50 & 6.72 & 388382.50 & 6.72 \\
RESERVE_MMBOE & 80 & 117354.40 & 433.51 & 404239.10 & 2113833.00 & 0.00 & 2113833.00 & 0.00
\end{tabular}




\section{Table 4.5A continued}

Variable definition: CAR11, CAR22, CAR33, and CAR44 are the cumulative abnormal returns for event periods $(-1,1),(-2,2),(-3,3)$ and $(-4,4)$ respectively across firms estimated using the two-factor market model based on equation (7). StdRET is the standard deviation of daily stock return during the estimation window (i.e. 120 days before the event period). BTM is the book-to-market ratio measured as book value per share scaled by market price per share. $L E V$ is the leverage measured as the summation of the short and long-term debt scaled by total assets. MCAP is market capitalisation used as proxy for size. The MCAP is transformed using the Inverse Hyperbolic Sine. IND is a dummy variable to check the effect of industry. The variable equals 1 if the company is an oil and gas firm and 0 otherwise. RESERVE is natural reserves expressed in million barrels of oil equivalent and transformed using the Inverse Hyperbolic Sine. ANALYST is the number of public equity financial analysts following a firm. This controls for stock market activity and is a monitoring mechanism for the firm. Dir_SH is directors' percentage of shareholding and is a measure of ownership structure. WCAP is the working capital balance and is measured as current assets minus current liabilities scaled by total assets. Asset_Turn is total sales scaled by total assets. 
Table 4.5B presents the pairwise correlation matrix of the variables which shows the strength and direction of the linear association existing between the variables employed in the cross-sectional analysis. Beginning with the event window $(-1$, 1) the correlation of CAR11 with the explanatory variables is significant at the 5\% level only with ANALYST. The correlation of event window $(-2,2)$ with the explanatory variables is significant at $5 \%$ only with IND. For the event window (3 , 3), the correlations with $B T M, L E V, M C A P$, and IND are statistically significant at the $5 \%$ level. Finally, for event window $(-4,4)$ the association of CAR44 with LEV, MCAP and IND are statistically significant at the 5\% level.

Overall, the associations of CAR33 and CAR44 with the explanatory variables suggest a reasonable fit. Variance inflation factor tests indicated that multicollinearity was not a problem for the regression tests. 
Table 4.5B. Pairwise correlation matrix for cross-sectional analysis

\begin{tabular}{|c|c|c|c|c|c|c|c|c|c|c|c|c|c|c|c|}
\hline & & 1 & 2 & 3 & 4 & 5 & 6 & 7 & 8 & 9 & 10 & 11 & 12 & 13 & 14 \\
\hline 1 & CAR11 & 1.00 & & & & & & & & & & & & & \\
\hline 2 & CAR22 & $0.81^{*}$ & 1.00 & & & & & & & & & & & & \\
\hline 3 & CAR33 & $0.54^{*}$ & $0.79^{*}$ & 1.00 & & & & & & & & & & & \\
\hline 4 & CAR44 & $0.69^{*}$ & $0.87^{*}$ & $0.92^{*}$ & 1.00 & & & & & & & & & & \\
\hline 5 & StdRET & -0.11 & -0.04 & -0.04 & -0.05 & 1.00 & & & & & & & & & \\
\hline 6 & BTM & 0.06 & 0.14 & $-0.29 *$ & -0.04 & -0.11 & 1.00 & & & & & & & & \\
\hline 7 & $L E V$ & -0.08 & 0.00 & $0.46^{*}$ & $0.22^{*}$ & 0.05 & $-0.76^{*}$ & 1.00 & & & & & & & \\
\hline 8 & $M C A P$ & 0.19 & -0.01 & $-0.38^{*}$ & $-0.24^{*}$ & -0.01 & $0.29 *$ & $-0.41^{*}$ & 1.00 & & & & & & \\
\hline 9 & $I N D$ & 0.19 & $0.29 *$ & $0.33^{*}$ & $0.27^{*}$ & 0.03 & -0.11 & -0.01 & 0.17 & 1.00 & & & & & \\
\hline 10 & RESERVE & -0.07 & 0.06 & 0.15 & 0.09 & 0.07 & -0.06 & 0.04 & -0.04 & -0.04 & 1.00 & & & & \\
\hline 11 & ANALYST & $0.23^{*}$ & 0.12 & -0.02 & -0.01 & -0.01 & 0.03 & -0.15 & $0.52^{*}$ & $0.28^{*}$ & $0.27^{*}$ & 1.00 & & & \\
\hline 12 & Dir_SH & -0.07 & 0.00 & 0.17 & 0.14 & 0.08 & -0.17 & $0.26^{*}$ & $-0.37^{*}$ & -0.14 & -0.07 & -0.20 & 1.00 & & \\
\hline 13 & WCAP & 0.13 & 0.18 & -0.16 & 0.04 & -0.06 & $0.77^{*}$ & $-0.51^{*}$ & $0.24^{*}$ & -0.18 & -0.17 & -0.07 & -0.12 & 1.00 & \\
\hline 14 & Asset_Turn & -0.09 & -0.14 & -0.10 & -0.07 & 0.20 & 0.00 & 0.01 & -0.06 & 0.06 & -0.22 & -0.13 & $0.26^{*}$ & 0.17 & 1.00 \\
\hline
\end{tabular}

*Significance level at $5 \%$

Variable definition: CAR11, CAR22, CAR33, and CAR44 are the cumulative abnormal returns for event periods $(-1,1),(-2,2),(-3,3)$ and $(-4,4)$ respectively across firms estimated using the two-factor market model based on equation (7). StdRET is the standard deviation of daily stock return during the estimation window (i.e. 120 days before the event period). BTM is the book-to-market ratio measured as book value per share scaled by market price per share. $L E V$ is the leverage measured as the summation of the short and long-term debt scaled by total assets. MCAP is market capitalisation used as proxy for size. The MCAP is transformed using the Inverse Hyperbolic Sine. IND is a dummy variable to check the effect of industry. The variable equals 1 if the company is an oil and gas firm and 0 otherwise. RESERVE is natural reserves expressed in million barrels of oil equivalent and transformed using the Inverse Hyperbolic Sine. ANALYST is the number of public equity financial analysts following a firm. This controls for stock market activity and is a monitoring mechanism for the firm. Dir_SH is directors' percentage of shareholding and is a measure of ownership structure. WCAP is the working capital balance and is measured as current assets minus current liabilities scaled by total assets. Asset_Turn is total sales scaled by total assets. 
The results of the multivariate regression analyses are reported in Table 4.5C. Focusing on the event period $(-3,3)$, the results show that leverage (LEV), market capitalisation (MCAP), the industry of firms (IND), proved exploration reserves (RESERVE), working capital (WCAP) and asset turnover (Asset_Turn) all had a significant association with the market price reaction. Specifically, the coefficient on $L E V$ suggests that the positive abnormal returns noted in the event study tests were more for firms with higher debt financing. The results also indicate that the market reacted more strongly to smaller firms. This perhaps suggests that the information released for small firms, with sparse information on their exploration activities, would provide the market with partial resolution of information asymmetry between the firms and investors (Bird et al., 2013). On the other hand, investors in large firms would likely have access to other information channels. The coefficient on IND is positive and significant indicating that market participants reacted more positively to firms in the oil and gas industry.

The coefficient on proved RESERVES is also positive but only weakly significant. The coefficients on WCAP and Asset_Turn are both significant but while the coefficient on WCAP is positive the sign on that for Asset_Turn is negative. This suggests that firms with higher working capital balance to total assets ratio and firms with lower sales to total assets ratio had a more positive reaction to the release of the information. 
Table 4.5C. The US sampled extractive companies' cross-sectional results for main and partitioned event intervals

\begin{tabular}{|c|c|c|c|c|c|c|c|c|c|c|c|c|}
\hline \multirow[b]{2}{*}{ Variable } & \multicolumn{3}{|c|}{$\begin{array}{c}\text { Model (1) } \\
\text { Window }(-4,4)\end{array}$} & \multicolumn{3}{|c|}{$\begin{array}{c}\text { Model }(2) \\
\text { Window }(-3,3)\end{array}$} & \multicolumn{3}{|c|}{$\begin{array}{c}\text { Model (3) } \\
\text { Window }(-2,2)\end{array}$} & \multicolumn{3}{|c|}{$\begin{array}{c}\text { Model }(4) \\
\text { Window }(-1,1)\end{array}$} \\
\hline & Coeff. & t-value & $\operatorname{Pr}>/ t /$ & Coeff. & t-value & $\operatorname{Pr}>/ t /$ & Coeff. & t-value & $\operatorname{Pr}>/ t /$ & Coeff. & t-value & $\operatorname{Pr}>/ t /$ \\
\hline Intercept & 0.060 & 0.340 & 0.736 & 0.117 & 0.710 & 0.479 & -0.004 & -0.040 & 0.972 & -0.014 & -0.130 & 0.895 \\
\hline StdRET & -0.296 & -0.500 & 0.618 & -0.533 & -0.960 & 0.342 & 0.047 & 0.130 & 0.894 & -0.398 & -1.310 & 0.193 \\
\hline BTM & 0.005 & 0.660 & 0.514 & -0.001 & -0.120 & 0.901 & 0.003 & 0.560 & 0.579 & -0.004 & -1.090 & 0.279 \\
\hline$L E V$ & 0.198 & 1.320 & 0.190 & 0.285 & 2.100 & $0.039 * *$ & 0.074 & 0.790 & 0.433 & -0.013 & -0.160 & 0.874 \\
\hline MCAP & -0.018 & -1.190 & 0.238 & -0.027 & -1.820 & $0.073^{*}$ & -0.006 & -0.630 & 0.534 & 0.001 & 0.080 & 0.939 \\
\hline$I N D$ & 0.140 & 3.900 & $0.000 * * *$ & 0.179 & 5.660 & $0.000 * * *$ & 0.085 & 3.870 & $0.000 * * *$ & 0.030 & 1.450 & 0.152 \\
\hline RESERVE & 0.002 & 1.290 & 0.201 & 0.004 & 1.970 & $0.052^{*}$ & 0.001 & 0.590 & 0.555 & -0.001 & -0.860 & 0.392 \\
\hline ANALYST & 0.001 & 0.490 & 0.624 & 0.001 & 0.780 & 0.438 & 0.001 & 1.060 & 0.293 & 0.002 & 1.640 & 0.105 \\
\hline Dir_SH & 0.001 & 1.100 & 0.274 & 0.001 & 1.040 & 0.301 & 0.001 & 0.790 & 0.432 & 0.000 & 0.410 & 0.683 \\
\hline$W C A P$ & 0.250 & 2.990 & $0.004^{* * *}$ & 0.290 & 3.260 & $0.002^{* * *}$ & 0.188 & 3.210 & $0.002^{* * *}$ & 0.139 & 3.110 & $0.003^{* * *}$ \\
\hline Asset_Turn & -0.018 & -2.500 & $0.015^{* *}$ & -0.022 & -3.320 & $0.001^{* * *}$ & -0.016 & -3.450 & $0.001^{* * *}$ & -0.008 & -1.970 & $0.053^{*}$ \\
\hline R-Squared & 0.30 & & & 0.50 & & & 0.26 & & & 0.15 & & \\
\hline Observations & 80 & & & 80 & & & 80 & & & 80 & & \\
\hline
\end{tabular}

$* * *, * *$ and ${ }^{*}$ denotes significance at $1 \%, 5 \%$ and $10 \%$ respectively.

This table presents results of the OLS regressions based on equation (4.22) across the main and partitioned event windows. The estimation regression is as follows:

$$
\begin{aligned}
& \operatorname{CAR}_{(t 1-t n)}=\beta_{0}+\beta_{1} \operatorname{StdRET}_{i}+\beta_{2} \text { BTM }_{i}+\beta_{3} L E V_{i}+\beta_{4} M C A P_{i}+\beta_{5} I N D_{i}+\beta_{6} R E S E R V E_{i}+\beta_{7} A N A L Y S T_{i}+\beta_{8} D_{i r} S H_{i}+\beta_{9} W C A P_{i} \\
& +\beta_{10} \text { Asset_Turn }_{i}+\varepsilon_{i}
\end{aligned}
$$

Variable definition: CAR11, CAR22, CAR33, and CAR44 are the cumulative abnormal returns for event periods $(-1,1),(-2,2),(-3,3)$ and $(-4,4)$ respectively across firms estimated using the two-factor market model based on equation (7). StdRET is the standard deviation of daily stock return during the estimation window (i.e. 120 days before the event period). BTM is the book-to-market ratio measured as book value per share scaled by market price per share. $L E V$ is the leverage measured as the summation of the short and long-term debt scaled by total assets. MCAP is market capitalisation used as proxy for size. The MCAP is transformed using the Inverse Hyperbolic Sine. IND is a dummy variable to check the effect of industry. The variable equals 1 if the company is an oil and gas firm and 0 otherwise. RESERVE is natural reserves expressed in million barrels of oil equivalent and transformed using the Inverse Hyperbolic Sine. ANALYST is the number of public equity financial analysts following a firm. This controls for stock market activity and is a monitoring mechanism for the firm. Dir_SH is directors' percentage of shareholding and is a measure of ownership structure. WCAP is the working capital balance and is measured as current assets minus current liabilities scaled by total assets. Asset_Turn is total sales scaled by total assets. 
Comparison of the results for the period $(-3,3)$ with the results for the periods $(-$ $4,4)$ and $(-2,2)$ show for the later periods a much lower $\mathrm{R}^{2}$ and only IND, WCAP and Asset_Turn had a significant impact of the price reaction. The result for the period $(-1,1)$ shows a still lower $\mathrm{R}^{2}$ and only WCAP and Asset_Turn had a significant impact.

To test the possible impact of the categories of the payment made by the extractive companies to the US government, additional analyses were conducted. In these supplementary tests, reported in Table 4.5D, the regression models estimated in Table 4.5C were rerun with dummy variables for each payment category. The coefficients for each of the dummy variables were significant only for Bonus at the $10 \%$ level in Models 6 and 8 . However, the results for all the other variables remained qualitatively similar to those reported in Table 4.5C.

Thus, taking an overall view of the regression results for the four partitions of the event period suggests that the price reaction to the release of the payments information by the US Department of the Interior is most strongly associated with IND, WCAP and Asset_Turn. 
Table 4.5D. US sampled extractive companies' cross-sectional results for main and partitioned event interval with payment categories

\begin{tabular}{|c|c|c|c|c|c|c|c|c|c|c|c|c|}
\hline \multirow[b]{2}{*}{ Variable } & \multicolumn{3}{|c|}{$\begin{array}{c}\text { Model }(5) \\
\text { Window }(-4,4)\end{array}$} & \multicolumn{3}{|c|}{$\begin{array}{c}\text { Model }(6) \\
\text { Window }(-3,3)\end{array}$} & \multicolumn{3}{|c|}{$\begin{array}{c}\text { Model }(7) \\
\text { Window }(-2,2)\end{array}$} & \multicolumn{3}{|c|}{$\begin{array}{c}\text { Model }(8) \\
\text { Window }(-1,1)\end{array}$} \\
\hline & Coeff. & t-value & $\operatorname{Pr}>/ t /$ & Coeff. & t-value & $\operatorname{Pr}>/ t /$ & Coeff. & t-value & $\operatorname{Pr}>/ t /$ & Coeff. & t-value & $\operatorname{Pr}>/ t /$ \\
\hline Intercept & 0.005 & 0.030 & 0.979 & 0.045 & 0.230 & 0.822 & -0.036 & -0.260 & 0.793 & -0.018 & -0.150 & 0.880 \\
\hline StdRET & -0.295 & -0.470 & 0.642 & -0.278 & -0.480 & 0.630 & 0.070 & 0.160 & 0.871 & -0.485 & -1.410 & 0.163 \\
\hline BTM & 0.006 & 0.770 & 0.443 & 0.001 & 0.140 & 0.888 & 0.003 & 0.640 & 0.522 & -0.003 & -0.800 & 0.427 \\
\hline$L E V$ & 0.249 & 1.460 & 0.148 & 0.356 & 2.270 & $0.026^{* *}$ & 0.106 & 0.970 & 0.333 & 0.001 & 0.010 & 0.992 \\
\hline МСAP & -0.021 & -1.200 & 0.234 & -0.033 & -1.900 & $0.062^{*}$ & -0.008 & -0.640 & 0.523 & 0.000 & 0.020 & 0.988 \\
\hline IND & 0.132 & 3.160 & $0.002^{* * *}$ & 0.175 & 4.700 & $0.000^{* * *}$ & 0.085 & 3.300 & $0.002^{* * *}$ & 0.027 & 1.160 & 0.251 \\
\hline RESERVE & 0.001 & 0.540 & 0.592 & 0.002 & 0.780 & 0.441 & 0.000 & 0.110 & 0.916 & -0.001 & -0.890 & 0.374 \\
\hline ANALYST & 0.002 & 0.890 & 0.376 & 0.002 & 1.180 & 0.241 & 0.001 & 1.210 & 0.231 & 0.002 & 1.670 & 0.100 \\
\hline Dir_SH & 0.001 & 0.600 & 0.548 & 0.001 & 0.500 & 0.620 & 0.000 & 0.410 & 0.684 & 0.000 & 0.070 & 0.942 \\
\hline$W C A P$ & 0.244 & 2.420 & $0.018^{* *}$ & 0.300 & 2.720 & $0.008^{* * *}$ & 0.189 & 2.720 & $0.008^{* * *}$ & 0.112 & 2.230 & $0.029^{* *}$ \\
\hline Asset_Turn & -0.022 & -3.120 & $0.003^{* * *}$ & -0.024 & -3.330 & $0.001^{* * *}$ & -0.019 & -4.100 & $0.000^{* * *}$ & -0.009 & -2.800 & $0.007^{* * *}$ \\
\hline Royalties & 0.144 & 1.140 & 0.258 & 0.130 & 0.990 & 0.325 & 0.078 & 1.070 & 0.288 & 0.049 & 0.910 & 0.365 \\
\hline Rent & 0.024 & 0.760 & 0.449 & 0.006 & 0.190 & 0.853 & -0.002 & -0.120 & 0.907 & 0.005 & 0.190 & 0.850 \\
\hline Bonus & 0.042 & 1.220 & 0.227 & 0.054 & 1.720 & $0.090^{*}$ & 0.028 & 1.350 & 0.181 & 0.030 & 1.870 & $0.066^{*}$ \\
\hline Civil_Penalties & 0.006 & 0.130 & 0.901 & 0.020 & 0.400 & 0.693 & -0.007 & -0.260 & 0.797 & 0.003 & 0.120 & 0.905 \\
\hline Inspection_Fees & 0.036 & 0.800 & 0.428 & 0.047 & 0.980 & 0.332 & 0.018 & 0.530 & 0.600 & 0.007 & 0.270 & 0.785 \\
\hline Other_Revenue & -0.122 & -1.340 & 0.184 & -0.061 & -0.690 & 0.494 & -0.052 & -0.940 & 0.353 & -0.062 & -1.350 & 0.181 \\
\hline R-Squared & 0.36 & & & 0.55 & & & 0.30 & & & 0.22 & & \\
\hline Observations & 80 & & & 80 & & & 80 & & & 80 & & \\
\hline
\end{tabular}

***, ${ }^{* *}$ and $*$ denotes significance at $1 \%, 5 \%$ and $10 \%$ respectively.

This table presents results of the OLS regressions based on a modified version of equation (4.22) across the main and partitioned event windows. The estimation regression is as follows: 


\title{
Table 4.5D continued
}

\author{
$\operatorname{CAR}_{(t 1-t n)}=\beta_{0}+\beta_{1} \operatorname{StdRET}_{i}+\beta_{2}$ BTM $_{i}+\beta_{3} L E V_{i}+\beta_{4}$ MCAP $_{i}+\beta_{5}{I N D D_{i}}+\beta_{6}$ RESERVE $_{i}+\beta_{7} A N A L Y S T_{i}+\beta_{8}$ Dir $_{-} S H_{i}+\beta_{9} W_{C A P_{i}}$ \\ $+\beta_{10}$ Asset_Turn $_{i}+\beta_{11}$ Royalties $_{i}+\beta_{12}$ Rent $_{i}+\beta_{13}$ Bonus $_{i}+\beta_{14}$ Civil_Penalties $_{i}+\beta_{15}$ Inspection_Fees $_{i}+\beta_{16}$ Other_Revenue ${ }_{i}$ \\ $+\varepsilon_{i}$
}

Variable definition: CAR11, CAR22, CAR33, and CAR44 are the cumulative abnormal returns for event periods $(-1,1),(-2,2),(-3,3)$ and $(-4,4)$ respectively across firms estimated using the two-factor market model based on equation (7). StdRET is the standard deviation of daily stock return during the estimation window (i.e. 120 days before the event period). BTM is the book-to-market ratio measured as book value per share scaled by market price per share. $L E V$ is the leverage measured as the summation of the short and long-term debt scaled by total assets. $M C A P$ is market capitalisation used as proxy for size. The MCAP is transformed using the Inverse Hyperbolic Sine. IND is a dummy variable to check the effect of industry. The variable equals 1 if the company is an oil and gas firm and 0 otherwise. RESERVE is natural reserves expressed in million barrels of oil equivalent and transformed using the Inverse Hyperbolic Sine. ANALYST is the number of public equity financial analysts following a firm. This controls for stock market activity and is a monitoring mechanism for the firm. Dir_SH is directors' percentage of shareholding and is a measure of ownership structure. WCAP is the working capital balance and is measured as current assets minus current liabilities scaled by total assets. Asset_Turn is total sales scaled by total assets. Royalties is a dummy variable that denotes 1 if the company paid royalties during the sample period and 0 otherwise. Rent is dummy variable that denotes 1 if the company made payments for rent during the sample period and 0 otherwise. Bonus is a dummy variable that denotes 1 if the company paid bonus during the sample period and 0 otherwise. Civil_Penalties is dummy variable that denotes 1 if the company paid any civil penalty during the sample period and 0 otherwise. Inspection_Fees is a dummy variable that denotes 1 if the company paid any inspection fees during the sample period and 0 otherwise. Other_Revenue is a dummy variable that denotes 1 if the company made any other payments to the US government for exploration and production of extractive resources during the sample period and 0 otherwise. 


\subsubsection{Value relevance analysis}

The Collins et al., (1999) adaptation of the Ohlson (1995) model was employed to examine the value relevance of the continuing disclosure of the USEITI information. Over the entire sample period 2013-2016, the study utilised a sample of 310 firm-year observations. Table 4.6A provides descriptive statistics for firm-specific characteristics employed in the value relevance analysis.

The mean (median) share price $(P)$ is $\$ 36.79(\$ 26.24)$, with a maximum and minimum of $\$ 151.21$ and $\$ 0.04$ respectively. The mean (median) value of Book Value per Share $\left(B V P S_{t-1}\right)$ at the beginning-of-year is $\$ 20.59(\$ 16.71)$ with a maximum (minimum) of $\$ 77.92$ (\$-20.25). Earnings per Share (EPS) mean (median) value is $\$-1.16$ (\$0.42) with maximum (minimum) $\$ 10.21$ (\$-35.55). The minimum book value per share and difference between the mean and median EPS indicate a skewed distribution for earnings with some companies making large losses. The mean (median) value of the USEITI payments per share $\left(E I T I \_O S\right)$ is $\$ 0.33(\$ 0.05)$ with maximum (minimum) $7.67(0.00)$. The distribution of EITI_OS is consistent with the payments data shown in Table 4.2. 
Table 4.6A. Descriptive statistics for value relevance analysis

\begin{tabular}{lrrrrrrrr}
\hline \multicolumn{1}{l}{ Firm variables used in valuation analysis } \\
Variable & Obs. & Mean & Median & Std. Dev. & Maximum & Minimum & P99 & P1 \\
\hline$P$ & 310 & 36.79 & 26.24 & 34.69 & 151.21 & 0.04 & 151.21 & 0.04 \\
$B V P S_{t-1}$ & 310 & 20.59 & 16.71 & 17.51 & 77.92 & -20.25 & 77.92 & -20.25 \\
$E P S$ & 310 & -1.16 & 0.42 & 6.85 & 10.21 & -35.55 & 10.21 & -35.55 \\
EITI_OS & 310 & 0.33 & 0.05 & 0.99 & 7.67 & 0.00 & 7.67 & 0.00 \\
\hline
\end{tabular}

Variable definition: $P$ is share price as at 30 June each year. $B V P S_{t-1}$ is firms' book value per share at the beginning-of-year. EPS is earnings per share basic excluding extraordinary items. EITI_OS is the USEITI information disclosure measured as the aggregate payment made each year by each extractive company to the US government for the exploration of natural resources and scaled by the company's outstanding common shares.

Table 4.6B presents the correlation matrix for the variables employed in the value relevance test. The table shows that there is a positive and significant relationship between share price and book value, and also between share price and EPS. The relationship between share price and the USEITI information is negative but not significant. However, the relationships need to be considered in a multivariate setting.

Table 4.6B. Correlation matrix for the value relevance analysis

\begin{tabular}{l|llll}
\hline \multicolumn{1}{c}{} & $P$ & BVPSt1 & EPS & EITI_OS \\
\hline$P$ & 1.00 & & & \\
$B V P S_{t-1}$ & $0.65^{*}$ & 1.00 & & \\
EPS & $0.31^{*}$ & 0.03 & 1.00 & \\
EITI_OS & -0.06 & -0.05 & $-0.35^{*}$ & 1.00 \\
\hline$* 5 \%$ level of Significan & & &
\end{tabular}

$* 5 \%$ level of significance

Variable definitions: $P$ is share price as at 30 June each year. $B V P S_{t-1}$ is book value per share at the beginning-of-year. EPS is basic earnings per share excluding extraordinary items. EITI_OS is the US Extractive Industries Transparency Initiative information disclosure measured as the aggregate payment made each year by each extractive company to the US government for the exploration of natural resources scaled by the company's outstanding common shares. 
Table 4.6C presents two variants of the value relevance test model. The results for Model 1, reports the base model regression using $B V P S_{t-1}$ and $E P S$ data only. The coefficient (p-value) for $B V P S_{t-1}$ is $1.280(0.000)$ and for EPS is 1.460 (0.000); both are positive and statistically significant at the $1 \%$ level. The impact of $B V P S_{t-1}$ and EPS is consistent with other value relevance studies (Chapple, Clarkson, \& Gold, 2013; Clarkson, Li, Pinnuck, \& Richardson, 2015). Book value per share and earnings per share of the firms jointly explain $51 \%$ of the variation in share price.

For Model 2, the coefficient on EITI_OS (i.e. the other information) is positive and significant at the $5 \%$ level (i.e. coefficient $=2.952$; $p$-value $=0.047$ ). The result thus supports the alternative hypothesis that the release of the USEITI information is value relevant and it is consistent with the price reaction result. The value relevance result can be interpreted in terms of economic significance as follows. One standard deviation increase in EITI_OS $(=0.99$, Table 4.6A) would lead to an increase of $\$ 2.92$ (i.e. $0.99 \times 2.952$ (the coefficient on EITI_OS)) in share price - which evaluated at the mean equals an increase of $7.9 \%$. 
Table 4.6C. Value relevance regression results

\begin{tabular}{lrrlrrrr}
\hline & \multicolumn{3}{c}{ Model 1 } & & \multicolumn{3}{c}{ Model 2 } \\
\cline { 1 - 3 } \cline { 5 - 7 } Variable & Coeff. & value & Pr $>/ \mathbf{t} /$ & & Coeff. & t-value & Pr $>/ \mathbf{t} /$ \\
\hline Intercept & 12.143 & 5.640 & $0.000^{* * *}$ & & 11.207 & 5.110 & $0.000^{* * *}$ \\
$B V P S_{t-1}$ & 1.280 & 16.190 & $0.000^{* * *}$ & & 1.286 & 16.330 & $0.000^{* * *}$ \\
EPS & 1.460 & 7.220 & $0.000^{* * *}$ & & 1.608 & 7.500 & $0.000^{* * *}$ \\
EITI_OS & & & & & 2.952 & 1.990 & $0.047^{* *}$ \\
R-Squared & 0.51 & & & & 0.52 & & \\
Observations & 310 & & & & 310 & & \\
\hline
\end{tabular}

${ }^{* * *}, * *$ and ${ }^{*}$ denotes significance at $1 \%, 5 \%$ and $10 \%$ respectively.

This table presents results from estimation of equation (4.23):

$$
P=\gamma_{0}+\gamma_{1} B V P S_{t-1}+\gamma_{2} E P S_{t}+\gamma_{3} E I T I_{-} O S_{t}+\varepsilon .
$$

$P$ is firm's share price as at 30 June each year. $B V P S_{t-1}$ is book value per share at the beginning-of-year. EPS is basic earnings per share excluding extraordinary items. EITI_OS is the US Extractive Industries Transparency Initiative Information measured as the aggregate payment made each year by each extractive company to the US government for the exploration of natural resources scaled by the company's outstanding common shares.

\subsection{Summary and conclusion}

In this chapter, I used data from the USEITI unilateral disclosure is used to illustrate the economic value of EITI information disclosure. The study utilised two distinct but related methods to assess the market impact of the USEITI unilateral information disclosure. First, the study tested for market reaction in terms of change in trading volume and share price. The results show that the USEITI disclosure produced both trading volume and price reactions indicating that the finer disclosure had information content relevant to the price setting. The results showed a volume reaction and a positive price reaction. As with the change in trading volume, the price reaction occurred mainly after the release of the information. The price reaction is most strongly associated with IND, WCAP and Asset_Turn. 
Secondly, the chapter assessed the value relevance of the USEITI information and found the USEITI information to be positively associated with the share price of the extractive firms and thus (value relevant). This result, taken together with the reaction tests, suggests that the information released had value at first release and that subsequent releases continued to provide additional value. To put it succinctly, all the tests conducted in this chapter reflect that fact that the information content of the USEITI information disclosed as part of the EITI implementation regime in the US had economic value. 


\section{CHAPTER FIVE}

\section{CONCLUSIONS AND IMPLICATIONS FOR FUTURE RESEARCH}

\subsection{Introduction}

In this thesis, I investigated the effectiveness of the EITI from two standpoints. First, based on country-level tests I investigated the impact of EITI implementation experience on the perceived control of corruption in EITI implementing countries. Secondly, using company-level data from the US extractive industries, I examined the information disclosed under the USEITI implementation regime to illustrate the economic value of information disclosed under the EITI.

This chapter proceeds as follows. Section 5.2 presents a summary of the results of the empirical tests. Section 5.3 outlines the contributions, and implications of the study. Section 5.4 discusses the limitations of the study. Finally, Section, 5.5 offers suggestions for future research. 


\subsection{Summary of findings}

\subsubsection{Summary of findings: The first two research questions}

\subsubsection{Chapter Three: Research question one}

Is EITI implementation experience associated with improved control of corruption in all implementing countries taken together?

Analysis of the data on the sample of 51 countries implementing the EITI Standards as at 2016 shows that the implementation experience of EITI countries taken together is not associated with improved control of corruption. The coefficient and p-value on EITI implementation experience (EXP), show that it is negatively associated with the Control of Corruption Index (CCI) and statistically significant at conventional levels in all specifications. Thus, the results did not support Hypothesis one. The finding is similar to that of prior studies investigating the effect of the EITI on country-level corruption (Corrigan, 2014; Kasekende et al., 2016; Öge, 2016; Ölcer, 2009).

\subsubsection{Chapter Three: Research question two}

Does the effect of EITI implementation experience on the perceived control of corruption vary across implementing countries?

The second question aimed to determine if there was variation in implementation benefits across countries implementing the EITI Standards. The results of the analyses show that Sub-Saharan African countries have a lesser 
negative association with implementation experience. Specifically, the coefficient on the interaction term $E X P^{*} S S A$ (and $E X P^{*} H I P C$ ) was positive and statistically significant. The results indicate that the effect of implementation experience is not uniform across all countries. The finding is thus consistent with Hypothesis two.

\subsubsection{Summary of findings: The second two research questions}

\subsubsection{Chapter Four: Research question one}

Did the initial release of non-tax payment made by extractive companies to the United States government evoke market reactions?

To address this question two market reaction tests were conducted viz, trading volume and price reaction followed by cross-sectional regression analyses of the variation in the price reaction. The results from the trading volume tests indicated abnormal trading volume around the days of the release of this information. The results of the price reaction tests show that the investors took notice of the information and considered it to be good news.

The cross-sectional regression analyses to assess the variation in abnormal returns show that firms working capital (WCAP) and asset turnover (Asset_Turn) had a significant effect on the price reaction. The coefficient on WCAP was positive and the sign on Asset_Turn was negative, with both statistically significant at conventional levels across all partitions of the event period. Thus, 
all sampled firms with higher working capital balance to total assets ratio and lower sales to total assets ratio had greater positive reaction to the release of the USEITI information.

\subsubsection{Chapter Four: Research question two}

What is the value relevance of USEITI information disclosure?

This is tested using the Collins et al., (1999) adaption of Ohlson (1995) model. The results indicate that the USEITI information is value relevant over the period 2013-2016. Specifically, the coefficient on EITI_OS (i.e. the other information) is positive and significant at the $5 \%$ level (coefficient $=2.952$ and $\mathrm{p}$-value $=0.047$ ) In terms of economic significance, this result shows that a standard deviation increase in EITI_OS ( $=0.99$ in Table $4.6 A$ ) would lead to an increase of $\$ 2.92$ (i.e. $0.99 \times 2.952$ ) in share price, which evaluated at the mean equals an increase of $7.9 \%$.

Taken together, the tests of market reaction and value relevance provide empirical evidence on the economic value of the USEITI information disclosure both at the initial 2013 calendar year release, and the continuing disclosure to 2016. 


\subsection{Contributions of the study}

This study fills significant gaps in the literature on the effectiveness of the EITI.

Firstly, the study documents the effect of EITI implementation experience on the reduction of perceived level of corruption in EITI implementing countries. In contrast to previous studies, which have focused more on the factors leading countries to join the EITI, this study has examined the real effect of countries' EITI commitment and implementation. The results of the tests indicate that implementation experience is negatively associated with control of corruption, but that impact varies across countries. In particular, the impact is less for SubSaharan African countries.

Secondly, this study provides the first empirical evidence on the economic value of the EITI information disclosure, using the USEITI as an illustration. Specifically, this study is first to examine how EITI information disclosure affects extractive companies in implementing countries, which has been absent in the EITI literature due to the unavailability of data in the past. In fact, the study provides the first evidence that investors indeed pay attention to EITI information disclosure in respect of extractive companies in the US. The attention is evident from abnormal trading volume and from the abnormal cumulative returns indicative that the information is regarded as good news. 
Thirdly, the tests for value relevance indicate that the USEITI disclosure is value relevant.

Finally, the study contributes to the financial information disclosure literature. Specifically, the study provides insight into the implication of the release of corporate information unilaterally by a government agency to third parties in the market. This study enriches the aspect of financial reporting literature that is sparse on unilateral financial information release. Additionally, the policy implication of the result is that government disclosure of information can usefully add to the level of information resulting from voluntary disclosure.

\subsection{Limitations of the study}

As with most corruption-based research, the data employed for the measurement of corruption reflects the perception of corruption rather than actual corruption. Furthermore, the Control of Corruption Index was the only measure used in the empirical tests. The measure certainly has limitations (Heywood, 2015) but no alternative measures that are consistent across the study period.

Secondly, the information used to illustrate the economic value of EITI information is from a large well-functioning capital market, the US, and thus the 
inferred value may not apply in countries with a less well-functioning capital market.

\subsection{Future research}

This study has examined aspects of the EITI that are identifiable at the time of this study. Moving forward, more specific country level investigation should become feasible as implementing countries become more open with the information produced and researchers begin to assess the actual quality of information produced. This could be extended to the examination of factors driving any variation in the quality of the information across countries. 


\section{References}

Aaronson, S. A. (2011). Limited partnership: Business, government, civil society, and the public in the Extractive Industries Transparency Initiative (EITI). Public Administration and Development, 31, 50-63. https://doi.org/10.1002/pad.588

Akerlof, G. A. (1970). The market for "Lemons": Quality uncertainty and the market mechanism. The Quarterly Journal of Economics, 84(3), 488-500. https://doi.org/doi.org/10.2307/1879431

Akyol, A. C., Lim, W. F., \& Verwijmeren, P. (2012). Shareholders in the boardroom: Wealth effects of the SEC's proposal to facilitate director nominations. Journal of Financial and Quantitative Analysis, 47(05), 10291057. https://doi.org/10.1017/S0022109012000373

Alesina, A., Devleeschauwer, A., Easterly, W., \& Kurlat, S. (2003). Fractionalization. Journal of Economic Growth, 8, 155-194.

Atiase, R. K., \& Bamber, L. S. (1994). Trading volume reactions to annual accounting earnings announcements. The incremental role of predisclosure information asymmetry. Journal of Accounting and Economics, 17(3), 309- 
329. https://doi.org/10.1016/0165-4101(94)90031-0

Auty, R. M. (1997). Natural resource endowment, the state and development strategy. Journal of International Development, 9(4), 651-663.

Auty, R. M. (2001). The political economy of resource-driven growth. European Economic Review, 45, 839-846. https://doi.org/10.1016/S00142921(01)00126-X

Avkiran, N. K., Kanol, D. K., \& Oliver, B. (2016). Knowledge of campaign finance regulation reduces perceptions of corruption. Accounting and Finance, 56, 961-984. https://doi.org/10.1111/acfi.12121

Bajo, E. (2010). The information content of abnormal trading volume. Journal of Business Finance and Accounting, 37(7-8), 950-978. https://doi.org/10.1111/j.1468-5957.2010.02197.x

Bale, M., \& Dale, T. (1998). Public sector reform in New Zealand and its relevance to developing countries. The World Bank Research Observer, 13(1), 103-121. https://doi.org/10.1093/wbro/13.1.103 
Ball, R., \& Brown, P. (1968). An empirical evaluation of accounting income numbers. Journal of Accounting Research, 6(2), 159-178. https://doi.org/doi:10.2307/2490232

Bamber, L. S., Barron, O. E., \& Stevens, D. E. (2011). Trading volume around earnings announcements and other financial reports: Theory, research design, empirical evidence, and directions for future research. Contemporary Accounting Research, 28(2), 431-471. https://doi.org/10.1111/j.1911-3846.2010.01061.x

Beaver, W. H. (1968). The information content of annual earnings announcements. Journal of Accounting Research, 6(Selected Studies), 6792. https://doi.org/10.2307/2490070

Berry, K. T., \& Wright, C. J. (2001). The value relevance of oil and gas disclosures: An assessment of the market's perception of firms' effort and ability to discover reserves. Journal of Business Finance and Accounting, 28(5-6), 741-769. https://doi.org/10.1111/1468-5957.00392

Bertomeu, J., \& Magee, R. P. (2015). Mandatory disclosure and asymmetry in financial reporting. Journal of Accounting and Economics, 59, 284-299. 
https://doi.org/10.1016/j.jacceco.2014.08.007

Bird, R., Grosse, M., \& Yeung, D. (2013). The market response to exploration, resource and reserve announcements by mining companies: Australian data. Australian Journal of Management, 38(2), 311-331. https://doi.org/10.1177/0312896212473401

Blackburn, K., Bose, N., Emranul Haque, M., \& Haque, M. E. (2010). Endogenous corruption in economic development. Journal of Economic Studies, 37(1), 425. https://doi.org/10.1108/01443581011012234

BP. (2017). BP Statistical Review of World Energy 2017. British Petroleum. https://doi.org/http://www.bp.com/content/dam/bp/en/corporate/pdf/ energy-economics/statistical-review-2017/bp-statistical-review-of-worldenergy-2017-full-report.pdf

Burbidge, J. B., Magee, L., \& Robb, A. L. (1988). Alternative transformations to handle extreme values of the dependent variable. Journal of the American Statistical Association, 83(401), 123-127. 
Campbell, C. J., \& Wasley, C. E. (1993). Measuring security price performance using daily NASDAQ returns. Journal of Financial Economics, 33(1), 73-92.

Campbell, C. J., \& Wasley, C. E. (1996). Measuring abnormal daily trading volume for samples of NYSE/ASE and NASDAQ securities using parametric and nonparametric test statistics. Review of Quantitative Finance and Accounting, 6(3), 309-326. https://doi.org/10.1007/BF00245187

Chae, J. (2005). Trading volume, information asymmetry, and timing information. The Journal of Finance, 60(1), 413-442. https://doi.org/10.1111/j.1540-6261.2005.00734.x

Chapple, L., Clarkson, P. M., \& Gold, D. L. (2013). The cost of carbon: Capital market effects of the proposed Emission Trading Scheme (ETS). Abacus, 49(1), 1-33. https://doi.org/10.1111/abac.12006

Chen, L. H., \& Sami, H. (2008). Trading volume reaction to the earnings reconciliation from IAS to U.S. GAAP. Contemporary Accounting Research, 25(1), 15-53. https://doi.org/10.1506/car.25.1.1 
Clarkson, P. M., Li, Y., Pinnuck, M., \& Richardson, G. D. (2015). The valuation relevance of greenhouse gas emissions under the European Union carbon emissions trading scheme. European Accounting Review, 24(3), 551-580. https://doi.org/10.1080/09638180.2014.927782

Clinch, G., \& Magliolo, J. (1992). Market perceptions of reserve disclosures under SFAS No. 69. The Accounting Review, 67(69), 843-861.

Cockx, L., \& Francken, N. (2016). Natural resources: A curse on education spending? Energy Policy, 92, 394-408.

Collins, D. W., Pincus, M., \& Xie, H. (1999). Equity valuation and negative earnings : The role of book value of equity. The Accounting Review, 74(1), 29-61. https://doi.org/10.2308/accr.1999.74.1.29

Corrado, C. J. (1989). A nonparametric test for abnormal security-price performance in event studies. Journal of Financial Economics, 23(2), 385395. https://doi.org/10.1016/0304-405X(89)90064-0 
Corrado, C. J. (2011). Event study: A Methodology Review. Accounting and Finance, 51(1), 207-234.

Corrado, C. J. ., \& Zivney, T. L. (1992). The specification and power of the sign test in event study hypothesis tests using daily stock returns. Journal of Financial and Quantitative Analysis, 27(3), 465-478. https://doi.org/10.2307/2331331

Corrado, C. J., \& Truong, C. (2008). Conducting event studies with Asia-Pacific security market data. Pacific Basin Finance Journal, 16(5), 493-521. https://doi.org/10.1016/j.pacfin.2007.10.005

Corrigan, C. C. (2014). Breaking the resource curse: Transparency in the natural resource sector and the Extractive Industries Transparency Initiative. Resources Policy, 41, 17-30. https://doi.org/10.1016/j.resourpol.2013.10.003

Cuervo-Cazurra, A. (2016). Corruption in international business. Journal of World Business, 51, 35-49. https://doi.org/10.1016/j.jwb.2015.08.015 
Department of Justice. (2014). Extractive Sector Transparency Measures Act. Retrieved from http://laws-lois.justice.gc.ca

Dreher, A., Mikosch, H., \& Voigt, S. (2015). Membership has its Privileges-The Effect of Membership in International Organizations on FDI. World Development, 66, 346-358.

Dyckman, T. R., \& Zeff, S. A. (2014). Some methodological deficiencies in empirical research articles in accounting. Accounting Horizons, 28(3), 695712.

Ehalaiye, D., Tippett, M., \& van Zijl, T. (2017). The predictive value of bank fair values. Pacific Basin Finance Journal, 41, 111-127. https://doi.org/10.1016/j.pacfin.2016.10.008

EITI. (2015). The Extractive Industries Transparency Initiative Standard.

EITI. (2016). The Extractive Industries Transparency Initiative Standard 2016. Retrieved from https://eiti.org/document/standard 
Elbahnasawy, N. G., \& Revier, C. F. (2012). The Determinants of Corruption:

Cross-Country-Panel-Data Analysis. Developing Economies, 50(4), 311-333. https://doi.org/10.1111/j.1746-1049.2012.00177.x

Emanuel, D., \& van Zijl, T. (2005). Agency theory and trust ownership of shares. New Zealand Economic Papers, 39(2), 195-207. https://doi.org/10.1080/00779950509558493

European Parliament and the Council. (2013). European Union Accounting Directive 2013/34/EU.

Fama, E. F., Fisher, L., Jensen, M. C., \& Roll, R. (1969). The Adjustment of Stock Prices to New Information. International Economic Review, 10(1), 1-21. https://doi.org/10.2307/2525569

Ferguson, A., Clinch, G., \& Kean, S. (2011). Predicting the failure of developmental gold mining projects. Australian Accounting Review, 21(1), 44-53. https://doi.org/10.1111/j.1835-2561.2010.00119.x 
Ferguson, A., Grosse, M., Kean, S., \& Scott, T. (2011). Your governance or mine? Australian Accounting Review, 21(4), 406-417. https://doi.org/10.1111/j.1835-2561.2011.00147.x

Ferguson, A., \& Pündrich, G. (2015). Does industry specialist assurance of nonfinancial information matter to investors? Auditing: A Journal of Practice \& Theory, 34(2), 121-146. https://doi.org/10.2308/ajpt-50930

Ferguson, A., \& Scott, T. (2011). Market reactions to Australian boutique resource investor presentations. Resources Policy, 36(4), 330-338. https://doi.org/10.1016/j.resourpol.2011.07.004

Furstenberg, S. (2015). Consolidating global governance in nondemocratic countries: Critical reflections on the Extractive Industries Transparency Initiative (EITI) in Kyrgyzstan. Extractive Industries and Society, 2(3), 462471. https://doi.org/10.1016/j.exis.2015.06.007

Gaventa, J., \& McGee, R. (2013). The impact of transparency and accountability initiatives. Development Policy Review, 31, 1-128. https://doi.org/10.1111/dpr.12017 
Graber, N., \& Flow, S. L. (2017). Congress Rolls Back SEC Resource Extraction Payments Rule. https://doi.org/www.corpgov.law.harvard.edu

Grewal, J., Riedl, E. J., \& Serafeim, G. (2015). Market reaction to mandatory nonfinancial disclosure. Harvard Business School Accounting and Management Unit Working Paper. https://doi.org/10.2139/ssrn.2657712

Griffin, P. A., Lont, D. H., \& Sun, Y. (2014). Supply chain sustainability: evidence on conflict minerals. Pacific Accounting Review, 26(1/2), 28-53. https://doi.org/10.1108/PAR-04-2013-0023

Healy, P. M., \& Palepu, K. G. (2001). Information asymmetry, corporate disclosure, and the capital markets: A review of the empirical disclosure literature. Journal of Accounting and Economics, 31, 405-440. https://doi.org/10.1016/S0165-4101(01)00018-0

Healy, P. M., \& Serafeim, G. (2016). An analysis of firms' self-reported anticorruption efforts. The Accounting Review, 91(2), 489-511. https://doi.org/10.2308/accr-51191 
Heywood, P. M. (2015). Measuring corruption: Perspectives, critiques and limits. In Routledge Handbook of Political Corruption (pp. 137-153)

Hilson, G. (2014). The extractive industries and development in sub-Saharan Africa: An introduction. Resources Policy, 41, 1-3. https://doi.org/10.1016/j.resourpol.2014.05.001

Hilson, G., \& Maconachie, R. (2008). "Good governance" and the extractive industries in Sub-Saharan Africa. Mineral Processing and Extractive Metallurgy Review, 30, 52-100. https://doi.org/10.1080/08827500802045511

Hombach, K., \& Sellhorn, T. (2017). Investors' Perception of Financial Disclosure Regulation to Achieve Public Policy Objectives: Evidence from Extractive Issuers. https://doi.org/University of Munich

Houqe, N. M., \& Monem, R. M. (2016). IFRS adoption, extent of disclosure, and perceived corruption: A cross-country study. International Journal of Accounting, 51, 363-378. https://doi.org/10.1016/j.intacc.2016.07.002 
Institute for Economics and Peace. (2016). Global Peace Index 2016. Global Peace Index. https://doi.org/10.1038/nature01405

International Federation of Accountants. (2015). A campaign for enhanced public financial reporting, sound decision making, and accountability. New York.

Islam, R. (2006). Does more transparency go along with better governance? Economics and Politics, 18(2), 121-167. https://doi.org/10.1111/j.14680343.2006.00166.x

Jensen, M. C., \& Meckling, W. H. (1976). Theory of the firm: Managerial behavior, agency costs and ownership structure. Journal of Financial Economics, 3(4), 305-360. https://doi.org/10.1016/0304-405X(76)90026-X

Johannesen, N., \& Larsen, D. T. (2016). The power of financial transparency: An event study of country-by-country reporting standards. Economics Letters, 145, 120-122. https://doi.org/10.1016/j.econlet.2016.05.029 
Joint Ore Reserve Committee. (2012). The JORC Code. Retrieved from http://www.jorc.org

Joshi, A., \& Houtzager, P. P. (2012). Widgets or watchdogs?: Conceptual explorations in social accountability. Public Management Review, 14(2), 145-162. https://doi.org/10.1080/14719037.2012.657837

Kasekende, E., Abuka, C., \& Sarr, M. (2016). Extractive industries and corruption: Investigating the effectiveness of EITI as a scrutiny mechanism. Resources Policy, 48, 117-128.

https://doi.org/10.1016/j.resourpol.2016.03.002

Kaufmann, D., Kraay, A., \& Mastruzzi, M. (2011). The Worldwide Governance Indicators: Methodology and Analytical Issues. Hague Journal on the Rule of Law, 3(02), 220-246.

Kolstad, I., \& Søreide, T. (2009). Corruption in natural resource management: Implications for policy makers. Resources Policy, 34(4), 214-226. https://doi.org/10.1016/j.resourpol.2009.05.001 
Kolstad, I., \& Wiig, A. (2009). Is transparency the key to reducing corruption in resource-rich countries? World Development, 37(3), 521-532. https://doi.org/10.1016/j.worlddev.2008.07.002

Kothari, S. P., \& Warner, J. B. (2007). Econometrics of event studies. In E. B. Eckbo (Ed.), Handbook of Corporate Finance: Empirical Corporate Finance (Vol. 1, pp. 3-36). Amsterdam: Elsevier.

Kryzanowski, L., \& Jenkins, C. (1993). The Market's Reaction to the Release of Drill-Core Assay Results by Junior Mining Firms. Journal of Accounting, Auditing and Finance, 8(3), 289-311.

La Porta, R., Lopez-de-silanes, F., Shleifer, A., \& Vishny, R. (2000). Investor protection and corporate governance. Journal of Financial Economics, 58, 3 27. https://doi.org/10.1016/S0304-405X(00)00065-9

Laubscher, N. F. (1961). On stabilizing the binomial and negative binomial variances. Journal of the American Statistical Association, 56(293), 143-150. https://doi.org/10.1080/01621459.1961.10482100 
Leuz, C., \& Wysocki, P. D. (2016). The economics of disclosure and financial reporting regulation: evidence and suggestions for future research. Journal of Accounting Research, 54(2), 525-622. https://doi.org/10.1111/1475679X.12115

Mackinlay, C. A. (1997). Event studies in economics and finance. Journal of Economic Literature, XXXV, 13-39.

Marsden, A. (2000). Shareholder wealth effects of rights issues: Evidence from the New Zealand capital market. Pacific-Basin Finance Journal, 8(3-4), 419442. https://doi.org/10.1016/S0927-538X(00)00020-2

Mehlum, H., Moene, K., \& Torvik, R. (2006). Institutions and the resource curse. The Economic Journal, 116, 1-20. https://doi.org/10.1111/j.14680297.2006.01045.x

Melgar, N., Rossi, M., \& Smith, T. W. (2010). The perception of corruption. International Journal of Public Opinion Research, 22(1), 120-131. https://doi.org/10.1093/ijpor/edp058 
Müller, S. (2015). Significance tests for event studies. Retrieved August 30, 2017, from https://www.eventstudytools.com

Neu, D., Everett, J., Rahaman, A. S., \& Martinez, D. (2013). Accounting and networks of corruption. Accounting, Organizations and Society, 38, 505524. https://doi.org/10.1016/j.aos.2012.01.003

O'Brien, R. M. (2007). A caution regarding rules of thumb for variance inflation factors. Quality and Quantity, 41(5), 673-690. https://doi.org/10.1007/s11135-006-9018-6

Öge, K. (2016). Which transparency matters? Compliance with anti-corruption efforts in extractive industries. Resources Policy, 49, 41-50.

Ohlson, J. (1995). Earnings, book values, and dividends in equity valuation. Contemporary Accounting Research, 11(2), 661-687. https://doi.org/10.1111/j.1911-3846.1995.tb00461.x

Ölcer, D. (2009). Extracting the maximum from the EITI. OECD Development Centre Working Papers, (276), 1. 
Papyrakis, E., Rieger, M., \& Gilberthorpe, E. (2017). Corruption and the Extractive Industries Transparency Initiative. Journal of Development Studies, 53, 295-309. https://doi.org/10.1080/00220388.2016.1160065

Pillay, S., \& Kluvers, R. (2014). An institutional theory perspective on corruption: The case of a developing democracy. Financial Accountability and Management, 30(1), 95-119. https://doi.org/10.1111/faam.12029

Pitlik, H., Frank, B., \& Firchow, M. (2010). The demand for transparency: An empirical note. Review of International Organizations, 5(2), 177-195. https://doi.org/10.1007/s11558-009-9073-6

Prather-Kinsey, J. J., \& Tanyi, P. N. (2015). The market reaction to SEC IFRSrelated announcements: The case of American Depository Receipt (ADR) firms in the U.S. Accounting Horizons, 28(3), 579-603. https://doi.org/10.2308/acch-50772

Rauter, T. (2017). Disclosure regulation, corruption, and investment: Evidence from natural resource extraction. Available at SSRN: https://ssrn.com/abstract=3049941. 
Revenue Watch Institute. (2013). The 2013 Resource Governance Index: A Measure of Transparency and Accountability in the Oil, Gas, and Mining Sector. Revenue Watch Institute. Retrieved from http://www.resourcegovernance.org/sites/default/files/country_pdfs/qat arRGI2013.pdf

Robinson, J. A., Torvik, R., \& Verdier, T. (2006). Political foundations of the resource curse. Journal of Development Economics, 106, 194-198. https://doi.org/10.1016/j.jdeveco.2006.01.008

Rose-Ackerman, S. (2002). Corruption and the ethics of global business. Journal of Banking and Finance, 26, 1889-1918. https://doi.org/10.1016/S03784266(02)00197-8

Ross, M. L. (1999). The political economy of development. World Politics, 51(2), 297-322.

Sachs, J. D., \& Warner, A. M. (1997). Sources of slow growth in African economies. Journal of African Economies, 6(3), 335-376. https://doi.org/10.1093/oxfordjournals.jae.a020932 
Sachs, J. D., \& Warner, A. M. (2001). The curse of natural resources. European Economic Review, 45, 827-838. https://doi.org/10.1016/S00142921(01)00125-8

Shleifer, A., \& Vishny, R. W. (1993). Corruption. The Quarterly Journal of Economics, 108(3), 599-617. https://doi.org/10.2307/2118402

Short, C. (2014). The development of the Extractive Industries Transparency Initiative. Journal of World Energy Law and Business, 7(1), 8-15. https://doi.org/10.1093/jwelb/jwt026

Shwilima-Ibrahim, J. A. (2015). Economic growth and nonrenewable resources: An empirical investigation. Asian Journal of Empirical Research Journal, 6(2), 26-41.

Sovacool, B. K., Walter, G., Van de Graaf, T., \& Andrews, N. (2016). Energy governance, transnational rules, and the resource curse: Exploring the effectiveness of the Extractive Industries Transparency Initiative (EITI). World Development, 83, 179-192. https://doi.org/10.1016/j.worlddev.2016.01.021 
Spence, M. (1973). Job market signaling. The Quarterly Journal of Economics, 87(3), 355. https://doi.org/10.2307/1882010

Summers, R., \& Heston, A. (1991). The Penn World Table (Mark 5): An expanded set of international comparisons, 1950-1988. The Quarterly Journal of Economics, 106(2), 327-368.

Svensson, J. (2005). Eight questions about corruption. Journal of Economic Perspectives, 19(3), 19-42. https://doi.org/10.1257/089533005774357860

Tanzi, V. (1998). Corruption around the world: Causes, consequences, scope, and cures. Staff Papers, 45(4), 559-594.

Transparency International. (2015). Corruption Perceptions Index 2015. Transparency International. https://doi.org/978-3-943497-18-2

U.S. Congress. (2010). Dodd-Frank Wall Street Reform and Consumer Protection Act. Pub. L. No. 111-203, 124 Stat. 1376 (2010). 
U.S. Energy Information Administration. (2013). Oil and Natural Gas in SubSaharan Africa Sub-Saharan Africa, 1-25. Retrieved from http://www.eia.gov/pressroom/presentations/howard_08012013.pdf

U.S. Energy Information Administration. (2016). U. S. Crude Oil and Natural Gas Proved Reserves, Year-end 2015. Retrieved from https://www.eia.gov/naturalgas/crudeoilreserves/pdf/usreserves.pdf

U.S. Energy Information Administration. (2017). United States remains the world's top producer of petroleum and natural gas hydrocarbons. Retrieved September 24, 2017, from https://www.eia.gov/todayinenergy/detail.php?id=31532

UNDP. (2015). Human Development Report 2015. Work for Human Development. United Nations Development Programme. Retrieved from http://hdr.undp.org/sites/all/themes/hdr_theme/country-notes/MEX.pdf

United States Extractive Industries Transparency Initiative. (2014). United States EITI Annual Activity Report 2014. Retrieved from https://www.doi.gov/sites/doi.opengov.ibmcloud.com/files/uploads/Ann ual Activity Report 2014 7_17_15 Final. \%281\%29 \%281\%29.pdf 
Vadlamannati, K. C., \& Cooray, A. (2017). Transparency pays? Evaluating the effects of the freedom of information laws on perceived government corruption. Journal of Development Studies, 53(1), 116-137. https://doi.org/10.1080/00220388.2016.1178385

Venables, A. J. (2016). Using natural resources for development: Why has it proven So difficult? Journal of Economic Perspectives, 30, 161-184. https://doi.org/10.1257/jep.30.1.161

Verrecchia, R. E. (2001). Essays on disclosure. Journal of Accounting and Economics, 32, 97-180. https://doi.org/10.1016/S0165-4101(01)00025-8

Watts, R. L., \& Zimmerman, J. L. (1986). Positive Accounting Theory. Englewood Cliffs, N.J: Prentice-hall.

Wells, W. H. (2004). A beginner's guide to event studies. Journal of Insurance Regulation, 22(4), 61-70.

Williams, A. (2011). Shining a light on the resource curse: An empirical analysis of the relationship between natural resources, transparency, and economic 
growth. World Development, 39(4), 490-505.

https://doi.org/10.1016/j.worlddev.2010.08.015

Wilson, E., \& Van Alstine, J. (2014). Localising transparency: Exploring EITI's contribution to sustainable development - IIED Publications Database. Shaping Sustainable Markets Papers. Retrieved from http://pubs.iied.org/16555IIED.html\%5Cnhttp://files/884/16555IIED.ht $\mathrm{ml}$

World Bank. (2004). World Development Report 2004: Making services work for poor people. World Bank and Oxford University Press. https://doi.org/10.1093/jae/ejh019 


\section{APPENDICES}


Appendix A. Low Human Development Index Countries 2014 HDI Rank Country

Value

\begin{tabular}{|c|c|c|}
\hline 145 & Kenya & 0.55 \\
\hline 145 & Nepal & 0.55 \\
\hline 147 & Pakistan & 0.54 \\
\hline 148 & Myanmar & 0.54 \\
\hline 149 & Angola & 0.53 \\
\hline 150 & Swaziland & 0.53 \\
\hline 151 & Tanzania (United Republic of) & 0.52 \\
\hline 152 & Nigeria & 0.51 \\
\hline 153 & Cameroon & 0.51 \\
\hline 154 & Madagascar & 0.51 \\
\hline 155 & Zimbabwe & 0.51 \\
\hline 156 & Mauritania & 0.51 \\
\hline 156 & Solomon Islands & 0.51 \\
\hline 158 & Papua New Guinea & 0.51 \\
\hline 159 & Comoros & 0.50 \\
\hline 160 & Yemen & 0.50 \\
\hline 161 & Lesotho & 0.50 \\
\hline 162 & Togo & 0.48 \\
\hline 163 & Haiti & 0.48 \\
\hline 163 & Rwanda & 0.48 \\
\hline 163 & Uganda & 0.48 \\
\hline 166 & Benin & 0.48 \\
\hline 167 & Sudan & 0.48 \\
\hline 168 & Djibouti & 0.47 \\
\hline 169 & South Sudan & 0.47 \\
\hline 170 & Senegal & 0.47 \\
\hline 171 & Afghanistan & 0.47 \\
\hline 172 & Côte d'Ivoire & 0.46 \\
\hline 173 & Malawi & 0.45 \\
\hline 174 & Ethiopia & 0.44 \\
\hline 175 & Gambia & 0.44 \\
\hline
\end{tabular}


Appendix A. Continued

\begin{tabular}{cll}
\hline HDI Rank & Country & Value \\
\hline 176 & Congo (Democratic Republic of the) & 0.43 \\
177 & Liberia & 0.43 \\
178 & Guinea-Bissau & 0.42 \\
179 & Mali & 0.42 \\
180 & Mozambique & 0.42 \\
181 & Sierra Leone & 0.41 \\
182 & Guinea & 0.41 \\
183 & Burkina Faso & 0.40 \\
184 & Burundi & 0.40 \\
185 & Chad & 0.39 \\
186 & Eritrea & 0.39 \\
187 & Central African Republic & 0.35 \\
188 & Niger & 0.35 \\
\hline
\end{tabular}

UNDP (2015)

This list of countries classified as low in Human Development Index is made up of more SubSaharan African countries. Generally, most countries listed are those considered to be rich in natural resources, yet citizens of such countries live in difficult human conditions. The Human Development Index is an important tool for raising awareness about failure in respect of human development around the world. It is a composite index measuring average achievement in three basic dimensions of human development-a long and healthy life, knowledge, and a decent standard of living. 
Appendix B. Countries Resource Governance Index Ranking (RGI) for 2013

\begin{tabular}{|c|c|c|c|}
\hline Rank & Country & Score & Resource measured \\
\hline 1 & Norway & 98 & Hydrocarbons \\
\hline 2 & United States (Gulf of Mexico) & 92 & Hydrocarbons \\
\hline 3 & United Kingdom & 88 & Hydrocarbons \\
\hline 4 & Australia (Western Australia) & 85 & Minerals \\
\hline 5 & Brazil & 80 & Hydrocarbons \\
\hline 6 & Mexico & 77 & Hydrocarbons \\
\hline 7 & Canada (Alberta) & 76 & Hydrocarbons \\
\hline 8 & Chile & 75 & Minerals \\
\hline 9 & Colombia & 74 & Hydrocarbons \\
\hline 10 & Trinidad and Tobago & 74 & Hydrocarbons \\
\hline 11 & Peru & 73 & Minerals \\
\hline 12 & India & 70 & Hydrocarbons \\
\hline 13 & Timor-Leste & 68 & Hydrocarbons \\
\hline 14 & Indonesia & 66 & Hydrocarbons \\
\hline 15 & Ghana & 63 & Minerals \\
\hline 16 & Liberia & 62 & Minerals \\
\hline 17 & Zambia & 61 & Minerals \\
\hline 18 & Ecuador & 58 & Hydrocarbons \\
\hline 19 & Kazakhstan & 57 & Hydrocarbons \\
\hline 20 & Venezuela & 56 & Hydrocarbons \\
\hline 21 & South Africa & 56 & Minerals \\
\hline 22 & Russia & 56 & Hydrocarbons \\
\hline 23 & Philippines & 54 & Minerals \\
\hline 24 & Bolivia & 53 & Hydrocarbons \\
\hline 25 & Morocco & 53 & Minerals \\
\hline 26 & Mongolia & 51 & Minerals \\
\hline 27 & Tanzania & 50 & Minerals \\
\hline 28 & Azerbaijan & 48 & Hydrocarbons \\
\hline 29 & Iraq & 47 & Hydrocarbons \\
\hline 30 & Botswana & 47 & Minerals \\
\hline 31 & Bahrain & 47 & Hydrocarbons \\
\hline 32 & Gabon & 46 & Hydrocarbons \\
\hline 33 & Guinea & 46 & Minerals \\
\hline 34 & Malaysia & 46 & Hydrocarbons \\
\hline 35 & Sierra Leone & 46 & Minerals \\
\hline 36 & China & 43 & Hydrocarbons \\
\hline 37 & Yemen & 43 & Hydrocarbons \\
\hline 38 & Egypt & 43 & Hydrocarbons \\
\hline 39 & Papua New Guinea & 43 & Minerals \\
\hline 40 & Nigeria & 42 & Hydrocarbons \\
\hline
\end{tabular}




\begin{tabular}{clcl}
\hline \multicolumn{2}{c}{ Appendix B. Continued } & Score & Resource measured \\
Rank & Country & 42 & Hydrocarbons \\
\hline 41 & Angola & 41 & Hydrocarbons \\
42 & Kuwait & 41 & Hydrocarbons \\
43 & Vietnam & 39 & Minerals \\
44 & Congo (DRC) & 38 & Hydrocarbons \\
45 & Algeria & 37 & Hydrocarbons \\
46 & Mozambique & 34 & Hydrocarbons \\
47 & Cameroon & 34 & Hydrocarbons \\
48 & Saudi Arabia & 33 & Minerals \\
49 & Afghanistan & 31 & Hydrocarbons \\
50 & South Sudan & 31 & Minerals \\
51 & Zimbabwe & 29 & Hydrocarbons \\
52 & Cambodia & 28 & Hydrocarbons \\
53 & Iran & 26 & Hydrocarbons \\
54 & Qatar & 19 & Hydrocarbons \\
55 & Libya & 13 & Hydrocarbons \\
56 & Equatorial Guinea & 5 & Hydrocarbons \\
57 & Turkmenistan & 4 & Hydrocarbons \\
58 & Myanmar & & \\
\hline
\end{tabular}

Revenue Watch Institute (2013) 
Appendix C. Sub-Saharan African Countries Resource Governance Index

Ranking for 2013

\begin{tabular}{clll} 
Rank & Country & Score & Resource measured \\
\hline 15 & Ghana & 63 & Minerals \\
16 & Liberia & 62 & Minerals \\
17 & Zambia & 61 & Minerals \\
21 & South Africa & 56 & Minerals \\
27 & Tanzania & 50 & Minerals \\
30 & Botswana & 47 & Minerals \\
32 & Gabon & 46 & Hydrocarbons \\
33 & Guinea & 46 & Minerals \\
35 & Sierra Leone & 46 & Minerals \\
40 & Nigeria & 42 & Hydrocarbons \\
41 & Angola & 42 & Hydrocarbons \\
44 & Congo (DRC) & 39 & Minerals \\
46 & Mozambique & 37 & Hydrocarbons \\
47 & Cameroon & 34 & Hydrocarbons \\
50 & South Sudan & 31 & Hydrocarbons \\
51 & Zimbabwe & 31 & Minerals \\
56 & Equatorial Guinea & 13 & Hydrocarbons \\
\hline
\end{tabular}

Revenue Watch Institute (2013)

The Resource Governance Index (RGI) for 2013 measured the quality of governance in the oil, gas and mining sector of 58 countries. The Index identifies critical achievements and challenges in natural resource governance. RGI evaluates four key components of resource governance in each country: Institutional and Legal Setting; Reporting Practices; Safeguards and Quality Controls; and Enabling Environment. The Index assigns a numerical score to each country and divides them into four performance ranges Satisfactory (71100), Partial (51-70), Weak (41-50) and Failing (0-40). Ranks are out of 58 countries in total. This subset of 17 Sub-Saharan African economies exhibits serious shortcomings in resource governance, confirming the dire need for improved resource governance in African countries rich in natural resources 
Appendix D. Sub-Saharan African Countries Corruption Perception Index for 2015

\begin{tabular}{|c|c|c|}
\hline Rank & Country & CPI Score \\
\hline 28 & Botswana & 63 \\
\hline 40 & Cape Verde & 55 \\
\hline 40 & Seychelles & 55 \\
\hline 44 & Rwanda & 54 \\
\hline 45 & Mauritius & 53 \\
\hline 45 & Namibia & 53 \\
\hline 56 & Ghana & 47 \\
\hline 61 & Lesotho & 44 \\
\hline 61 & Senegal & 44 \\
\hline 61 & South Africa & 44 \\
\hline 66 & Sao Tome and Principe & 42 \\
\hline 76 & Burkina Faso & 38 \\
\hline 76 & Zambia & 38 \\
\hline 83 & Benin & 37 \\
\hline 83 & Liberia & 37 \\
\hline 95 & Mali & 35 \\
\hline 99 & Djibouti & 34 \\
\hline 99 & Gabon & 34 \\
\hline 99 & Niger & 34 \\
\hline 103 & Ethiopia & 33 \\
\hline 107 & Côte d'Ivoire & 32 \\
\hline 107 & Togo & 32 \\
\hline 112 & Malawi & 31 \\
\hline 112 & Mauritania & 31 \\
\hline 112 & Mozambique & 31 \\
\hline 117 & Tanzania & 30 \\
\hline 119 & Sierra Leone & 29 \\
\hline 123 & Gambia & 28 \\
\hline 123 & Madagascar & 28 \\
\hline 130 & Cameroon & 27 \\
\hline
\end{tabular}




\begin{tabular}{clc}
\hline $\begin{array}{c}\text { Appendix D. Continued } \\
\text { Rank }\end{array}$ & Country & CPI Score \\
\hline 136 & Comoros & 26 \\
136 & Nigeria & 26 \\
139 & Guinea & 25 \\
139 & Kenya & 25 \\
139 & Uganda & 25 \\
145 & Central African Republic & 24 \\
146 & Congo Republic & 23 \\
147 & Chad & 22 \\
147 & Democratic Republic of the Congo & 22 \\
150 & Burundi & 21 \\
150 & Zimbabwe & 21 \\
154 & Eritrea & 18 \\
158 & Guinea-Bissau & 17 \\
163 & Angola & 15 \\
163 & South Sudan & 15 \\
165 & Sudan & 12 \\
167 & Somalia & 8 \\
\hline$T r a n s a r e n c y ~$ &
\end{tabular}

Transparency International (2015).

The CPI Sub-Saharan African countries rank and score for 2015, indicate the challenging nature of corruption to the Continent. Only six countries had scores greater than 50\%. Countries whose main source of revenue is natural resources e.g. Nigeria, Angola, Sierra Leone, Democratic Republic of the Congo and Sudan all lag behind relative to other countries in the world. The CPI is the most widely used indicator of corruption, that ranks countries based on how corrupt their public sector is perceived to be. The score indicates the perceived level of public sector corruption on a scale of 0-100, where 0 means that a country is perceived as highly corrupt and a 100 means that a country is perceived as very clean. A country's rank indicates its position relative to the other countries included in the index. 
Appendix E: Extractive Industries Transparency Initiative Principles

1 We share a belief that the prudent use of natural resource wealth should be an important engine for sustainable economic growth that contributes to sustainable development and poverty reduction, but if not managed properly, can create negative economic and social impacts.

2 We affirm that management of natural resource wealth for the benefit of a country's citizens is in the domain of sovereign governments to be exercised in the interests of their national development.

3 We recognise that the benefits of resource extraction occur as revenue streams over many years and can be highly price dependent.

4 We recognise that a public understanding of government revenues and expenditure over time could help public debate and inform choice of appropriate and realistic options for sustainable development.

5 We underline the importance of transparency by governments and companies in the extractive industries and the need to enhance public financial management and accountability.

6 We recognise that achievement of greater transparency must be set in the context of respect for contracts and laws.

7 We recognise the enhanced environment for domestic and foreign direct investment that financial transparency may bring.

8 We believe in the principle and practice of accountability by government to all citizens for the stewardship of revenue streams and public expenditure.

9 We are committed to encouraging high standards of transparency and accountability in public life, government operations and in business.

10 We believe that a broadly consistent and workable approach to the disclosure of payments and revenues is required, which is simple to undertake and to use.

11 We believe that payments' disclosure in a given country should involve all extractive industry companies operating in that country.

12 In seeking solutions, we believe that all stakeholders have important and relevant contributions to make - including governments and their agencies, extractive industry companies, service companies, multilateral organisations, financial organisations, investors and non-governmental organisations.

EITI Standards (2013) 
Appendix F: Extractive Industries Transparency Initiative countries and their status

\begin{tabular}{|c|c|c|c|}
\hline Country & Country Status & Country & Country Status \\
\hline Albania & Complaint & Afghanistan & Candidate \\
\hline Burkina Faso & Complaint & Azerbaijan & Candidate \\
\hline Cameroon & Complaint & Colombia & Candidate \\
\hline Chad & Complaint & Dominican Republic & Candidate \\
\hline Cote d'Ivoire & Complaint & Ethiopia & Candidate \\
\hline Democratic Republic of Congo & Complaint & Germany & Candidate \\
\hline Ghana & Complaint & Honduras & Candidate \\
\hline Guatemala & Complaint & Madagascar & Candidate \\
\hline Guinea & Complaint & Malawi & Candidate \\
\hline Indonesia & Complaint & Myanmar & Candidate \\
\hline Iraq & Complaint & Papua New Guinea & Candidate \\
\hline Kazakhstan & Complaint & Peru & Candidate \\
\hline Kyrgyz Republic & Complaint & Senegal & Candidate \\
\hline Liberia & Complaint & Seychelles & Candidate \\
\hline Mali & Complaint & Tajikistan & Candidate \\
\hline Mauritania & Complaint & Ukraine & Candidate \\
\hline Mongolia & Complaint & United Kingdom & Candidate \\
\hline Mozambique & Complaint & United States of America* & Candidate \\
\hline Niger & Complaint & Zambia & Candidate \\
\hline Nigeria & Complaint & & \\
\hline Norway & Complaint & Central African Republic & Complaint but Suspended \\
\hline Philippines & Complaint & Yemen & Complaint but Suspended \\
\hline Republic of the Congo & Complaint & & \\
\hline Sao Tome and Principe & Complaint & & \\
\hline Sierra Leone & Complaint & & \\
\hline Solomon Islands & Complaint & & \\
\hline Tanzania & Complaint & & \\
\hline Timor-Leste & Complaint & & \\
\hline Togo & Complaint & & \\
\hline Trinidad and Tobago & Complaint & & \\
\hline
\end{tabular}

51 implementing countries signed up to the EITI, of which 31 are fully compliant as at June 30, 2016.

*The US withdrew its membership from the EITI in November 2017. 
Appendix G. 2016 State of Peace and Ethnic Fractionalisation of EITI Countries

\begin{tabular}{|c|c|c|c|c|c|}
\hline Country & $\begin{array}{l}\text { Country } \\
\text { Status }\end{array}$ & $\begin{array}{r}\text { Global } \\
\text { Ranking } \\
\text { for Peace } \\
\end{array}$ & $\begin{array}{l}\text { State } \\
\text { Peace } \\
\text { Score } \\
\end{array}$ & $\begin{array}{l}\text { State of Peace } \\
\text { Categorisation }\end{array}$ & $\begin{array}{c}\text { Ethnic } \\
\text { Fractionalisation }\end{array}$ \\
\hline Afghanistan & Candidate & 160 & 3.538 & Very low & 0.769 \\
\hline Albania & Complaint & 54 & 1.867 & High & 0.220 \\
\hline Azerbaijan & Candidate & 134 & 2.45 & Low & 0.205 \\
\hline Burkina Faso & Complaint & 88 & 2.063 & Medium & 0.738 \\
\hline Cameroon & Complaint & 130 & 2.356 & Medium & 0.864 \\
\hline Central African Republic & Suspended & 157 & 3.354 & Very low & 0.830 \\
\hline Chad & Complaint & 136 & 2.464 & Low & 0.862 \\
\hline Colombia & Candidate & 147 & 2.764 & Low & 0.601 \\
\hline Cote d'Ivoire & Complaint & 118 & 2.279 & Medium & 0.820 \\
\hline Democratic Republic of Congo & Complaint & 152 & 3.112 & Very low & 0.875 \\
\hline Dominican Republic & Candidate & 99 & 2.143 & Medium & 0.429 \\
\hline Ethiopia & Candidate & 119 & 2.284 & Medium & 0.724 \\
\hline Germany & Candidate & 16 & 1.486 & High & 0.168 \\
\hline Ghana & Complaint & 44 & 1.809 & High & 0.673 \\
\hline Guatemala & Complaint & 117 & 2.27 & Medium & 0.512 \\
\hline Guinea & Complaint & 101 & 2.148 & Medium & 0.739 \\
\hline Honduras & Candidate & 111 & 2.237 & Medium & 0.187 \\
\hline Indonesia & Complaint & 42 & 1.799 & High & 0.735 \\
\hline Iraq & Complaint & 161 & 3.57 & Very low & 0.369 \\
\hline Kazakhstan & Complaint & 75 & 2.019 & Medium & 0.617 \\
\hline Kyrgyz Republic & Complaint & 124 & 2.297 & Medium & 0.675 \\
\hline Liberia & Complaint & 72 & 1.988 & Medium & 0.908 \\
\hline
\end{tabular}




\begin{tabular}{|c|c|c|c|c|c|}
\hline \multicolumn{6}{|l|}{ Appendix G. Continued } \\
\hline Country & $\begin{array}{l}\text { Country } \\
\text { Status }\end{array}$ & $\begin{array}{r}\text { Global } \\
\text { Ranking } \\
\text { for Peace }\end{array}$ & $\begin{array}{l}\text { State } \\
\text { Peace } \\
\text { Score } \\
\end{array}$ & $\begin{array}{l}\text { State of Peace } \\
\text { Categorisation }\end{array}$ & $\begin{array}{c}\text { Ethnic } \\
\text { Fractionalisation }\end{array}$ \\
\hline Madagascar & Candidate & 38 & 1.763 & High & 0.879 \\
\hline Malawi & Candidate & 45 & 1.817 & High & 0.674 \\
\hline Mali & Complaint & 137 & 2.489 & Low & 0.691 \\
\hline Mauritania & Complaint & 123 & 2.295 & Medium & 0.615 \\
\hline Mongolia & Complaint & 50 & 1.838 & High & 0.368 \\
\hline Mozambique & Complaint & 68 & 1.963 & Medium & 0.693 \\
\hline Myanmar & Candidate & 115 & 2.256 & Medium & 0.506 \\
\hline Niger & Complaint & 113 & 2.239 & Medium & 0.652 \\
\hline Nigeria & Complaint & 149 & 2.877 & Very low & 0.851 \\
\hline Norway & Complaint & 17 & 1.500 & High & 0.059 \\
\hline Papua New Guinea & Candidate & 99 & 2.143 & Medium & 0.272 \\
\hline Peru & Candidate & 85 & 2.056 & Medium & 0.657 \\
\hline Philippines & Complaint & 139 & 2.511 & Low & 0.239 \\
\hline Republic of the Congo & Complaint & 114 & 2.249 & Medium & 0.875 \\
\hline Sao Tome and Principe & Complaint & NA & NA & Not included & 0.000 \\
\hline Senegal & Candidate & 70 & 1.978 & Medium & 0.694 \\
\hline Seychelles & Candidate & NA & NA & Not included & 0.203 \\
\hline Sierra Leone & Complaint & 43 & 1.805 & High & 0.819 \\
\hline Solomon Islands & Complaint & NA & NA & Not included & 0.111 \\
\hline Tajikistan & Candidate & 122 & 2.293 & Medium & 0.511 \\
\hline Tanzania & Complaint & 58 & 1.899 & High & 0.735 \\
\hline Timor-Leste & Complaint & 56 & 1.879 & High & 0.000 \\
\hline
\end{tabular}




\begin{tabular}{llrrcc}
\hline Appendix G. Continued & & & & & \\
Country & $\begin{array}{l}\text { Country } \\
\text { Status }\end{array}$ & $\begin{array}{r}\text { Global } \\
\text { Ranking } \\
\text { for Peace }\end{array}$ & $\begin{array}{c}\text { State } \\
\text { Peace } \\
\text { Score }\end{array}$ & $\begin{array}{c}\text { State of Peace } \\
\text { Categorisation }\end{array}$ & $\begin{array}{c}\text { Fthnic } \\
\text { Fractionalisation }\end{array}$ \\
\hline Togo & Complaint & 66 & 1.954 & Medium & 0.710 \\
Trinidad and Tobago & Complaint & 84 & 2.056 & Medium & 0.648 \\
Ukraine & Candidate & 156 & 3.554 & Very low & 0.474 \\
United Kingdom & Candidate & 47 & 1.83 & High & 0.121 \\
United States of America & Candidate & 103 & 2.154 & Medium & 0.490 \\
Yemen & Suspended & 158 & 3.399 & Very low & 0.000 \\
Zambia & Candidate & 40 & 1.783 & High & 0.781 \\
\hline
\end{tabular}

Source: 2016 Global Peace Index ${ }^{59}$ (Institute for Economics and Peace, 2016) and Ethnic Fractionalisation ${ }^{60}$ (Alesina,

Devleeschauwer, Easterly, \& Kurlat, 2003).

59 The GPI is computed using 23 indicators of the violence or fear of violence. The indicators are selected with the assistance of the expert panel and reviewed on an annual basis. All scores for each indicator are normalised on a scale of 1-5, whereby qualitative indicators are banded into five groupings and quantitative ones are scored from 1-5, to the third decimal point

${ }^{60}$ This is defined as the combination of racial and linguistic characteristics of a country. Higher scores denote that country is more heterogeneous ethnic groups. 
Appendix H. EITI countries CPI Ranking overtime

\begin{tabular}{|c|c|c|c|c|c|c|}
\hline $\mathbf{S} / \mathbf{N}$ & EITI Country & $\begin{array}{c}\text { Average } \\
\text { Ranking } \\
2003-2011 \\
\end{array}$ & $\begin{array}{c}\text { Average } \\
\text { Ranking } \\
2011-2015 \\
\end{array}$ & $\begin{array}{c}\text { Average change } \\
\text { in Ranking } \\
\text { overtime }\end{array}$ & SSA & OECD \\
\hline 1 & Afghanistan & 50 & 50 & 0 & & \\
\hline 2 & Albania & 16 & 20 & 4 & & \\
\hline 3 & Azerbaijan & 39 & 34 & -5 & & \\
\hline 4 & Burkina Faso & 10 & 11 & 1 & $\sqrt{ }$ & \\
\hline 5 & Cameroon & 37 & 36 & -1 & $\sqrt{ }$ & \\
\hline 6 & Central African Republic & 42 & 41 & -1 & $\sqrt{ }$ & \\
\hline 7 & Chad & 49 & 46 & -3 & $\sqrt{ }$ & \\
\hline 8 & Colombia & 6 & 15 & 9 & & \\
\hline 9 & Cote d'Ivoire & 43 & 29 & -14 & $\sqrt{ }$ & \\
\hline 10 & Democratic Republic of Congo & 46 & 45 & -1 & $\sqrt{ }$ & \\
\hline 11 & Dominican Republic & 13 & 24 & 11 & & \\
\hline 12 & Ethiopia & 27 & 21 & -6 & $\sqrt{ }$ & \\
\hline 13 & Germany & 3 & 2 & -1 & & $\sqrt{ }$ \\
\hline 14 & Ghana & 7 & 6 & -1 & $\sqrt{ }$ & \\
\hline 15 & Guatemala & 21 & 26 & 5 & & \\
\hline 16 & Guinea & 47 & 42 & -5 & $\sqrt{ }$ & \\
\hline 17 & Honduras & 31 & 33 & 2 & & \\
\hline 18 & Indonesia & 32 & 19 & -13 & & \\
\hline 19 & Iraq & 48 & 49 & 1 & & \\
\hline 20 & Kazakhstan & 29 & 35 & 6 & & \\
\hline 21 & Kyrgyz Republic & 44 & 39 & -5 & & \\
\hline 22 & Liberia & 23 & 10 & -13 & $\sqrt{ }$ & \\
\hline 23 & Madagascar & 12 & 32 & 20 & $\sqrt{ }$ & \\
\hline 24 & Malawi & 14 & 17 & 3 & $\sqrt{ }$ & \\
\hline 25 & Mali & 15 & 22 & 7 & $\sqrt{ }$ & \\
\hline 26 & Mauritania & 25 & 27 & 2 & $\sqrt{ }$ & \\
\hline 27 & Mongolia & 17 & 12 & -5 & & \\
\hline
\end{tabular}




\begin{tabular}{|c|c|c|c|c|c|c|}
\hline \multicolumn{7}{|c|}{ Appendix H. Continued } \\
\hline $\mathbf{S} / \mathbf{N}$ & EITI Country & $\begin{array}{c}\text { Average } \\
\text { Ranking } \\
\text { 2003-2011 } \\
\end{array}$ & $\begin{array}{c}\text { Average } \\
\text { Ranking } \\
2011-2015 \\
\end{array}$ & $\begin{array}{c}\text { Average change } \\
\text { in Ranking } \\
\text { overtime }\end{array}$ & SSA & OECD \\
\hline 28 & Mozambique & 24 & 25 & 1 & $\sqrt{ }$ & \\
\hline 29 & Myanmar & 51 & 47 & -4 & & \\
\hline 30 & Niger & 26 & 18 & -8 & $\sqrt{ }$ & \\
\hline 31 & Nigeria & 40 & 37 & -3 & $\sqrt{ }$ & \\
\hline 32 & Norway & 1 & 1 & 0 & & $\sqrt{ }$ \\
\hline 33 & Papua New Guinea & 38 & 40 & 2 & & \\
\hline 34 & Peru & 9 & 14 & 5 & & \\
\hline 35 & Philippines & 30 & 16 & -14 & & \\
\hline 36 & Republic of the Congo & 41 & 43 & 2 & $\sqrt{ }$ & \\
\hline 37 & Sao Tome and Principe & 19 & 7 & -12 & $\sqrt{ }$ & \\
\hline 38 & Senegal & 11 & 8 & -3 & $\sqrt{ }$ & \\
\hline 39 & Seychelles & 5 & 5 & 0 & $\sqrt{ }$ & \\
\hline 40 & Sierra Leone & 36 & 28 & -8 & $\sqrt{ }$ & \\
\hline 41 & Solomon Islands & 20 & & -20 & & \\
\hline 42 & Tajikistan & 45 & 44 & -1 & & \\
\hline 43 & Tanzania & 18 & 23 & 5 & $\sqrt{ }$ & \\
\hline 44 & Timor-Leste & 34 & 31 & -3 & & \\
\hline 45 & Togo & 28 & 30 & 2 & $\sqrt{ }$ & \\
\hline 46 & Trinidad and Tobago & 8 & 9 & 1 & & \\
\hline 47 & Ukraine & 33 & 38 & 5 & & \\
\hline 48 & United Kingdom & 2 & 3 & 1 & & $\sqrt{ }$ \\
\hline 49 & United States of America & 4 & 4 & 0 & & $\sqrt{ }$ \\
\hline 50 & Yemen & 35 & 48 & 13 & & \\
\hline 51 & Zambia & 22 & 13 & -9 & $\sqrt{ }$ & \\
\hline
\end{tabular}

Source: Corruption perception Index (2003-2015) 
Appendix I: Variable description and data sources

\begin{tabular}{|c|c|c|c|}
\hline Code & Variable Name & Description & Source \\
\hline$C C I$ & $\begin{array}{l}\text { Control of } \\
\text { Corruption } \\
\text { Index }\end{array}$ & $\begin{array}{l}\text { Yearly score of Control of Corruption Index. } \\
\text { The CCI measures the perception to which } \\
\text { public power is exercised for private gain, } \\
\text { including both petty and grand forms of } \\
\text { corruption, as well as the capture of the } \\
\text { state by elites and private interest. The } \\
\text { variable ranged from }-1.70 \text { to } 2.30 \text { with } \\
\text { higher values indicating better control of } \\
\text { corruption. }\end{array}$ & $\begin{array}{l}\text { Worldwide Governance } \\
\text { Indicator and (Kaufmann } \\
\text { et al., 2011). }\end{array}$ \\
\hline$E X P$ & $\begin{array}{l}\text { EITI } \\
\text { Implementation } \\
\text { Experience }\end{array}$ & $\begin{array}{l}\text { EXP is the number of years since a country } \\
\text { publicly committed to implementing the } \\
\text { EITI Standards, using the official } \\
\text { announcement date provided by each } \\
\text { country's national EITI and/or EITI } \\
\text { International Secretariat. The measures are } \\
\text { taken on } 31 \text { st December each year from } \\
2003 \text { to } 2015 \text {. The EITI length of } \\
\text { Experience is constructed as the number of } \\
\text { months a country has been committed to } \\
\text { the EITI scaled by } 12 \text { months. }\end{array}$ & $\begin{array}{l}\text { EITI International } \\
\text { https://eiti.org and } \\
\text { countries national } \\
\text { websites }\end{array}$ \\
\hline FOI & $\begin{array}{l}\text { Freedom of } \\
\text { Information }\end{array}$ & $\begin{array}{l}\text { FOI is the duration for which a country has } \\
\text { adopted FOI law is measured as the } \\
\text { cumulative number of years since } \\
\text { enactment of the law. FOI laws empowers } \\
\text { citizens to question the activities of their } \\
\text { governments and can be a mechanism for } \\
\text { unearthing corruption }\end{array}$ & $\begin{array}{l}\text { Freedominfo.org } \\
\underline{\text { http://www.freedominfo. }} \\
\underline{\text { org }}\end{array}$ \\
\hline$R R D$ & $\begin{array}{l}\text { Resource } \\
\text { Revenue } \\
\text { Dependence }\end{array}$ & $\begin{array}{l}\text { The Natural Resources Revenue } \\
\text { Dependence level of a country is measured } \\
\text { as total primary export scaled by total } \\
\text { merchandise export. }\end{array}$ & $\begin{array}{l}\text { UNCTAD-Merchandise } \\
\text { trade matrix. } \\
\text { www.unctad.org }\end{array}$ \\
\hline$M I N$ & $\begin{array}{l}\text { Mineral rents } \\
(\% \text { of GDP) }\end{array}$ & $\begin{array}{l}\text { Mineral rents are the difference between } \\
\text { the value of production for a stock of } \\
\text { minerals at world prices and their total } \\
\text { costs of production. Minerals included in } \\
\text { the calculation are tin, gold, lead, zinc, iron, } \\
\text { copper, nickel, silver, bauxite, and } \\
\text { phosphate }\end{array}$ & $\begin{array}{l}\text { World Bank } \\
\text { www.worldbank.org }\end{array}$ \\
\hline$O I L$ & $\begin{array}{l}\text { Oil rents (\% of } \\
\text { GDP) }\end{array}$ & $\begin{array}{l}\text { Oil rents are the difference between the } \\
\text { value of crude oil production at world } \\
\text { prices and total costs of production. }\end{array}$ & $\begin{array}{l}\text { World Bank } \\
\text { www.worldbank.org }\end{array}$ \\
\hline
\end{tabular}




\begin{tabular}{|c|c|c|c|}
\hline \multicolumn{4}{|c|}{ Appendix I. Continued } \\
\hline Code & Variable Name & Description & Source \\
\hline Pol_Inst & $\begin{array}{l}\text { Political } \\
\text { Institution and } \\
\text { Stability }\end{array}$ & $\begin{array}{l}\text { Aggregate score of Government } \\
\text { Effectiveness and Political Stability and } \\
\text { Absence of Violence in a country. } \\
\text { Government Effectiveness captures the } \\
\text { perceptions of the quality of public services, } \\
\text { the quality of the civil service and the } \\
\text { degree of its independence from political } \\
\text { pressures, the quality of policy formulation } \\
\text { and implementation, and the credibility of } \\
\text { the government's commitment to such } \\
\text { policies. While Political Stability and } \\
\text { Absence of Violence reflects the perceived } \\
\text { likelihood that a government will be } \\
\text { destabilised or overthrown by } \\
\text { unconstitutional or violent means, } \\
\text { including politically-motivated violence } \\
\text { and terrorism. }\end{array}$ & $\begin{array}{l}\text { World Bank Worldwide } \\
\text { Governance Indicator } \\
\text { (WGI) project } \\
\text { www.worldbank.org }\end{array}$ \\
\hline$G D P$ & $\begin{array}{l}\text { Natural } \\
\text { logarithm of } \\
\text { Gross Domestic } \\
\text { Product per } \\
\text { capita }\end{array}$ & $\begin{array}{l}\text { GDP per capita (current US\$) is gross } \\
\text { domestic product divided by midyear } \\
\text { population. GDP is the sum of gross value } \\
\text { added by all resident producers in the } \\
\text { economy plus any product taxes and minus } \\
\text { any subsidies not included in the value of } \\
\text { the products. }\end{array}$ & $\begin{array}{l}\text { World Bank national } \\
\text { accounts data } \\
\text { www.worldbank.org }\end{array}$ \\
\hline$S S A$ & $\begin{array}{l}\text { Sub-Saharan } \\
\text { African Country }\end{array}$ & $\begin{array}{l}\text { Dummy variable that takes the value of } 1 \text { if } \\
\text { a country is classified as Sub-Saharan } \\
\text { African Country and } 0 \text { otherwise }\end{array}$ & World Factbook, US CIA \\
\hline HIPC & $\begin{array}{l}\text { Heavily } \\
\text { Indebted Poor } \\
\text { Countries }\end{array}$ & $\begin{array}{l}\text { A dummy variable that scores a country } 1 \text { if } \\
\text { categorised a Heavily Indebted Poor } \\
\text { Country and } 0 \text { otherwise. }\end{array}$ & $\begin{array}{l}\text { International Monetary } \\
\text { Fund } \\
\text { https://www.imf.org }\end{array}$ \\
\hline
\end{tabular}




\section{Appendix J: EITI countries geographical and economic categorization}

\begin{tabular}{|c|c|c|c|c|c|}
\hline S/N & Country & OECD & $\begin{array}{l}\text { Developing } \\
\text { countries }\end{array}$ & SSA & HIPC \\
\hline 1 & Afghanistan & & $\sqrt{ }$ & & $\sqrt{ }$ \\
\hline 2 & Albania & & $\sqrt{ }$ & & \\
\hline 3 & Azerbaijan & & $\sqrt{ }$ & & \\
\hline 4 & Burkina Faso & & $\sqrt{ }$ & $\sqrt{ }$ & $\sqrt{ }$ \\
\hline 5 & Cameroon & & $\sqrt{ }$ & $\sqrt{ }$ & $\sqrt{ }$ \\
\hline 6 & Central African Republic & & $\sqrt{ }$ & $\sqrt{ }$ & $\sqrt{ }$ \\
\hline 7 & Chad & & $\sqrt{ }$ & $\sqrt{ }$ & $\sqrt{ }$ \\
\hline 8 & Colombia & & $\sqrt{ }$ & & \\
\hline 9 & Cote d'Ivoire & & $\sqrt{ }$ & $\sqrt{ }$ & $\sqrt{ }$ \\
\hline 10 & Democratic Republic of Congo & & $\sqrt{ }$ & $\sqrt{ }$ & $\sqrt{ }$ \\
\hline 11 & Dominican Republic & & $\sqrt{ }$ & & \\
\hline 12 & Ethiopia & & $\sqrt{ }$ & $\sqrt{ }$ & $\sqrt{ }$ \\
\hline 13 & Germany & $\sqrt{ }$ & & & \\
\hline 14 & Ghana & & $\sqrt{ }$ & $\sqrt{ }$ & $\sqrt{ }$ \\
\hline 15 & Guatemala & & $\sqrt{ }$ & & \\
\hline 16 & Guinea & & $\sqrt{ }$ & $\sqrt{ }$ & $\sqrt{ }$ \\
\hline 17 & Honduras & & $\sqrt{ }$ & & $\sqrt{ }$ \\
\hline 18 & Indonesia & & $\sqrt{ }$ & & \\
\hline 19 & Iraq & & $\sqrt{ }$ & & \\
\hline 20 & Kazakhstan & & $\sqrt{ }$ & & \\
\hline 21 & Kyrgyz Republic & & $\sqrt{ }$ & & \\
\hline 22 & Liberia & & $\sqrt{ }$ & $\sqrt{ }$ & $\sqrt{ }$ \\
\hline 23 & Madagascar & & $\sqrt{ }$ & $\sqrt{ }$ & $\sqrt{ }$ \\
\hline 24 & Malawi & & $\sqrt{ }$ & $\sqrt{ }$ & $\sqrt{ }$ \\
\hline 25 & Mali & & $\sqrt{ }$ & $\sqrt{ }$ & $\sqrt{ }$ \\
\hline 26 & Mauritania & & $\sqrt{ }$ & $\sqrt{ }$ & $\sqrt{ }$ \\
\hline 27 & Mongolia & & $\sqrt{ }$ & & \\
\hline 28 & Mozambique & & $\sqrt{ }$ & $\sqrt{ }$ & $\sqrt{ }$ \\
\hline 29 & Myanmar & & $\sqrt{ }$ & & \\
\hline 30 & Niger & & $\sqrt{ }$ & $\sqrt{ }$ & $\sqrt{ }$ \\
\hline 31 & Nigeria & & $\sqrt{ }$ & $\sqrt{ }$ & \\
\hline 32 & Norway & $\sqrt{ }$ & & & \\
\hline 33 & Papua New Guinea & & $\sqrt{ }$ & & \\
\hline 34 & Peru & & $\sqrt{ }$ & & \\
\hline 35 & Philippines & & $\sqrt{ }$ & & \\
\hline 36 & Republic of the Congo & & $\sqrt{ }$ & $\sqrt{ }$ & $\sqrt{ }$ \\
\hline 37 & Sao Tome and Principe & & $\sqrt{ }$ & $\sqrt{ }$ & $\sqrt{ }$ \\
\hline 38 & Senegal & & $\sqrt{ }$ & $\sqrt{ }$ & $\sqrt{ }$ \\
\hline 39 & Seychelles & & $\sqrt{ }$ & $\sqrt{ }$ & \\
\hline 40 & Sierra Leone & & $\sqrt{ }$ & $\sqrt{ }$ & $\sqrt{ }$ \\
\hline 41 & Solomon Islands & & $\sqrt{ }$ & & \\
\hline 42 & Tajikistan & & $\sqrt{ }$ & & \\
\hline 43 & Tanzania & & $\sqrt{ }$ & $\sqrt{ }$ & $\sqrt{ }$ \\
\hline 44 & Timor-Leste & & $\sqrt{ }$ & & \\
\hline 45 & Togo & & $\sqrt{ }$ & $\sqrt{ }$ & $\sqrt{ }$ \\
\hline 46 & Trinidad and Tobago & & $\sqrt{ }$ & & \\
\hline 47 & Ukraine & & $\sqrt{ }$ & & \\
\hline 48 & United Kingdom & $\sqrt{ }$ & & & \\
\hline 49 & United States of America & $\sqrt{ }$ & & & \\
\hline 50 & Yemen & & $\sqrt{ }$ & & \\
\hline 51 & Zambia & & $\sqrt{ }$ & $\sqrt{ }$ & $\sqrt{ }$ \\
\hline
\end{tabular}


Appendix K: USEITI Initial listed sample companies for 2013

Ticker

S/N PERMNO Symbol Company Name

11850 XOM EXXON MOBIL CORP

12291 RNO RHINO RESOURCE PARTNERS L P

12786 VOC VOC ENERGY TRUST

12903 SARA SARATOGA RESOURCES INC

13116 BCEI BONANZA CREEK ENERGY INC

13124 LPI LAREDO PETROLEUM INC

13141 WPX WPX ENERGYINC

13163 MEMP MEMORIAL PRODUCTION PARTNERS L P

13244

13356

13928

14026

14134

14179

14541 CVX

15069 MRO

19166 FMC

23835 MDU

$25590 \quad$ NFG

26470 EGN

27756 STR

28118 NC

28345 MUR

28484 HES

32803

HFC

MATADOR RESOURCES CO

PHILLIPS 66

CONOCOPHILLIPS

JONES ENERGY INC

O C I RESOURCES LP

ANTERO RESOURCES CORP

CHEVRON CORP NEW

MARATHON OIL CORP

F M C CORP

M D U RESOURCES GROUP INC

NATIONAL FUEL GAS CO N J

ENERGEN CORP

QUESTAR CORP

NACCO INDUSTRIES INC

MURPHY OIL CORP

HESS CORP

HOLLYFRONTIER CORP

S/N PERMNO Symbol Company Name

2634833 OXY OCCIDENTAL PETROLEUM CORP

$\begin{array}{llll}27 & 37234 & \text { FST } & \text { FOREST OIL CORP }\end{array}$

2847723 HNRG HALLADOR ENERGY CO

2950017 RRC RANGE RESOURCES CORP

$30 \quad 59467$ WLB WESTMORELAND COAL CO

$31 \quad 61487$ AE ADAMS RESOURCES \& ENERGY INC

$3261815 \quad$ NBL

$33 \quad 61946 \quad$ BKH

\section{1}

63781 UNT UNIT CORP

64936 D DOMINION RESOURCES INC VA NEW

75039 BHP B H P BILLITON LTD

75241 PXD

$75326 \quad$ ACI

75825 EOG

76082 COG

76127 TTI

76888 AXAS

$78186 \quad P Q$

$78877 \quad$ CHK

79159 CWEI

79444 SGY

79915 NFX

PIONEER NATURAL RESOURCES CO

ARCH COAL INC

EOG RESOURCES INC

CABOT OIL \& GAS CORP

TETRA TECHNOLOGIES INC

ABRAXAS PETROLEUM CORP

PETROQUEST ENERGY INC

CHESAPEAKE ENERGY CORP

CLAYTON WILLIAMS ENERGY INC

80926 CPE

STONE ENERGY CORP

NEWFIELD EXPLORATION CO

CALLON PETROLEUM CO DEL 
Appendix K: USEITI Initial listed sample companies for 2013

\begin{tabular}{|c|c|c|c|c|c|c|c|}
\hline $\mathbf{S} / \mathbf{N}$ & PERMNO & $\begin{array}{l}\text { Ticker } \\
\text { Symbol }\end{array}$ & Company Name & $\mathbf{S} / \mathbf{N}$ & PERMNO & $\begin{array}{l}\text { Ticker } \\
\text { Symbol }\end{array}$ & Company Name \\
\hline 51 & 81598 & AGU & AGRIUM INC & 74 & 90494 & BBG & BILL BARRETT CORP \\
\hline 52 & 82196 & DNR & DENBURY RESOURCES INC & 75 & 90533 & WTI & W \& T OFFSHORE INC \\
\hline 53 & 84167 & GEL & GENESIS ENERGY L P & 76 & 91081 & LINE & LINN ENERGY LLC \\
\hline 54 & 86223 & EPD & ENTERPRISE PRODUCTS PARTNERS LP & 77 & 91100 & ROSE & ROSETTA RESOURCES INC \\
\hline 55 & 86759 & KWK & QUICKSILVER RESOURCES INC & 78 & 91111 & ETE & ENERGY TRANSFER EQUITY L P \\
\hline 56 & 86799 & CNX & CONSOL ENERGY INC & 79 & 91135 & BTE & BAYTEX ENERGY CORP \\
\hline 57 & 87137 & DVN & DEVON ENERGY CORP NEW & 80 & 91283 & HK & HALCON RESOURCES CORP \\
\hline 58 & 87471 & TGC & TENGASCO INC & 81 & 91376 & ATLS & ATLAS ENERGY L P \\
\hline 59 & 88818 & ERF & ENERPLUS CORP & 82 & 91494 & BBEP & BREITBURN ENERGY PARTNERS L P \\
\hline 60 & 88871 & $\mathrm{MCF}$ & CONTANGO OIL AND GAS COMPANY & 83 & 91739 & LGCY & LEGACY RESERVES L P \\
\hline 61 & 88882 & UPL & ULTRA PETROLEUM CORP & 84 & 91983 & CLR & CONTINENTAL RESOURCES INC \\
\hline 62 & 88991 & BTU & PEABODY ENERGY CORP & 85 & 91985 & DEJ & DEJOUR ENERGY INC \\
\hline 63 & 89016 & STO & STATOIL A S A & 86 & 92215 & EXXI & ENERGY XXI LTD \\
\hline 64 & 89134 & ECA & ENCANA CORP & 87 & 92239 & CXO & CONCHO RESOURCES INC \\
\hline 65 & 89509 & $\mathrm{XEC}$ & CIMAREX ENERGY CO & 88 & 92375 & VNR & VANGUARD NATURAL RESOURCES LLC \\
\hline 66 & 89547 & NRP & NATURAL RESOURCE PARTNERS L P & 89 & 92421 & SD & SANDRIDGE ENERGY INC \\
\hline 67 & 89858 & PAA & PLAINS ALL AMERN PIPELINE L P & 90 & 92478 & FOR & FORESTAR GROUP INC \\
\hline 68 & 89901 & WLL & WHITING PETROLEUM CORP NEW & 91 & 92530 & $\mathrm{CPN}$ & CALPINE CORP \\
\hline 69 & 90071 & NRG & N R G ENERGY INC & 92 & 92621 & IPI & INTREPID POTASH INC \\
\hline 70 & 90386 & MOS & MOSAIC COMPANY NEW & 93 & 93095 & CLD & CLOUD PEAK ENERGY INC \\
\hline 71 & 90444 & ORA & ORMAT TECHNOLOGIES INC & 94 & 93152 & CIE & COBALT INTERNATIONAL ENERGY INC \\
\hline 72 & 90458 & NEW & NORTHWESTERN CORP & 95 & 93420 & OAS & OASIS PETROLEUM INC \\
\hline 73 & 90492 & WRES & WARREN RESOURCES INC & & & & \\
\hline
\end{tabular}


Appendix L. Companies with confounding news excluded from the final sample

\begin{tabular}{ccll}
\hline S/N & PERMNO & Ticker Symbol & Company Name \\
\hline 1 & 76888 & AXAS & ABRAXAS PETROLEUM CORP \\
2 & 91376 & ATLS & ATLAS ENERGY GROUP LLC \\
3 & 37234 & FST & FOREST OIL CORP \\
4 & 91283 & HK & HALCON RESOURCES CORP \\
5 & 14026 & JONE & JONES ENERGY INC \\
6 & 91739 & LGCY & LEGACY RESERVES LP \\
7 & 28118 & NC & NACCO INDUSTRIES \\
8 & 93420 & OAS & OASIS PETROLEUM INC \\
9 & 62341 & PDCE & PDC ENERGY INC \\
10 & 92421 & SD & SANDRIDGE ENERGY INC \\
11 & 79444 & SGY & STONE ENERGY CORP \\
12 & 76127 & TTI & TETRA TECHNOLOGIES INC \\
13 & 88882 & UPL & ULTRA PETROLEUM CORP \\
14 & 90492 & WRES & WARREN RESOURCES INC \\
15 & 13141 & WPX & WPX ENERGY INC \\
\hline
\end{tabular}

For each of the sample 95 companies a search on FACTIVA for confounding news affecting the companies around the event period was conducted. The search revealed confounding news for the 15 companies listed in this table. These events included insiders buying shares, business acquisitions, business spin-offs, class action lawsuits, and a range of share price sensitive announcements made by the companies. 
Appendix M. Comparison of legislative requirement for extractive reporting at firm level

\begin{tabular}{|c|c|c|c|c|}
\hline & $\begin{array}{l}\text { Extractive } \\
\text { Industries } \\
\text { Transparency } \\
\text { Initiative }\end{array}$ & United States of America & 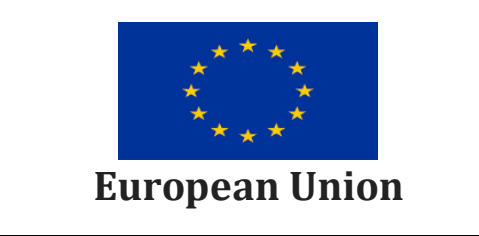 & Canada \\
\hline Legislation (s) & The EITI Standards & $\begin{array}{l}\text { Section } 1504 \text { of the Dodd-Frank } \\
\text { Wall Street Reform and } \\
\text { Consumer Protection Act } \\
\text { (2010). Requires the SEC to } \\
\text { issue a Final Rule adopting the } \\
\text { legislation. }\end{array}$ & $\begin{array}{l}\text { Chapter } 10 \text { of Accounting } \\
\text { Directive } 2013 / 34 / E U ; \\
\text { and } \\
\text { Transparency Directive } \\
\text { 2013/50/EU }\end{array}$ & $\begin{array}{l}\text { Extractive Sector } \\
\text { Transparency } \\
\text { Measures Act (2014) }\end{array}$ \\
\hline $\begin{array}{l}\text { Entities } \\
\text { (companies) } \\
\text { affected }\end{array}$ & $\begin{array}{l}\text { All extractive companies } \\
\text { operating in an EITI } \\
\text { implementing country }\end{array}$ & $\begin{array}{l}\text { Resource issuers listed on the } \\
\text { US stock markets. }\end{array}$ & $\begin{array}{l}\text { Large undertakings and } \\
\text { all public-interest entities } \\
\text { active in the extractive } \\
\text { industry. }\end{array}$ & $\begin{array}{l}\text { The law affects the } \\
\text { following: } \\
\text { (a) an entity that is listed } \\
\text { on a stock exchange in } \\
\text { Canada; } \\
\text { (b) an entity that has a } \\
\text { place of business in } \\
\text { Canada, does business in }\end{array}$ \\
\hline
\end{tabular}




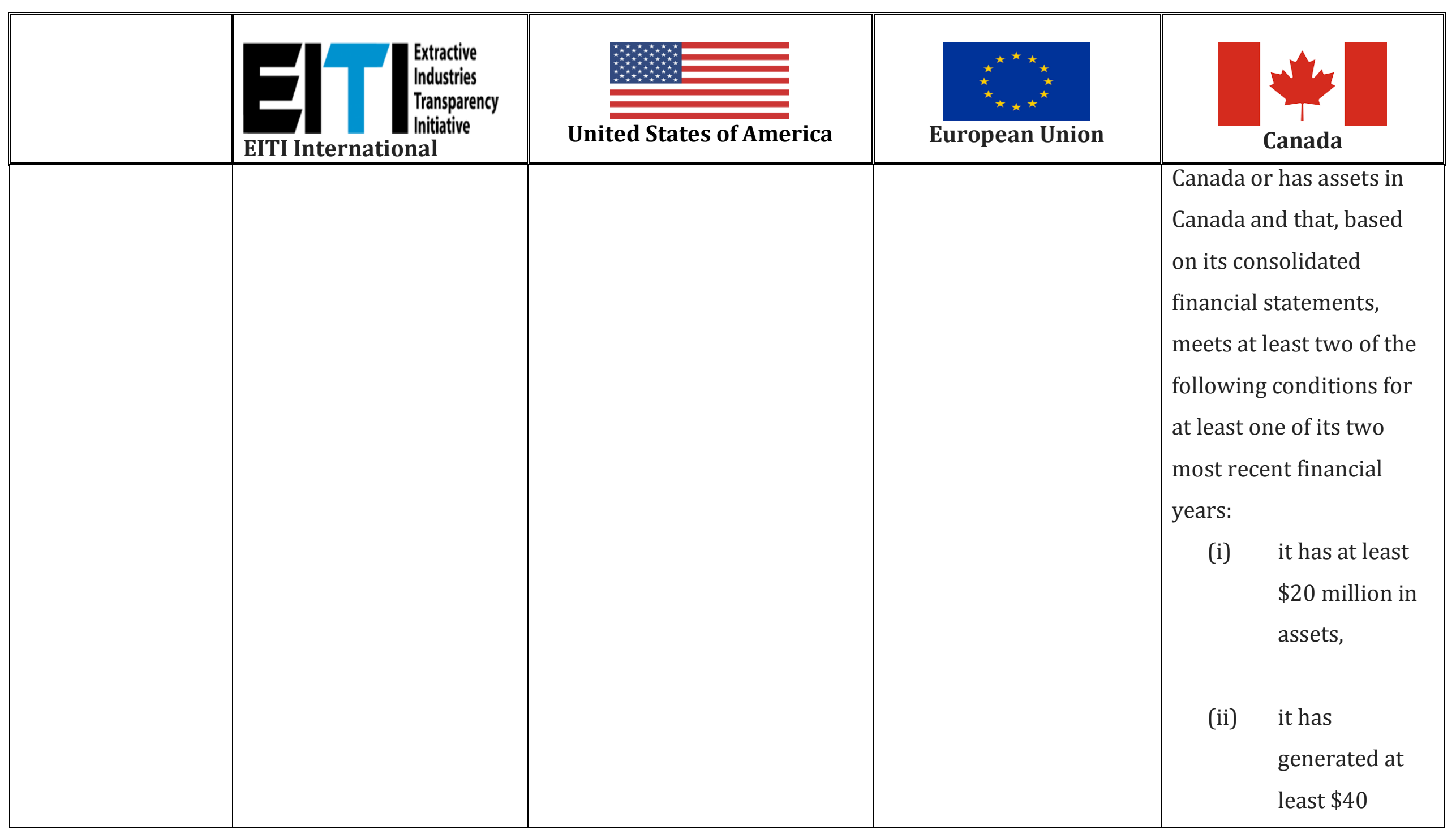




\begin{tabular}{|c|c|c|c|c|}
\hline & $\begin{array}{ll}\text { Extractive } \\
\text { Industries } \\
\text { Transparency } \\
\text { Initiative }\end{array}$ & United States of America & $\begin{array}{c}\stackrel{\star \star}{\star \star}^{\star \star}{ }^{\star}{ }^{\star} \star^{\star} \\
\text { European Union }\end{array}$ & Canada \\
\hline & & & & $\begin{array}{ll} & \begin{array}{l}\text { million in } \\
\text { revenue, }\end{array} \\
\text { (iii) } & \text { it employs an } \\
& \text { average of at } \\
& \text { least } 250 \\
\text { employees; }\end{array}$ \\
\hline Effective date & $\begin{array}{l}\text { To be determined by each } \\
\text { country }\end{array}$ & September 26, 2016 & July 20, 2015 & June 1, 2015 \\
\hline Compliance date & $\begin{array}{l}\text { To be determined by each } \\
\text { country }\end{array}$ & $\begin{array}{l}\text { Fiscal years ending on or after } \\
\text { September } 30,2018\end{array}$ & $\begin{array}{l}\text { Financial year beginning } \\
\text { on } 1 \text { January 2016, or } \\
\text { during the calendar year } \\
2016 \text {. }\end{array}$ & June 1, 2015 \\
\hline
\end{tabular}




\begin{tabular}{|c|c|c|c|c|}
\hline & $\begin{array}{ll} & \begin{array}{l}\text { Extractive } \\
\text { Industries } \\
\text { Transparency } \\
\text { Initiative }\end{array} \\
\text { EITI International }\end{array}$ & United States of America & $\begin{array}{c}\star^{\star^{\star \star}}{ }^{\star \star}{ }^{\star} \star^{\star} \\
\text { European Union }\end{array}$ & Canada \\
\hline $\begin{array}{l}\text { Definition of } \\
\text { payment } \\
\text { (threshold) or de } \\
\text { minimis }\end{array}$ & $\begin{array}{l}\text { In advance of the reporting } \\
\text { process, the multi- } \\
\text { stakeholder group is } \\
\text { required to agree which } \\
\text { payments and revenues } \\
\text { are material and therefore } \\
\text { must be disclosed, } \\
\text { including appropriate } \\
\text { materiality definitions and } \\
\text { thresholds. }\end{array}$ & $\begin{array}{l}\text { Any payment, whether as a } \\
\text { single payment or a series of } \\
\text { related payments, that equals } \\
\text { or exceeds } \$ 100,000 \text { during the } \\
\text { most recent fiscal year. }\end{array}$ & $\begin{array}{l}\text { Any payment, whether } \\
\text { made as a single payment } \\
\text { or as a series of related } \\
\text { payments, need not be } \\
\text { taken into account in the } \\
\text { report if it is below EUR } \\
100000 \text { within a financial } \\
\text { year. }\end{array}$ & $\begin{array}{l}\text { An entity must disclose } \\
\text { any payments within a } \\
\text { category of payments } \\
\text { that are made to the same } \\
\text { payee, if } \\
\text { the total amount of all } \\
\text { those payments during } \\
\text { the financial year is at } \\
\text { least } \\
\text { (a) the amount } \\
\text { prescribed by } \\
\text { regulation for the } \\
\text { category of } \\
\text { payment; or } \\
\text { (b) if no amount is } \\
\text { prescribed for the }\end{array}$ \\
\hline
\end{tabular}




\begin{tabular}{|c|c|c|c|c|}
\hline & $\begin{array}{l}\text { Extractive } \\
\text { Industries } \\
\text { Transparency } \\
\text { Initiative }\end{array}$ & United States of America & $\begin{array}{c}\star^{\star \star}{ }^{\star \star}{ }^{\star} \\
{ }^{\star} \star^{\star} \\
\text { European Union }\end{array}$ & Canada \\
\hline & & & & $\begin{array}{l}\text { category, } \\
\$ 100,000 .\end{array}$ \\
\hline $\begin{array}{l}\text { Level of data } \\
\text { aggregation } \\
\text { (disaggregation) }\end{array}$ & $\begin{array}{l}\text { The multi-stakeholder } \\
\text { group is required to agree } \\
\text { on the level of } \\
\text { disaggregation for the } \\
\text { publication of data. It is } \\
\text { required that EITI data is } \\
\text { presented by individual } \\
\text { company, government } \\
\text { entity and revenue stream. } \\
\text { Reporting at the project } \\
\text { level is required, provided } \\
\text { that it is consistent with } \\
\text { the US SEC rules and the } \\
\text { EU requirements. }\end{array}$ & Project level & $\begin{array}{l}\text { Disclosure of payments is } \\
\text { made on a project and per } \\
\text { government basis. }\end{array}$ & $\begin{array}{l}\text { The Minister may specify, } \\
\text { in writing, the way in } \\
\text { which payments are to be } \\
\text { organized or broken } \\
\text { down in the report - } \\
\text { including on a project } \\
\text { basis -and the form and } \\
\text { manner in which a report } \\
\text { is to be provided. }\end{array}$ \\
\hline
\end{tabular}




\begin{tabular}{|c|c|c|c|c|c|c|c|c|}
\hline & EITI & $\begin{array}{l}\text { Extractive } \\
\text { Industries } \\
\text { Transparency } \\
\text { Initiative }\end{array}$ & & ted States of America & & $\begin{array}{c}\star^{\star^{\star}} \stackrel{\star \star}{\star^{\star}}{ }^{\star \star} \\
\text { European Union }\end{array}$ & & Canada \\
\hline $\begin{array}{l}\text { Information (type } \\
\text { of payment) to be } \\
\text { reported } \\
\text { (disclosed) }\end{array}$ & i. & $\begin{array}{l}\text { The host } \\
\text { government's } \\
\text { production } \\
\text { entitlement } \\
\text { National state- } \\
\text { owned company } \\
\text { production } \\
\text { entitlement } \\
\text { Profit taxes } \\
\text { Royalties } \\
\text { Dividends }\end{array}$ & $\begin{array}{l}\text { i. } \\
\text { ii. } \\
\text { iii. } \\
\text { iv. } \\
\text { v. }\end{array}$ & $\begin{array}{l}\text { Taxes; } \\
\text { Royalties; } \\
\text { Fees; } \\
\text { Production entitlements; } \\
\text { Bonuses; } \\
\text { Dividends; } \\
\text { Payments for } \\
\text { infrastructure } \\
\text { improvements; and }\end{array}$ & i. & $\begin{array}{l}\text { Production } \\
\text { entitlements; } \\
\text { taxes levied on the } \\
\text { income, production } \\
\text { or profits of } \\
\text { companies, } \\
\text { excluding taxes } \\
\text { levied on } \\
\text { consumption such } \\
\text { as value added } \\
\text { taxes, personal } \\
\text { income taxes or } \\
\text { sales taxes; } \\
\text { royalties; } \\
\text { dividends; }\end{array}$ & i. & $\begin{array}{l}\text { Taxes, other than } \\
\text { consumption taxes } \\
\text { and personal } \\
\text { income taxes; } \\
\text { royalties; } \\
\text { fees, including } \\
\text { rental fees, entry } \\
\text { fees and } \\
\text { regulatory charges } \\
\text { as well as fees or } \\
\text { other } \\
\text { consideration for } \\
\text { licences, permits } \\
\text { or concessions; }\end{array}$ \\
\hline
\end{tabular}




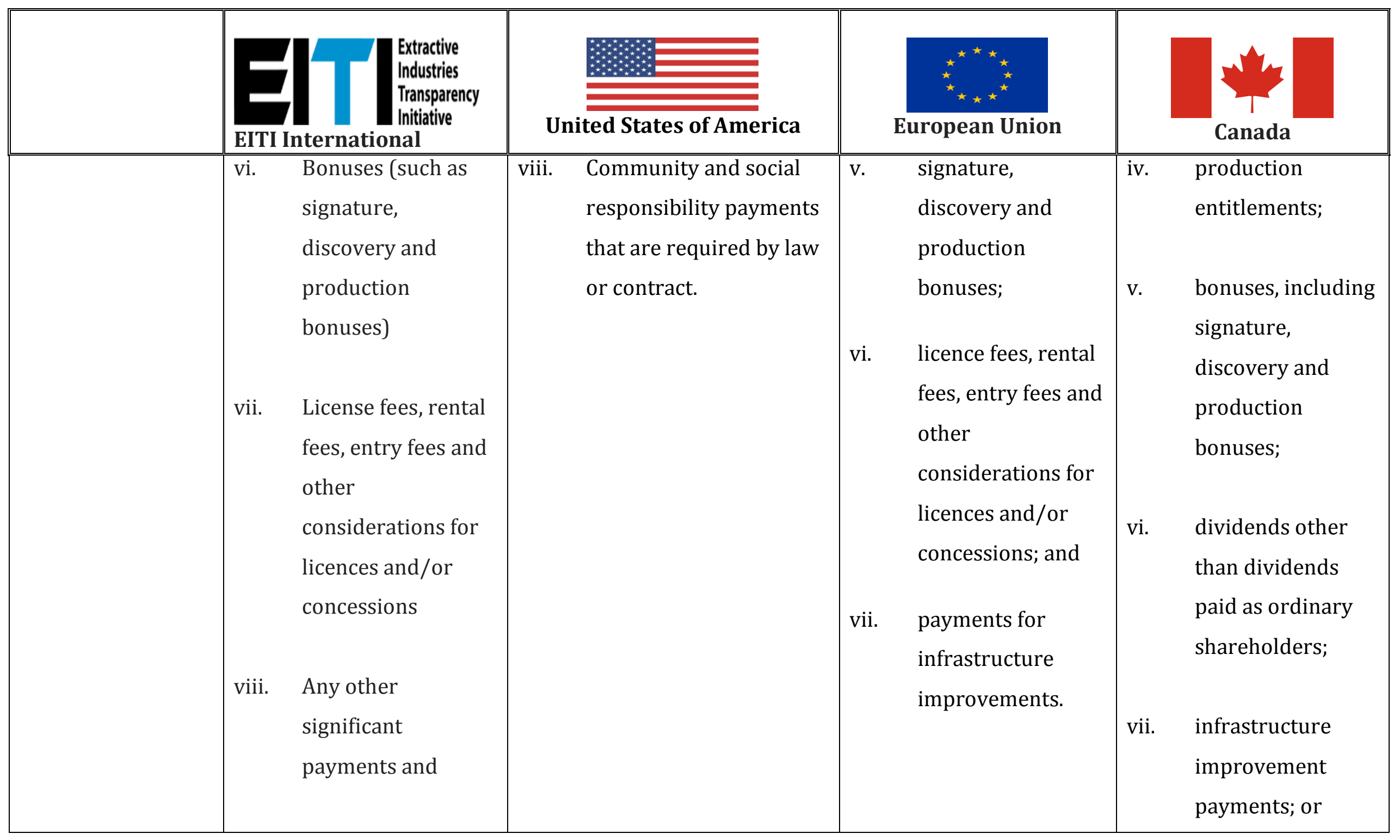




\begin{tabular}{|c|c|c|c|c|}
\hline & $\begin{array}{ll}\text { Extractive } \\
\text { Industries } \\
\text { Transparency } \\
\text { Initiative }\end{array}$ & United States of America & 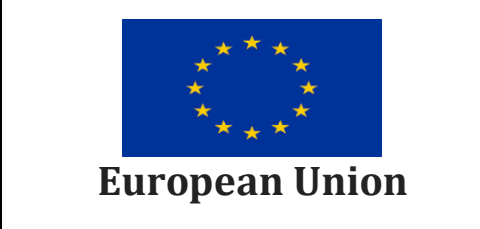 & Canada \\
\hline & $\begin{array}{l}\text { material benefit to } \\
\text { the government. }\end{array}$ & & & 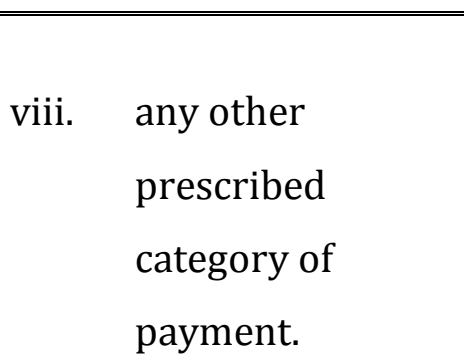 \\
\hline $\begin{array}{l}\text { Reporting } \\
\text { (disclosure) } \\
\text { format }\end{array}$ & $\begin{array}{l}\text { To be determined by the } \\
\text { multi-stakeholder group of } \\
\text { each implementing } \\
\text { country. }\end{array}$ & $\begin{array}{l}\text { Interactive data format on Form } \\
\text { SD using the SEC's Electronic } \\
\text { Data Gathering, Analysis, and } \\
\text { Retrieval System ("EDGAR"). In } \\
\text { addition, a separate public } \\
\text { compilation of the payment } \\
\text { information submitted must be } \\
\text { made available online. }\end{array}$ & $\begin{array}{l}\text { This is disclosed on } \\
\text { reporting firms' websites } \\
\text { and uploaded to the } \\
\text { electronic filling platform } \\
\text { of their national } \\
\text { securities. }\end{array}$ & $\begin{array}{l}\text { Published on the internet } \\
\text { with a link available to } \\
\text { the Canadian } \\
\text { government. }\end{array}$ \\
\hline
\end{tabular}




\begin{tabular}{|c|c|c|c|c|}
\hline & $\begin{array}{l}\text { Extractive } \\
\text { Industries } \\
\text { Transparency } \\
\text { Initiative }\end{array}$ & United States of America & 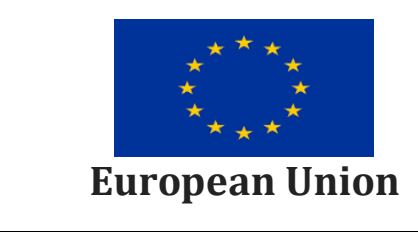 & Canada \\
\hline $\begin{array}{l}\text { Reporting } \\
\text { deadline for } \\
\text { companies }\end{array}$ & $\begin{array}{l}\text { Country-specific. Thus } \\
\text { each county to determine. }\end{array}$ & $\begin{array}{l}\text { No later than } 150 \text { days after the } \\
\text { end of the issuer's most recent } \\
\text { fiscal year. }\end{array}$ & $\begin{array}{l}6 \text { to } 11 \text { months of the } \\
\text { firms' fiscal year end. }\end{array}$ & $\begin{array}{l}\text { Not later than } 150 \text { days } \\
\text { after the end of each of its } \\
\text { financial year. }\end{array}$ \\
\hline Exceptions & Non- specified & $\begin{array}{l}\text { Includes two exemptions that } \\
\text { provide for transitional relief or } \\
\text { delayed reporting in limited } \\
\text { circumstances. These } \\
\text { exemptions provide a longer } \\
\text { transition period for recently } \\
\text { acquired companies that were } \\
\text { not previously subject to } \\
\text { reporting under the final rules } \\
\text { and a one-year delay in } \\
\text { reporting payments related to } \\
\text { exploratory activities. }\end{array}$ & No exceptions & $\begin{array}{l}\text { No clear exemptions but } \\
\text { the Act authorizes the } \\
\text { adoption of the } \\
\text { regulations respecting, } \\
\text { among other matters, } \\
\text { "the circumstances in } \\
\text { which any provisions of } \\
\text { this Act do not apply to } \\
\text { entities, payments or } \\
\text { payees. }\end{array}$ \\
\hline
\end{tabular}




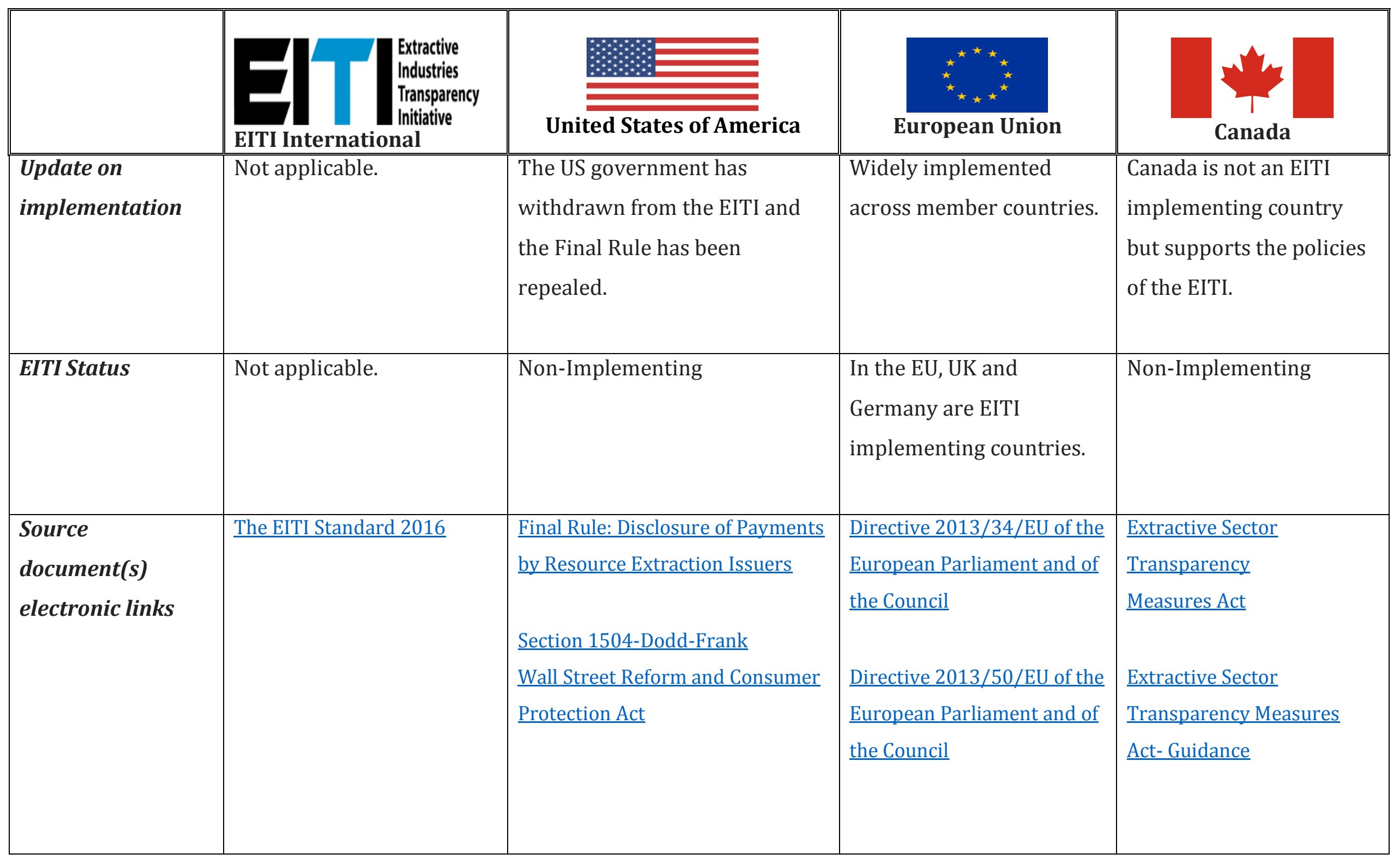


Appendix N. Summary of key empirical studies reviewed

\begin{tabular}{|c|c|c|c|c|}
\hline$S / N$ & CITATION & OBJECTIVE & $\begin{array}{c}\text { METHODS AND } \\
\text { SAMPLE }\end{array}$ & FINDINGS \\
\hline
\end{tabular}

\section{A. STUDIES ON CORRUPTION}

\begin{tabular}{|c|c|c|c|c|}
\hline 1 & $\begin{array}{l}\text { Tanzi, V. (1998). } \\
\text { Corruption } \\
\text { around the world: } \\
\text { Causes, } \\
\text { consequences, } \\
\text { scope, and cures. } \\
\text { Staff Papers, } \\
45(4), 559-594 .\end{array}$ & $\begin{array}{l}\text { To survey and } \\
\text { discuss issues } \\
\text { related to the } \\
\text { causes, } \\
\text { consequences, and } \\
\text { scope of } \\
\text { corruption, and } \\
\text { also addressed } \\
\text { possible corrective } \\
\text { actions. }\end{array}$ & $\begin{array}{l}\text { The study was based on } \\
\text { a literature survey and } \\
\text { theoretical } \\
\text { conceptualisation. } \\
\text { The data was accessed } \\
\text { from the Transparency } \\
\text { International } \\
\text { Corruption Perception } \\
\text { Index for the period } \\
\text { 1995-1998. }\end{array}$ & $\begin{array}{l}\text { The study argued that corruption is closely linked to } \\
\text { the way governments conduct their affairs in modem } \\
\text { societies, and also linked to the growth of some of the } \\
\text { government's activities in the economy. } \\
\text { The author claimed that it is unlikely that corruption } \\
\text { can be substantially reduced without modifying the } \\
\text { way governments operate. } \\
\text { Specifically, the study documented four strategies to } \\
\text { reduce corruption, as follows: } \\
\text { 1. Honest and visible commitment by leadership to } \\
\text { the fight against corruption; }\end{array}$ \\
\hline
\end{tabular}




\begin{tabular}{|c|c|c|c|c|}
\hline $\mathrm{S} / \mathrm{N}$ & CITATION & OBJECTIVE & $\begin{array}{c}\text { METHODS AND } \\
\text { SAMPLE }\end{array}$ & FINDINGS \\
\hline & & & & $\begin{array}{l}\text { 2. Policy changes that reduce the demand for } \\
\text { corruption by scaling down regulations and } \\
\text { other policies such as tax incentives, and by } \\
\text { making the policies that are retained as } \\
\text { transparent and as nondiscretionary as } \\
\text { possible; } \\
\text { 3. Reducing the supply of corruption by increasing } \\
\text { public sector wages, increasing incentives } \\
\text { toward honest behaviour, and instituting } \\
\text { effective controls and penalties on the public } \\
\text { servants; and } \\
\text { 4. Solving the problem of the financing of political } \\
\text { parties. }\end{array}$ \\
\hline
\end{tabular}




\begin{tabular}{|c|c|c|c|c|}
\hline $\mathrm{S} / \mathrm{N}$ & CITATION & OBJECTIVE & $\begin{array}{l}\text { METHODS AND } \\
\text { SAMPLE }\end{array}$ & FINDINGS \\
\hline 2 & $\begin{array}{l}\text { Rose-Ackerman, } \\
\text { S. (2002). } \\
\text { Corruption and } \\
\text { the ethics of } \\
\text { global business. } \\
\text { Journal of } \\
\text { Banking and } \\
\text { Finance, 26, } \\
\text { 1889-1918. }\end{array}$ & $\begin{array}{l}\text { To explore the } \\
\text { ethical obligations } \\
\text { of global business } \\
\text { to refrain from } \\
\text { corruption. }\end{array}$ & $\begin{array}{l}\text { The study employed a } \\
\text { qualitative approach. }\end{array}$ & $\begin{array}{l}\text { The author affirmed that corruption in contracting, the } \\
\text { award of concessions and privatization promotes } \\
\text { inefficiency and undermines state legitimacy. } \\
\text { The author concluded that business firms have } \\
\text { responsibilities in political-economic systems in which } \\
\text { they operate and should go beyond the mere pursuit of } \\
\text { profit to also operate ethically. Additionally, firms have } \\
\text { an obligation that goes beyond a mere refusal to deal in } \\
\text { corruption, to include an affirmative duty to at least } \\
\text { publicize the situation and to build coalitions to work } \\
\text { for reform. }\end{array}$ \\
\hline 3 & $\begin{array}{l}\text { Pillay, S., \& } \\
\text { Kluvers, R. } \\
\text { (2014). An } \\
\text { institutional } \\
\text { theory } \\
\text { perspective on }\end{array}$ & $\begin{array}{l}\text { To gain insight } \\
\text { into how } \\
\text { corruption } \\
\text { develops and } \\
\text { remains } \\
\text { entrenched }\end{array}$ & $\begin{array}{l}\text { The study used a survey } \\
\text { research method based } \\
\text { on Lou (2005). } \\
\text { The sample employed } \\
\text { comprised of nine }\end{array}$ & $\begin{array}{l}\text { The study found that corruption was pervasive and of a } \\
\text { serious nature in the South Africa public service. It also } \\
\text { found that regulatory control was perceived to be poor } \\
\text { in the presence of a high degree of structural } \\
\text { uncertainty. The authors explain structural uncertainty } \\
\text { as resulting from a lack of transparency and a }\end{array}$ \\
\hline
\end{tabular}




\begin{tabular}{|c|c|c|c|c|}
\hline S/N & CITATION & OBJECTIVE & $\begin{array}{l}\text { METHODS AND } \\
\text { SAMPLE }\end{array}$ & FINDINGS \\
\hline & $\begin{array}{l}\text { corruption: The } \\
\text { case of a } \\
\text { developing } \\
\text { democracy. } \\
\text { Financial } \\
\text { Accountability } \\
\text { and Management, } \\
30(1), 95-119 .\end{array}$ & $\begin{array}{l}\text { despite the } \\
\text { introduction of } \\
\text { anti-corruption } \\
\text { legislation. }\end{array}$ & $\begin{array}{l}\text { provinces and twenty- } \\
\text { six national government } \\
\text { departments in South } \\
\text { Africa. The survey was } \\
\text { conducted by } \\
\text { distributing 1,500 } \\
\text { questionnaires, } \\
\text { designed to determine } \\
\text { the perceptions and } \\
\text { attitudes of public } \\
\text { servants towards } \\
\text { corruption. However, } \\
\text { only a total of } 702 \\
\text { national public servants } \\
\text { completed the } \\
\text { questionnaire. }\end{array}$ & $\begin{array}{l}\text { concentration of power through steep hierarchical } \\
\text { systems. } \\
\text { The study provided evidence suggesting that there had } \\
\text { been a lack of institutional transparency and fairness in } \\
\text { the system. Thus, implying that the environment did } \\
\text { not encourage whistleblowing which could improve } \\
\text { transparency and mitigate corruption. } \\
\text { Overall, the findings of the study suggest that both the } \\
\text { task and institutional environments in South Africa } \\
\text { public service were inadequate in mitigating } \\
\text { corruption. Furthermore, in line with Luo's model, the } \\
\text { study found evidence that the weak task and } \\
\text { institutional environments had led to malfeasant } \\
\text { behaviour experienced in the system. }\end{array}$ \\
\hline 4 & $\begin{array}{l}\text { Healy, P. M., \& } \\
\text { Serafeim, G. }\end{array}$ & $\begin{array}{l}\text { To examine } \\
\text { whether the }\end{array}$ & $\begin{array}{l}\text { A quantitative } \\
\text { methodology using }\end{array}$ & $\begin{array}{l}\text { Overall, the study found that firms' self-reported } \\
\text { anticorruption efforts are associated with enforcement }\end{array}$ \\
\hline
\end{tabular}




\begin{tabular}{|c|c|c|c|c|}
\hline S/N & CITATION & OBJECTIVE & $\begin{array}{l}\text { METHODS AND } \\
\text { SAMPLE }\end{array}$ & FINDINGS \\
\hline & $\begin{array}{l}\text { (2016). An } \\
\text { analysis of firms' } \\
\text { self-reported } \\
\text { anticorruption } \\
\text { efforts. The } \\
\text { Accounting } \\
\text { Review, 91(2), } \\
\text { 489-511. }\end{array}$ & $\begin{array}{l}\text { Transparency } \\
\text { International's } \\
\text { ratings of firms' } \\
\text { self-reported } \\
\text { anticorruption } \\
\text { efforts reflect } \\
\text { these firms' real } \\
\text { efforts to combat } \\
\text { corruption. }\end{array}$ & $\begin{array}{l}\text { regression analysis was } \\
\text { used in the study. } \\
\text { Data for the study was } \\
\text { obtained from the } \\
\text { Transparency } \\
\text { International ratings. } \\
\text { The sample comprised } \\
480 \text { firms. }\end{array}$ & $\begin{array}{l}\text { and monitoring costs, such as home country } \\
\text { enforcement, US stock exchange listing, Big } 4 \text { auditors, } \\
\text { and prior enforcement actions. } \\
\text { The authors also found that firms with abnormally high } \\
\text { anticorruption ratings have a lower frequency of cites } \\
\text { in subsequent media articles on corruption. }\end{array}$ \\
\hline 5 & $\begin{array}{l}\text { Cuervo-Cazurra, } \\
\text { A. (2016). } \\
\text { Corruption in } \\
\text { international } \\
\text { business. Journal } \\
\text { of World Business, } \\
\text { 51,35-49. }\end{array}$ & $\begin{array}{l}\text { To analyse the } \\
\text { concept of } \\
\text { corruption in } \\
\text { international } \\
\text { business, and } \\
\text { provide } \\
\text { suggestions for } \\
\text { future research. }\end{array}$ & $\begin{array}{l}\text { Literature review of } \\
\text { published articles on } \\
\text { business corruption. }\end{array}$ & $\begin{array}{l}\text { The study advocates for the extension of the research } \\
\text { on corruption by analysing the incentives on the } \\
\text { supply and the demand sides of bribery; the } \\
\text { consequences of bribery at the country and firm level, } \\
\text { and the implementation of controls at the country and } \\
\text { firm level to reduce both the supply of and the demand } \\
\text { for bribes. }\end{array}$ \\
\hline
\end{tabular}




\begin{tabular}{|c|c|c|c|c|}
\hline S/N & CITATION & OBJECTIVE & $\begin{array}{c}\text { METHODS AND } \\
\text { SAMPLE }\end{array}$ & FINDINGS \\
\hline & & & & $\begin{array}{l}\text { The study suggests the incidence of corruption as a } \\
\text { laboratory for extending traditional theories. } \\
\text { Specifically, the author recommended the extension of } \\
\text { agency theory by analysing the existence of unethical } \\
\text { agency relationships; extending transaction cost } \\
\text { economics by analysing illegal transaction costs } \\
\text { minimization; extending the resource-based view by } \\
\text { studying corporate social irresponsibility capability; } \\
\text { extending resource dependence by analysing the } \\
\text { ethical power escape; and extending the neo- } \\
\text { institutional theory by studying illegal legitimacy. }\end{array}$ \\
\hline$\overline{6}$ & $\begin{array}{l}\text { Shleifer, A., \& } \\
\text { Vishny, R. W. } \\
\text { (1993). } \\
\text { Corruption. The } \\
\text { Quarterly Journal } \\
\text { of Economics, }\end{array}$ & $\begin{array}{l}\text { To examine two } \\
\text { propositions on } \\
\text { the determinants } \\
\text { of the level of } \\
\text { corruption: (i) the } \\
\text { structure of } \\
\text { government }\end{array}$ & $\begin{array}{l}\text { The paper constructs a } \\
\text { theoretical model of } \\
\text { corruption that } \\
\text { addresses the spread } \\
\text { and cost of corruption. }\end{array}$ & $\begin{array}{l}\text { The paper shows that the weakness of government can } \\
\text { allow various governmental agencies and } \\
\text { bureaucracies to impose independent bribes on private } \\
\text { agents seeking permits from these agencies. } \\
\text { The other key finding from the paper is that corruption } \\
\text { is costly because of the distortions entailed by secrecy. }\end{array}$ \\
\hline
\end{tabular}




\begin{tabular}{|c|c|c|c|c|}
\hline S/N & CITATION & OBJECTIVE & $\begin{array}{c}\text { METHODS AND } \\
\text { SAMPLE }\end{array}$ & FINDINGS \\
\hline & $108(3), 599-617$. & $\begin{array}{l}\text { institutions, and } \\
\text { (ii) political } \\
\text { processes. }\end{array}$ & & $\begin{array}{l}\text { In particular, the authors argue that the demands for } \\
\text { secrecy can shift a country's investments away from } \\
\text { the highest value projects, into potentially useless } \\
\text { projects, if the latter offers better opportunities for } \\
\text { secret corruption. It also affirms that secrecy can cause } \\
\text { leaders of a country to maintain monopolies, to } \\
\text { prevent entry, and to discourage innovation by } \\
\text { outsiders if expanding the ranks of the elite can expose } \\
\text { existing corruption practices. } \\
\text { As a preventive approach, the study suggests the use of } \\
\text { economic and political competition to reduce the level } \\
\text { of corruption and its adverse effects. }\end{array}$ \\
\hline$\overline{77}$ & $\begin{array}{l}\text { Svensson, J. } \\
\text { (2005). Eight } \\
\text { questions about } \\
\text { corruption. } \\
\text { Journal of }\end{array}$ & $\begin{array}{l}\text { To examine the } \\
\text { following eight } \\
\text { research questions } \\
\text { on public sector } \\
\text { corruption (i) }\end{array}$ & $\begin{array}{l}\text { The study used both a } \\
\text { theoretical review and } \\
\text { descriptive analysis to } \\
\text { address the eight } \\
\text { questions posed. }\end{array}$ & $\begin{array}{l}\text { The study acknowledged that no definition of } \\
\text { corruption is completely clear-cut, however, affirmed } \\
\text { that the common definition of public corruption is the } \\
\text { misuse of public office for private gain. }\end{array}$ \\
\hline
\end{tabular}




\begin{tabular}{|c|c|c|c|c|}
\hline $\mathrm{S} / \mathrm{N}$ & CITATION & OBJECTIVE & $\begin{array}{c}\text { METHODS AND } \\
\text { SAMPLE }\end{array}$ & FINDINGS \\
\hline & $\begin{array}{l}\text { Economic } \\
\text { Perspectives, } \\
\text { 19(3), 19-42. }\end{array}$ & $\begin{array}{l}\text { What is } \\
\text { corruption? (ii) } \\
\text { Which countries } \\
\text { are the most } \\
\text { corrupt? (iii) What } \\
\text { are the common } \\
\text { characteristics of } \\
\text { countries with } \\
\text { high corruption? } \\
\text { (iv) What is the } \\
\text { magnitude of } \\
\text { corruption? (v) Do } \\
\text { higher wages for } \\
\text { bureaucrats } \\
\text { reduce } \\
\text { corruption? (vi) } \\
\text { Can competition } \\
\text { reduce } \\
\text { corruption? (vii) }\end{array}$ & $\begin{array}{l}\text { Data on corruption was } \\
\text { accessed from several } \\
\text { sources: such as } \\
\text { Kaufmann, Kraay and } \\
\text { Mastruzzi (2003) } \\
\text { Control of Corruption } \\
\text { Index; Corruption } \\
\text { Perception Index for } \\
2003 \text { from } \\
\text { Transparency } \\
\text { International; the } \\
\text { International Country } \\
\text { Risk Guide's corruption } \\
\text { indicator for 2001; and } \\
\text { the International Crime } \\
\text { Victim Surveys, (2003). }\end{array}$ & $\begin{array}{l}\text { In terms of the characteristics of the most corrupt } \\
\text { countries, the study found that } \\
\text { (i) countries with the highest levels of } \\
\text { corruption are developing or transition } \\
\text { countries. } \\
\text { most of the corrupt countries are governed } \\
\text { by socialist or have recently been governed } \\
\text { by socialist governments (with some } \\
\text { exceptions) } \\
\text { they have low-income levels, and } \\
\text { (iii) all of the most corrupt countries operate a } \\
\text { closed economic system, except Indonesia. } \\
\text { (iv) The study further affirmed that research quantifying } \\
\text { and identifying corruption is still emerging and often } \\
\text { context specific. }\end{array}$ \\
\hline
\end{tabular}




\begin{tabular}{|c|c|c|c|c|}
\hline $\mathrm{S} / \mathrm{N}$ & CITATION & OBJECTIVE & $\begin{array}{l}\text { METHODS AND } \\
\text { SAMPLE }\end{array}$ & FINDINGS \\
\hline & & $\begin{array}{l}\text { Why have there } \\
\text { been so few } \\
\text { (recent) successful } \\
\text { attempts to fight } \\
\text { corruption? (viii) } \\
\text { Does corruption } \\
\text { adversely affect } \\
\text { growth? }\end{array}$ & & $\begin{array}{l}\text { With respect to higher wages as a mitigating factor in } \\
\text { corruption, the author suggested that wage incentives } \\
\text { can reduce bribery, but only under certain conditions. } \\
\text { Hence, it should be employed under a well-functioning } \\
\text { enforcement system; the bribe being offered (or } \\
\text { demanded) must not be a function of the official's } \\
\text { wage, and the cost of paying higher wages must not be } \\
\text { too high. } \\
\text { Whether competition can reduce corruption remains } \\
\text { unclear. The findings of the study indicated that there } \\
\text { is no convincing evidence that competition among } \\
\text { officials actually reduced corruption. }\end{array}$ \\
\hline 8 & $\begin{array}{l}\text { Houqe, N. M., \& } \\
\text { Monem, R. M. } \\
\text { (2016). IFRS } \\
\text { adoption, extent }\end{array}$ & $\begin{array}{l}\text { To examine } \\
\text { whether IFRS } \\
\text { adoption and the } \\
\text { extent of }\end{array}$ & $\begin{array}{l}\text { Regression analysis of } \\
\text { historical data was the } \\
\text { method employed in } \\
\text { the study. }\end{array}$ & $\begin{array}{l}\text { The study found that the perception of low corruption } \\
\text { is positively associated with the length of IFRS } \\
\text { experience and the extent of information disclosure in } \\
\text { the country. It also found that developing countries }\end{array}$ \\
\hline
\end{tabular}




\begin{tabular}{|c|c|c|c|c|}
\hline $\mathrm{S} / \mathrm{N}$ & CITATION & OBJECTIVE & $\begin{array}{l}\text { METHODS AND } \\
\text { SAMPLE }\end{array}$ & FINDINGS \\
\hline & $\begin{array}{l}\text { of disclosure, and } \\
\text { perceived } \\
\text { corruption: A } \\
\text { cross-country } \\
\text { study. } \\
\text { International } \\
\text { Journal of } \\
\text { Accounting, 51, } \\
363-378 .\end{array}$ & $\begin{array}{l}\text { information } \\
\text { disclosure affect } \\
\text { the perceived level } \\
\text { of corruption in } \\
\text { IFRS adopting } \\
\text { countries. }\end{array}$ & $\begin{array}{l}\text { The sample of the study } \\
\text { comprised } 104 \\
\text { countries for the period } \\
\text { of } 2009 \text {-2011. The data } \\
\text { for the study was } \\
\text { obtained from the } \\
\text { Kaufmann et al. (2012) } \\
\text { Worldwide } \\
\text { Governance Indicators, } \\
\text { PwC survey } 2013 \text {, and } \\
\text { the World Bank } \\
\text { website. }\end{array}$ & $\begin{array}{l}\text { benefit more from IFRS experience compared to } \\
\text { developed countries. }\end{array}$ \\
\hline 9 & $\begin{array}{l}\text { Melgar, N., Rossi, } \\
\text { M., \& Smith, T. } \\
\text { W. (2010). The } \\
\text { perception of } \\
\text { corruption. }\end{array}$ & $\begin{array}{l}\text { To address the } \\
\text { following research } \\
\text { questions } \\
\text { (i) what are the } \\
\text { individual }\end{array}$ & $\begin{array}{l}\text { Ordered probit model } \\
\text { estimation was used for } \\
\text { analyses of the data. }\end{array}$ & $\begin{array}{l}\text { In the terms of the first question addressed by the } \\
\text { study, the finding indicated that the personal } \\
\text { characteristics of individuals play a relevant role in } \\
\text { shaping corruption perceptions at the micro level. }\end{array}$ \\
\hline
\end{tabular}




\begin{tabular}{|c|c|c|c|c|}
\hline $\mathrm{S} / \mathrm{N}$ & CITATION & OBJECTIVE & $\begin{array}{l}\text { METHODS AND } \\
\text { SAMPLE }\end{array}$ & FINDINGS \\
\hline & $\begin{array}{l}\text { International } \\
\text { Journal of Public } \\
\text { Opinion Research, } \\
22(1), 120-131 .\end{array}$ & $\begin{array}{l}\text { characteristics } \\
\text { that shape } \\
\text { corruption } \\
\text { perceptions? } \\
\text { (ii) how important } \\
\text { is the incidence of } \\
\text { the country of } \\
\text { residence in } \\
\text { determining } \\
\text { corruption } \\
\text { perceptions? and } \\
\text { (iii) is there a } \\
\text { relationship } \\
\text { between the } \\
\text { macroeconomic } \\
\text { performance of }\end{array}$ & $\begin{array}{l}\text { The dataset utilised for } \\
\text { the study was the } \\
\text { module on Citizenship } \\
\text { for the } 2004 \\
\text { International Social } \\
\text { Survey Program. The } \\
\text { survey asked } \\
\text { respondents for their } \\
\text { opinions on a variety of } \\
\text { issues, including trade, } \\
\text { migration, politics, } \\
\text { taxes and corruption, as } \\
\text { well as demographic } \\
\text { and socio-economic } \\
\text { information, such as } \\
\text { age, gender, education, } \\
\text { religiosity, and others. }\end{array}$ & $\begin{array}{l}\text { Specifically, the study provided evidence that suggests } \\
\text { that being a woman, divorced, unemployed, working in } \\
\text { the private sector or self-employed are positively } \\
\text { correlated with the perception of corruption. However, } \\
\text { being married, working full-time, attending religious } \\
\text { services frequently, having completed higher } \\
\text { secondary or above and having a favourable opinion on } \\
\text { the way that democracy works in one's country are } \\
\text { negatively correlated with the perception of } \\
\text { corruption. }\end{array}$ \\
\hline
\end{tabular}




\begin{tabular}{|c|c|c|c|c|}
\hline S/N & CITATION & OBJECTIVE & $\begin{array}{c}\text { METHODS AND } \\
\text { SAMPLE }\end{array}$ & FINDINGS \\
\hline & & $\begin{array}{l}\text { a country and the } \\
\text { perceptions of } \\
\text { corruption? }\end{array}$ & & \\
\hline 10 & $\begin{array}{l}\text { Heywood, P. M. } \\
\text { (2015). } \\
\text { Measuring } \\
\text { corruption: } \\
\text { Perspectives, } \\
\text { critiques and } \\
\text { limits. In } \\
\text { Routledge } \\
\text { Handbook of } \\
\text { Political } \\
\text { Corruption (pp. } \\
\text { 137-153). }\end{array}$ & $\begin{array}{l}\text { To examine the } \\
\text { current state of } \\
\text { the different } \\
\text { corruption } \\
\text { measures used in } \\
\text { research } \\
\text { addressing } \\
\text { corruption-related } \\
\text { topics. }\end{array}$ & $\begin{array}{l}\text { The study was based on } \\
\text { a literature review } \\
\text { comprising published } \\
\text { works on the measures } \\
\text { and methodologies for } \\
\text { measuring corruption. }\end{array}$ & $\begin{array}{l}\text { The study identified the difficulty involved in } \\
\text { measuring corruption. In particular, the author } \\
\text { questioned, "why (researchers) should want to } \\
\text { measure a phenomenon (like corruption) that is not } \\
\text { only covert but notoriously difficult even to define?" } \\
\text { One plausible explanation as suggested by the author is } \\
\text { that it is necessary to "assess the scale of the issue, in } \\
\text { terms of its extent, location and trends, so as to know } \\
\text { what one is dealing with." Another reason is that it also } \\
\text { needed to establish a clear pattern of corruption and } \\
\text { also understand why and where corruption thrives. } \\
\text { The author acknowledged that one major impediment } \\
\text { to the effective measurement of corruption is the } \\
\text { clarity of what constitutes corruption (i.e. the lack of an }\end{array}$ \\
\hline
\end{tabular}




\begin{tabular}{|c|c|c|c|c|}
\hline $\mathrm{S} / \mathrm{N}$ & CITATION & OBJECTIVE & $\begin{array}{c}\text { METHODS AND } \\
\text { SAMPLE }\end{array}$ & FINDINGS \\
\hline & & & & $\begin{array}{l}\text { authoritatively agreed upon definition of what counts } \\
\text { as corruption). } \\
\text { Overall, the study concluded that all major corruption } \\
\text { measures are limited by inherent methodological and } \\
\text { political issues. } \\
\text { As a solution, the author recommended that } \\
\text { researchers endeavour to identify these limitations in } \\
\text { their research work (by knowing the underlying } \\
\text { construct of the data used for their study). Hence, the } \\
\text { author stated that "despite these drawbacks, available } \\
\text { data should not be jettisoned out of hand, but be } \\
\text { employed to generate a better index, through analysis } \\
\text { of methodological choices on the basis of available } \\
\text { data". }\end{array}$ \\
\hline
\end{tabular}




\begin{tabular}{|l|l||c|c||c|}
\hline S/N & CITATION & OBJECTIVE & METHODS AND & FINDINGS \\
\hline
\end{tabular}

\section{B. STUDIES ON EITI AND NATURAL RESOURCE DEPENDENCE}

\begin{tabular}{|c|c|c|c|c|}
\hline 11 & $\begin{array}{l}\text { Ölcer, D. (2009). } \\
\text { Extracting the } \\
\text { Maximum from } \\
\text { the EITI. OECD } \\
\text { Development } \\
\text { Centre Working } \\
\text { Papers, (276), } 1 .\end{array}$ & $\begin{array}{l}\text { To examine the } \\
\text { effectiveness of } \\
\text { the EITI, } \\
\text { scrutinising } \\
\text { deficiencies in the } \\
\text { way the EITI has } \\
\text { operated. }\end{array}$ & $\begin{array}{l}\text { The study used } \\
\text { descriptive statistics for } \\
\text { its data analyses. The } \\
\text { data employed in the } \\
\text { study was accessed } \\
\text { from the World } \\
\text { Governance Indicator } \\
\text { (WGI) and EITI website. }\end{array}$ & $\begin{array}{l}\text { The study found that although the EITI had drawn the } \\
\text { attention of the international development community } \\
\text { to extractive sector issues, it was very much an } \\
\text { initiative still in progress. The study also found that } \\
\text { EITI countries were worse than non-EITI resource-rich } \\
\text { countries on the World Governance Indicator for } \\
\text { Control of Corruption. } \\
\text { The author confirmed the challenges that faced the } \\
\text { EITI six years after its establishment and with then } \\
\text { only } 26 \text { members. A major limitation, at the time of the } \\
\text { study, contributing to the EITI lack of success as noted } \\
\text { by the authors, was its minimum standards not being } \\
\text { sufficient to provide quality information on revenue } \\
\text { streams. In particular, the high-level set for payments } \\
\text { to be regarded as material. }\end{array}$ \\
\hline
\end{tabular}




\begin{tabular}{|c|c|c|c|c|}
\hline $\mathrm{S} / \mathrm{N}$ & CITATION & OBJECTIVE & $\begin{array}{l}\text { METHODS AND } \\
\text { SAMPLE }\end{array}$ & FINDINGS \\
\hline 12 & $\begin{array}{l}\text { Kolstad, I., \& } \\
\text { Wiig, A. (2009). } \\
\text { Is transparency } \\
\text { the key to } \\
\text { reducing } \\
\text { corruption in } \\
\text { resource-rich } \\
\text { countries? World } \\
\text { Development, } \\
\text { 37(3), 521-532. }\end{array}$ & $\begin{array}{l}\text { To review the } \\
\text { mechanisms } \\
\text { through which } \\
\text { transparency can } \\
\text { reduce corruption. } \\
\text { To analyse the } \\
\text { relationship } \\
\text { between } \\
\text { transparency and } \\
\text { corruption, with a } \\
\text { specific focus on } \\
\text { resource-rich } \\
\text { developing } \\
\text { countries. }\end{array}$ & $\begin{array}{l}\text { Regression analysis of } \\
\text { archival data was } \\
\text { employed in the study. } \\
\text { The study utilised the } \\
\text { dataset employed by } \\
\text { Sachs and Warner } \\
\text { (1997) and Mehlum, } \\
\text { Moene, \& Torvik } \\
\text { (2006). }\end{array}$ & $\begin{array}{l}\text { The authors argue that transparency alone is not } \\
\text { sufficient to reduce corruption. They found, as in the } \\
\text { study conducted by Sachs and Warner (1997), that } \\
\text { resource abundance had a negative impact on } \\
\text { economic growth. However, with respect to the study } \\
\text { by Mehlum, Moene, \& Torvik (2006), they found a } \\
\text { significant positive relationship between the } \\
\text { interaction term for the rule of law and resource } \\
\text { abundance, and economic growth. Suggesting that the } \\
\text { rule of law mitigates the negative impact of resource } \\
\text { abundance. } \\
\text { The study concluded that transparency or access to } \\
\text { information can have an impact on corruption only } \\
\text { under certain conditions. Therefore, the authors } \\
\text { hypothesise that the impact of transparency or access } \\
\text { to information will depend on the level of literacy, and } \\
\text { the extent to which stakeholders have the power to } \\
\text { hold governments accountable. }\end{array}$ \\
\hline
\end{tabular}




\begin{tabular}{|c|c|c|c|c|}
\hline $\mathrm{S} / \mathrm{N}$ & CITATION & OBJECTIVE & $\begin{array}{c}\text { METHODS AND } \\
\text { SAMPLE }\end{array}$ & FINDINGS \\
\hline & & & & $\begin{array}{l}\text { With respect to the effectiveness of the EITI, the } \\
\text { authors believed that the emphasis on revenue } \\
\text { transparency is misplaced. }\end{array}$ \\
\hline 13 & $\begin{array}{l}\text { Sachs, J. D., \& } \\
\text { Warner, A. M. } \\
\text { (1997). Sources } \\
\text { of slow growth in } \\
\text { African } \\
\text { economies. } \\
\text { Journal of African } \\
\text { Economies, 6(3), } \\
\text { 335-376. }\end{array}$ & $\begin{array}{l}\text { To investigate the } \\
\text { determinants of } \\
\text { slow economic } \\
\text { growth in Sub- } \\
\text { Saharan Africa } \\
\text { countries from } \\
1965 \text { to } 1990 .\end{array}$ & $\begin{array}{l}\text { Regression analysis of } \\
\text { archival data. } \\
\text { The sample period for } \\
\text { the study was from } \\
1965 \text { to 1990. The data } \\
\text { employed in the study } \\
\text { are country-level data } \\
\text { accessed from several } \\
\text { sources: GDP from was } \\
\text { the Penn World Tables } \\
\text { data described in } \\
\text { (Summers \& Heston, } \\
\text { 1991) and others from } \\
\text { the Center for }\end{array}$ & $\begin{array}{l}\text { The study found that part of the explanation tendered } \\
\text { for Africa's slow growth lies with natural factors such } \\
\text { as limited access to the sea, natural resource } \\
\text { abundance, and tropical climate. } \\
\text { Other findings determining the slow growth of Africa } \\
\text { include basic economic policies such as openness to } \\
\text { international trade, government saving, market- } \\
\text { supporting institutions and African countries } \\
\text { differences in life expectancy and demographic factors. } \\
\text { The authors note that the available evidence so far is } \\
\text { that African countries that have engaged in pro-growth } \\
\text { economic reforms have achieved impressive growth } \\
\text { rates. Thus, the study found no compelling empirical }\end{array}$ \\
\hline
\end{tabular}




\begin{tabular}{|c|c|c|c|c|}
\hline $\mathrm{S} / \mathrm{N}$ & CITATION & OBJECTIVE & $\begin{array}{l}\text { METHODS AND } \\
\text { SAMPLE }\end{array}$ & FINDINGS \\
\hline & & & $\begin{array}{l}\text { Institutional Reform } \\
\text { and the } \\
\text { Informal Sector (IRIS). }\end{array}$ & $\begin{array}{l}\text { evidence to support growth pessimism for Sub- } \\
\text { Saharan Africa. } \\
\text { In all, the study found that in spite of the empirical } \\
\text { results documented African countries still had three } \\
\text { issues to overcome before enjoying full economic } \\
\text { progress. These were landlockedness for no fewer than } \\
14 \text { economies, a high natural-resource dependence, } \\
\text { with the consequent Dutch-disease costs to long-term } \\
\text { growth; and a higher incidence of disease and lower } \\
\text { life expectancy, linked to the very difficult geographical } \\
\text { conditions in tropical Africa. }\end{array}$ \\
\hline 14 & $\begin{array}{l}\text { Mehlum, H., } \\
\text { Moene, K., \& } \\
\text { Torvik, R. } \\
\text { (2006). } \\
\text { Institutions and } \\
\text { the resource }\end{array}$ & $\begin{array}{l}\text { To investigate the } \\
\text { extent to which } \\
\text { countries rich in } \\
\text { natural resources } \\
\text { enjoy or suffer } \\
\text { economic growth }\end{array}$ & $\begin{array}{l}\text { Econometric modelling } \\
\text { was utilised in the } \\
\text { study. } \\
\text { The sample period of } \\
\text { the study covered the } \\
\text { period of } 1965 \text { to } 1990\end{array}$ & $\begin{array}{l}\text { The finding of this study indicate that the quality of } \\
\text { institutions determines whether countries can escape } \\
\text { the resource curse or not. Specifically, the authors } \\
\text { suggest that the combination of friendly institutions } \\
\text { and resource abundance leads to low growth. However, }\end{array}$ \\
\hline
\end{tabular}




\begin{tabular}{|c|c|c|c|c|}
\hline$S / N$ & CITATION & OBJECTIVE & $\begin{array}{l}\text { METHODS AND } \\
\text { SAMPLE }\end{array}$ & FINDINGS \\
\hline & $\begin{array}{l}\text { curse. The } \\
\text { Economic Journal, } \\
116,1-20 .\end{array}$ & $\begin{array}{l}\text { as a result of their } \\
\text { systematic } \\
\text { institutional } \\
\text { arrangements. }\end{array}$ & $\begin{array}{l}\text { and the study employed } \\
\text { the Sachs \& Warner, } \\
\text { (2001) dataset. }\end{array}$ & $\begin{array}{l}\text { friendly institutions, help resource-rich countries to } \\
\text { take full advantage of their natural resources. }\end{array}$ \\
\hline 15 & $\begin{array}{l}\text { Pitlik, H., Frank, } \\
\text { B., \& Firchow, M. } \\
\text { (2010). The } \\
\text { demand for } \\
\text { transparency: An } \\
\text { empirical note. } \\
\text { Review of } \\
\text { International } \\
\text { Organizations, } \\
\text { 5(2), 177-195. }\end{array}$ & $\begin{array}{l}\text { To analyse the } \\
\text { political and socio- } \\
\text { economic factors } \\
\text { which determine a } \\
\text { country's } \\
\text { participation in } \\
\text { EITI, which can be } \\
\text { interpreted as a } \\
\text { revealed } \\
\text { willingness to } \\
\text { pursue national } \\
\text { reform. }\end{array}$ & $\begin{array}{l}\text { Probit regression } \\
\text { analysis of data. } \\
\text { The study employed a } \\
\text { sample of } 143 \text { countries } \\
\text { mainly comprising of } \\
\text { developing countries. } \\
\text { Data were accessed } \\
\text { from the World Trade } \\
\text { Organization's (2008) } \\
\text { and Data Bank; Control } \\
\text { of Corruption variable } \\
\text { from }\end{array}$ & $\begin{array}{l}\text { The study found that countries with a higher share of } \\
\text { natural resources in their exports are more likely to } \\
\text { join the EITI. } \\
\text { The study also found that countries with more (Ethnic) } \\
\text { fractionalization are more likely to join the EITI. One } \\
\text { explanation for this, as suggested by the authors is that } \\
\text { joining EITI could serve as a panacea to reduce conflict } \\
\text { between rival ethnic groups, who may be at war over } \\
\text { accruing resource rents, and in a sense, reduce the } \\
\text { portion of natural resources that can be distributed } \\
\text { among rivalling interest groups. }\end{array}$ \\
\hline
\end{tabular}




\begin{tabular}{|c|c|c|c|c|}
\hline $\mathrm{S} / \mathrm{N}$ & CITATION & OBJECTIVE & $\begin{array}{l}\text { METHODS AND } \\
\text { SAMPLE }\end{array}$ & FINDINGS \\
\hline & & & $\begin{array}{l}\text { the World Bank's } \\
\text { Governance indicator } \\
\text { dataset (Kaufmann et } \\
\text { al. 2007). The sample } \\
\text { period across the } \\
\text { datasets was from } 1990 \\
\text { to } 2006 \text {. }\end{array}$ & $\begin{array}{l}\text { Further, the study found corrupt countries to also be } \\
\text { more likely to join the EITI. This perhaps builds on the } \\
\text { fact that EITI as a mechanism for transparency and } \\
\text { accountability aims at this cohort of countries. } \\
\text { Overall, the study documents that democratic freedom, } \\
\text { political liberties and higher presence of Non- } \\
\text { Governmental Organizations increase the likelihood of } \\
\text { joining EITI. However, in contrast, the Pitlik et al., } \\
\text { (2010) results show that countries with OPEC } \\
\text { membership have a lower probability of joining the } \\
\text { EITI. }\end{array}$ \\
\hline 16 & $\begin{array}{l}\text { Aaronson, S. A. } \\
\text { (2011). Limited } \\
\text { partnership: } \\
\text { Business, } \\
\text { government, civil } \\
\text { society, and the }\end{array}$ & $\begin{array}{l}\text { To assess the } \\
\text { multi-stakeholder } \\
\text { partnership of the } \\
\text { Extractive } \\
\text { Industries }\end{array}$ & $\begin{array}{l}\text { Interview and surveys } \\
\text { were used. } \\
\text { The data for the study } \\
\text { was based on a } 2008 \\
\text { survey of } 23 \text { EITI }\end{array}$ & $\begin{array}{l}\text { The study found that the effectiveness of the EITI was } \\
\text { limited by the different interests of the three } \\
\text { stakeholders (governments, companies and CSOs). } \\
\text { Furthermore, EITI's effectiveness was also constrained } \\
\text { by implementing governments' restriction on full } \\
\text { participation by CSOs (viz, that little or no access to }\end{array}$ \\
\hline
\end{tabular}




\begin{tabular}{|c|c|c|c|c|}
\hline $\mathbf{S} / \mathbf{N}$ & CITATION & OBJECTIVE & $\begin{array}{c}\text { METHODS AND } \\
\text { SAMPLE }\end{array}$ & FINDINGS \\
\hline & $\begin{array}{l}\text { public in the } \\
\text { Extractive } \\
\text { Industries } \\
\text { Transparency } \\
\text { Initiative (EITI). } \\
\text { Ecology and } \\
\text { Society, 31, 50- } \\
63 .\end{array}$ & $\begin{array}{l}\text { Transparency } \\
\text { Initiative (EITI). }\end{array}$ & $\begin{array}{l}\text { members, } 38 \\
\text { supporting firms, and } \\
\text { interviews with EITI } \\
\text { staff. }\end{array}$ & $\begin{array}{l}\text { information was being provided to CSOs to enable } \\
\text { them to hold governments accountable) and the low } \\
\text { public and legislators' awareness of EITI. } \\
\text { In particular, the study found that 71\% of respondents } \\
\text { believed that the EITI signals government's credibility } \\
\text { in addressing corruption and attracting investment, } \\
64 \% \text { thought it had increased transparency, but only } \\
43 \% \text { perceived EITI to have increased citizens' } \\
\text { monitoring capability of government activities. Thus, } \\
\text { the study suggested a general acceptance of the EITI as } \\
\text { an effective signal for reform, but weak in enforcing } \\
\text { accountability due to the limited access to information } \\
\text { by CSOs. } \\
\text { The author argued that despite the fact that the } \\
\text { number of implementing countries had grown to } 32 \text {, at } \\
\text { the time of the study, EITI still struggled with a clear } \\
\text { roadmap for success, slow progression from candidate }\end{array}$ \\
\hline
\end{tabular}




\begin{tabular}{|c|c|c|c|c|}
\hline $\mathrm{S} / \mathrm{N}$ & CITATION & OBJECTIVE & $\begin{array}{l}\text { METHODS AND } \\
\text { SAMPLE }\end{array}$ & FINDINGS \\
\hline & & & & $\begin{array}{l}\text { to compliant status by countries, stakeholders' power } \\
\text { imbalance, and repression of CSOs by some } \\
\text { implementing countries. } \\
\text { The study concluded that although the EITI MSG } \\
\text { partnership is not optimal, nevertheless, experience } \\
\text { suggested that it presents important learning } \\
\text { opportunities for governments and CSOs. }\end{array}$ \\
\hline 17 & $\begin{array}{l}\text { Corrigan, C. C. } \\
\text { (2014). Breaking } \\
\text { the resource } \\
\text { curse: } \\
\text { Transparency in } \\
\text { the natural } \\
\text { resource sector } \\
\text { and the } \\
\text { Extractive } \\
\text { Industries }\end{array}$ & $\begin{array}{l}\text { To critically } \\
\text { examine the } \\
\text { impact of the EITI } \\
\text { from its } \\
\text { establishment up } \\
\text { until } 2009 .\end{array}$ & $\begin{array}{l}\text { The study employed } \\
\text { regressions analysis. It } \\
\text { used a pooled cross- } \\
\text { sectional panel data } \\
\text { covering } 200 \text { countries } \\
\text { for the period } 1995 \text { - } \\
2009 \text { for its tests. } \\
\text { The data for the } \\
\text { analyses was accessed }\end{array}$ & $\begin{array}{l}\text { The study found that EITI membership appeared to } \\
\text { have helped countries achieve greater transparency } \\
\text { and to improve in terms of natural resources benefiting } \\
\text { all. } \\
\text { The study also found that EITI membership had } \\
\text { lessened the negative effects of resource abundance on } \\
\text { economic growth and some aspects of governance. } \\
\text { However, the effect of membership of EITI remained }\end{array}$ \\
\hline
\end{tabular}




\begin{tabular}{|c|c|c|c|c|}
\hline $\mathbf{S} / \mathbf{N}$ & CITATION & OBJECTIVE & $\begin{array}{l}\text { METHODS AND } \\
\text { SAMPLE }\end{array}$ & FINDINGS \\
\hline & $\begin{array}{l}\text { Transparency } \\
\text { Initiative. } \\
\text { Resources Policy, } \\
41,17-30 \text {. }\end{array}$ & & $\begin{array}{l}\text { from the World Bank } \\
\text { website. }\end{array}$ & $\begin{array}{l}\text { unclear in terms of political stability, control of } \\
\text { corruption, and voice and accountability. } \\
\text { Overall, the study indicated that EITI membership had } \\
\text { helped countries improve in terms of natural resources } \\
\text { benefiting all but had not achieved a reduction in the } \\
\text { perceived level of corruption. }\end{array}$ \\
\hline 18 & $\begin{array}{l}\text { Furstenberg, } \mathbf{S} \text {. } \\
\text { (2015). } \\
\text { Consolidating } \\
\text { global } \\
\text { governance in } \\
\text { nondemocratic } \\
\text { countries: Critical } \\
\text { reflections on the } \\
\text { Extractive } \\
\text { Industries } \\
\text { Transparency }\end{array}$ & $\begin{array}{l}\text { To critically } \\
\text { examine the EITI } \\
\text { experience in } \\
\text { nondemocratic } \\
\text { countries, with a } \\
\text { special focus on } \\
\text { Kyrgyzstan. }\end{array}$ & $\begin{array}{l}\text { The study was based on } \\
\text { qualitative } \\
\text { methodology. } \\
\text { The study reported on } \\
23 \text { semi-structured } \\
\text { in-depth expert } \\
\text { interviews with state } \\
\text { officials, civil society } \\
\text { representatives, } \\
\text { academic scholars, }\end{array}$ & $\begin{array}{l}\text { The study found that the functioning of the EITI as a } \\
\text { multi-stakeholder initiative presents certain challenges } \\
\text { in its 'one-size-fits-all' approach, for all countries. } \\
\text { This was exacerbated by communication deficiencies } \\
\text { and limited cooperation (in some jurisdictions) among } \\
\text { the members of the MSG. } \\
\text { A major finding from the study is that EITI } \\
\text { effectiveness, based on the Kyrgyzstan setting, is } \\
\text { conditional on significant domestic factors (such as the }\end{array}$ \\
\hline
\end{tabular}




\begin{tabular}{|c|c|c|c|c|}
\hline $\mathrm{S} / \mathrm{N}$ & CITATION & OBJECTIVE & $\begin{array}{l}\text { METHODS AND } \\
\text { SAMPLE }\end{array}$ & FINDINGS \\
\hline & $\begin{array}{l}\text { Initiative (EITI) } \\
\text { in Kyrgyzstan. } \\
\text { Extractive } \\
\text { Industries and } \\
\text { Society, } 2(3) \text {, } \\
462-471 .\end{array}$ & & $\begin{array}{l}\text { donor agencies, } \\
\text { international } \\
\text { development agencies, } \\
\text { intergovernmental } \\
\text { institutions and } \\
\text { business } \\
\text { representatives from } \\
\text { the mining industry. }\end{array}$ & $\begin{array}{l}\text { form of governance and level of citizens' participation } \\
\text { awareness in the national decision-making process. }\end{array}$ \\
\hline 19 & $\begin{array}{l}\text { Kasekende, E., } \\
\text { Abuka, C., \& } \\
\text { Sarr, M. (2016). } \\
\text { Extractive } \\
\text { industries and } \\
\text { corruption: } \\
\text { Investigating the } \\
\text { effectiveness of } \\
\text { EITI as a scrutiny } \\
\text { mechanism. }\end{array}$ & $\begin{array}{l}\text { To investigate the } \\
\text { effectiveness of } \\
\text { the EITI as a } \\
\text { mechanism for the } \\
\text { control of } \\
\text { corruption. } \\
\text { Specifically, this } \\
\text { study addressed } \\
\text { two research } \\
\text { questions (i) what }\end{array}$ & $\begin{array}{l}\text { The study employed } \\
\text { regression analysis of } \\
\text { archival data. } \\
\text { The data for the study } \\
\text { was accessed from the } \\
\text { World Bank and IMF } \\
\text { websites. The sample } \\
\text { period for the study } \\
\text { covered the first decade }\end{array}$ & $\begin{array}{l}\text { The study found that corrupt countries, countries } \\
\text { attracting greater shares of Foreign Direct Investment } \\
\text { (FDI), and countries with lower per capita GDP are } \\
\text { more likely to join the EITI. Corrupt poor resource-rich } \\
\text { countries possibly join the EITI, as window dressing for } \\
\text { better access to foreign donors' support. } \\
\text { Overall, Kasekende et al., (2016) found that countries } \\
\text { with more press freedom have more incentive to join }\end{array}$ \\
\hline
\end{tabular}




\begin{tabular}{|c|c|c|c|c|}
\hline $\mathrm{S} / \mathrm{N}$ & CITATION & OBJECTIVE & $\begin{array}{c}\text { METHODS AND } \\
\text { SAMPLE }\end{array}$ & FINDINGS \\
\hline & $\begin{array}{l}\text { Resources Policy, } \\
48,117-128 .\end{array}$ & $\begin{array}{l}\text { are the observable } \\
\text { factors that lead a } \\
\text { country to } \\
\text { voluntarily join } \\
\text { the EITI? (ii) does } \\
\text { EITI membership } \\
\text { lead to greater } \\
\text { corruption } \\
\text { control? }\end{array}$ & $\begin{array}{l}\text { of the EITI existence } \\
\text { from } 2002 \text { to } 2012 \text {. } \\
\text { The choice of countries } \\
\text { in the sample was } \\
\text { based on their natural } \\
\text { resource endowment as } \\
\text { listed by the EITI } \\
\text { website and the IMF } \\
\text { (2007). }\end{array}$ & $\begin{array}{l}\text { the EITI. One explanation for this is that governments } \\
\text { of countries with press freedom tend to operate in a } \\
\text { relatively open manner since it is easier for citizens in } \\
\text { those countries to hold them (government) to account } \\
\text { through unrestricted access to information. } \\
\text { Regarding EITI's effectiveness in reducing corruption, } \\
\text { they found no evidence that EITI had been able to } \\
\text { reduce corruption. }\end{array}$ \\
\hline 20 & $\begin{array}{l}\text { Papyrakis, E., } \\
\text { Rieger, M., \& } \\
\text { Gilberthorpe, E. } \\
\text { (2017). } \\
\text { Corruption and } \\
\text { the Extractive } \\
\text { Industries } \\
\text { Transparency }\end{array}$ & $\begin{array}{l}\text { To examine how } \\
\text { EITI membership } \\
\text { links to changes in } \\
\text { corruption levels. } \\
\text { In particular, it } \\
\text { investigated } \\
\text { whether the } \\
\text { different stages in }\end{array}$ & $\begin{array}{l}\text { The study used cross- } \\
\text { country panel } \\
\text { regressions analysis of } \\
\text { archival data. } \\
\text { Data for the study was } \\
\text { accessed from the } \\
\text { World Bank and the }\end{array}$ & $\begin{array}{l}\text { In all, the findings of the study indicate that resource- } \\
\text { rich countries that joined EITI experienced an increase } \\
\text { in corruption but no more than non-EITI countries. } \\
\text { This is not surprising, as national reforms do not } \\
\text { necessarily yield immediate results. }\end{array}$ \\
\hline
\end{tabular}




\begin{tabular}{|c|c|c|c|c|}
\hline $\mathrm{S} / \mathrm{N}$ & CITATION & OBJECTIVE & $\begin{array}{c}\text { METHODS AND } \\
\text { SAMPLE }\end{array}$ & FINDINGS \\
\hline & $\begin{array}{l}\text { Initiative. Journal } \\
\text { of Development } \\
\text { Studies, 53, 295- } \\
309 .\end{array}$ & $\begin{array}{l}\text { EITI } \\
\text { implementation } \\
\text { (initial } \\
\text { commitment, } \\
\text { candidature, full } \\
\text { compliance) } \\
\text { influence the pace } \\
\text { of changes in } \\
\text { corruption. }\end{array}$ & $\begin{array}{l}\text { Corruption Perception } \\
\text { Index (CPI) by } \\
\text { Transparency } \\
\text { International. The } \\
\text { sample period for the } \\
\text { study was from } 2001 \text { to } \\
2011 \text {. }\end{array}$ & $\begin{array}{l}\text { The finding of the study suggests that natural resource- } \\
\text { rich countries could remedy corruption and introduce } \\
\text { sound reforms by joining the EITI Standards. }\end{array}$ \\
\hline
\end{tabular}




\begin{tabular}{|c|l||c|c|c|}
\hline S/N & CITATION & OBJECTIVE & METHODS AND & FINDINGS \\
\hline
\end{tabular}

C. STUDIES ON MARKET BEHAVIOUR AND INFORMATION DISCLOSURE

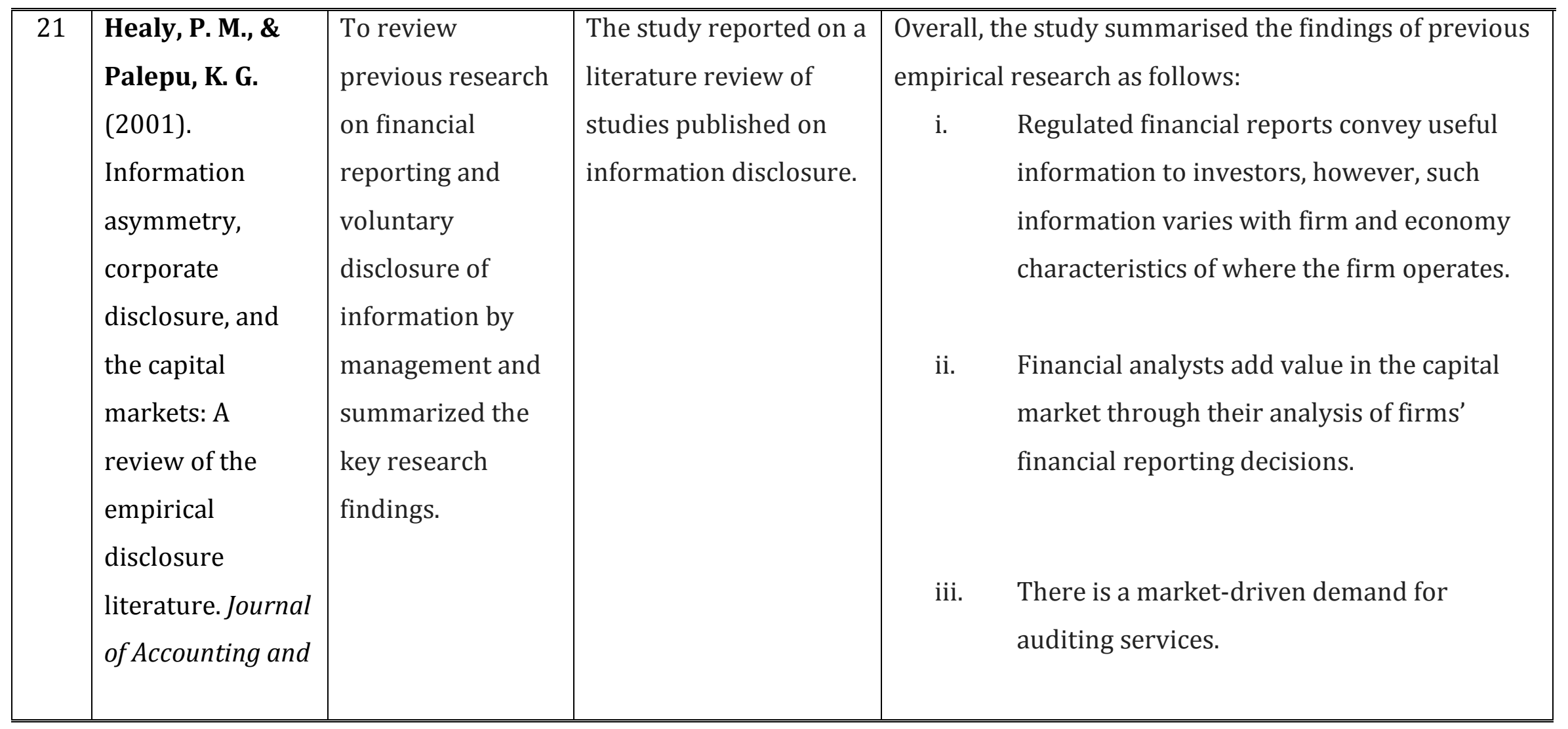




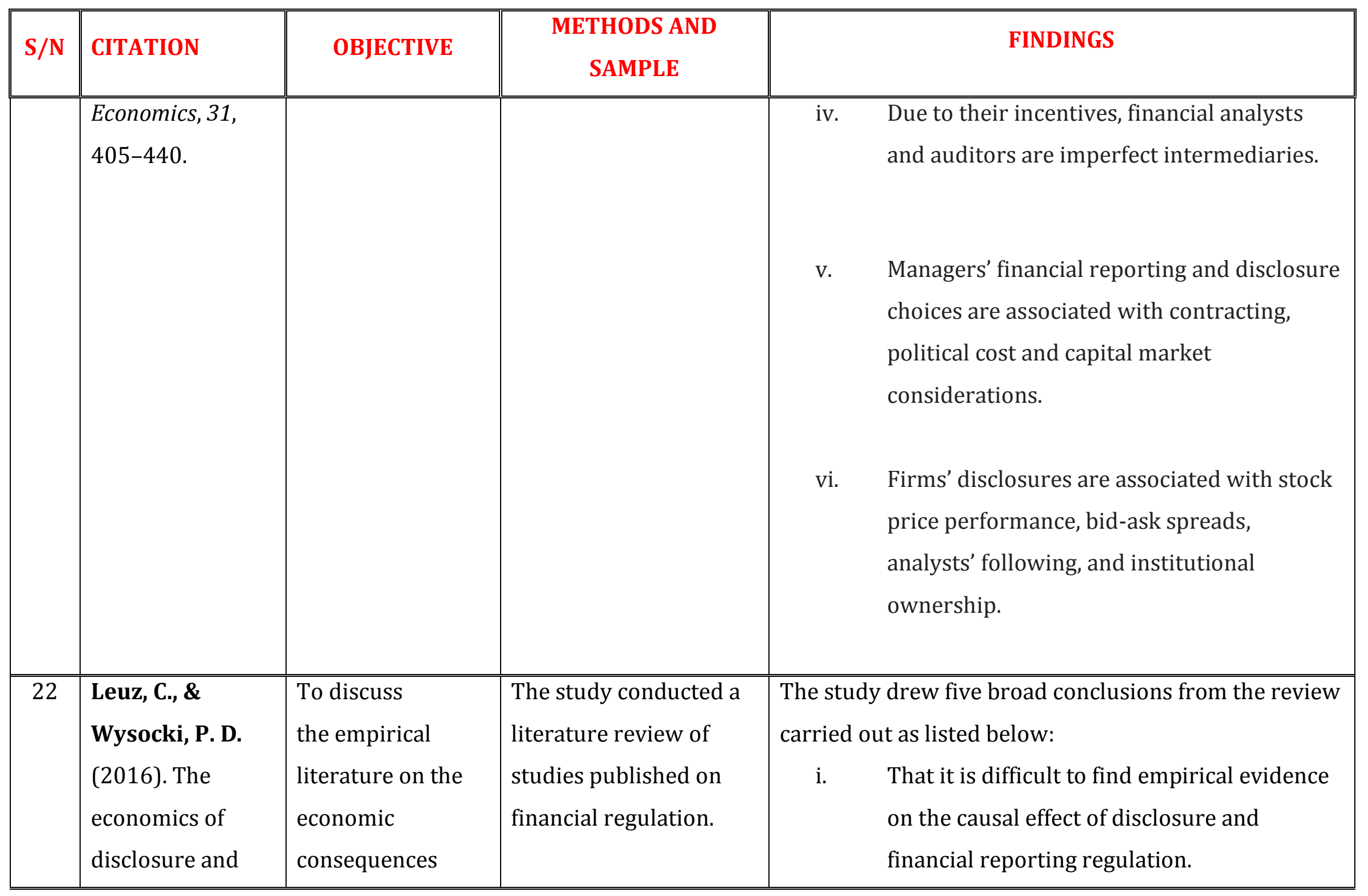




\begin{tabular}{|c|c|c|c|c|c|}
\hline $\mathrm{S} / \mathrm{N}$ & CITATION & OBJECTIVE & $\begin{array}{c}\text { METHODS AND } \\
\text { SAMPLE }\end{array}$ & & FINDINGS \\
\hline & $\begin{array}{l}\text { financial } \\
\text { reporting } \\
\text { regulation: } \\
\text { evidence and } \\
\text { suggestions for } \\
\text { future research. } \\
\text { Journal of } \\
\text { Accounting } \\
\text { Research, 54(2), } \\
\text { 525-622. }\end{array}$ & $\begin{array}{l}\text { of disclosure and } \\
\text { financial reporting } \\
\text { regulation. }\end{array}$ & & ii. & $\begin{array}{l}\text { There are insufficient studies to draw } \\
\text { general conclusions on the market-wide } \\
\text { effects from regulation. } \\
\text { Most of the prior studies surveyed focused } \\
\text { on disclosure regulation in the United States } \\
\text { of America. } \\
\text { That global IFRS adoption is one major } \\
\text { regulatory event in accounting that has } \\
\text { attracted a significant volume of research on } \\
\text { the economic consequences of financial } \\
\text { reporting standards. } \\
\text { For significant progress to be achieved } \\
\text { researchers likely need the help of } \\
\text { legislators and regulators. }\end{array}$ \\
\hline
\end{tabular}




\begin{tabular}{|c|c|c|c|c|}
\hline $\mathrm{S} / \mathrm{N}$ & CITATION & OBJECTIVE & $\begin{array}{c}\text { METHODS AND } \\
\text { SAMPLE }\end{array}$ & FINDINGS \\
\hline 23 & $\begin{array}{l}\text { Griffin, P. A., } \\
\text { Lont, D. H., \& } \\
\text { Sun, Y. (2014). } \\
\text { Supply chain } \\
\text { sustainability: } \\
\text { evidence on } \\
\text { conflict minerals. } \\
\text { Pacific Accounting } \\
\text { Review, 26(1/2), } \\
\text { 28-53. }\end{array}$ & $\begin{array}{l}\text { To assess the } \\
\text { economic costs } \\
\text { imposed on capital } \\
\text { markets by } \\
\text { Section } 1502 \text { of } \\
\text { the Dodd-Frank } \\
\text { Act of } 2010 \text { on } \\
\text { conflict minerals. }\end{array}$ & $\begin{array}{l}\text { Market reaction tests } \\
\text { and regression analysis. } \\
\text { Data for the study } \\
\text { covered } 59 \text { unique US } \\
\text { companies for the } \\
\text { period } 2010-2012 \text {. The } \\
\text { data sources used for } \\
\text { the study were from } \\
\text { CRSP; the Kenneth } \\
\text { French website; IBES; } \\
\text { and Compustat. }\end{array}$ & $\begin{array}{l}\text { The study found a negative relationship between } \\
\text { market response and conflict mineral disclosure, } \\
\text { where the response occurs over days } 21 \text { to } 20 \text { and days } \\
21 \text { to } 10 \text {. } \\
\text { The authors explain that the market assessed a cost to } \\
\text { shareholders based on the expected changes relating to } \\
\text { conflict mineral re-sourcing. }\end{array}$ \\
\hline 24 & $\begin{array}{l}\text { Verrecchia, R. E. } \\
\text { (2001). Essays on } \\
\text { disclosure. } \\
\text { Journal of } \\
\text { Accounting and } \\
\text { Economics, 32, }\end{array}$ & $\begin{array}{l}\text { To survey } \\
\text { prominent models } \\
\text { in accounting } \\
\text { literature that } \\
\text { have been } \\
\text { employed by prior }\end{array}$ & $\begin{array}{l}\text { Literature review of } \\
\text { studies in accounting } \\
\text { and finance that } \\
\text { discussed information } \\
\text { disclosure. }\end{array}$ & $\begin{array}{l}\text { The findings of the study are summarised under three } \\
\text { themes based on the extant literature in accounting } \\
\text { disclosure: } \\
\begin{array}{l}\text { i. Association-based disclosure- these studies } \\
\text { focused on how exogenous disclosure is }\end{array}\end{array}$ \\
\hline
\end{tabular}




\begin{tabular}{|c|c|c|c|c|}
\hline$S / N$ & CITATION & OBJECTIVE & $\begin{array}{c}\text { METHODS AND } \\
\text { SAMPLE }\end{array}$ & FINDINGS \\
\hline & $97-180$. & $\begin{array}{l}\text { studies to discuss } \\
\text { disclosure in the } \\
\text { context of capital } \\
\text { markets. }\end{array}$ & & $\begin{array}{l}\text { associated to change in the activities of } \\
\text { investors under a capital market setting. } \\
\text { ii. } \quad \text { Discretionary-based disclosure- under this } \\
\text { theme, the author categorised studies that } \\
\text { examined how discretion is exercised by } \\
\text { managers/firms in the disclosure of } \\
\text { information that they have knowledge of. } \\
\text { iii. } \\
\text { Efficiency-based disclosure- under this } \\
\text { theme the author categorised studies that } \\
\text { examined which disclosure arrangements } \\
\text { are preferred in the absence of prior } \\
\text { knowledge of the information. }\end{array}$ \\
\hline 25 & $\begin{array}{l}\text { Grewal, J., Riedl, } \\
\text { E. J., \& Serafeim, } \\
\text { G. (2015). Market }\end{array}$ & $\begin{array}{l}\text { To examine the } \\
\text { equity market } \\
\text { reaction to events }\end{array}$ & $\begin{array}{l}\text { The study employed } \\
\text { market reaction tests } \\
\text { and regression analysis }\end{array}$ & $\begin{array}{l}\text { In the first part of the analysis, the study found, on } \\
\text { average, a negative market reaction to the three events } \\
\text { examined. The authors linked these findings to the }\end{array}$ \\
\hline
\end{tabular}




\begin{tabular}{|c|c|c|c|c|}
\hline $\mathrm{S} / \mathrm{N}$ & CITATION & OBJECTIVE & $\begin{array}{l}\text { METHODS AND } \\
\text { SAMPLE }\end{array}$ & FINDINGS \\
\hline & $\begin{array}{l}\text { reaction to } \\
\text { mandatory } \\
\text { nonfinancial } \\
\text { disclosure. } \\
\text { Harvard Business } \\
\text { School Accounting } \\
\text { and Management } \\
\text { Unit Working } \\
\text { Paper. }\end{array}$ & $\begin{array}{l}\text { associated with } \\
\text { the passage } \\
\text { of a directive in } \\
\text { the European } \\
\text { Union (EU) } \\
\text { mandating } \\
\text { increased } \\
\text { nonfinancial } \\
\text { disclosure. In } \\
\text { particular, the } \\
\text { study investigated } \\
\text { the passage of EU } \\
\text { Directive } 2014 / 95 \\
\text { on disclosure of } \\
\text { nonfinancial } \\
\text { information. }\end{array}$ & $\begin{array}{l}\text { of cross-sectional } \\
\text { variation in abnormal } \\
\text { return. } \\
\text { Data for the study was } \\
\text { obtained from different } \\
\text { sources: Bloomberg; } \\
\text { EUR-Lex database and } \\
\text { Worldscope databases. } \\
\text { The study sample } \\
\text { comprised of } 12,162 \\
\text { firms, covering three } \\
\text { events during the } \\
\text { period 2011-2014. }\end{array}$ & $\begin{array}{l}\text { equity market anticipation of net costs to regulation } \\
\text { the firms sampled. } \\
\text { In the second test, the study found a more negative } \\
\text { reaction for firms with lower environmental, social and } \\
\text { governance disclosure, lower performance on } \\
\text { nonfinancial issues or lower proportion of ownership } \\
\text { by institutional asset owners. } \\
\text { In all, the findings of the study indicated that equity } \\
\text { market participants perceived that regulation would } \\
\text { lead to net costs for the affected firms. In addition, } \\
\text { firms with weaker nonfinancial disclosure and } \\
\text { performance before the introduction of regulation } \\
\text { would likely suffer a more severe impact. }\end{array}$ \\
\hline 26 & $\begin{array}{l}\text { Prather-Kinsey, } \\
\text { J. J., \& Tanyi, P. } \\
\text { N. (2015). The }\end{array}$ & $\begin{array}{l}\text { To study whether } \\
\text { the IFRS in the } \\
\text { United States is }\end{array}$ & $\begin{array}{l}\text { Multivariate regression } \\
\text { analysis to estimate } \\
\text { abnormal returns. }\end{array}$ & $\begin{array}{l}\text { Findings from the study indicated that the market } \\
\text { reaction for the } 11 \text { identified SEC IFRS-related } \\
\text { announcement event dates show a }\end{array}$ \\
\hline
\end{tabular}




\begin{tabular}{|c|c|c|c|c|}
\hline $\mathrm{S} / \mathrm{N}$ & CITATION & OBJECTIVE & $\begin{array}{c}\text { METHODS AND } \\
\text { SAMPLE }\end{array}$ & FINDINGS \\
\hline & $\begin{array}{l}\text { market reaction } \\
\text { to SEC IFRS- } \\
\text { related } \\
\text { announcements: } \\
\text { The case of } \\
\text { American } \\
\text { Depository } \\
\text { Receipt (ADR) } \\
\text { firms in the U.S. } \\
\text { Accounting } \\
\text { Horizons, 28(3), } \\
\text { 579-603. }\end{array}$ & $\begin{array}{l}\text { perceived } \\
\text { positively } \\
\text { by American } \\
\text { Depository } \\
\text { Receipt (ADR) } \\
\text { firms' equity } \\
\text { market } \\
\text { participants. In } \\
\text { particular, it } \\
\text { examined the } \\
\text { reactions of } \\
\text { investors of ADR } \\
\text { to the potential } \\
\text { adoption of IFRS } \\
\text { in the US. }\end{array}$ & $\begin{array}{l}\text { The sample of the study } \\
\text { covered foreign cross- } \\
\text { listed firms (ADRs) in } \\
\text { the US. Data for the } \\
\text { study was collected } \\
\text { from Datastream and } \\
\text { CRISP. In all, a total of } \\
571 \text { unique firms made } \\
\text { the final sample. }\end{array}$ & $\begin{array}{l}\text { significant and positive market reaction to the } \\
\text { potential adoption of IFRS in the US for ADR firms } \\
\text { reporting their financial statements using IFRS. } \\
\text { Also, the study found that the market reaction of IFRS } \\
\text { ADRs in IFRS-dominant industries to SEC IFRS-related } \\
\text { announcements was more positive compared to IFRS- } \\
\text { reporting ADRs in US GAAP-dominant industries. }\end{array}$ \\
\hline 27 & $\begin{array}{l}\text { Clinch, G., \& } \\
\text { Magliolo, J. } \\
\text { (1992). Market }\end{array}$ & $\begin{array}{l}\text { To examine the } \\
\text { value-relevance of } \\
\text { reserve quantity }\end{array}$ & $\begin{array}{l}\text { Two-stage regression } \\
\text { analysis to measure } \\
\text { market valuation and }\end{array}$ & $\begin{array}{l}\text { Overall, the study found that these disclosures do not } \\
\text { provide supplementary value-relevant information to } \\
\text { investors when production estimates are known. }\end{array}$ \\
\hline
\end{tabular}




\begin{tabular}{|c|c|c|c|c|}
\hline $\mathrm{S} / \mathrm{N}$ & CITATION & OBJECTIVE & $\begin{array}{l}\text { METHODS AND } \\
\text { SAMPLE }\end{array}$ & FINDINGS \\
\hline & $\begin{array}{l}\text { perceptions of } \\
\text { reserve } \\
\text { disclosures under } \\
\text { SFAS No. 69. The } \\
\text { Accounting } \\
\text { Review, 67(69), } \\
843-861 .\end{array}$ & $\begin{array}{l}\text { disclosures } \\
\text { required by SFAS } \\
\text { No. } 69 . \\
\text { Specifically, the } \\
\text { study addressed } \\
\text { two issues (i) } \\
\text { whether reserve } \\
\text { estimates are } \\
\text { value-relevant, } \\
\text { given a benchmark } \\
\text { estimate of } \\
\text { reserves based on } \\
\text { firms' current oil } \\
\text { production levels, } \\
\text { and (ii) whether } \\
\text { the association } \\
\text { between market } \\
\text { valuation and } \\
\text { firms' reserve }\end{array}$ & $\begin{array}{l}\text { cross-sectional } \\
\text { variation. } \\
\text { The sample comprised } \\
86 \text { US firms from } 1984 \\
\text { to } 1987 \text {. Data for the } \\
\text { study emanated from } \\
\text { the company's annual } \\
\text { accounts and/or oil and } \\
\text { gas reserve disclosures, } \\
\text { published by Arthur } \\
\text { Andersen, Inc. Other } \\
\text { sources included CRSP } \\
\text { daily New York Stock } \\
\text { Exchange / American } \\
\text { Stock Exchange } \\
\text { (NYSE/AMEX) or over- } \\
\text { the-counter (OTC) and } \\
\text { the Wall Street Journal. }\end{array}$ & $\begin{array}{l}\text { However, the study found evidence that these } \\
\text { disclosures are value-relevant for firms whose reserve } \\
\text { quantity estimates appear more reliable. The authors } \\
\text { interpreted their results as suggesting that investors' } \\
\text { reliance on disclosures varies as a function of } \\
\text { disclosure quality. }\end{array}$ \\
\hline
\end{tabular}




\begin{tabular}{|c|c|c|c|c|}
\hline S/N & CITATION & OBJECTIVE & $\begin{array}{c}\text { METHODS AND } \\
\text { SAMPLE }\end{array}$ & FINDINGS \\
\hline & & $\begin{array}{l}\text { disclosures differs } \\
\text { across firms } \\
\text { according to } \\
\text { characteristics of } \\
\text { the disclosed data. }\end{array}$ & & \\
\hline 28 & $\begin{array}{l}\text { Berry, K. T., \& } \\
\text { Wright, C. J. } \\
\text { (2001). The value } \\
\text { relevance of oil } \\
\text { and gas } \\
\text { disclosures: An } \\
\text { assessment of the } \\
\text { market's } \\
\text { perception of } \\
\text { firms' effort and } \\
\text { ability to discover } \\
\text { reserves. Journal } \\
\text { of Business }\end{array}$ & $\begin{array}{l}\text { To study the value } \\
\text { relevance of } \\
\text { supplemental } \\
\text { quantity } \\
\text { disclosures by } \\
\text { examining the } \\
\text { extent to which } \\
\text { they conveyed } \\
\text { information } \\
\text { regarding firms' } \\
\text { effort and ability } \\
\text { to discover proved } \\
\text { reserves. }\end{array}$ & $\begin{array}{l}\text { The study employed the } \\
\text { Ohlson's (1995) value } \\
\text { relevance model, in a } \\
\text { cross-sectional } \\
\text { regression model of } \\
\text { accounting data from } \\
1990 \text { to } 1993 . \\
\text { The sample comprised } \\
246 \text { firms' data } \\
\text { accessed from the } \\
\text { Arthur Andersen oil and }\end{array}$ & $\begin{array}{l}\text { The study found the market value of firms to be } \\
\text { positively associated with firms' efforts expended to } \\
\text { discover and extend proved reserves. } \\
\text { The results from the study demonstrated that full cost } \\
\text { firms' information regarding effort and ability to } \\
\text { discover new reserves are value relevant. However, for } \\
\text { successful efforts firms, proved developed reserves are } \\
\text { more value relevant than information on effort and } \\
\text { ability. }\end{array}$ \\
\hline
\end{tabular}




\begin{tabular}{|c|c|c|c|c|}
\hline $\mathrm{S} / \mathrm{N}$ & CITATION & OBJECTIVE & $\begin{array}{l}\text { METHODS AND } \\
\text { SAMPLE }\end{array}$ & FINDINGS \\
\hline & $\begin{array}{l}\text { Finance and } \\
\text { Accounting, 28(5- } \\
6), 741-769 .\end{array}$ & & $\begin{array}{l}\text { gas reserve disclosure } \\
\text { database, }\end{array}$ & \\
\hline 29 & $\begin{array}{l}\text { Ferguson, A., \& } \\
\text { Scott, T. (2011). } \\
\text { Market reactions } \\
\text { to Australian } \\
\text { boutique } \\
\text { resource investor } \\
\text { presentations. } \\
\text { Resources Policy, } \\
\text { 36(4), 330-338. }\end{array}$ & $\begin{array}{l}\text { To examine the } \\
\text { market reaction to } \\
817 \text { investor } \\
\text { presentations by } \\
325 \text { Australian } \\
\text { resource } \\
\text { Firms. }\end{array}$ & $\begin{array}{l}\text { Study of market } \\
\text { reaction to resource } \\
\text { firms' investor } \\
\text { presentation. The } \\
\text { sample was obtained by } \\
\text { contacting the } \\
\text { organisers of resource } \\
\text { conferences and mining } \\
\text { clubs and asking for the } \\
\text { date and name of the } \\
\text { presenting firms. Other } \\
\text { data for the study was } \\
\text { obtained from SIRCA } \\
\text { daily data file, firm- }\end{array}$ & $\begin{array}{l}\text { The study found a significant positive abnormal return } \\
\text { around the presentation date, indicative that the } \\
\text { events were important to the market. Although the } \\
\text { study focused on firm voluntary disclosure of non- } \\
\text { financial information, the findings nevertheless } \\
\text { provide incremental insight into the impact of } \\
\text { extractive firms' information disclosure with specific } \\
\text { reference to the Australian setting. } \\
\text { Overall, the findings from the study indicated that } \\
\text { these presentations were informative to market } \\
\text { participants. }\end{array}$ \\
\hline
\end{tabular}




\begin{tabular}{|c|c|c|c|c|}
\hline S/N & CITATION & OBJECTIVE & $\begin{array}{c}\text { METHODS AND } \\
\text { SAMPLE }\end{array}$ & FINDINGS \\
\hline & & & $\begin{array}{l}\text { level financial data from } \\
\text { Aspect Huntley, and } \\
\text { word count measures } \\
\text { from ISYS. The sample } \\
\text { period covered } 2000 \text { to } \\
2009 .\end{array}$ & \\
\hline 30 & $\begin{array}{l}\text { Bird, R., Grosse, } \\
\text { M., \& Yeung, D. } \\
\text { (2013). The } \\
\text { market response } \\
\text { to exploration, } \\
\text { resource and } \\
\text { reserve } \\
\text { announcements } \\
\text { by mining } \\
\text { companies: } \\
\text { Australian data. } \\
\text { Australian Journal }\end{array}$ & $\begin{array}{l}\text { To examine the } \\
\text { market response } \\
\text { to Joint Ore } \\
\text { Reserve } \\
\text { Committee (JORC) } \\
\text { compliant } \\
\text { announcements } \\
\text { made by } \\
\text { Australian mining } \\
\text { firms. }\end{array}$ & $\begin{array}{l}\text { Market reaction tests. } \\
\text { The study utilised JORC- } \\
\text { compliant exploration, } \\
\text { resource and reserve } \\
\text { announcements from } \\
\text { Australian Stock } \\
\text { Exchange firms } \\
\text { between } 17 \text { December } \\
2004 \text { and } 31 \text { December } \\
2008 .\end{array}$ & $\begin{array}{l}\text { The results demonstrated that investors took note of } \\
\text { the release of this information and that the } \\
\text { announcements had economic value. One explanation } \\
\text { offered for this is the complexity surrounding the } \\
\text { operations of extractive companies which makes the } \\
\text { release of information pertinent to the estimation of } \\
\text { their mineral resources and reserves relevant to } \\
\text { investors. } \\
\text { In addition, the results suggested that the market was } \\
\text { able to quickly respond to these announcements. Thus, } \\
\text { despite the highly technical nature of the reports }\end{array}$ \\
\hline
\end{tabular}




\begin{tabular}{|c|c|c|c|c|}
\hline $\mathrm{S} / \mathrm{N}$ & CITATION & OBJECTIVE & $\begin{array}{c}\text { METHODS AND } \\
\text { SAMPLE }\end{array}$ & FINDINGS \\
\hline & $\begin{array}{l}\text { of Management, } \\
38(2), 311-331 .\end{array}$ & & & $\begin{array}{l}\text { investors are still able to quickly evaluate and react to } \\
\text { the information content. } \\
\text { Another finding documented by the authors was the } \\
\text { fact that since geological information could pass } \\
\text { through multiple hands within and sometimes outside } \\
\text { the firm before being released to the market, there is a } \\
\text { great potential for the information to be leaked before } \\
\text { it is officially released to the public. }\end{array}$ \\
\hline 31 & $\begin{array}{l}\text { Ferguson, A., \& } \\
\text { Pündrich, G. } \\
\text { (2015). Does } \\
\text { industry } \\
\text { specialist } \\
\text { assurance of non- } \\
\text { financial } \\
\text { information } \\
\text { matter to }\end{array}$ & $\begin{array}{l}\text { To examine } \\
\text { market reactions } \\
\text { to specialist non- } \\
\text { financial } \\
\text { assurance. In } \\
\text { particular, the } \\
\text { study examined } \\
\text { the market } \\
\text { reaction to the }\end{array}$ & $\begin{array}{l}\text { The study used a two- } \\
\text { day buy-and-hold } \\
\text { abnormal returns } \\
\text { (BHAR) to estimate the } \\
\text { cross-sectional returns } \\
\text { and regression analysis } \\
\text { to predict stock returns } \\
\text { around } \\
\text { resource/reserve }\end{array}$ & $\begin{array}{l}\text { Overall, findings provide weak evidence that specialist } \\
\text { assurance is relevant to investors, except for base } \\
\text { metal reserve disclosures. } \\
\text { The author affirmed that the finding from their study } \\
\text { support the insurance hypothesis in that specialist } \\
\text { assurance does not matter in the absence of litigation } \\
\text { risk. }\end{array}$ \\
\hline
\end{tabular}




\begin{tabular}{|c|c|c|c|c|}
\hline $\mathrm{S} / \mathrm{N}$ & CITATION & OBJECTIVE & $\begin{array}{c}\text { METHODS AND } \\
\text { SAMPLE }\end{array}$ & FINDINGS \\
\hline & $\begin{array}{l}\text { investors? } \\
\text { Auditing: A } \\
\text { Journal of } \\
\text { Practice \& Theory, } \\
34(2), 121-146 .\end{array}$ & $\begin{array}{l}\text { mandatory } \\
\text { specialist non- } \\
\text { financial } \\
\text { information } \\
\text { assurance of } \\
\text { mining } \\
\text { development stage } \\
\text { entities in } \\
\text { Australia. }\end{array}$ & $\begin{array}{l}\text { disclosures. The sample } \\
\text { of the study comprised } \\
414 \text { Australian } \\
\text { extractive firms from } \\
1996 \text { to } 2012 \text {. The data } \\
\text { used was from } \\
\text { companies in the } \\
\text { materials sector listed } \\
\text { on the Australian Stock } \\
\text { Exchange (ASX). }\end{array}$ & \\
\hline 32 & $\begin{array}{l}\text { Hombach, K., \& } \\
\text { Sellhorn, T. } \\
\text { (2017). Investors' } \\
\text { Perception of } \\
\text { Financial } \\
\text { Disclosure } \\
\text { Regulation to } \\
\text { Achieve Public }\end{array}$ & $\begin{array}{l}\text { To examine the } \\
\text { market reaction to } \\
\text { the SEC final rule } \\
\text { for the } \\
\text { implementation of } \\
\text { Section } 1504 \text { of } \\
\text { the Dodd-Frank } \\
\text { Act requiring }\end{array}$ & $\begin{array}{l}\text { An event study focused } \\
\text { on periods ranging } \\
\text { from the first proposal } \\
\text { of the SEC final rule in } \\
\text { December } 2010 \text { to a re- } \\
\text { proposal of the rule in } \\
\text { December } 2015 \text {. }\end{array}$ & $\begin{array}{l}\text { The results from the study show a negative cumulative } \\
\text { abnormal return for three-days around the } \\
\text { implementation of the events, suggesting, on average, } \\
\text { that investors believe extractive firms affected by this } \\
\text { regulation will incur a net cost from a strict } \\
\text { implementation of the rule by the SEC. In particular, } \\
\text { the authors document that the sampled extractive }\end{array}$ \\
\hline
\end{tabular}




\begin{tabular}{|c|c|c|c|c|}
\hline $\mathrm{S} / \mathrm{N}$ & CITATION & OBJECTIVE & $\begin{array}{l}\text { METHODS AND } \\
\text { SAMPLE }\end{array}$ & FINDINGS \\
\hline & $\begin{array}{l}\text { Policy Objectives: } \\
\text { Evidence from } \\
\text { Extractive Issuers. } \\
\text { https://doi.org/U } \\
\text { niversity of } \\
\text { Munich }\end{array}$ & $\begin{array}{l}\text { project-level } \\
\text { disclosures of } \\
\text { payments made by } \\
\text { extractive issuers } \\
\text { to governments } \\
\text { for the exploration } \\
\text { of natural } \\
\text { resources. } \\
\text { Specifically, the } \\
\text { study investigated } \\
\text { (i) the perception } \\
\text { of investors with } \\
\text { regards to a likely } \\
\text { strict } \\
\text { implementation of } \\
\text { this regulation by } \\
\text { the SEC, and (ii) } \\
\text { the cross-sectional }\end{array}$ & $\begin{array}{l}\text { The study is based on a } \\
\text { sample of } 95 \text { unique US } \\
\text { extractive firms across } \\
\text { Oil and Gas Extraction, } \\
\text { Petroleum Refining, and } \\
\text { Petroleum and } \\
\text { Petroleum Products } \\
\text { Wholesales sub-sectors. }\end{array}$ & $\begin{array}{l}\text { firms on average experience cumulative abnormal } \\
\text { returns of - } 1.17 \% \text { during the event period. } \\
\text { With regards to the second question examined in the } \\
\text { study, the findings suggest that extractive firms subject } \\
\text { to strong public scrutiny suffered more negative } \\
\text { cumulative abnormal returns on event dates compared } \\
\text { to their counterparts not subject to intense public } \\
\text { scrutiny. An explanation for this is that non-traditional } \\
\text { monitors, (e.g. media and NGOs,) can use this } \\
\text { extraction payment disclosure to compel extractive } \\
\text { firms to act responsibly or face public backlash } \\
\text { especially with respect to their relationship with local } \\
\text { communities or other environmental activities. }\end{array}$ \\
\hline
\end{tabular}




\begin{tabular}{|c|c|c|c|c|}
\hline $\mathrm{S} / \mathrm{N}$ & CITATION & OBJECTIVE & $\begin{array}{l}\text { METHODS AND } \\
\text { SAMPLE }\end{array}$ & FINDINGS \\
\hline & & $\begin{array}{l}\text { variation of the } \\
\text { intended use of } \\
\text { the proposed } \\
\text { disclosures by } \\
\text { non-traditional } \\
\text { monitors. }\end{array}$ & & \\
\hline 33 & $\begin{array}{l}\text { Johannesen, N., } \\
\text { \& Larsen, D. T. } \\
\text { (2016). The } \\
\text { power of financial } \\
\text { transparency: An } \\
\text { event study of } \\
\text { country-by- } \\
\text { country reporting } \\
\text { standards. } \\
\text { Economics } \\
\text { Letters, 145, 120- }\end{array}$ & $\begin{array}{l}\text { To investigate the } \\
\text { effect of the } \\
\text { European Union } \\
\text { legislation } \\
\text { requiring country- } \\
\text { by-country } \\
\text { disclose of tax } \\
\text { payments on } \\
\text { extractive firms' } \\
\text { market value. In } \\
\text { particular, the } \\
\text { study focused on }\end{array}$ & $\begin{array}{l}\text { Event study } \\
\text { methodology to } \\
\text { estimate the market } \\
\text { reaction to the specified } \\
\text { disclosure. } \\
\text { The study employed a } \\
\text { sample of } 3642 \\
\text { extractive firms listed } \\
\text { in } 13 \text { different } \\
\text { countries. The list of }\end{array}$ & $\begin{array}{l}\text { The study found a significant decrease in extractive } \\
\text { firms' market value around the first two events. With } \\
\text { no evidence of a market reaction around the third and } \\
\text { fourth events. Specifically, the study documented a } \\
\text { negative cumulative abnormal return that is strongly } \\
\text { significant for event one (-4.6\%) and event two (-5.1). } \\
\text { Overall, the result suggested a negative firm value } \\
\text { decrease for the extractive companies ranging between } \\
5 \text { and } 10 \text { percent during the adoption of this reporting } \\
\text { rules cumulated over the four major events in the } \\
\text { legislative process. }\end{array}$ \\
\hline
\end{tabular}




\begin{tabular}{|c|c|c|c|c|}
\hline $\mathbf{S} / \mathbf{N}$ & CITATION & OBJECTIVE & $\begin{array}{l}\text { METHODS AND } \\
\text { SAMPLE }\end{array}$ & FINDINGS \\
\hline & 122. & $\begin{array}{l}\text { four events } \\
\text { relating to the } \\
\text { European } \\
\text { legislative process } \\
\text { leading to the } \\
\text { adoption of the } \\
\text { disclosure rules. }\end{array}$ & $\begin{array}{l}\text { firms and daily stock } \\
\text { prices were accessed } \\
\text { from the Natural } \\
\text { Resource Governance } \\
\text { Institute and the stock } \\
\text { prices from Yahoo } \\
\text { Finance respectively, } \\
\text { for the period 2009- } \\
2014 \text {. }\end{array}$ & $\begin{array}{l}\text { The interpretation for this, as suggested by the authors, } \\
\text { is that EU country-by-country disclosure } \\
\text { rules are important mechanisms for reducing } \\
\text { extractive firms rents due from tax evasion in } \\
\text { developing countries. }\end{array}$ \\
\hline 34 & $\begin{array}{l}\text { Rauter, } \mathbf{T} . \\
\text { (2017). } \\
\text { Disclosure } \\
\text { regulation, } \\
\text { corruption, and } \\
\text { investment: } \\
\text { Evidence from } \\
\text { natural resource } \\
\text { extraction. }\end{array}$ & $\begin{array}{l}\text { To examine the } \\
\text { effect of EU } \\
\text { mandatory } \\
\text { extraction } \\
\text { payment } \\
\text { disclosures } \\
\text { requiring } \\
\text { extractive } \\
\text { companies in the }\end{array}$ & $\begin{array}{l}\text { Difference-in-Difference } \\
\text { regression estimation } \\
\text { model was employed in } \\
\text { the study. } \\
\text { Data for the study was } \\
\text { hand-collected from the } \\
\text { EITI website of } 13 \text { EITI } \\
\text { implementing countries } \\
\text { reconciliation reports }\end{array}$ & $\begin{array}{l}\text { The findings of this study indicate that adoption of this } \\
\text { regulation in Europe is associated with higher } \\
\text { payments to host countries. In particular, results } \\
\text { suggest that extractive companies increased their } \\
\text { payments to foreign host governments by } £ 83.86 \\
\text { million following the commencement of granular } \\
\text { disclosures in the reports. The explanation for this is } \\
\text { due to the fact that extractive firms engage in less tax } \\
\text { avoidance and corrupt practices since they are aware }\end{array}$ \\
\hline
\end{tabular}




\begin{tabular}{|c|c|c|c|c|}
\hline $\mathrm{S} / \mathrm{N}$ & CITATION & OBJECTIVE & $\begin{array}{l}\text { METHODS AND } \\
\text { SAMPLE }\end{array}$ & FINDINGS \\
\hline & $\begin{array}{l}\text { Available at } \\
\text { SSRN: } \\
\text { https://ssrn.com } \\
\text { /abstract=30499 } \\
41 .\end{array}$ & $\begin{array}{l}\text { EU to publish their } \\
\text { payments to } \\
\text { foreign host } \\
\text { government in a } \\
\text { granular report on } \\
\text { their website. }\end{array}$ & $\begin{array}{l}\text { across Africa, Asia and } \\
\text { Europe. } \\
\text { The reports relate to } \\
\text { payments made by EU } \\
\text { extractive companies to } \\
\text { foreign host countries } \\
\text { from } 2010 \text { to } 2017 \text {. The } \\
\text { adoption dates of the } \\
\text { staggered } \\
\text { implementation of this } \\
\text { directive across EU } \\
\text { countries was collected } \\
\text { from the European } \\
\text { Commission. Firm-level } \\
\text { data was collected from } \\
\text { Compustat Global, } \\
\text { Compustat North } \\
\text { America, and } \\
\text { WorldScope Geographic }\end{array}$ & $\begin{array}{l}\text { that their information is publicly available now and can } \\
\text { be used by different actors to demand more } \\
\text { accountability. } \\
\text { Other findings documented by the study indicated that } \\
\text { disclosing EU extractive companies reduced their } \\
\text { investment relative to tightly-matched non-disclosing } \\
\text { competitors across the globe. Suggesting that affected } \\
\text { firms in the EU reallocated their investment following } \\
\text { this regulation when compared with unregulated firms. } \\
\text { Finally, the effect was stronger for firms that have } \\
\text { direct consumer dealings, in line with corporate social } \\
\text { responsibility best practices these firms seem to be } \\
\text { aware of the penalties they stand to suffer from public } \\
\text { shaming if found to be engaged in unethical business } \\
\text { dealings. }\end{array}$ \\
\hline
\end{tabular}




\begin{tabular}{|l|l|l|l|l|}
\hline S/N & CITATION & OBJECTIVE & \multicolumn{1}{|c|}{$\begin{array}{c}\text { METHODS AND } \\
\text { SAMPLE }\end{array}$} & \multicolumn{1}{|c|}{ FINDINGS } \\
\hline \multirow{3}{*}{} & & $\begin{array}{l}\text { Segments; while } \\
\text { country-level data was } \\
\text { obtained from }\end{array}$ & \\
& & Transparency & \\
& & International, World & Bank, and the \\
& & International Monetary & \\
& & Fund. & \\
\hline
\end{tabular}

